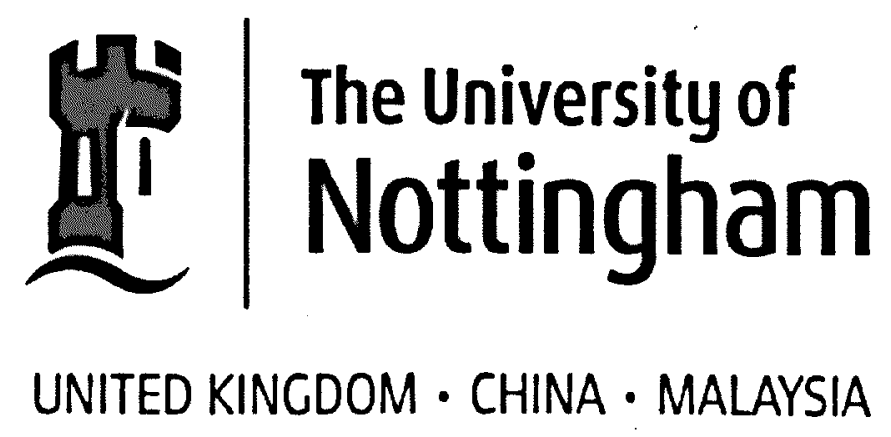

ACADEMIC DIVISION OF CHILD HEALTH SCHOOL OF GRADUATE ENTRY MEDICINE AND HEALTH UNIVERSITY OF NOTTINGHAM

\title{
MEDICATION ERRORS IN CHILDREN
}

ZAYED NAMA F. ALSULAMI

BPharm, MSc.

THESIS SUBMITTED TO THE UNIVERSITY OF NOTTINGHAM FOR THE DEGREE OF DOCTOR OF PHILOSOPHY

OCTOBER, 2013

MEDICAL LIBRARP

QUEENS MEDICALCENTSE 


\section{IMAGING SERVICES NORTH}

Boston Spa, Wetherby

West Yorkshire, LS23 7BQ

www.bl.uk

\section{PAGE/PAGES EXCLUDED UNDER INSTRUCTION \\ FROM THE UNIVERSITY}


DEDICATED WITH LOVE TO MY PARENTS AND ALL MY FAMILY MEMBERS IN SAUDI ARABIA... 


\section{ABSTRACT}

Medication errors are a significant global concern and can cause serious medical consequences in children. Double checking of medicines by two nurses is one strategy used by many children's hospitals to prevent errors from reaching paediatric patients. This thesis involves different studies that evaluated the effectiveness of the double checking process in reducing and preventing medication administration errors in a children's hospital. In addition, a systematic review was conducted of medication errors studies in the Middle East.

A systematic review was also conducted of published studies of double checking. Six electronic databases were searched for articles that assessed the double checking process during the administration of medicines. Sixteen articles were identified. Only one of them was a randomised controlled clinical trial in a clinical setting. Only one study was conducted in a children's hospital. The review found that there is insufficient evidence to either support or refute the practice of double checking and more clinical trials are needed to evaluate the double checking process in children's hospitals.

Based on the findings that were highlighted from the systematic review, a prospective observational study of paediatric nurses using the double checking process for medication administration was undertaken. The study aimed to evaluate how closely double checking policies are followed by nurses in different paediatric areas, and also to identify any.medication administration errors during the study period. 2,000 drug dose administration events were observed. There was variation between paediatric nurses adherence to double checking steps and different medication administration errors were identified. 
Based on the observational study, a semi-structured questionnaire study was developed. It was designed to explore the paediatric nurses' knowledge and opinions about the double checking process. The study showed that many nurses have insufficient knowledge on the double checking process and the hospital policy for medication administration.

A simulation study was conducted to examine whether single or double checking is more effective in detecting and reducing medication errors in children. Each participant in this study was required to prepare and administer medicines in scenarios for two "dummy patients" either with another nurse (double checking) or alone (single checking). Different confounders were built into each scenario (prescribing and administration) for nurses to identify and address during the administration process. Errors in drug preparation, administration and failure to address confounders were observed and documented. The main findings from this study were that the double checking process is more likely to identify medication administration errors and contraindicated drugs than single checking. The time taken for drug administration was similar for both processes.

Another systematic review was conducted to identify the published medication errors studies that have been undertaken in the Middle East. The review identified 45 studies from 10 Middle Eastern countries. Nine of the studies focused on medication errors in paediatric patients. Educational programmes on drug therapy for doctors and nurses are urgently needed in the Middle East.

These studies have contributed to the field of medication safety by providing more information about double and single checking medication administration processes in paediatric hospitals. More educational and training programmes for nurses about the importance of double checking and improving their adherence rate to the double 
checking steps during medication administration are required to improve it's effectiveness. 


\section{PUBLICATIONS AND PRESENTATIONS RELATED TO THIS THESIS}

\section{PUBLISHED PAPERS:}

- Alsulami Z, Conroy S, Choonara I. Double Checking the administration of medicines: what is the evidence? A systematic review. Archives of Disease in Childhood. 2012, 97:833-837.

- Alsulami Z, Conroy S, Choonara I. Medication errors in the Middle East countries: A systematic review of the literature. European Journal of Clinical Pharmacology. 2013, 69, 4: 995 - 1008.

- Alsulami Z, Choonara I, Conroy S. Paediatric nurses adherence to the double checking process steps during medication administration in a children's hospital: an observational study (Paper provisionally accepted by Journal of Advanced Nursing).

- Alsulami Z, Choonara I, Conroy S. Nurses' knowledge, perception and opinions of double checking - a questionnaire study (Paper submitted).

- Alsulami Z, Choonara I, Conroy S. Medication errors with single and double checking in paediatric patients: simulation study (Paper in preparation). 


\section{PUBLISHED ABSTRACTS}

- Alsulami Z, Conroy S, Choonara I. A systematic review of the effectiveness of double checking in preventing medication errors. Archives of Disease in Childhood, 2012, 97: e2.

- Alsulami Z, Choonara I, Conroy S. Adherence of paediatric nurses to double checking process steps during medication administration in a children's hospital: an observational study. Archives of Diseases in Childhood, 2013, 98: e1

- Alsulami Z, Choonara I, Conroy S. Single and double checking in paediatric drug administration - which is most effective in reducing errors? 14 Biannual Congress of the European Society for Development Perinatal \& Paediatric Pharmacology (ESDPPP), German Medical Science (GMS), 2013, Doc FP10, DOI: $10.3205 / 13$. 


\section{ORAL PRESENTATIONS}

- A systematic review of the effectiveness of the double checking process in reducing medication errors, National Child Health Workshop, 10 May 2011, Derby, UK.

- Double checking of medication administration in a children's hospital: An observational study, National Child Health Workshop, 11 September 2012, Derby, UK.

- Adherence of paediatric nurses to double checking process steps during medication administration in a children's hospital: an observational study, $18^{\text {th }}$ Annual Neonatal and Paediatric Pharmacists Group (NPPG), $9^{\text {th }}-11^{\text {th }}$ November 2012, Liverpool, UK.

- Single and double checking in paediatric drug administration - which is most effective in reducing errors? $14^{\text {th }}$ Biannual European Society for Developmental Perinatal \& Paediatric Pharmacology (ESDPPP) Congress, June 4 - 7, 2013, Salzburg, Austria, (Presented by Dr Sharon Conroy on behalf of Alsulami, $\mathbf{Z}$ and Choonara I).

- Single and double checking in paediatric drug administration. $19^{\text {th }}$ Annual Neonatal and Paediatric Pharmacists Group (NPPG), $8^{\text {th }}-10^{\text {th }}$ November 2013, London, UK. (Presented by Dr Sharon Conroy on behalf of Alsulami, Z and Choonara I). 


\section{POSTER PRESENTATIONS:}

- A systematic review of the effectiveness of the double checking process in reducing medication errors, $13^{\text {th }}$ Biannual ESDPPP Congress, June $15^{\text {th }}$ to $17^{\text {th }}, 2011$, Oslo, Norway.

- A systematic review of the effectiveness of double checking in preventing medication errors, $17^{\text {th }}$ Annual NPPG Conference, $11-13$ November 2011, Bristol, UK.

- Medication errors in the Middle East countries: A systematic review of the literature, Dubai International Pharmaceutical and Technologies Conference and Exhibition (DUPHAT), $12^{\text {th }}-14^{\text {th }}$ March 2012, Dubai, United Arab Emirates. 


\section{ACKNOWLEDGEMENTS}

Grateful thanks are extended to the following people for their expertise, time patience and support throughout the writing of this thesis.

Firstly, I would like to thank my supervisors Professor Imti Choonara and Dr Sharon Conroy, who dedicated much of their valuable time and effort to this thesis. I am deeply grateful for the advice and continuing support that they have given me. I could not have wished for better supervisors, thank you so much.

I would not have reached this stage without my supervisors support.

Secondly, I also extend thanks to the Academic Division of Child Health at the Medical School at Derby for their wonderful hospitality during my study period.

I also extend special thanks to the postgraduate administration office staff at the Medical School at Derby for their guidance and help.

I appreciate my parents and my family members (my lovely wife and daughters Wateen and Hoor) who were always there to help and support me in a stressful time.

My thanks also go to the Saudi Arabia Government (Ministry of Defence, Medical Services Department) for their financial support during my study period.

I would like to thank all my friends and colleagues for their enthusiasm and help.

Finally, I would like to acknowledge all the above people for their kind contribution to this thesis, as without their help this thesis would have been impossible. 


\section{LIST OF ABBREVIATIONS}

BNF-C British National Formulary for children

CDSS Clinical Decision Support System

$\mathrm{Cl}$

Confidence Interval

CINAHL Cumulative Index to Nursing \& Allied Health Literature

CIVAS Centralised Intravenous Additive Service

COPE Computerised Physician Order Entry

COSMIC Co-operative of Safety of Medicines in Children

ED

Emergency Department

EMBASE Excerpta Medica Database

ESDPPP European Society for Developmental Perinatal \& Paediatric Pharmacology

GDP Gross Domestic Product

GMS German Medical Science

HIC High Income Countries

IIP Intelligent Infusion Pumps

IV Intravenous

LASA . Look Alike Sound Alike

LMIC Lower-Middle Income Countries

MAEs Medication Administration Errors

MAR Medication Administration Record

ME Medication Error

MEs Medication Errors

MPEs Medication Prescribing Errors

NCCMERP National Co-ordinating Council for Medication Error Reporting and Prevention

NeLM National electronic Library for Medicines

NHS National Health Service

NICU Neonatal Intensive Care Unit

NOE Nurse Order Entry 


$\begin{array}{ll}\text { NPSA } & \text { National Patient Safety Agency } \\ \text { OES } & \text { Opportunities for Errors } \\ \text { OTC } & \text { Over-the Counter } \\ \text { PCCD } & \text { Paediatric Clinical Care Department } \\ \text { PICU } & \text { Paediatric Intensive Care Unit } \\ \text { POE } & \text { Physician Order Entry } \\ \text { PPP } & \text { Purchasing Power Parity } \\ \text { R\&D } & \text { Research and Development } \\ \text { UAE } & \text { United Arab Emirates } \\ \text { UDDS } & \text { Unit Dose Dispensing System } \\ \text { UK } & \text { United Kingdom } \\ \text { UMIC } & \text { Upper-Middle Income Countries } \\ \text { UNICEF } & \text { United Nations International Children Emergency Fund } \\ \text { US } & \text { United States } \\ \text { SPSS } & \text { Statistical Package for Social Science }\end{array}$




\section{TABLE OF CONTENTS}

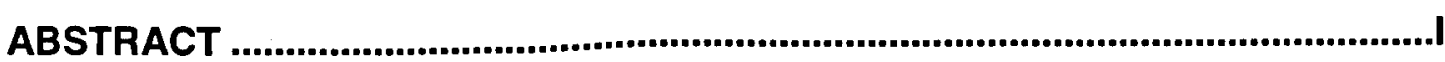

PUBLICATIONS AND PRESENTATIONS RELATED TO THIS THESIS................ IV

ACKNOWLEDGEMENTS .................................................................................. VIII

LIST OF ABBREVIATIONS .................................................................................. IX

TABLE OF CONTENTS....................................................................................... XI

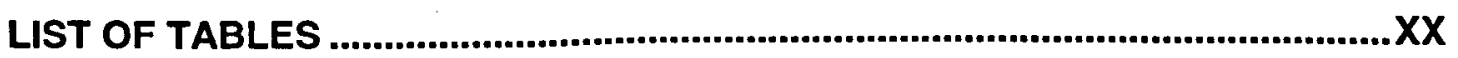

LIST OF FIGURES..................................................................................................XXII

\section{CHAPTER ONE}

GENERAL INTRODUCTION AND OVERVIEW .....................................................

1. INTRODUCTION.....................................................................................................2

1.1 General Background.............................................................................

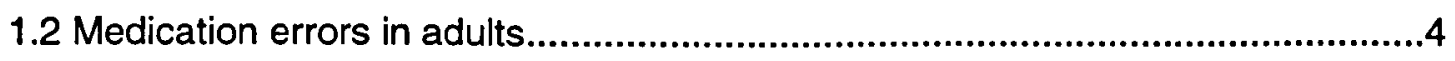

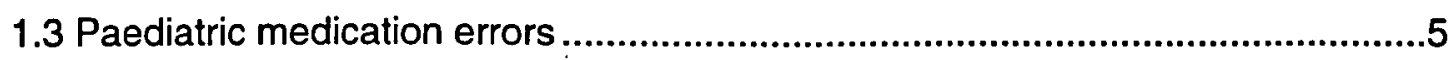

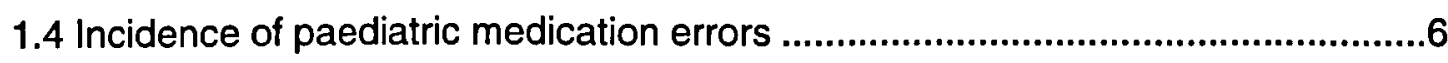

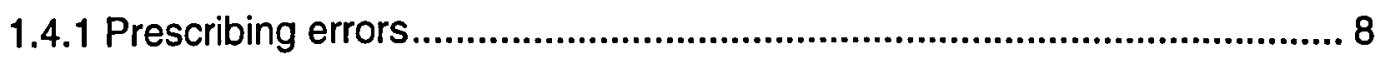

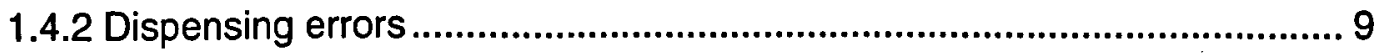

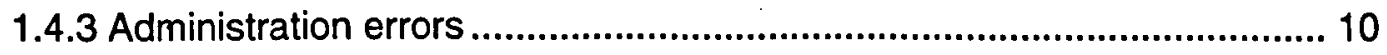

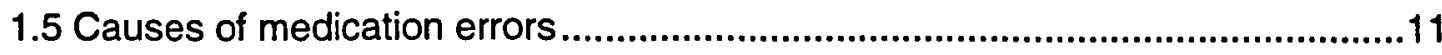

1.5.1 Off-label and unlicensed medication use ............................................ 11

1.5.2 Drug dosage calculation and guidelines ............................................ 12

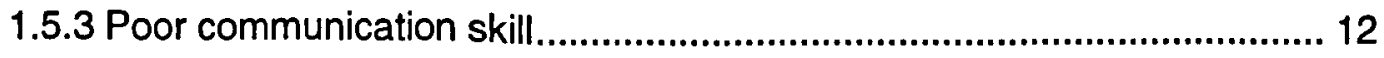


1.6 Interventions that may reduce paediatric medication errors ............................13

1.6.1 Computerized Physician Order Entry (CPOE) Systems........................... 13

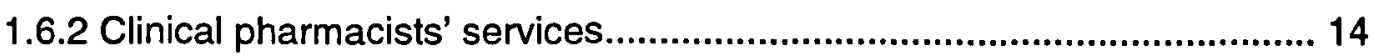

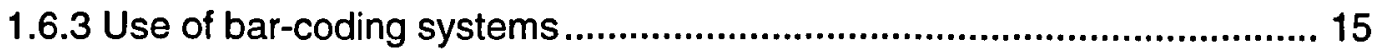

1.6.4 Double checking process .................................................................... 15

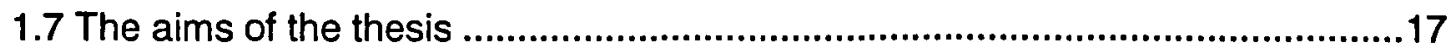

\section{CHAPTER TWO}

DOUBLE CHECKING THE ADMINISTRATION OF MEDICINES: A SYSTEMATIC REVIEW

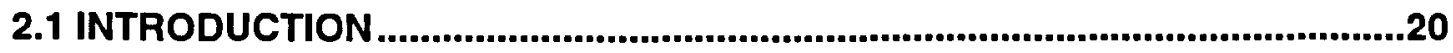

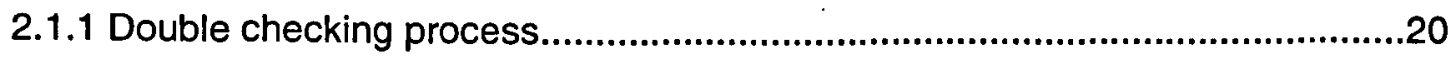

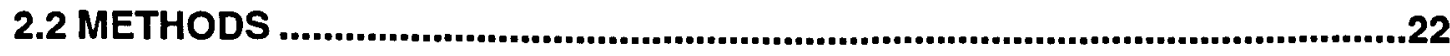

2.2.1 Identification of relevant literature ............................................................22

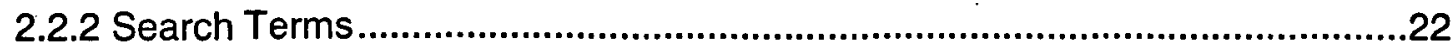

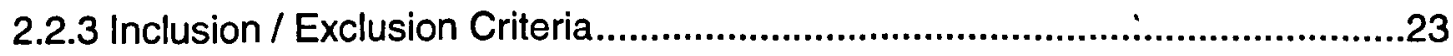

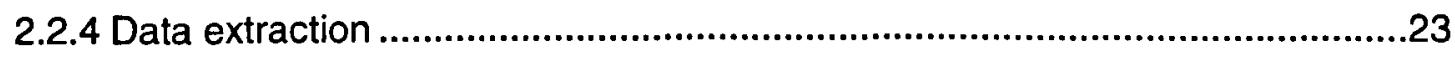

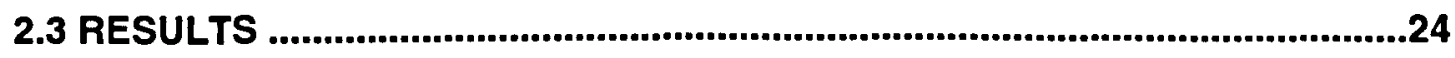

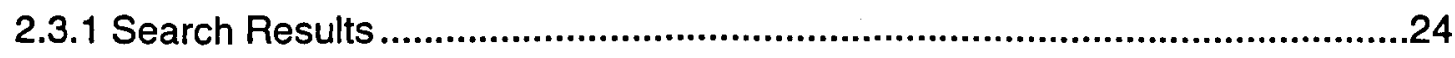

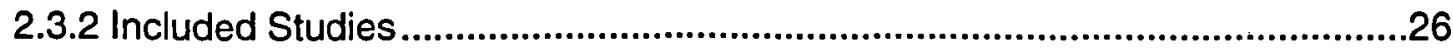

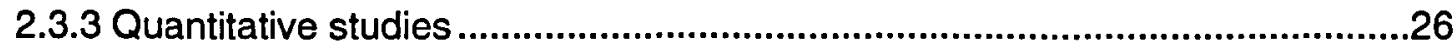

2.3.4 Mixed (Quantitative and Qualitative) studies.................................................31 
2.3.6 Previous systematic reviews.......................................................................39

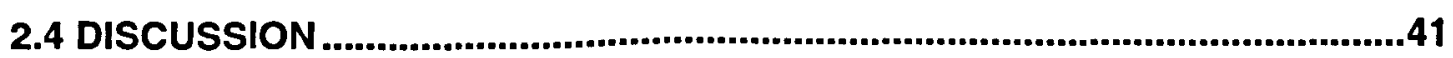

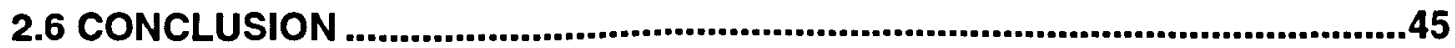

\section{CHAPTER THREE}

ADHERENCE OF PAEDIATRIC NURSES TO DOUBLE CHECKING PROCESS STEPS DURING MEDICATION ADMINISTRATION IN A CHILDREN'S HOSPITAL:

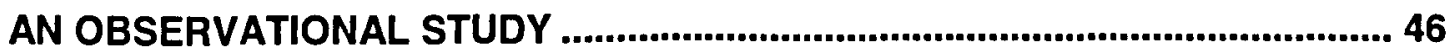

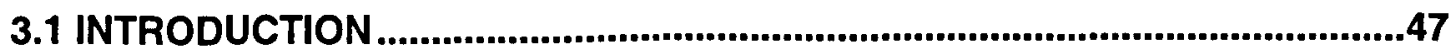

3.2 DERBYSHIRE CHILDREN'S HOSPITAL NHS TRUST .................................49

3.3 STUDY AIMS AND OBJECTIVES ...................................................................50

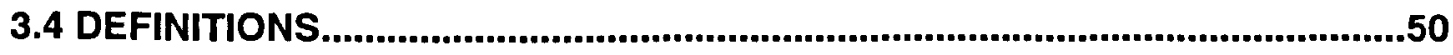

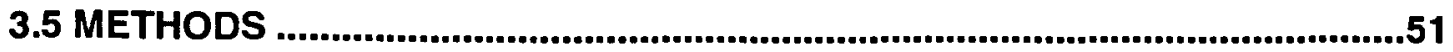

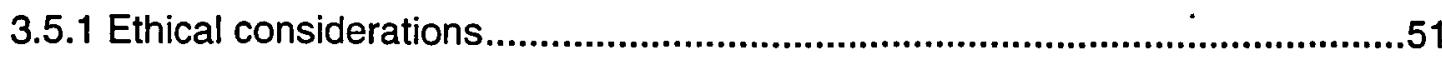

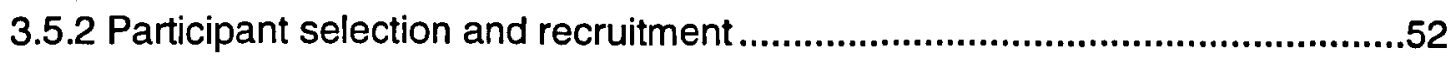

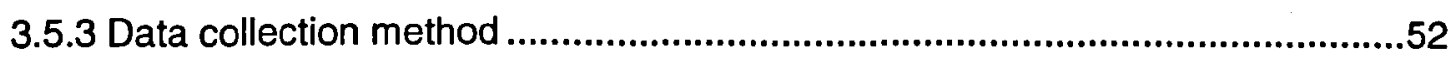

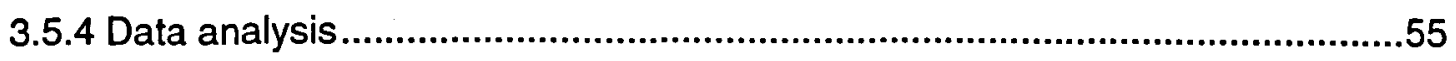

3.6 RESULTS ...........................................................................................................56

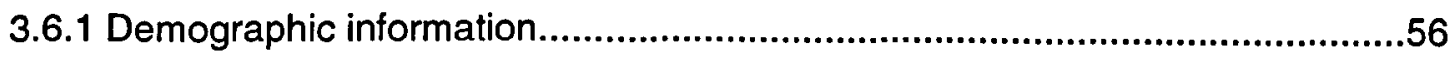

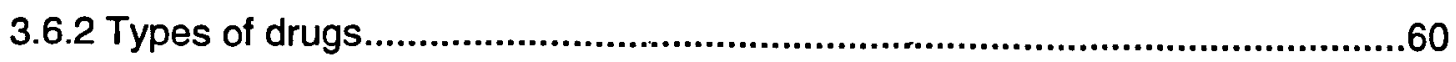

3.6.3 Adherence rate to double checking policy steps .......................................62

3.6.4 Comparison between weekdays and weekends adherence rates..................64

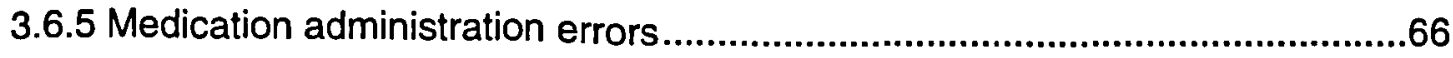


3.6.6 Clinical significance of errors

3.6.7 Factors affecting adherence to the double checking process........................69

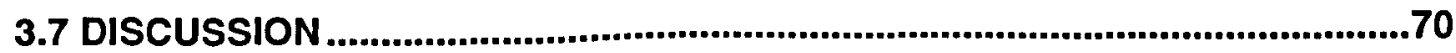

3.7.1 Nurses adherence to double checking steps ...............................................70

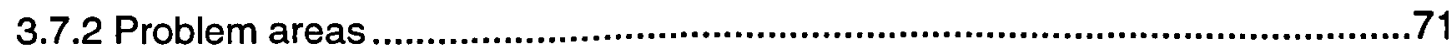

3.7.3 Adherence rate during weekdays and weekends.........................................72

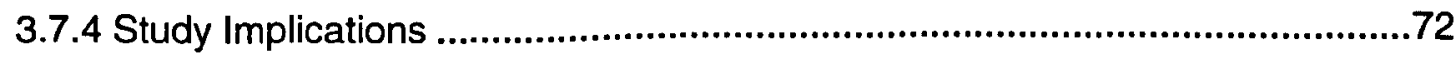

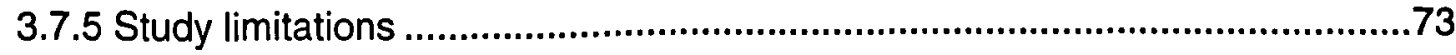

3.8 CONCLUSION

\section{CHAPTER FOUR}

NURSES' KNOWLEDGE, PERCEPTION AND OPINIONS OF THE DOUBLE CHECKING PROCESS: A QUESTIONNAIRE STUDY ............................................. 75

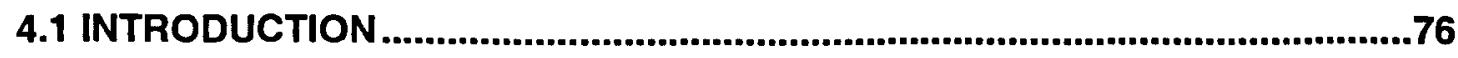

4.2 METHODS AND MATERIALS ......................................................................77

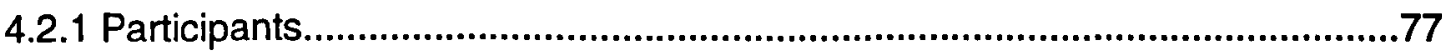

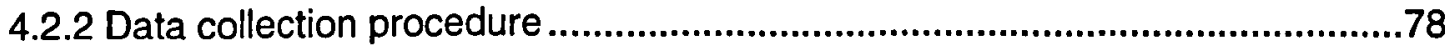

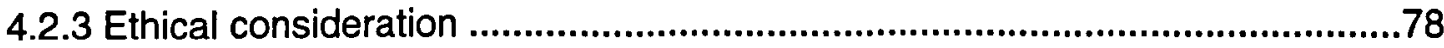

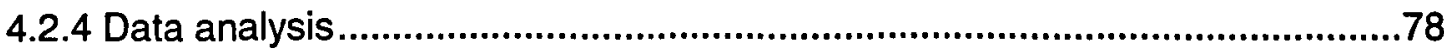

4.3 RESULTS .................................................................................................................78

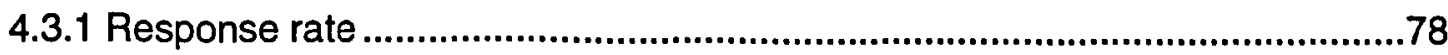

4.3.2 Demographic and background information of respondents ...........................79

4.3.3 Nurses' knowledge and feelings about double checking .................................80 
4.3.4 Factors affecting nurses' adherence to double checking

4.3.5 Differences in the double checking process during days and shifts .83

4.3.6 Recognition of medication administration errors .84

4.3.7 Opinions on effectiveness .85

4.3.8 Opinions of the single checking .86

4.3.9 Additional comments .86

4.4 DISCUSSION 87

4.5 STUDY LIMITATIONS .89

4.6 CONCLUSION .89

CHAPTER FIVE

MEDICATION ADMINISTRATION ERRORS WITH SINGLE AND DOUBLE CHECKING IN PAEDIATRIC PATIENTS: SIMULATION STUDY. 90

5.1 INTRODUCTION .91

5.1.1 Overview 91

5.1.2 Nurses role in medication administration .91

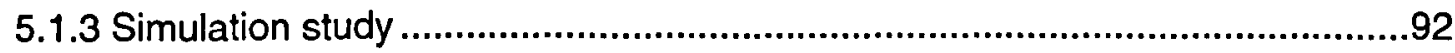

5.2 AIMS AND OBJECTIVES ...................................................................92

5.3 METHODS AND MATERIALS ..................................................................93

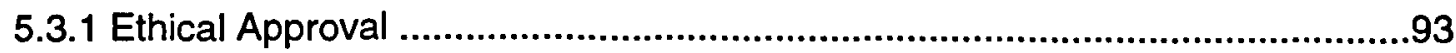

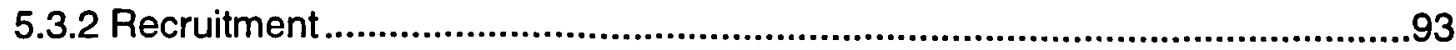

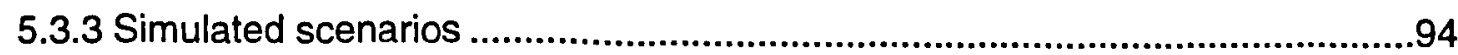

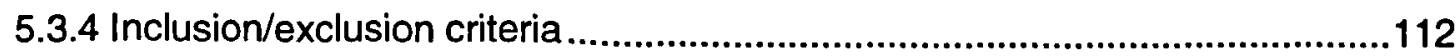


5.3.5 Sample size

5.3.6 Duration of the study

5.3.7 Data collection forms 112

5.3.8 Data analysis 113

5.4 RESULTS 113

5.4.1 Demographic data .113

5.4.2 Confounders in scenarios .115

5.4.3 Undetected confounders. 117

5.4.4 Influence of simulation on participants 117

5.4.5 Actual errors made by participants .118

5.4.6 Time taken for medication administration .119

5.4.7 Qualitative evaluation .121

5.4.7.1 Level of confidence 121

5.4.7.2 Clinical performance feedback .121

5.5 DISCUSSION .122

5.6 Barriers and challenges .123

5.7 Limitations .125

5.8 Future research .125

5.9 CONCLUSION 125 
MEDICATION ERRORS IN THE MIDDLE EAST COUNTRIES: A SYSTEMATIC REVIEW OF THE LITERATURE.

6.1 INTRODUCTION.

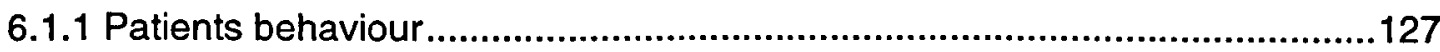

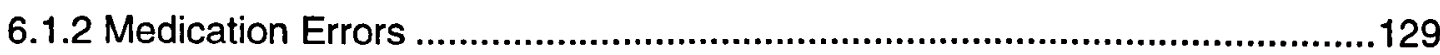

6.2 AIMS AND OBJECTIVES ............................................................................130

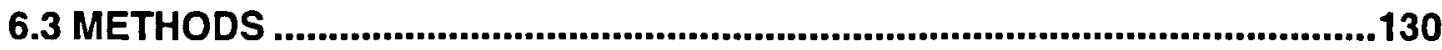

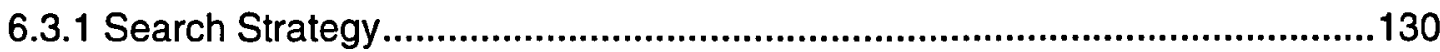

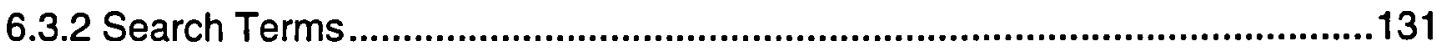

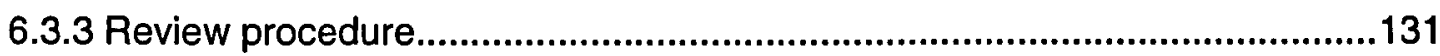

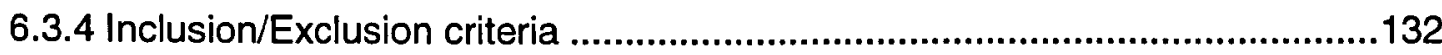

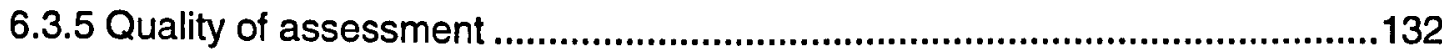

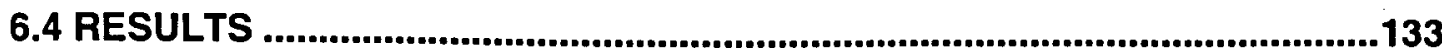

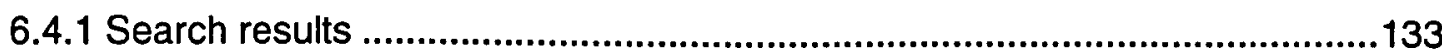

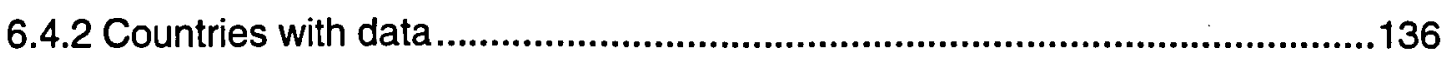

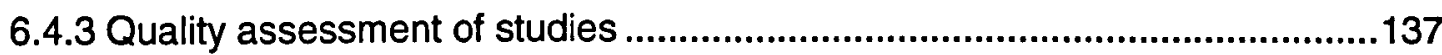

6.4.4 Types of included studies .......................................................................138

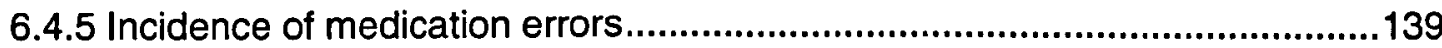

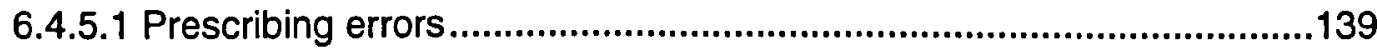

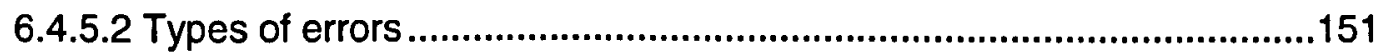

6.4.5.3 Transcribing errors ...........................................................................153

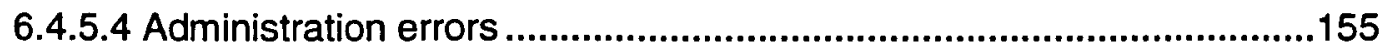


6.4.9.1 Lack of knowledge of prescribing skills.

6.4.9.2 Lack of pharmacological knowledge between physicians and nurses.171

6.4.9.3 Poor compliance with drug prescribing and administration guidelines 173

6.4.9.4 Unreported medication errors

6.4.9.5 Heavy workload and new staff.

6.4.9.6 Miscommunications between health care professionals

6.5 DISCUSSION

6.5.1 A limited and unclear picture 175

6.5.2 Prescribing errors 176

6.5.3 Transcribing errors 177

6.5.4 Administration errors 177

6.5.5 Frequency and Types of medication errors 178

6.5.6 Contributory factors for medication errors 178

6.5.7 Limitations of this review .178

6.5.8 Further research .179

6.6 CONCLUSION 179

6.7 RECOMMENDATIONS FOR FUTURE RESEARCH. .180 


\section{CHAPTER SEVEN}

CONCLUSION 182

7.1 INTRODUCTION. 183

7.2 SUMMARY OF FINDINGS .183

7.3 PRACTICE IMPLICATIONS.. 186

7.4 LIMITATIONS OF THIS THESIS. 186

7.6 FINAL CONCLUSION 187

REFERENCES. 188

APPENDICES 215

APPENDIX A

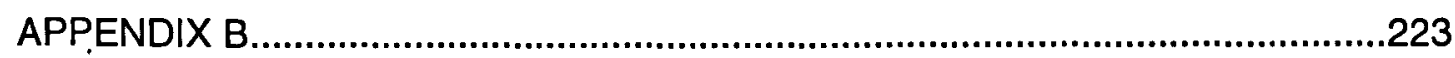

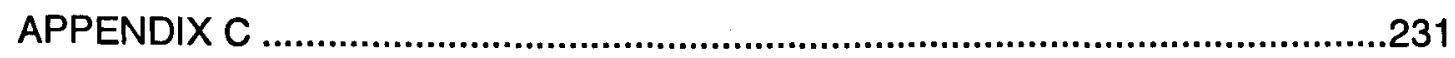

COPIES OF PUBLISHED WORKS FROM THIS THESIS...................................249 


\section{LIST OF TABLES}

Table 2.1: Types of double checking and reliability levels.........................21

Table 2.2: Quantitative studies of actual error rates...................................29

Table 2.3: Quantitative and qualitative (mixed) studies.............................32

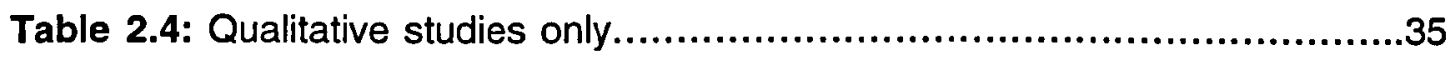

Table 2.5: Previous systematic reviews..............................................40

Table 3.1: Characteristics of the observed wards and nurses......................56

Table 3.2: Patients and drugs administered.........................................58

Table 3.3: Adherence rate to double checking policy steps........................63

Table 3.4: Comparison between weekdays and weekends double checking policy

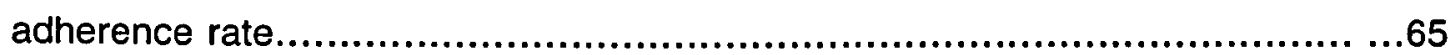

Table 3.5: Medication administration errors identified..........................67

Table 3.6: Medication errors observed on weekdays versus weekends.......68

Table 4.1: Demographic data of the paediatric nurse respondents............79

Table 4.2: Paediatric nurses knowledge about double checking..............81

Table 4.3: Nurses perceptions about double checking.......................82

Table 4.4: Paediatric nurses perceptions about double checking effective days and

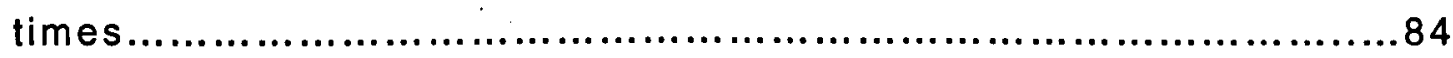

Table 4.5: Nurses identification of medication administration errors......85

Table 4.6: Paediatric nurses perception about single checking.............86 
Table 5.1: Participants distributed randomly between two simulations.

Table 5.2: Demographic data.

Table 5.3: Undetected confounders for single and double checking.

Table 5.4: Comparison between first and second simulation results .118

Table 5.5: Type and frequency of errors made by nurses .119

Table 5.6: Time taken for drug administration .120

Table 6.1: Describes the number of studies for each country. .136

Table 6.2: Prospective observational studies describing prescribing errors.....142

Table 6.3: Retrospective studies describing prescribing errors

Table 6.4: Questionnaire studies describing prescribing errors. .150

Table 6.5: Prescriptions with dosing errors. .152

Table 6.6: Prospective studies describing transcribing errors. .154

Table 6.7: Prospective studies describing administration errors .156

Table 6.8: Retrospective studies describing administration errors. .158

Table 6.9: Questionnaire studies of nurses perceptions of describing administration errors. 160

Table 6.10: Interventional studies describing MEs in adults. .163

Table 6.11: Interventional studies describing MEs in paediatric and neonatal patients. 167

Table 6.12: Clinical consequences of reported medication errors. .170 


\section{LIST OF FIGURES}

Figure 2.1: Flow diagram of search and review process.........................25

Figure 3.1: Types of observed dosage form administered in each ward........59

Figure 3.2: Drug class of medications administered and observed during study

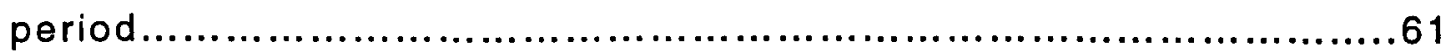

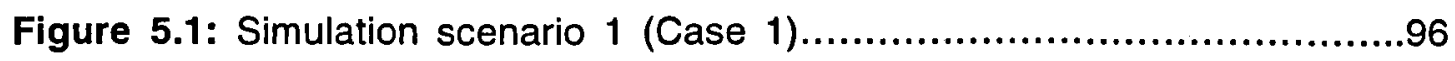

Figure 5.2: Simulation scenario 1 (Case 2)....................................102

Figure 5.3: Simulation scenario 2 (Case 1)......................................105

Figure 5.4: Simulation scenario 2 (Case 2) ........................................109

Figure 6.1: Flow chart for search and review process.........................135

Figure 6.2: Quality Assessment criteria of included studies........................137

Figure 6.3: Study Classification by stage of medication process..................138 
CHAPTER ONE

GENERAL INTRODUCTION AND OVERVIEW 


\section{INTRODUCTION}

\subsection{General Background}

A safe environment is a high priority in health care systems. Safety culture has been defined as "the product of individual and group values, attitudes, perceptions and patterns of behaviour that determine a group or organisation's commitment to safety management in general or particularly in certain processes" (INSAG, 1991).

The phrase 'medical errors' is a broad term used to describe all errors that happen within the healthcare system, including Medication Errors (MEs), mistakes in surgery, or technical failures. MEs have ranked as the most common type of medical error that occurs in health care organisations (Kohn et al., 2000). In the last decade, the awareness of and attention about MEs has increased.

MEs are a universal and global concern in all health care systems and can occur in any country. Different classifications for MEs in different studies are used (Kaushal et al, 2001a; Ferner \& Aronson, 2006), and there are different definitions and different methods that can be used to detect errors. One of these classifications depends on a psychological approach which categorizes errors as mistakes (which are errors in the planning of an action), slips (which are action-based errors) or lapses (memory-based errors) (Leape et al., 1995). MEs are also classified according to where they happen in the medication process which includes drug prescribing or ordering, transcription, dispensing, administration, monitoring and documentation (Leape et al., 1995). These differences in the classifications of MEs are reflected in the studies' results.

MEs have a range of definitions according to different studies (Ghaleb et al., 2006). The variation in these definitions and in the methods that are used to detect errors make comparisons between these studies results difficult. Cimino and his 
colleagues defined MEs as "any error either large or small at any point in the medication system from the time the drug is ordered until the patient received it" (Cimino et al., 2004). Another definition used has been "any error in the medication process, including ordering, dispensing, transcribing, administering and monitoring, even if the error was intercepted and corrected prior to reaching the patient" (Gandhi et al., 2005). Moreover, MEs have also been defined as "a dose administered to the patient that deviates from the physician's orders, such as an omission, wrong dosage or unauthorized drug". For example, when one patient was given a dose intended for another patient (Barker et al., 1982). On the other hand, Kaushal and colleagues defined MEs as an error in drug ordering, transcribing, dispensing, administering, or monitoring (Kaushal et al., 2001b), and differentiate between errors which are preventable and not preventable.

The definition which is accepted by the United Kingdom (UK) Department of Health and the United State National Co-ordinating Council for ME Reporting and Prevention (NCCMERP) is "any preventable event that may cause or lead to inappropriate medication use or patient harm, while the medication is in the control of the health care professional, patient, or consumer. Such events may be related to professional practice, healthcare products, order communication, product labelling, packaging and nomenclature, compounding, dispensing, distribution, administration, education, monitoring, and use" (DoH, 2004). One study has argued that this definition is inadequate because it includes any preventable adverse events that cause harm or lead to harmful effects for the patients. The study suggests that events are preventable both when they result from error and when they are a consequence of the careful and rational decision to use a drug that causes unavoidable harm (Ferner and Aronson, 2006). 
Moreover, Ferner and Aronson (2006) have proposed the following definition for MEs which is "A medication error is a failure in the treatment process that leads to, or has the potential to lead to harm to the patient". They use the word "failure" to signify that the process has fallen below standard, and they include all the medication treatment process stages. Their definition however, does not make the required treatment process standard explicit. Also, it does not indicate who may make the error.

\subsection{Medication errors in adults}

MEs are the most common error that can happen in hospitals and the most common single preventable cause of adverse events (IOM, 2001). The Institute of Medicines (IOM) estimated that between 44,000 to 98,000 hospitalised patients die every year as a result of medical errors in the US (IOM, 2001). Approximately 7000 deaths occur annually across the patient population due to MEs in the US (Kohn et al., 2000). Another study reported that $1-2 \%$ of the patients admitted to the hospitals in the US suffer from MEs that result in harm, and $12 \%$ of the Adverse Drug Events (ADEs) were life - threatening (Bates et al., 1995). There is also evidence that the death rate from MEs is increasing. Phillips and his colleagues investigated fatal MEs by examining US death certificates for a ten year period (1983 - 1993) (Phillips et al., 1998). They reported that the inpatient deaths which occurred due to MEs showed a 2.3 fold increase for that time period (Phillips et al., 1998). Leape et al (1995) conducted a prospective cohort study of MEs in 11 medical and surgical units in two tertiary care hospitals. They found that $39 \%$ of errors occurred during the prescribing stage and nearly half of those errors were detected by nurses or pharmacists prior to them reaching the patient. They also reported that $38 \%$ of the errors occurred in the administration stage of the medication process but only $2 \%$ of those errors were intercepted before reaching the patient (Leape et al., 1995). 
The incidence of MEs in the UK is likely to be similar. In British hospitals 1 in 250 prescriptions had a serious error (DoH, 2004). Approximately, $9 \%$ of hospital inpatients may suffer severe harm from MEs (NPSA, 2007a). Another study reported a $500 \%$ increase in drug errors over the last decade, leading to 1200 deaths in England and Wales in 2001 (Scott, 2002). A study involving screening of 36,200 medication orders by 25 ward pharmacists identified that $1.5 \%$ of orders contained errors, and most of those errors $(54 \%)$ were in the drug dose, and were serious in $0.4 \%$ of cases (Dean et al., 2002).

\subsection{Paediatric medication errors}

Most of the MEs studies have been performed on adults. Relatively, few studies of MEs have been conducted in children. Several studies have confirmed that MEs are a significant problem and occur more frequently in children (Lesar et al, 1990; Kaushal et al, 2001a; Cousins et al, 2002; Ghaleb et al., 2006). They are more common in the paediatric and neonatal population for several reasons:

- Drug doses must be calculated for each individual child's weight or body surface area involving sometimes complex calculations.

- Most commercially available drugs purchased by the pharmacy are adult designed standard dosage forms which need re-calculation or manipulation for administration to the child patient.

- The pharmacokinetics of many drugs vary with age, and this affects dosage, meaning that doses need to be adjusted with age (gestational and postnatal) as well as weight and surface area.

- Most of the drugs used in paediatrics are off label and/or unlicensed and this may lead to MEs (Conroy et al, 2000; Conroy, 2011). 
- Because many formulations used are adult designed, the amount of the drug in vials that are used to administer medicines to neonates potentially allows 10 fold or even 100 fold errors) (Chappell \& Newman, 2004).

These factors make the paediatric patients more susceptible to adverse drug events, which may be three times higher than in adult patients (Kaushal et al., 2001a).

There is a difference between medication use and types of errors in children compared to adults such as dosing calculation based on the body weight, and so the strategies used to prevent errors in children should also be different.

The UK Department of Health has recognised that children are a challenging group of patients for safe medication practice $(\mathrm{DoH}, 2004)$. The safety of paediatric medication use is also an important issue in international organizations. The World Health Organization (WHO), UNICEF, European Society for Developmental Perinatal and Paediatric Pharmacology (ESDPPP), as well as other organizations, have all highlighted that children's medicines are a global problem. The WHO have launched a campaign to "make medicines child size" (Choonara, 2009). This campaign aims to raise awareness and to accelerate action in order to address the need for improved availability and access to safe child-specific medicines for all children (WHO, 2007).

\subsection{Incidence of paediatric medication errors}

A number of studies have been published during the last 10 years reporting the incidence rate of paediatric MEs in hospitals (Wilson et al., 1998; Ross et al., 2000; Kaushal et al., 2001a; Cousins et al., 2002; Wong et al., 2004; Ghaleb et al., 2006; Miller et al., 2007; Wong et al, 2009; Ghaleb et al., 2010). Different incidence rates are reported among these studies $(0.15 \%$ to $27 \%)$ and comparison is difficult because each study used different denominators. 
The variation in MEs rates between studies may be due to the differences in the definitions of MEs used, in the methods used to collect data and in the area of study. MEs in the prescribing stage occur in children more frequently than in adults: 5.89 per 1,000 orders and 4.12 per 1,000 orders, respectively (Lesar et al., 1997).

An eight year review of MEs in children in the UK using press reports identified at least 29 deaths associated with MEs (Cousins et al., 2002). A systematic review estimated that $5-27 \%$ prescriptions for children contain an error somewhere in the process, in the prescribing $3-37 \%$, dispensing $5-58 \%$, administration $72-75 \%$ and in the documentation stages $17-21 \%$ (Miller et al., 2007). A prospective study in five hospitals in the UK found the MEs incidence rate in the prescribing stage to be $13.2 \%$ of medication orders and in the administration stage was $19.1 \%$ of drug administrations (Ghaleb et al., 2010).

One estimated suggested that at least 1675 avoidable MEs may happen every year in paediatric inpatients of which 85 errors were likely to be moderate/severe (Stephenson, 2000).

Patients in a Neonatal Intensive Care Unit (NICU) may be at higher risk for 10 fold dosing errors due to the dosing calculations needed in prescribing and in drug preparation (Chappell and Newman, 2004; Stavroudis et al, 2008). Raju and colleagues in 1989 reported a ME rate of $14.7 \%$ of all admissions to a Paediatric Intensive Care Unit (PICU) and NICU over 4 year period. Vincer et al (1989) reported another incidence rate of MEs of 13.4 per 1000 patient days over 2 years in NICU (Vincer et al., 1989). Due to the different denominators used it is impossible to compare these error rates.

A systematic review reported that antibiotics and sedative drugs were the most frequent drug classes associated with errors in children (Ghaleb et al., 2006). In 
addition, Holdsworth et al (2003) reported that most of the adverse drug events in a general paediatric unit and PICU were related to opiates and antibiotic drugs.

MEs in children are also classified according to where they occur during the medication treatment process, i.e. prescribing, transcribing, dispensing, administration, monitoring and documentation (Leape et al, 1995).

\subsubsection{Prescribing errors}

Different studies have used different definitions of prescribing errors (Dean et al., 2000; Condern et al., 2009; Aronson, 2009; Ghaleb et al., 2010). Prescribing errors include the incorrect choice of medication, wrong dose, wrong strength, wrong frequency, incorrect route of administration, inadequate instruction for use of a medication and wrong formulation. As already highlighted most paediatric drug doses are calculated individually according to the patient's weight, age, body surface area and the clinical condition of the patient. These differing parameters enhance the opportunities of prescribing errors and particularly dosing errors (Kozer et al., 2002). Ten-fold dosing errors occur due to calculation mistakes, misplacement of the decimal point, omission of a zero prior to the decimal point, the use of the trailing zeroes and use of incorrect units (Fortescue et al., 2003).

Several studies have found that dosing errors are one of the most frequent type of paediatric prescribing errors (Wong et al., 2004; Condern et al., 2009; Ghaleb et al., 2010).

As dosing error is the commonest type of paediatric prescribing error, interventions are needed to reduce such errors. Wong and colleagues in their Co-operative of Safety of Medicines in Children (COSMIC) report identified and analysed the interventions that have been implemented to reduce dosing errors in children. Key interventions included: electronic prescribing, guidelines/formularies, double 
checking, intelligent infusion pumps and Centralised Intravenous Additive Services (CIAS) (Wong et al, 2007).

As yet no specific tool has been validated that can be used to assess paediatric prescribers in order to identify weak prescribing (Sammons \& Conroy, 2008).

\subsubsection{Dispensing errors}

Most drug formulations are designed to be used in adults because most clinical trials have been conducted on adults (Conroy et al., 2000). The pharmaceutical services in most hospitals contribute to the safe and efficient use of medication and have an essential role in preventing errors. Studies have however found an incidence of dispensing errors of about $10 \%$ even in hospitals with advanced medication dispensing systems, such as Unit dose system (Allan \& Barker, 1990; Hughes \& Edgerton, 2005). Different definitions have been used to identify dispensing errors but the most common definition used in hospital and community pharmacies is an error detected and reported after the medication has left the pharmacy. The UK NPSA reported that around 900 million medicines every year are dispensed through community and hospital pharmacies in England and Wales (NPSA, 2007a). Also this report estimated that over 134,000 dispensing errors are detected in community pharmacies, most of these errors (85\%) are detected by pharmacists before the drug is supplied to the patient (NPSA, 2007b).

Dispensing errors involve dispensing the wrong drug, the wrong dose or providing an incorrect label, out of date medicines and wrong strength. Look Alike and Sound Alike (LASA) drug names have been estimated to cause $33 \%$ of errors in dispensing according to the UK dispensing error analysis scheme, for example, Lasix® is (Frusemide) but Losec $\circledast$ is (Omeprazole) (NPSA, 2007b). A previous systematic review reported that the dispensing error rate in children ranged from $5 \%$ to $58 \%$ of all errors (Miller et al, 2007). Preventing a ME from reaching the patient decreased 
in the later stages of the medication treatment process (Antonow et al., 2000; Stratton et al., 2004). Antonow and colleagues (2000) estimated the extent of ME underreporting by comparing a nurse questionnaire survey results with hospital incident reports for the previous 6 months. 177 errors had been observed and identified by paediatric nurses. $76 \%$ of these errors had been detected at the prescribing stage, $70 \%$ at the transcription stage, $61 \%$ at the dispensing stage (which involved wrong medications, wrong dose and known allergy). Only $40 \%$ of the MEs were identified at the administration stage and prevented from reaching the patients. In contrast, only 51 incident reports were written within the 6 month period. Of these only $30 \%$ had a fully completed incident report. $5(10 \%)$ of the incident reports were related to the dispensing stage (Antonow et al., 2000).

The NPSA found that more than half $(59.3 \%)$ of reported MEs in primary care happened during the dispensing of medicines (NPSA, 2007b). It has been suggested that dispensing errors may be reduced by putting double checking measures in place (Mahajan et al, 2009).

\subsubsection{Administration errors}

One of the last steps in the medication treatment process is the administration of medicines which is usually performed by nurses when patients are in hospital. During drug preparation the nurse should follow the five rights as a part of everyday nursing routine: the right patient, the right drug, the right time, the right dose and the right route of administration.

Administration errors have different definitions in practice (Barker et al., 2002; Prot et al., 2005; Ghaleb et al., 2010). Ghaleb and colleagues defined Medication Administration Errors (MAEs) as the administration of a dose of medication that deviates from the prescription, as written on the patient medication chart, or from 
standard hospital policy and procedures. This also includes errors in the preparation, and administration of intravenous medicines on the ward.

MAEs include errors of incorrect preparation of medicines, omission errors, drugs given to the wrong patient, incorrect dose calculation, wrong route of administration, wrong rate and wrong administration time.

Two studies reported that errors in the administration stage are more frequent than in prescribing (Miller et al., 2007; Ghaleb et al.; 2010). Miller et al (2007) reported that $5-27 \%$ of prescriptions for children have an error somewhere in the medication treatment process. $72-75 \%$ of these occur during drug administration compared to $3-37 \%$ in prescribing (Miller et al., 2007). Errors have also been found in $19.1 \%$ episodes of drug administration compared to $13.2 \%$ in prescribing (Ghaleb et al., 2010).

\subsection{Causes of medication errors}

An understanding of the causes of MEs is important for all healthcare professionals.

\subsubsection{Off-label and unlicensed medication use}

Lack of evidence from clinical trials and a lack of clinical trials in children have led to the use of medicines which are not licensed or more commonly are used outside the terms of their product license (off label) (Turner et al., 1998). Both are more common in children than in adults and this may increase the chance of MEs occurring in children (Conroy, 2011).

Conroy et al (2000) conducted a survey of unlicensed and off label drug use in paediatric wards in five European countries to examine the extent of their use, and found that $46 \%$ of all paediatric prescriptions were off label or unlicensed, and $67 \%$ of 624 paediatric patients received unlicensed or off label drugs. They concluded 
that off label and unlicensed prescribing of drugs in paediatrics is a European problem.

Mclntyre et al (2000) conducted a general practice study and also found that a significant number of prescribed medications for children were off label (Mclntyre et al., 2000). Unlicensed prescribing was less of a problem in this setting.

Conroy (2011) explored the relationship between the MEs reported in a hospital and use of off label and unlicensed drugs. Unlicensed drugs were more likely to be associated with reported errors compared to licensed drugs in both paediatric wards (OR 2.24, 95\% Cl 1.31 to 3.87), $\mathrm{p}=0.0001$, and neonates (OR 5.81, 95\% $\mathrm{Cl} 2.32$ to 14.55), $p=0.0001$ (Conroy, 2011).

\subsubsection{Drug dosage calculation and guidelines}

Doses vary in children and are calculated according to age, weight, body surface area, organ system maturity and clinical condition (AAP, 2003). As noted earlier, drug dosage errors were the most frequent errors reported in the local and national media in the UK (Cousins et al, 2002). Some studies have suggested that healthcare professionals have inadequacies in mathematical dose calculation (Glover and Sussmane, 2002, Rowe et al., 1998). Wong et al (2004) found that drug dosage calculation errors were a significant problem in all ages of paediatric patients. In England, the incidence of dosing errors in paediatrics is estimated to be around 500,000 every year (Wong et al., 2004). In addition, dosing errors occur with neonatal patients in the NICU and incorrect doses have been found in $13.7 \%$ of reports (Raju et al., 1989).

\subsubsection{Poor communication}

Poor communication is one of the most common causes for MEs (Stebbing et al., 2007, Wilson et al., 1998). In a study in primary care, doctors discovered that $50 \%$ 
of adverse events resulted from communication difficulties (Bhasale et al., 1998). Poor communication may result from poor handwriting, incorrect abbreviations, unclear drug labeling, and confusion between drug names. Communication skills in medical practice between care providers and their patients or parents are therefore important because they affect healthcare outcomes, especially when the patient is a child.

\subsubsection{Unfamiliarity with paediatric treatment}

Unfamiliarity of health care providers with paediatric patients and their medications may lead to MEs in their treatment. Also, inadequacy in education or lack of training for paediatricians and other healthcare professionals increase the chance of errors in the medication they are prescribing, dispensing or administering to paediatric patients (Folli et al., 1987). Studies have found that poor practical experience of health care providers in paediatric hospitals or areas may contribute to recurrent MEs (Folli et al., 1987, Wilson et al., 1998). In addition, the problems may increase when new doctors or junior doctors make the transition from general medical practice to paediatrics (Wilson et al., 1998).

\subsection{Interventions that may reduce paediatric medication errors}

Different interventions have been suggested by different studies to reduce or prevent MEs and to improve patient safety.

\subsubsection{Computerized Physician Order Entry (CPOE) Systems}

Computerised Physician Order Entry (CPOE) systems play an important role in reducing prescribing errors by allowing physician orders to be entered into the computer rather than on paper. This system can be linked to drug - drug interaction warnings and decision support systems. Some studies evaluated the CPOE in general hospitals and suggest that after electronic prescribing is applied with a 
CPOE system the prescribing quality in hospital inpatients significantly increases (Shulman et al., 2005, Colpaert et al., 2006, Donyai et al., 2008). Vaidya and colleagues (2006) in their crossover study compared a handwritten group with a CPOE system in a PICU for ordering continuous IV drug infusions. They found a significant reduction in the prescribing error rate from $73 \%$ in the handwritten group compared to $4.3 \%$ in the CPOE system group (Vaidya et al., 2006).

In paediatric intensive care units that implemented $\mathrm{CPOE}$ the prescribing errors reduced by $99 \%$ (Potts et al., 2004). Another study by King et al. (2003) found that CPOE systems implemented in the paediatric settings produced a significant beneficial effect on ME rates but not on the number of ADEs.

In a recent systematic review, the authors conclude that there is some evidence of the effectiveness of CPOE to reduce prescribing errors in adult hospitals but the evidence base was limited by the modest study sample sizes and designs (Reckmann et al., 2009).

Despite CPOE systems being useful and effective in reducing MEs, some studies have reported new errors being introduced. These errors included the selection of an inappropriate formulation for a specific route, selection of an inappropriate item (Mahoney et al., 2007), and inappropriate use or selection of default doses (Donyai et al., 2008).

\subsubsection{Clinical pharmacists' services}

Pharmacists, clinical pharmacists and clinical pharmacologists play an important role in reducing MEs. After a clinical pharmacist was involved in a medical team round of the patients in the ICU, it was reported that more than $66 \%$ of errors were reduced relating to ordering errors or prescribing errors (Leape et al., 1999), and that reviewing medication charts by pharmacists is very important to detect MEs. 
While Kaushal et al (2008) found that the unit-based clinical pharmacists in the PICU found that $79 \%$ decrease in the rate of serious MEs in the PICU (Kaushal et al., 2008).

In general, all reviewed studies have shown that pharmacists can reduce serious preventable MEs (Koren et al., 1991; Fortescue et al., 2003, Sanghera et al., 2006, Conroy et al., 2007b). Fortescue and colleagues (2003) reported that physician residents estimated that $81 \%$ of errors could be avoided by ward - based clinical pharmacists monitoring. Improving the communication between physicians, nurses and pharmacists e.g. by increasing nursing involvement in physician clinical ward rounds could avoid $86 \%$ of potentially harmful MEs that may occur (Fortescue et al., 2003).

\subsubsection{Use of bar-coding systems}

Bar coding replaces manual documentation with electronic scanning of unique identifier codes that are transmitted to a database. Bar-coding technology has been used previously in markets outside of health care, mainly in supermarkets and shopping centres (Simpson, 2001). In the health care system bar-coding technology has been used to prevent MAEs by verifying that the patient has received the right drug in the right dose via the right route at the right time. Bar-coding technology has also been used in hospital pharmacies to prevent dispensing errors during the dispensing process (Poon et al., 2006). This study found that bar-code technology in a hospital pharmacy reduced the rate of dispensing errors from $0.37 \%$ to $0.06 \%$ including wrong formulations, wrong dose and wrong medication.

\subsubsection{Double checking process}

Double checking or checklists have been employed in the nuclear industries and aviation safety to reduce errors or human mistakes and to improve safety (Toft \& 
Mascie - Taylor, 2005). In aviation statistics, 2 errors happen per flight, and 60 $80 \%$ of flight accidents involve human mistakes (Foushee, 1984).

Double checking is one of the strategies that have been used in both medical and non-medical areas to reduce the risk of errors (Hales \& Pronovost, 2006). In aviation, double checking or checklists have become a mandatory part of practice, to reduce human error. They significantly decrease the risk of errors and improve the outcomes in aviation safety (Hales \& Pronovost, 2006). In healthcare systems, blood transfusion, anaesthesia and radiotherapy have all implemented the checklist or double checking concept to improve patient safety (Duggan et al, 1997; Toft \& Mascie-Taylor, 2005).

Double checking of medications has been recommended as an intervention to reduce MEs (Grissinger, 2003; Merry \& Webster, 2008; Conroy et al., 2012) and has become standard practice in many children's hospitals and paediatric units in the UK (Conroy et al., 2012). Many hospital policies in the UK require that the majority of children's medicines administration must be double checked (Conroy et al, 2012). Double checking is defined as a procedure that requires two qualified health professionals, usually nurses, to independently check the medication before administration to patients (Conroy et al., 2012). Grissinger in recommending double checking suggests that this process should be implemented in situations involving high risk medications, complex administration processes and/or high risk patients such as children (Grissinger, 2003). This thesis will focus mainly on the evaluation of the double checking process performed by paediatric nurses in a children's hospital.

Double checking depends on the effort of individual nurses, their knowledge, power of observation and ability to apply this strategy in practice. Some authors suggest that double checking should be applied only in certain situations, in high risk 
patients (neonates, infants), or with high risk medications (chemotherapy, opiates, intravenous route), or in a complicated dose calculation process (Grissinger, 2003).

\subsection{The aims of the thesis}

Despite the fact that little research is available about the effectiveness of the double checking process in reducing MEs compared to other interventions in paediatric settings, the double checking process is widely used in hospitals and supported by healthcare professionals (Conroy et al., 2012). Jarman et al (2002) suggested that single checking in adult inpatient units was as safe as double checking. However, MEs still occur in practice.

I initially decided to perform a systematic review of the literature in order to establish what evidence was available to support the use of double checking of medicines (Chapter two).

Based on the findings that were highlighted from my systematic review, which was that "there is insufficient evidence to either support or refute the practice of double checking the administration of medicines", 1 decided to do more studies and research to evaluate the double checking of the administration of medicines and its effectiveness in reducing MEs in practice in a children's hospital.

Chapter three is a prospective observational study of the double checking process during medication administration and drug round times in a children's hospital. The study evaluated all the double checking process steps in different wards and with different paediatric nurses. Also, the study was performed to identify the MAEs that occurred during the study period despite double checking. The MAEs rate was reported and all types of errors were documented in detail.

Chapter four, a questionnaire (survey) study was conducted to assess the paediatric nurses' perceptions about the double checking process and also to 
evaluate their opinions about its effectiveness in reducing MAEs. The survey is based on the observational study results (chapter 3 )

Chapter five A simulation study was used to compare paediatric nurses' drug administration with single checking against administration with the double checking process. This study was performed to measure the error rate and time of medication administration with each process.

Chapter six provides a description of MEs in Middle Eastern countries using a systematic review of all MEs published in studies within the region. I did this systematic literature review because I am originally from this area and my future aims are to improve the use of medicines, both in Saudi Arabia and also in neighbouring Arab countries. This systematic review also describes all medication treatment stages, rates of incidence and suggests recommendations for future studies. This systematic review was conducted to determine what research on MEs has been done and is still required in that region in the future.

Chapter Seven contains the conclusions of the thesis. 
CHAPTER TWO

DOUBLE CHECKING THE ADMINISTRATION OF MEDICINES: A SYSTEMATIC REVIEW 


\subsection{INTRODUCTION}

Patient and medication safety is a priority for the government, researchers and providers in the healthcare system (DoH, 2004). Reduction of MEs leads to an improvement in healthcare systems and positively affects patient safety (Lehmann \& Kim, 2005). A number of strategies have been introduced to try to reduce errors. Computerized Physician Order Entry in prescribing is one such strategy to prevent MEs in the prescribing stage and can reduce serious prescribing error by $55 \%$ (Bates et al, 1999). Bar-Coding technology, which is widely used in marketing outside the healthcare system, can prevent errors in dispensing or the administration of medicines (Poon et al., 2006). Double checking is also used to prevent MEs in the whole medication treatment process including prescribing, dispensing, administration and documentation. Double checking is a strategy that has been used in both medical and non-medical areas (Hales, 2006).

\subsubsection{Double checking process}

Although, MEs are a significant problem in the medication treatment process, the administration of medicines is the process where the greatest numbers of MEs are identified (Kaushal et al, 2001a; Miller et al., 2007; Ghaleb et al., 2010).

Not all double checking methods are equally effective in preventing or minimising errors because double checking processes vary in definition among different organisations with different reliability levels (Table 2.1). 
Table 2.1: Types of double checking and reliability levels (adapted from ISMP, 2006).

\begin{tabular}{|l|l|}
\hline Type of double check & Reliability Level \\
\hline $\begin{array}{l}\text { (A) One person double checking } \\
\text { themselves }\end{array}$ & $\begin{array}{l}\text { Poor reliability because one person can } \\
\text { easily make the same mistake twice }\end{array}$ \\
\hline $\begin{array}{l}\text { (B) Second person looking to verify the } \\
\text { result }\end{array}$ & $\begin{array}{l}\text { Slightly more reliable because it involves } \\
\text { a second person }\end{array}$ \\
\hline $\begin{array}{l}\text { (C) Second person repeating a } \\
\text { calculation after watching the first } \\
\text { person perform the calculation }\end{array}$ & $\begin{array}{l}\text { More reliable than A \& B because the } \\
\text { person performing the double check is } \\
\text { actually performing the calculation; } \\
\text { however, observing the first person } \\
\text { doing the same calculation makes it } \\
\text { easy to duplicate an error. }\end{array}$ \\
\hline $\begin{array}{l}\text { (D) Second person doing a calculation } \\
\text { without having seen the first person's } \\
\text { calculation }\end{array}$ & $\begin{array}{l}\text { Called an Independent Double Check } \\
\text { and is the most reliable method because } \\
\text { it eliminates the possibility of one } \\
\text { practitioner biasing another. }\end{array}$ \\
\hline
\end{tabular}

Independent double checking is thought to be the most reliable method of double checking. It is defined as a procedure that requires two qualified health professionals, usually nurses, independently checking the medication before administration to the patients. The word 'independent' means a second person follows a series of steps to arrive at a calculation result without prior knowledge of any previous calculation (ISMP, 2006). This approach is thought to reduce the possibility of bias which occurs when the person checking the medication is likely to see what they expect to see even if an error has occurred $(U, 2003)$. It is, however, the most labour intensive method in that each health professional needs time to perform the calculations.

This systematic review was performed to determine the existing evidence base on the effectiveness of the double checking process in reducing ME rates in dose calculation, dispensing and in administration. 


\subsection{METHODS}

\subsubsection{Identification of relevant literature}

A search for articles describing double checking for medication in dose calculation, dispensing and administration in both children and adults was conducted in October 2010. Also included were any studies reporting a double checking process for devices that were used in the patient medication administration process. In this search six databases were used: EMBASE (1980 to October 2010), MEDLINE (1950 to October 2010), BRITISH NURSING INDEX \& ARCHIVE (1985 to October 2010), CUMULATIVE INDEX to NURSING \& ALLIED HEALTH LITERATURE (CINAHL) (1982 to October 2010), NATIONAL ELECTRONIC LIBRARY FOR MEDICINES (NeLM) (1998 to October 2010) and PsycINFO (1806 to October 2010). These databases were used to ensure that all articles were included in this search. The search strategy included adults and children because evidence identified from studies in adults may be applicable to children. The search strategy included all languages and types of trials and studies.

\subsubsection{Search Terms}

In this search the keyword 'double check' was used in combination with AND for the terms 'drug safety', OR 'nurse', OR 'pharmacist' OR 'pharmacy technician', OR 'drug administration', OR 'medication administration', in order to include all articles that had been published in the databases listed above. The term 'double check' was used as it is the term used by healthcare professionals and in most hospital policies. 


\subsubsection{Inclusion / Exclusion Criteria}

All abstracts were evaluated and assessed according to the following inclusion criteria. Inclusion criteria were papers assessing or discussing double checking for medication drug dose calculation, dispensing or administration in hospitalised patients. This included patient identity, prescribing, dispensing and administration of medication. This search included quantitative and qualitative studies to obtain a full picture of the double checking process in drug administration. Full articles of the relevant abstracts were then searched and retrieved. The references of the retrieved articles were searched manually in order to identify additional appropriate studies. The relevant additional articles that met the inclusion criteria were also obtained. Any studies or articles that were obviously not related to double checking for medication preparation and administration such as opinion papers, letters, case reports and comments, were excluded. Duplicates were identified and removed.

\subsubsection{Data extraction}

All identified abstracts were read for their relativity to the inclusion and exclusion criteria. Full articles that were considered relevant were obtained and examined, and the following data was extracted: year of study; study design and sample size; patient population and place of study; efficacy outcome measures; type of medication in each study; error rate with double checking and without if applicable. Also, the Pharmline database was searched through the NeLM database and no further studies were identified. 


\subsection{RESULTS}

\subsubsection{Search Results}

The search strategies yielded 752 abstracts from the five databases. There were 289 duplicates. A further 357 articles were excluded because they were unrelated to double checking in the medication treatment process, patient identity or devices used in treatment (Figure 2.1). The full text of the articles that were remaining (106 references) was reviewed and 92 further references were excluded because they were not evaluating the double checking of medications. Two additional studies were added after the references of relevant articles were reviewed manually. In total, 16 studies identified double checking in the medication treatment process and are included in this systematic review. 


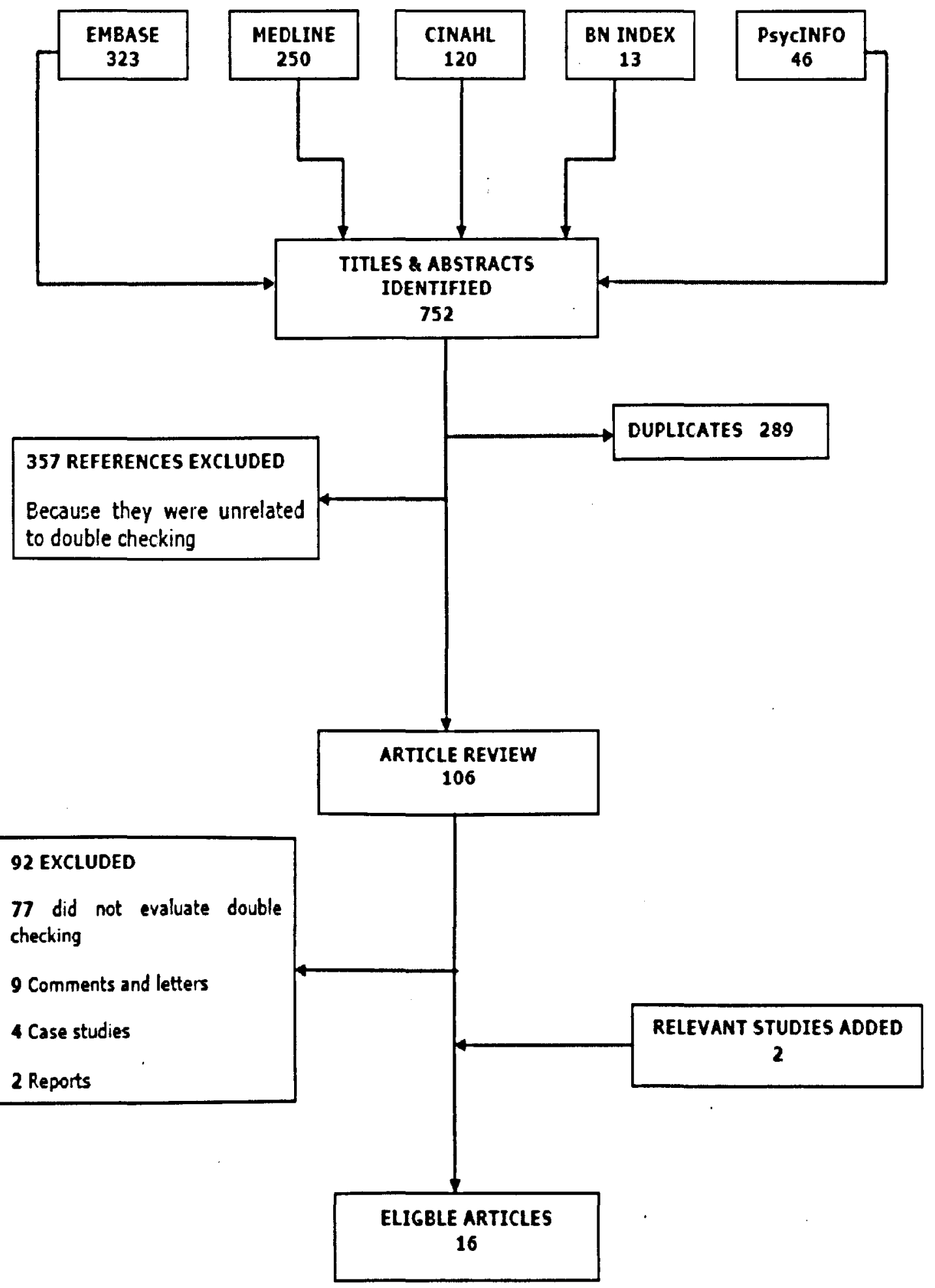

Figure 2.1: Flow diagram of search and review process 


\subsubsection{Included Studies}

Full details of the studies are classified and summarised in Tables 2.2, 2.3, 2.4 and 2.5. There were three quantitative studies (Kruse et al, 1992; Ross et al, 2000; White et al, 2010). Two studies used both qualitative and quantitative methods (Leung et al, 2007; Jarman et al, 2002). Nine were qualitative studies (questionnaire and interviews) (Armitage G, 2008; Manias et al, 2005; Evley et al, 2010; Dickinson et al, 2010; Sheu et al, 2008; Davis et al, 2010; Wong et al, 2007; Winson et al, 1991; O'Connell et al, 2007). Two studies were systematic reviews (Hodgkinson et al, 2006; Jensen et al, 2004).

\subsubsection{Quantitative studies}

Three quantitative studies were conducted to assess the effectiveness of double checking processes in reducing MEs for hospitalised patients (Table 2.2). The first study was conducted in Australia in 1992 (Kruse, 1992). It was a cross over study in three wards in a geriatric hospital. A total of 319 MEs were detected during the 46 week study period. The authors found that the use of two nurses as opposed to one in administering medication significantly reduced the MEs rate from 2.98 per 1000 medications administered $(95 \% \mathrm{Cl}, 2.45-3.51)$ to 2.12 per 1000 medications administered (95\% Cl, 1.69-2.55). The clinical advantages, however, were unclear because the difference was so small and $95 \%$ of the reported errors were of a relatively minor nature.

The second study was a retrospective review of all MEs reports in a large children's hospital in the UK completed prospectively from April 1994 to August 1999 (65 months) (Ross et al, 2000). The main finding was that 195 MEs were reported during the study period. 130 of these errors occurred despite double checking being performed. There were 58 errors where it was confirmed that double checking did not occur and in seven errors it was uncertain whether double 
checking was performed or not. In addition, during this study period a new pharmacy policy was introduced, where two people were involved in double checking all drugs before dispensing. This resulted in a reduction in drug dispensing errors. 18 dispensing errors were reported in 22 months, i.e. 9.8 errors per year, before the double checking process was introduced. Following the introduction of double checking, there were only 21 dispensing errors in 43 months, i.e. 6 per year.

The third study was a high-fidelity (simulators respond to the nurses intervention such as heart and lung sound, chest rise and fall with respiration) simulation study of outpatient chemotherapy administration with ten nurses from that unit (White et al, 2010). An existing and a new checklist for an Ambulatory Infusion Pump (AIP) (a pump used to deliver chemotherapy agents) were compared to determine their effectiveness in detection of MAEs during nurses' practice. The old checklist had been used in the unit for a few months. One nurse programmed the AIP using the prescription and the drug label. The second nurse independently checked the pump programming using a checklist to double check the programming of the pump against the drug label and prescription. The new checklist was a revision of the old one including rearranging the steps that should be checked by the second nurse and including a specific item to check patient identity. In this simulation study a total of 130 errors were built into the simulation. Overall, the new checklist helped nurses to detect 76 errors (59\%) compared to 66 errors (51\%) with the old checklist. There was no significant difference in the detection of pump programming errors between the two checklists despite the changes made. There was however a major difference in error detection between the two checklists in relation to patient identification $(16 / 20,80 \%$ versus $3 / 20,15 \%)$ respectively. Therefore the additional specific items incorporated in the new checklist such as check the medical record 
number and patient name from the armband and medication label had a positive impact on error detection. 
Table 2.2: Quantitative studies of actual error rates

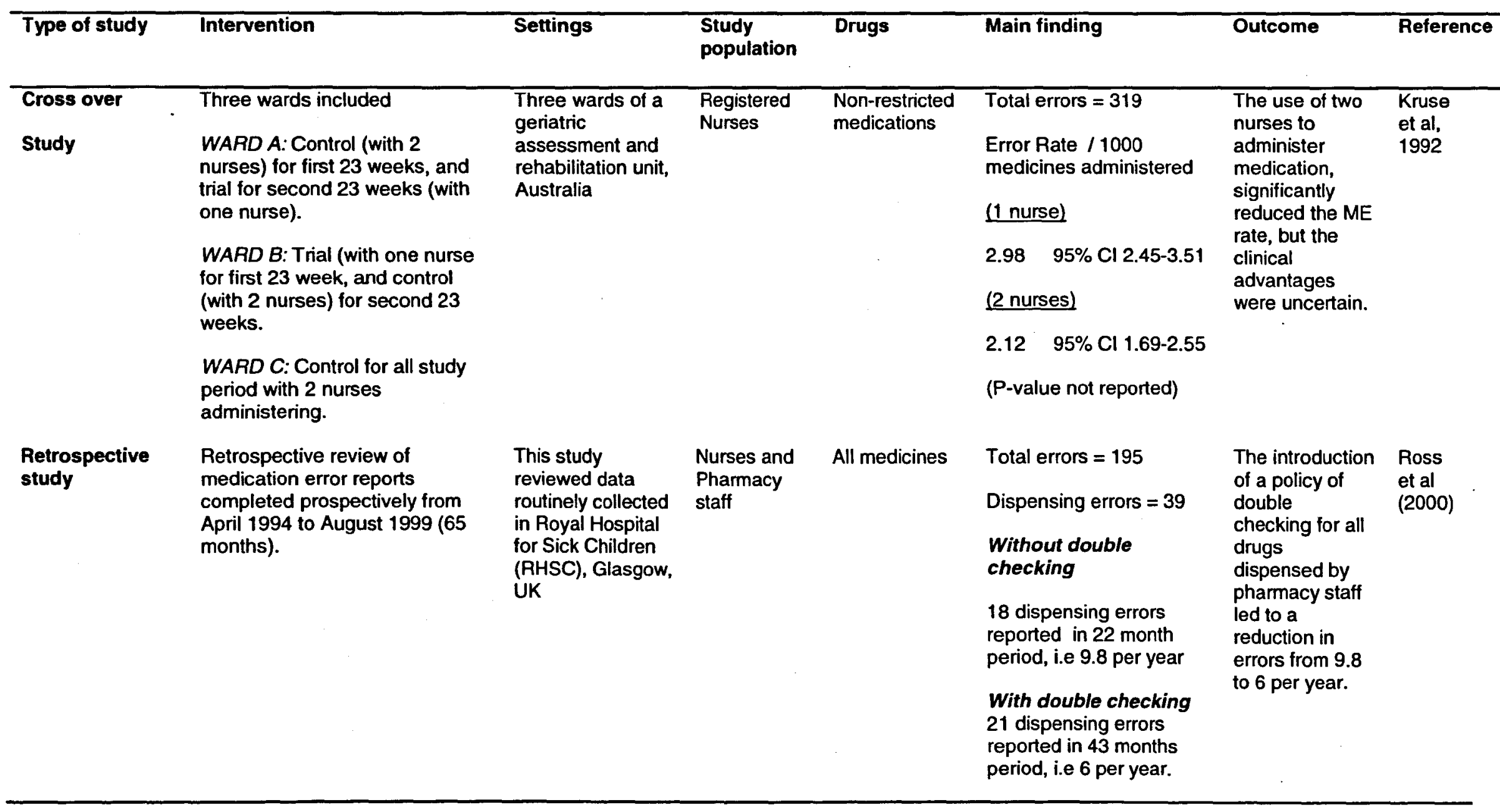


Table 2.2: Contd.

\begin{tabular}{|c|c|c|c|c|c|c|c|}
\hline Type of study & Intervention & Settings & $\begin{array}{l}\text { Study } \\
\text { population }\end{array}$ & Drugs & Main finding & Outcome & Reference \\
\hline $\begin{array}{l}\text { Simulation } \\
\text { study }\end{array}$ & $\begin{array}{l}\text { Two checklists for ambulatory } \\
\text { infusion pump (AIP) were } \\
\text { compared, one old, and one } \\
\text { new. New checklist had a } \\
\text { specific item to check patient } \\
\text { identity. Study focussed on the } \\
\text { ability of second nurse to detect } \\
\text { errors by using the checklists. } \\
14 \text { pumps were checked by } \\
\text { each nurse }\end{array}$ & $\begin{array}{l}\text { Simulated setting } \\
\text { Toronto University } \\
\text { Hospital, Canada }\end{array}$ & $\begin{array}{l}10 \\
\text { Registered } \\
\text { Nurses }\end{array}$ & Chemotherapy & $\begin{array}{l}\text { Overall, the new } \\
\text { checklist helped } \\
\text { nurses to detect } \\
76 / 130(59 \%) \text { of } \\
\text { errors compared to } \\
66 / 130(51 \%) \text { with old } \\
\text { checklist } \\
(P<0.01)\end{array}$ & $\begin{array}{l}\text { No significant } \\
\text { difference in } \\
\text { detection of pump } \\
\text { programming } \\
\text { errors, but } \\
\text { detection of errors } \\
\text { in patient } \\
\text { identification with } \\
\text { new checklist } \\
(80 \%) \text { was } \\
\text { significantly higher } \\
\text { than with the old } \\
\text { checklist (15\%) }\end{array}$ & $\begin{array}{l}\text { White et al } \\
(2010)\end{array}$ \\
\hline
\end{tabular}




\subsubsection{Mixed (Quantitative and Qualitative) studies}

Two studies included quantitative and qualitative data as shown in Table 2.3. The first study monitored ME reports after double checking for seven months and then after single checking for a similar time period in an adult hospital (Jarman et al, 2002). This was a study evaluating the effect of a change in policy that was introduced in the hospital whereby single checking replaced double checking. Unfortunately, the number of MEs identified in each time period was very small. There were five reports during the period with double checking compared to four reports during the period with single checking. The very small number of reports suggests that not all MEs were reported and makes statistical comparison impossible. The qualitative part of the study consisted of 129 nurses completing a questionnaire which asked them if they preferred double checking or single checking. The questionnaires revealed that the nurses preferred single checking.

The other study involved a review of 52 MEs that occurred in a general hospital in Hong Kong (Leung et al, 2007). The review of the MEs, however, did not contain any information about double checking. The qualitative part of the study involved focus groups and a questionnaire which 466 out of 748 nurses returned. The nurses felt that double checking was preferable to triple checking (which was the current practice). There was strong support for the principles of the five rights for drug administration (right patient, right drug, right dose, right route and right time). 
Table 2.3: Quantitative and qualitative (mixed) studies

\begin{tabular}{|c|c|c|c|c|c|c|c|}
\hline Type of study & Intervention & Settings & Study population & Drugs & Main finding & Outcomes & Reference \\
\hline $\begin{array}{l}\text { Mixed methods } \\
\text { (Quantitative \& } \\
\text { Qualitative) }\end{array}$ & $\begin{array}{l}\text { Monitoring of medication errors } \\
\text { after single checking and then } \\
\text { compared with double checking } \\
\text { over } 7 \text { months in } 3 \text { clinical services }\end{array}$ & $\begin{array}{l}\text { all adult } \\
\text { inpatient units, } \\
\text { Operating, } \\
\text { Birthing and } \\
\text { ED within } \\
\text { Geelong } \\
\text { hospital } \\
\text { (Australia) }\end{array}$ & $\begin{array}{l}129 \text { nurses } \\
\text { completed } \\
\text { questionnaire }\end{array}$ & $\begin{array}{l}\text { Not } \\
\text { reported }\end{array}$ & $\begin{array}{l}\text { Only } 5 \text { reported } \\
\text { medication incidents } \\
\text { were identified over } \\
\text { the } 7 \text { months period } \\
\text { with double checking } \\
\text { compared to } 4 \\
\text { reported incidents } \\
\text { during same period } \\
\text { with single checking. }\end{array}$ & $\begin{array}{l}\text { No significant } \\
\text { difference in error } \\
\text { rates between } \\
\text { single and double } \\
\text { checking. } \\
\text { However, very few } \\
\text { MEs detected. }\end{array}$ & $\begin{array}{l}\text { Jarman et al } \\
(2002)\end{array}$ \\
\hline $\begin{array}{l}\text { Mixed methods } \\
\text { (Quantitative \& } \\
\text { Qualitative) }\end{array}$ & $\begin{array}{l}\text { This study involved } 2 \text { stages, over } \\
18 \text { months, to review and examine } \\
\text { the current drug administration } \\
\text { procedure of } 3 \text { checks and five } \\
\text { rights. } \\
\text { In stage 1: medication and drug } \\
\text { incident forms submitted over a } 1 \\
\text { year period were reviewed. Focus } \\
\text { group interviews were conducted } \\
\text { with nurses, self-administered } \\
\text { questionnaires distributed \& } \\
\text { observational studies conducted in } \\
\text { the wards. } \\
\text { In stage } 2 \text { : data from stage } 1 \text { was } \\
\text { analysed, new clinical model of } \\
\text { drug administration was tested in } \\
\text { each selected area for at least } 3 \\
\text { months. }\end{array}$ & $\begin{array}{l}27 \text { selected } \\
\text { clinical } \\
\text { settings in } \\
\text { General } \\
\text { Hospital in } \\
\text { Hong Kong }\end{array}$ & $\begin{array}{l}\text {-Focus group } \\
\text { interviews }(n=29) \\
\text {-Questionnaires } \\
\text { (n=466) } \\
\text {-Individual interview } \\
(n=3)\end{array}$ & $\begin{array}{l}\text { Not } \\
\text { reported }\end{array}$ & $\begin{array}{l}\text { Total errors = } 52 \\
\text { In review of drug } \\
\text { incident forms, main } \\
\text { causes of MEs were } \\
\text { noncompliance with } \\
\text { policies or procedure } \\
(48 \%) \text {, } \\
\text { communication failure } \\
\text { or misinterpretation of } \\
\text { orders }(23 \%) \text {. In this } \\
\text { study most nurses } \\
(63 \%, n=29) \\
\text { performed three } \\
\text { checks during drug } \\
\text { administration, while } \\
(35 \%, n=16) \text { did two } \\
\text { checks }\end{array}$ & $\begin{array}{l}\text { From this study } \\
\text { two checks and } \\
\text { five rights for drug } \\
\text { administration } \\
\text { was more } \\
\text { practical, safe, } \\
\text { saved nurses } \\
\text { time, enhance } \\
\text { effective checking } \\
\text { over three checks } \\
\text { model. }\end{array}$ & $\begin{array}{l}\text { Leung et al } \\
(2007)\end{array}$ \\
\hline
\end{tabular}




\subsubsection{Qualitative studies}

Nine studies identified in this review were qualitative studies as shown in Table 2.4 (Armitage G, 2008; Manias et al, 2005; Evley et al, 2010; Dickinson et al, 2010; Winson G, 1991; O'Connell et al, 2007; Sheu et al, 2008; Davis et al, 2010; Wong et al, 2007). In six of the studies health professionals preferred double checking as they felt this was more likely to detect drug administration errors (Armitage, 2008; Manias et al, 2005; Evley et al, 2010; Dickinson et al, 2010; Sheu et al, 2008; Davis et al, 2010). In two of the studies the majority of the participants felt that single checking was adequate (Winson, 1991; O'Connell et al, 2007). In one study the double checking process was identified as an intervention with significant potential to reduce MEs (Wong et al, 2007).

A collaborative qualitative study, between the National Patient Safety Agency, Royal College of Anaesthetists and Association of Anaesthetists of Great Britain and Ireland, explored the feasibility of introducing a practice of double checking of drugs used during anaesthesia (Evley et al, 2010). Two different methods (second person checking and electronic bar code checking) were considered. Subsequently, focus groups were held to determine whether health professionals felt that either system would help reduce MEs. The pilot study found that health professionals had the opinion that double checking would have a significant effect on patient safety if it is performed properly without any distraction or time pressure. However, they also found that the problem with this method was the second person availability. It was therefore felt that the electronic system was probably more feasible. Different models of double checking were identified as being used in different healthcare centres in a survey of 35 health professionals and parents/carers in the COSMIC report (Wong et al, 2007). Interviews were performed with 40 health professionals in a single hospital in the UK (Armitage $G, 2008$ ). Many of the individuals 
interviewed felt that the double checking process was inconsistent and may lead to reduced responsibility, accountability and lack of time. Despite this the participants still preferred double checking. 
Table 2.4: Qualitative studies only

\begin{tabular}{|c|c|c|c|c|c|c|}
\hline Type of study & Intervention & Settings & Study population & Drugs & Outcomes & Reference \\
\hline $\begin{array}{l}\text { Interview } \\
\text { study }\end{array}$ & $\begin{array}{l}\text { Data analysed from a } \\
\text { review of } 991 \text { drug error } \\
\text { reports, and interviews with } \\
40 \text { health professionals to } \\
\text { assess the effectiveness of } \\
\text { double checking medicines, } \\
\text { for } 3 \text { months period. }\end{array}$ & $\begin{array}{l}\text { Teaching } \\
\text { hospital in } \\
\text { Northern } \\
\text { England }\end{array}$ & $\begin{array}{l}40 \text { health } \\
\text { professionals (15 } \\
\text { doctors, } 15 \text { nurses, } 7 \\
\text { pharmacists, and } 3 \\
\text { pharmacy } \\
\text { technicians) }\end{array}$ & Not reported & $\begin{array}{l}\text { Errors occurred despite } \\
\text { double checking. Most } \\
\text { participants (34/40) } \\
\text { believed that double } \\
\text { checking process is } \\
\text { inconsistent. }\end{array}$ & Armitage G (2008) \\
\hline $\begin{array}{l}\text { Prospective } \\
\text { Cohort study }\end{array}$ & $\begin{array}{l}\text { Incorporating participants } \\
\text { observation during } \\
\text { medication administration } \\
\text { and interviews }\end{array}$ & $\begin{array}{l}\text { University } \\
\text { teaching } \\
\text { hospital, in } \\
\text { Australia }\end{array}$ & $\begin{array}{l}12 \text { graduate nurses in } \\
\text { medical and surgical } \\
\text { units }\end{array}$ & $\begin{array}{l}\text { Parenteral } \\
\text { medication, Opioid } \\
\text { analgesics and } \\
\text { certain oral } \\
\text { medication }\end{array}$ & $\begin{array}{l}\text { Found that double } \\
\text { checking for high alert } \\
\text { medication is strongly } \\
\text { recommended. But double } \\
\text { checking may be } \\
\text { sacrificed when time is } \\
\text { short and there are not } \\
\text { enough qualified staff }\end{array}$ & Manias et al (2005) \\
\hline $\begin{array}{l}\text { Qualitative } \\
\text { study }\end{array}$ & $\begin{array}{l}\text { To assess the feasibility of } \\
\text { introducing second-person or } \\
\text { electronic bar-code } \\
\text { confirmation of drugs } \\
\text { administered during } \\
\text { anaesthesia. Seven NHS } \\
\text { settings in UK (five used } \\
\text { second-person \& two used } \\
\text { bar code confirmation) }\end{array}$ & $\begin{array}{l}\text { Seven NHS } \\
\text { settings in UK, } \\
\text { for } 3 \text { month } \\
\text { period }\end{array}$ & $\begin{array}{l}61 \text { participants ( } 36 \\
\text { consultant } \\
\text { anaesthetists, } 3 \\
\text { trainees, } 15 \text { Operating } \\
\text { Department } \\
\text { Practitioners and } 7 \\
\text { anaesthetic nurses } \\
\text { participated). }\end{array}$ & $\begin{array}{l}\text { Drugs given during } \\
\text { anaesthesia }\end{array}$ & $\begin{array}{l}\text { Both methods were } \\
\text { perceived to contribute to } \\
\text { the prevention of drug } \\
\text { errors. Two person } \\
\text { confirmation has significant } \\
\text { effect on practice but has } \\
\text { less feasibility than } \\
\text { electronic confirmation }\end{array}$ & Evley et al (2010) \\
\hline
\end{tabular}


Table 2.4: Contd.

\begin{tabular}{|c|c|c|c|c|c|c|}
\hline Type of study & Intervention & Settings & Study population & Drugs & Outcomes & Reference \\
\hline $\begin{array}{l}\text { Descriptive } \\
\text { qualitative } \\
\text { design }\end{array}$ & $\begin{array}{l}\text { To understand a practice of } \\
\text { double checking medication } \\
\text { \& identify barriers to the } \\
\text { process. Data collected via } \\
\text { three focus group interviews. } \\
\text { Seven paediatric nurses } \\
\text { participated in homogenous } \\
\text { groups based on level of } \\
\text { practice. }\end{array}$ & $\begin{array}{l}\text { Children's hospital, } \\
\text { New Zealand }\end{array}$ & 19 paediatric nurses & Not reported & $\begin{array}{l}\text { Independent double check } \\
\text { is accepted and promoted } \\
\text { as best practice in the } \\
\text { paediatric settings. There } \\
\text { is a lack of clarity of double } \\
\text { check process in both } \\
\text { practice and literature. This } \\
\text { study supports the findings } \\
\text { of others in relation to the } \\
\text { influence of workload } \\
\text { distraction and } \\
\text { environmental factors }\end{array}$ & $\begin{array}{l}\text { Dickinson } \\
\text { et al }(2010)\end{array}$ \\
\hline $\begin{array}{l}\text { Semi- } \\
\text { structured } \\
\text { questionnaire }\end{array}$ & $\begin{array}{l}\text { To encourage nurses to } \\
\text { describe their feelings around } \\
\text { administration errors, and to } \\
\text { increase the understanding of } \\
\text { nurses for error related problem } \\
\text { and to identify high alert } \\
\text { situations, by using snowball } \\
\text { sampling to recruit participants. } \\
\text { A semi structured questionnaire } \\
\text { was used to record types of } \\
\text { error. }\end{array}$ & Taiwan & 85 nurses participated & $\begin{array}{l}\text { High alert situation } \\
\text { (insulin, 15\% KCL and } \\
\text { Pitocin (oxytocin } \\
\text { injection) and two } \\
\text { conditions: patients on } \\
\text { IV pumps and patients } \\
\text { undergoing CPR. }\end{array}$ & $\begin{array}{l}\text { Survey results suggest } \\
\text { that nurses should double } \\
\text { check medication } \\
\text { administration in known } \\
\text { high alert situations. }\end{array}$ & $\begin{array}{l}\text { Sheu et al } \\
(2008)\end{array}$ \\
\hline
\end{tabular}


Table 2.4: Contd.

\begin{tabular}{|c|c|c|c|c|c|c|}
\hline Type of study & Intervention & Settings & Study population & Drugs & Outcomes & Reference \\
\hline $\begin{array}{l}\text { Questionnaire } \\
\text { Survey }\end{array}$ & $\begin{array}{l}\text { A questionnaire survey of responses to a } \\
\text { number of factorial vignettes. These vignettes } \\
\text { considered a combination of seven contextual } \\
\text { and policy factors that influence nurses } \\
\text { judgments relating to medication administration }\end{array}$ & $\begin{array}{l}\text { A tertiary } \\
\text { paediatric } \\
\text { hospital in } \\
\text { Australia }\end{array}$ & $\begin{array}{l}185 \text { paediatric } \\
\text { nurses }\end{array}$ & Not reported & $\begin{array}{l}\text { Double checking the } \\
\text { patient, double checking } \\
\text { the drug and checking the } \\
\text { legality of the prescription } \\
\text { were the three strongest } \\
\text { predictors of nurses } \\
\text { actions regarding } \\
\text { medication administration. }\end{array}$ & $\begin{array}{l}\text { Davis et al } \\
(2010)\end{array}$ \\
\hline $\begin{array}{l}\text { Descriptive } \\
\text { study }\end{array}$ & $\begin{array}{l}\text { Survey questionnaire to identify any } \\
\text { interventions used in reducing dose calculation } \\
\text { errors in paediatrics. }\end{array}$ & $\begin{array}{l}\text { Different } \\
\text { paediatric } \\
\text { healthcare } \\
\text { settings from UK, } \\
\text { US and EU. }\end{array}$ & $\begin{array}{l}35 \text { participants } \\
\text { (nurses, pharmacists, } \\
\text { doctors and parents) }\end{array}$ & $\begin{array}{c}\text { Not } \\
\text { reported }\end{array}$ & $\begin{array}{l}\text { Different double checking } \\
\text { models identified but no } \\
\text { evidence to support one over } \\
\text { another. Also, no available } \\
\text { data for effectiveness of } \\
\text { double checking in reducing } \\
\text { medication calculation } \\
\text { errors. }\end{array}$ & $\begin{array}{l}\text { Wong et al } \\
(2007)\end{array}$ \\
\hline
\end{tabular}


Table 2.4: Contd.

\begin{tabular}{|c|c|c|c|c|c|c|}
\hline Type of study & Intervention & Settings & Study population & Drugs & Outcomes & Reference \\
\hline $\begin{array}{l}\text { Questionnaire } \\
\text { Survey }\end{array}$ & $\begin{array}{l}\text { Survey questionnaire to measure the } \\
\text { registered nurses opinion regarding } \\
\text { to single checking of the } \\
\text { administration of medicines. }\end{array}$ & $\begin{array}{l}\text { General } \\
\text { hospital, UK }\end{array}$ & 328 nurses & NA & $\begin{array}{l}\text { Determined that most } \\
\text { children's nurses in a small } \\
\text { general hospital agreed } \\
\text { that registered nurses } \\
\text { should be able to } \\
\text { administer medicines on } \\
\text { their own. }\end{array}$ & Winson, 1991 \\
\hline $\begin{array}{l}\text { Questionnaire } \\
\text { Sunvey }\end{array}$ & $\begin{array}{l}\text { Structured evaluation involved } \\
\text { conducting two surveys, prior to and } \\
\text { after implementation of single } \\
\text { checking. }\end{array}$ & $\begin{array}{l}\text { Acute-Care } \\
\text { hospital, } \\
\text { Australia }\end{array}$ & 124 nurses & NA & $\begin{array}{l}\text { Nurses welcomed the } \\
\text { single checking medication } \\
\text { procedure, and felt more } \\
\text { confident using single } \\
\text { checking, and perceived } \\
\text { that it made them more } \\
\text { accountable for } \\
\text { administering medications. }\end{array}$ & $\begin{array}{l}\text { O'Connell et al, } \\
2007\end{array}$ \\
\hline
\end{tabular}




\subsubsection{Previous systematic reviews}

Two previous systematic reviews were identified in this review (Table 2.5). The first systematic review (Hodgkinson et al, 2006) evaluated interventions in minimising or reducing MEs in elderly adults. They identified a total of 20 studies and three systematic reviews but only two studies that evaluated the effectiveness of single checking against double checking (Kruse et al, 1992; Jarman et al, 2002).

The second systematic review was of studies conducted to prevent errors in intravenous drug administration in anaesthesia (Jensen et al, 2004). In their review Jensen et al introduced a list of recommendations. One of these recommendations was that drug labels should be checked with a second person or a device before a drug is administered. They strongly support the double checking of drugs before administration. 
Table 2.5: Previous systematic reviews

\begin{tabular}{|c|c|c|c|}
\hline Focus of review & Methods & Main findings & References \\
\hline Medication errors in the elderly & $\begin{array}{l}\text { 1986-2005 } \\
\text { PubMed } \\
\text { Embase } \\
\text { CINAHL } \\
\text { Current Contents } \\
\text { Cochrane }\end{array}$ & $\begin{array}{l}\text { Six strategies were identified that may reduce } \\
\text { medication errors. These included double checking. }\end{array}$ & Hodgkinson et al (2006) \\
\hline $\begin{array}{l}\text { Errors in intravenous drug } \\
\text { administration in anaesthesia }\end{array}$ & $\begin{array}{l}1978-2002 \\
\text { PubMed } \\
\text { Medline } \\
\text { Embase }\end{array}$ & $\begin{array}{l}\text { List of } 12 \text { recommendations that reflect the best } \\
\text { evidence available. One of them was that labels } \\
\text { should be checked with a second person or a } \\
\text { device before a drug is administered. }\end{array}$ & Jensen et al, (2004) \\
\hline
\end{tabular}




\subsection{DISCUSSION}

The aim of this review was to evaluate the effectiveness of double checking for medication administration, in reducing or preventing MEs. Each year several children die in the UK as a result of MEs (Cousins et al, 2002). MEs are therefore a major clinical problem and measures to reduce MEs should be welcomed.

Double checking was introduced into nursing practice, as it was assumed that it would reduce MEs. It is now standard nursing policy in many children's hospitals (Conroy et al, 2012). Double checking the administration of medicines is labour intensive in that it requires two qualified health professionals. This has a significant impact on nursing time and it is therefore surprising that double checking is a widespread process with minimal supportive evidence. It is of concern that there has only been one randomised controlled clinical trial, a study involving adult patients on a geriatric unit in Australia (Kruse et al, 1992). This clinical trial suggested that double checking may be beneficial but that the clinical advantages are unclear. The retrospective review of MEs in Glasgow Children's Hospital reported that dispensing errors were reduced following the introduction of double checking procedures in the pharmacy department (Ross et al., 2000). The overall incidence of reported errors in this study, however, was very small and this suggests that a significant number of errors not reported. This questions the validity of the findings in this paper.

The vast majority of the papers identified consisted of asking health professionals (usually nurses) whether they felt double checking was helpful or not. The majority of the studies confirmed that the nursing staff felt that double checking, if done properly, would result in fewer MEs. These studies, however, all identified that there were practical problems associated with ensuring the double checking process was 
performed correctly. These often involved staff shortages or an emergency situation. Three studies reported that nurses preferred single checking over double checking process (Winson, 1991; Jarman et al, 2002; O'Connell et al, 2007). Reported disadvantages of double checking were that the process is time consuming, reduces the responsibility and may be associated with deference to authority (Armitage, 2008). It is dependent on the availability of sufficient nurses. Some nurses raised concerns that the double checking process reduced their responsibility and may actually predispose to MEs. It was felt by some nurses that double checking should be used only in high risk patients (neonates, infants or with high risk medications such as chemotherapy, opiates and intravenous routes (Sheu et al, 2009).

A number of different interventions have been suggested to reduce errors in calculations of paediatric drug doses such as Centralised Intravenous Additive Services (CIVAS), CPOE, Unit Dose Dispensing Systems (UDDS) and Intelligent Infusion pumps (IIP) (Wong et al, 2007). These are likely to contribute to a reduction in other types of paediatric errors through they may however also introduce new errors. It is however beyond the scope of this chapter to discuss them further.

The time saving from using the single checking process was estimated in two studies (Ross et al, 2000; Jarman et al, 2002). In the randomised controlled clinical trial the authors found that one nurse rather than two nurses administering medications would save 17.1 hours of nursing time per 1000 medications administered (Kruse et al, 1992). In one study following the introduction of single checking, nursing staff felt that approximately 20 minutes was saved on each medication round (Jarman et al, 2002). 
I feel that the process of double checking of the administration of medicines should be evaluated scientifically. We recognise that there are major practical difficulties in performing such a clinical trial in children within the UK, as double checking is now accepted as a standard nursing procedure. One could, however, perform clinical trials in adult inpatients, where double checking is not routinely used, to establish whether double checking is effective in reducing MEs.

However, from this review of the literature we can summarize that the lack of studies evaluating the effectiveness of double checking means that there is insufficient evidence to confirm or refute the effectiveness of double checking in reducing errors.

All qualitative studies described the researchers' suggestion and their assessments or measurements, and the theoretical opinion of participants or their feeling regarding double checking, rather than the practical measurement of double checking effects on clinical practice. These qualitative studies therefore provide limited evidence to verify that the double checking process may be able to reduce MEs or may be considered as a contributory factor for MEs. In most of the qualitative studies that have been conducted the participants were nurses. The nurses explain their opinion according to their place of work, their environment and their dealing or experience with double checking, however, this does not necessarily reflect the reality of all nurses practice during drug administration process.

In spite of some evidence for double checking, some studies believe that the double checking process may lead to more MEs, rather than reduce MEs. Some studies indicated that the change from double checking to single checking saves nurses' time and gives them more space to do more work with their patients. Also, one study suggests that the number of MEs does not change when the process of double checking is switched to single checking (Jarman et al, 2002). 
Healthcare providers disagree in their opinions of the double checking process but some of them consider that double checking process is useless and believe that the double checking process does not improve patient and medication safety (Armitage, 2008).

This systematic review suffered from some limitations. There were very few studies and the comparison between those identified studies was difficult as they were performed in different situations and settings. They differed in design, duration, methodology, and each study used a different definition of MEs and the double checking process. Although, the double checking process in theory is a good idea and some studies identified in this review suggested that it can reduce MEs, publication bias was not excluded from this study. Also, in this review we did not distinguish between practical intervention studies and technological intervention studies.

For future work, this systematic review for the evidence base regarding the effectiveness of the double checking process in reducing MEs reveals that there is insufficient evidence to prove that double checking of medication reduces the risk of MEs and the generalisability of the results is limited. In contrast, the evaluation of this process and its effect on ME rates would be a useful step forward. Most researchers suggest that the randomized controlled clinical trial is the gold standard for study design. It is difficult to perform this type of study in medication error prevention research (Conroy et al, 2007a; Reckmann et al, 2009). This is because there is a complicated interaction between health care providers, systems, patients and drugs, and these may impact on the study results. Where double checking is in place it would be unethical to remove this without good evidence. 


\subsection{CONCLUSION}

This systematic review was performed to determine the existing evidence base for the effectiveness of the double checking process in reducing MEs rates in dose calculation, dispensing and in administration. There is insufficient evidence to confirm that double checking of medication reduces the risk of MEs. This does not mean that double checking is ineffective but simply that its effectiveness has not yet been proven. Further work is required to examine scientifically, the effectiveness of the double checking process in reducing MEs for hospitalized paediatric patients. 


\section{CHAPTER THREE}

\section{ADHERENCE OF PAEDIATRIC NURSES TO DOUBLE CHECKING PROCESS STEPS DURING MEDICATION ADMINISTRATION IN A CHILDREN'S HOSPITAL: AN OBSERVATIONAL STUDY}




\subsection{INTRODUCTION}

Medication safety is important for both the hospitalised and non-hospitalised patient. In hospital, safety is reliant upon the medication management systems used, along with clear policy, procedures, human factors and organisational factors (e.g. work environment, communication).

Studies have revealed that MEs in children occur most frequently during administration (Miller et al, 2007; Ghaleb et al, 2010). Few studies in the UK have investigated MAEs in children's hospitals and none of them have formally evaluated the double checking process during the administration of medicines (Nixon and Dhillon, 1996; Conroy et al., 2007; Ghaleb et al., 2010). Different rates of administration errors have been reported in different studies: $1.2 \%$ (Conroy et al, 2007), $5.1 \%$ (Nixon and Dhillon, 1996) of administrations and $19.1 \%$ of opportunities of error (Ghaleb et al, 2010).

One study conducted in the Derbyshire Children's Hospital, which has a double checking process for medication administration, observed 752 drug administrations in total (642 oral and 110 IV) (Conroy et al, 2007). This study commented that the failure of paediatric nurses to follow double checking and patient identity procedures were risk areas for errors in drug administration.

Double checking of medication before and during administration by two qualified paediatric nurses is an intervention used in many hospitals to reduce errors (Conroy et al, 2012), particularly in neonates and children. However as shown in chapter 2 , there is little research to confirm or refute its effectiveness. This is especially true in children's hospitals and in the UK.

Different methods are available to detect MEs in hospitals. Most researchers have recognised that no single method of MEs detection will work in all areas or settings 
(Barker et al, 2002). The observational method has been described as one of the best methods to detect MAEs (Allan and Barker, 1990; Barker, 1980). The first observational method used to detect MEs in drug administration was conducted in 1962 (Baker and McConnell, 1962). The observation technique is reported to produce results that are significantly more valid and reliable than other methods used to achieve the same objectives (Dean and Barker, 2001; Flynn et al, 2002).

This study focused on the everyday, routine processes of medication administration in the Derbyshire Children's Hospital and, in particular, focused on how the double checking process is conducted. According to the hospital policy and procedures all medications should be double checked before administration to children (Derby Hospitals NHS Foundation Trust, Medicines Code, 2008 (accessed 23 January 2012).

Double checking is defined as a procedure that requires two qualified health professionals, usually registered nurses, checking the medication before administration to the patients (White et al, 2010; Conroy et al, 2012). Checking the prescription and medication occurs before administration, during preparation, calculation or administration to the patient or a combination of all steps.

A previous literature review of factors contributing to MEs identified personnel, systems and managerial problems (O'Shea, 1999). Factors involved mathematical skills of nurses, nurses' knowledge of medications, length of nurses experience and nurses shifts, workload, distractions and interruptions (O'Shea, 1999). However, another study added that the poor drug dose calculation competency and poor knowledge of drugs were the most common identified factors that lead to MAEs (Pauly-O'Neil, 2009).

In addition, other factors can contribute to MAEs; for example, heavy workload due to a shortage in nursing staff, distractions and interruptions to the nurses during 
their drug round time or during their delivery of care to paediatric patients. These can have a direct effect on the safety of medication administration (Fry \& Dacey, 2007).

\subsection{DERBYSHIRE CHILDREN'S HOSPITAL NHS TRUST}

This study took place in the Derbyshire Children's Hospital at the Royal Derby Hospital. This hospital is part of the Derby Hospitals NHS Foundation Trust in the East Midlands area of the UK. The Trust provides health care services to a local population of over 600,000 children. Derbyshire Children's Hospital is a teaching hospital with 78 beds. The hospital itself consists of outpatient clinics, a children's Emergency Department and four inpatient wards. In addition, there is a Neonatal Intensive Care Unit which opened in a new building in the autumn of 2007. The Derbyshire Children's Hospital has a long history of excellence and the staff are proud to deliver a health service to the children and young people of the Derbyshire area (Cooke, 2004).

The children's outpatient clinics see more than 39,000 children per year in different clinics. In 2010, over 60,000 children and young people used the Derbyshire Children's Hospital's services throughout their departments. The Children's Emergency Department reviews over 25,000 children and young people per year. Four wards are available for children who need admission or observation and these include: Puffin ward, which looks after children and teenagers with medical and surgical problems; Dolphin ward, which is a paediatric Intensive Care Unit (PICU); Sunflower ward, which is a trauma and elective surgical ward; Ladybird ward, which at the time of the study was a day-case and observation unit; and the NICU, which is a patient care area that provides care to premature babies and infants who are 
either critically ill or who remain in hospital for extended observation or to gain weight.

The Trust provides acute medical and surgical services for children and neonates across a wide range of specialities and the findings from this study are likely to be generalisable to other paediatric clinical areas in the country. A double checking process for medication administration is well established in this hospital for all types of drugs by all routes of administration and in all clinical paediatric areas.

\subsection{STUDY AIMS AND OBJECTIVES}

This study was conducted to establish how closely the Derbyshire Children's Hospital's double checking policies were followed by nurses in paediatric areas. I also wished to identify the types and frequency of MAEs occurring despite the double checking process.

\subsection{DEFINITIONS}

Many different definitions have been established for MAEs (Pepper G, 1995; Dean B, 1999; Greengold et al, 2003; Ghaleb et al, 2010). In my study I followed the definition set out by Ghaleb et al. (2010) which defined a MAE as an administration of a dose of medication that deviates from the prescription, as written on the patient's medication chart, or from standard hospital policy and procedures. This includes errors in the preparation and administration of IV medicines on the ward (Ghaleb et al, 2010).

The double checking process has previously been defined as a procedure that requires two qualified health professionals, usually nurses, checking the medication 
before administration to the patients (ISMP, 2005; White et al, 2010; Conroy et al, 2012).

\subsection{METHODS}

This study was a prospective, direct and undisguised observational study of nurses administering medicines prescribed for children as part of their routine medical care, which was conducted in the wards of the children's hospital. In this study, I observed and documented how paediatric nurses implemented the double checking process for medication preparation and administration according to the process described later. Data was collected on the number, type and frequency of MAEs that occurred in spite of the double checking process being used. All medicines observed were prescribed for the patient as part of their routine care.

The process of observation was conducted during weekdays and at the weekend. I attended at different times of the day in order to observe medicines administration by different nurses and shift patterns.

\subsubsection{Ethical considerations}

The study was considered to be service evaluation by the National Research Ethics Service. It therefore did not require ethical or Research and Development department approval. Derby Hospitals NHS Foundation Trust clinical governance procedures were followed. This included attending the Trust induction day and an honorary contract was obtained for me following Criminal Records Bureau clearance and other Trust procedures. To comply with National Information Governance Board procedures written, informed consent was obtained from the parents/carers of all patients observed before observation took place. 


\subsubsection{Participant selection and recruitment}

Paediatric nurses in the hospital were informed about all aspects of the study by the Chief Investigator (a Paediatric Clinical Pharmacist who works in the hospital as well as for the University of Nottingham) by attending ward meetings. I also attended the ward meetings and clarified the information for all participating nurses in the hospital. Before each observation, I asked each nurse for verbal permission to accompany them on the drug administration round. If permission was refused I would not observe drug administration for that nurse during their shift. During the study period, however all nurses agreed to be involved in the observation process. Also, all patients' parents agreed for me to observe drug administration to their child except in 3 cases.

For a participant to be included in this study they had to satisfy the following criteria:

A - The participant should be a registered paediatric nurse.

B - The participant should be employed by the Derby Hospitals NHS Foundation Trust where the study took place.

C - The participant should have a responsibility for administering medicines.

In addition:

D - Written informed consent from the parents/carers of patients must have been obtained before any observation of medicines administered to that child took place.

\subsubsection{Data collection method}

The data collection form for this study was designed to collect details of adherence to all steps during the medication administration and double checking process (Appendix A). I planned to observe 2000 drug administration events, which would be the highest number observed in the UK in a children's hospital. A one day pilot 
study was conducted by the project chief investigator and myself on selected wards shortly prior to the actual data collection period. This was to introduce me to the nursing staff and to make them aware of the project and its aims. The pilot study checked the practicability and feasibility of the methodology used and the effectiveness of the data collection form. All data collected on this day was excluded from analysis.

The data collection form used reflected the drug administration process in the Derby Hospitals NHS Foundation Trust's Medicines Code.

The process of observation was conducted during weekdays (Monday - Friday) and also at the weekend. I attended different work shifts of the day in order to observe the medication administration process by different paediatric nurses and shift patterns ( 8 am, 2 pm, 4 pm, 6 pm and 8 pm). During the observation process I tried to avoid interrupting or disturbing the nurses during their drug administration. In one situation, when a potentially serious error was identified however, I made the nurses aware in a polite manner without disturbing the nurse or the patient before the medication was administered.

I observed each drug administration and recorded all the steps of the double checking and drug administration process on a data collection form. For each observation, demographic information including the patient's initials, date of birth, weight and drug name was recorded. In addition, adherence to the following steps was recorded on the data collection form:

- Drug due: Both nurses should check the frequency of the prescribed medication, that the time of administration is correct and when the last dose was given. 
- Correct drug: The packaging or pharmacy label and instructions or any precautions stated should be checked by both nurses.

- Correct dosage form: The dosage form for each prescribed drug should be checked with the one prepared for administration and its appropriateness for the patient's clinical situation.

- Dose calculation: Two qualified nurses should independently calculate the drug dose that is to be prepared or administered and confirm the result with each other.

- Measurement of dose: The two nurses should prepare and check the drug dose measurement before administration.

- Drug route: The route of drug administration should be checked and confirmed by the nurses and should be suitable for the patient's situation and age.

- Drug expiry date: Both nurses should check the drug expiry date before administration and that it is in an acceptable condition for administration.

- Rate of IV bolus: Both nurses should check the drug is given at the correct administration rate.

- IV infusion volume and rate: Both nurses should check the pump settings for volume and rates are correct for the prescribed drug.

- Drug diluents and volume: Both nurses should check that the appropriate diluents and volume have been used according to the hospital IV preparation guidelines.

- Flush syringes labelled: Syringes filled with sodium chloride $0.9 \%$ (saline) for use to flush IV access devices should be labelled. 
- Drug allergy: The patient's drug or food allergy status should be checked by both nurses by asking the patient himself or his parents or checking what is written on the medication chart

- Patient identity (ID) (using wristband): The patient name, date of birth and ID number (as written on the wristband) should be checked by two nurses and compared with the information written on the medication chart

- Administration to the patient: Both nurses should be present at the patient's bed to administer the medicines to the patient. If parents wish to give the medicine to their child both nurses should witness the patient when he/she takes the medicine.

- Documentation to Medication Administration Record (MAR): Both nurses should document and record the drug administration after giving the prescribed drug by signing the MAR.

All the data that was collected from this observational study was anonymous and only initial letters were used for each patient. All data was transferred and entered onto an Excel database. All data was stored on a password protected University of Nottingham computer. All papers based data was stored securely in locked offices in the University of Nottingham.

\subsubsection{Data analysis}

The data was analysed using a Microsoft Office Excel programme. Numbers of drug doses that were observed and administered were documented and the adherence rate to the hospital policy was calculated from the total drug doses observed. For IV medications, the adherence rate was calculated according to the total number of IV drugs observed during the study period. Also, the difference between the double checking steps adherence rate was calculated for week days and weekends. 
Identified MAEs were categorised according to their type and frequency. The incidence rate was calculated by dividing the total number of MAEs by the total number of drug doses observed during the study period multiplied by 100 . Probability value was calculated by Chi - square test to compare the MAEs results between week days and weekends.

\subsection{RESULTS}

\subsubsection{Demographic information}

Data was collected from April to July 2012. The characteristics of the wards and the nurses are shown in Table 3.1.

Table 3.1: Characteristics of the observed wards and nurses

\begin{tabular}{|l|c|c|c|c|c|}
\hline Characteristics & Medical & Surgical & PICU & NICU & Total \\
\hline Number of beds & 31 & 25 & 4 & 18 & 78 \\
\hline $\begin{array}{l}\text { Number of } \\
\text { nurses/shift }\end{array}$ & 5 & 3 & 2 & 4 & 14 \\
\hline $\begin{array}{l}\text { Total number of } \\
\text { nurses }\end{array}$ & 30 & 25 & 16 & 53 & 124 \\
\hline
\end{tabular}


Two thousand drug doses were observed and evaluated in terms of the adherence of nurses to the double checking procedure during drug preparation and administration. MAEs, types and frequency were also documented. In total, drug administration to 876 patients was observed during the study period. Demographic information of the patients is described in Table 3.2. The rate of drug doses observed for each patient was 2.3 administered doses per patient.

More than half of the patients $(60 \%)$ were observed on the surgical ward and just under one third (32\%) on the medical ward. Most of the observations of drug administration occurred on these two wards with a relatively even split between them ( $45.6 \%$ on the surgical ward and $42 \%$ on the medical ward). There were relatively few patients on either of the ICUs and subsequently there was less observation of drug administrations in these areas. The smallest number of patients observed was on the NICU due to difficulties in obtaining consent from the babies' parents. This was due to parents often visiting in the evenings when I was not present, together with there being no scheduled drug-round times in these areas with nurses preparing each drug for each individual patient separately.

Oral medications (liquids and tablets) made up the vast majority (80.7\%) of the formulations that were observed during the medication administration process (Table 3.2). Oral drugs were administered and observed most frequently on the surgical ward (Figure 3.1). Both IV and inhaled drugs were administered and observed most frequently on the medical ward. 
Table 3.2: Patients and drugs administered:

\begin{tabular}{|c|c|c|c|c|c|}
\hline Characteristic & Medical & Surgical & PICU & NICU & Total \\
\hline No. of patients (\%) & $281(32 \%)$ & $523(60 \%)$ & $52(6 \%)$ & $20(2 \%)$ & 876 \\
\hline \multicolumn{6}{|l|}{ Age (months) } \\
\hline Median & 67 & 84 & 36 & 6.8 (days) & - \\
\hline (Range) & $(0.9-211)$ & $(32-204)$ & $(0.6-205)$ & (2-119 days) & \\
\hline \multicolumn{6}{|l|}{ Weight (in kg) } \\
\hline Median & 14.4 & 22.6 & 12.8 & 2.27 & - \\
\hline (Range) & $(2.13-108.7)$ & $(4-105.2)$ & $(2.8-54)$ & $(0.9-3.8)$ & \\
\hline No. of oral drugs observed (\% total) & $588(29.4 \%)$ & $899(45 \%)$ & $112(5.6 \%)$ & $15(0.7 \%)$ & $1,614(80.7 \%)$ \\
\hline No. of IV drugs observed (\% total) & $176(8.8 \%)$ & $11(0.6 \%)$ & $77(3.8 \%)$ & $38(1.9 \%)$ & $302(15.1 \%)$ \\
\hline No. of inhalers drugs observed (\% total) & $74(3.7 \%)$ & $\mathbf{0}$ & $7(0.4 \%)$ & 0 & $81(4.1 \%)$ \\
\hline No. of topical drugs observed (\% total) & $1(0.05 \%)$ & $2(0.1 \%)$ & 0 & $\mathbf{0}$ & $3(0.15 \%)$ \\
\hline $\begin{array}{l}\text { Total no. of drugs administered \& } \\
\text { observed }\end{array}$ & $839(42 \%)$ & $912(45.6 \%)$ & $196(9.8 \%)$ & $53(2.6 \%)$ & $2,000(100 \%)$ \\
\hline
\end{tabular}




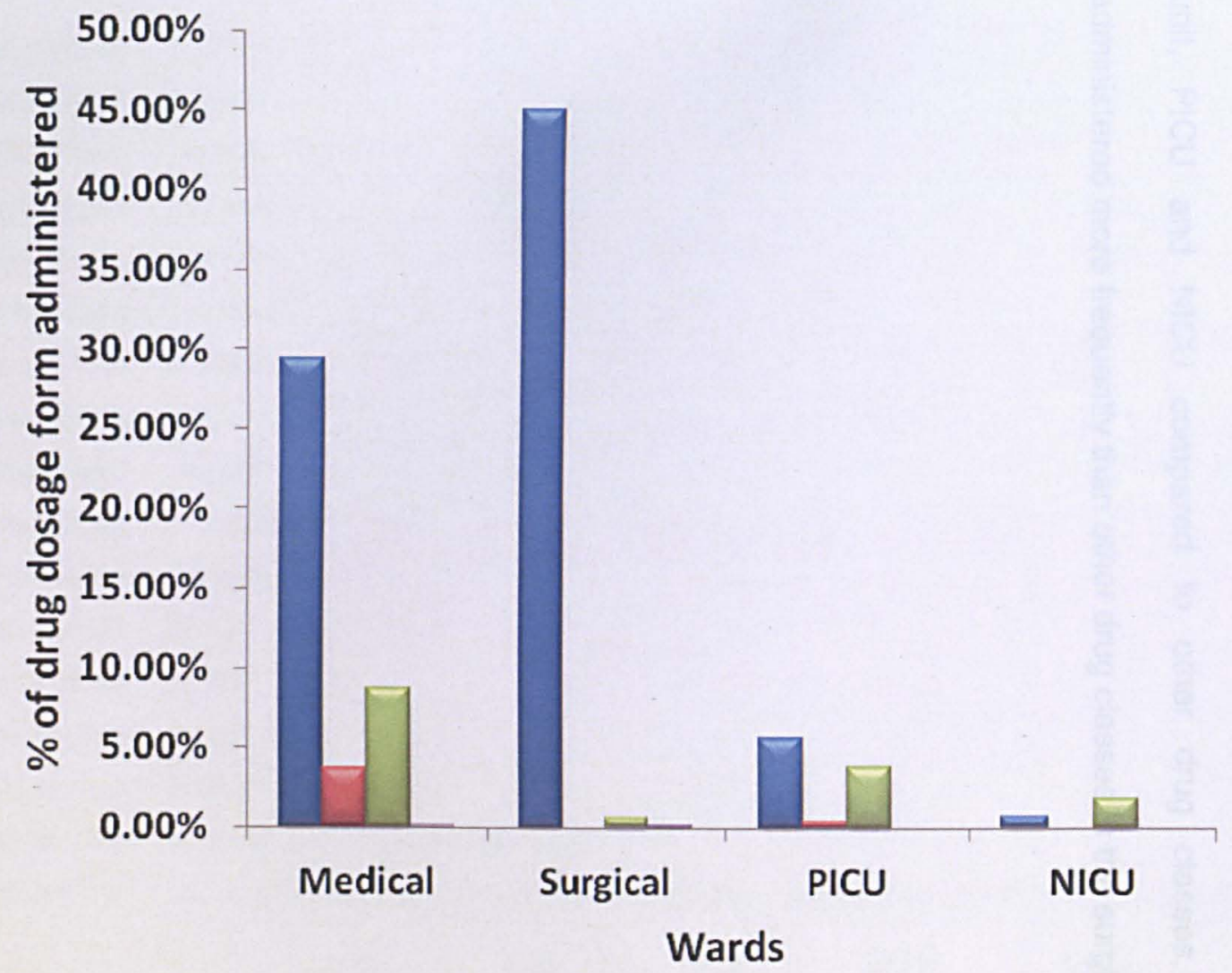

D Oral drugs

$\square$ Inhaler drugs

$\triangle$ Intravenous drugs

- Topical drugs

Figure 3.1: Types of observed dosage form administered in each ward. 


\subsubsection{Types of drugs}

Different types of medications were administered and observed during the study period. Non-opioid analgesics (including paracetamol and non-steroidal antiinflammatory drugs) were the drug class most frequently administered and observed in this study (Figure 3.2). The other main group of drugs were antibacterial drugs, which made up just under one quarter of the drug administrations observed. Antibacterial drugs were more commonly administered and observed in the medical unit, PICU and NICU compared to other drug classes. Analgesics were administered more frequently than other drug classes in the surgical ward. 


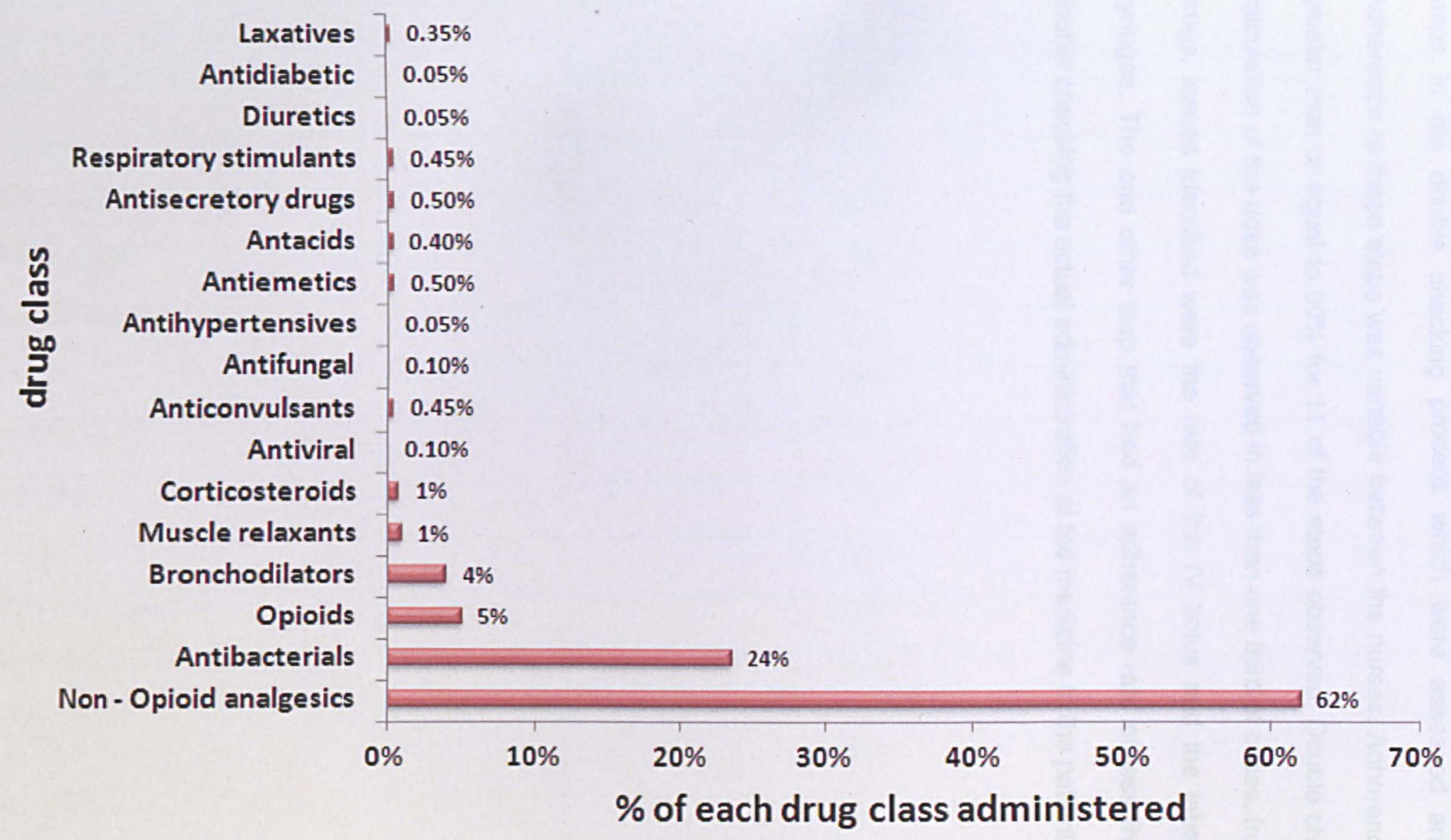

Figure 3.2: Drug class of medications administered and observed during study period. 


\subsubsection{Adherence rate to double checking policy steps}

In this study, 11 double check steps for each administered drug dose were assessed and evaluated (Table 3.3). For IV drugs, there were an additional four steps in the double checking process which were assessed and evaluated. Adherence to these steps was variable between the nurses. Adherence rates were greater than or equal to $90 \%$ for 11 of the steps observed. Double checking of the calculation of the dose was observed in less than one third of cases. In relation to IV drugs, issues identified were the rate of the IV bolus and the labelling of flush syringes. The one other step that had an adherence rate of less than $90 \%$ was double checking the actual administration of the medicine to the patient. 
Table 3.3: Adherence rate to double checking policy steps

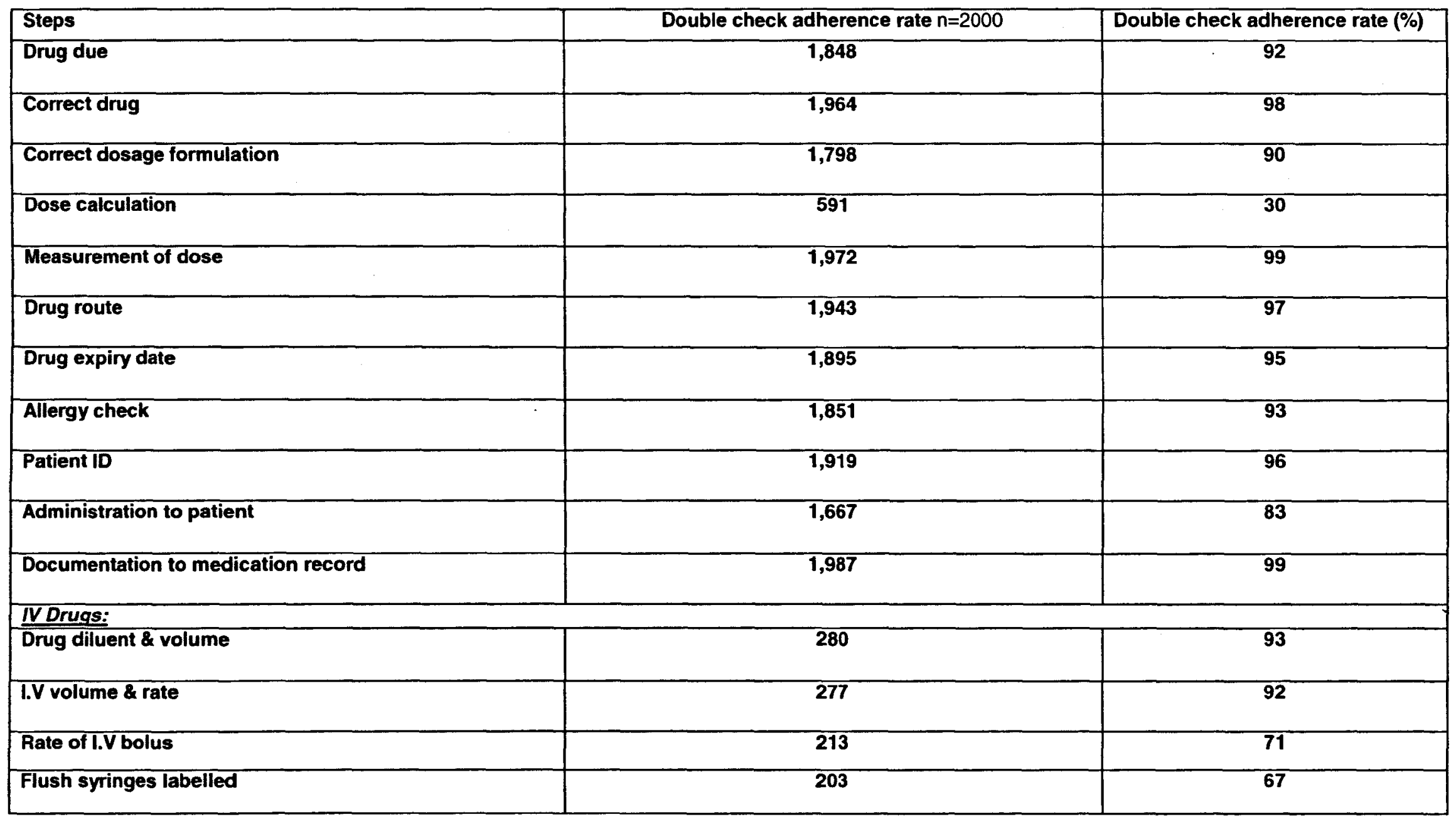


1,594 drug administrations (including 173 IV drug administrations) were observed during weekdays (56 days). During weekends (22 days), 406 administrations (including 129 IV drug administrations) were observed (Table 3.4). There was a statistically significant difference in nurses' adherence rate to the double checking steps between weekdays and weekends in 9 steps $(P<0.05)$ (Table 3.4). Overall nurses adhered more closely to double checking steps at weekends compared to weekdays. 
Table 3.4: Comparison between weekdays (Monday to Friday) and weekends (Saturday and Sunday) double checking policy adherence rate

\begin{tabular}{|c|c|c|c|c|c|}
\hline \multirow[t]{2}{*}{ Steps } & \multicolumn{2}{|c|}{$\begin{array}{l}\text { Week days (56 days) (1,594 drug doses } \\
\text { observed, } 173 \text { IV drugs) }\end{array}$} & \multicolumn{2}{|c|}{$\begin{array}{l}\text { Weekend days (22 days) (406 drug } \\
\text { doses observed, } 129 \text { IV drugs) }\end{array}$} & \multirow[t]{2}{*}{ P-value } \\
\hline & $\begin{array}{l}\text { Adherence rate } \\
\text { (N) }\end{array}$ & Adherence rate (\% & $\begin{array}{l}\text { Adherence rate } \\
\text { (N) }\end{array}$ & Adherence rate (\%) & \\
\hline Drug due & 1,459 & 92 & 389 & 96 & 0.005 \\
\hline Correct drug & 1,591 & 99 & 406 & 100 & 0.875 \\
\hline Correct dosage form & 1,383 & 87 & 397 & 98 & $<0.0001$ \\
\hline Dose calculation & 398 & 25 & 193 & 48 & $<0.0001$ \\
\hline Measurement of dose & 1,589 & 99 & 383 & 94 & $<0.0001$ \\
\hline Drug route & 1,542 & 97 & 401 & 99 & 0.0425 \\
\hline Drug expiry date & 1,507 & 95 & 388 & 96 & 0.483 \\
\hline Allergy check & 1,455 & 91 & 396 & 98 & $<0.0001$ \\
\hline Patient ID & 1,525 & 96 & 394 & 97 & 0.2662 \\
\hline Administration to patient & 1,389 & 87 & 278 & 68 & $<0.0001$ \\
\hline Document to MAR & 1,583 & 99 & 404 & 99 & $0 . \overline{923}$ \\
\hline \multicolumn{6}{|l|}{ IV Drugs } \\
\hline Drug diluents \& volume & 150 & 87 & 127 & 98 & 0.0006 \\
\hline I.V volume \& rate & 153 & 88 & 124 & 96 & 0.0288 \\
\hline Rate of I.V bolus & 114 & 66 & 99 & 77 & 0.0551 \\
\hline Flush syringes labelled & 117 & 68 & 86 & 67 & 0.958 \\
\hline
\end{tabular}




\subsubsection{Medication administration errors}

191 MAEs were detected during the study observation period; giving a MAEs rate of $9.6 \%$ of drug administrations (Table 3.5). These errors were classified according to type and their incidence (Ghaleb et al, 2010). The most frequent type of administration error involved the medicine being given to the parents to administer to the child when the nurse was not present. There were 64 instances where this occurred. The nurse not observing the administration of the drug by the parent is a deviation from the hospital policy and procedure for drug administration. The other administration errors identified included incorrect administration of the medicine (IV bolus drugs being given too rapidly usually), incorrect preparation errors and medicines being given at incorrect times. 
Table 3.5: Medication administration errors identified

\begin{tabular}{|l|l|l|}
\hline Type of error & \multicolumn{1}{|c|}{ Examples } & Number of errors \\
\hline $\begin{array}{l}\text { Drug given by } \\
\text { parents (i.e. not } \\
\text { observed by nurse) }\end{array}$ & $\begin{array}{l}\text { Ranitidine oral dose was given by mum without observation from } \\
\text { the nurses. } \\
\text { Ibuprofen oral dose was given by parents without observation from } \\
\text { the nurses. }\end{array}$ & $\mathbf{6 4}$ \\
$\begin{array}{l}\text { Wrong administration } \\
\text { techniques }\end{array}$ & $\begin{array}{l}\text { Co-Amoxiclav IV bolus administered within } 2 \text { minutes instead of } 5 \\
\text { minutes as prescribed. } \\
\text { Salbutamol inhaler given with poor technique. }\end{array}$ & $\mathbf{5 1}$ \\
$\begin{array}{l}\text { Incorrect preparation } \\
\text { errors }\end{array}$ & $\begin{array}{l}\text { Saline flush syringes were prepared without labels. } \\
\text { Cefuroxime IV bolus prepared \& diluent was added but not mixed } \\
\text { properly. }\end{array}$ & $\mathbf{4 4}$ \\
$\begin{array}{l}\text { Wrong time of drug } \\
\text { administration (i.e. } \\
\pm 1 \text { thour of prescribed } \\
\text { time) }\end{array}$ & $\begin{array}{l}\text { Ceftriaxone IV bolus given } 11: 17 \text { am instead of } 10: 00 \text { am (1 hour } \\
17 \text { minutes late). } \\
\text { Amoxicillin IV bolus given at } 9: 38 \text { am instead of } 8: 00 \text { am (1 hour } 38 \\
\text { minutes late). }\end{array}$ & 32 \\
\hline
\end{tabular}


There was no statistically significant difference in the rate of MAEs between weekdays and weekends. Drugs being given by parents unsupervised by nurses were the most frequent administration errors during both weekdays and weekends. For example, incorrect preparation errors were observed less at weekends (1\%) compared to during drug administration on weekdays (2.5\%) (Table 3.6).

Table 3.6: Medication errors observed on weekdays versus weekends

\begin{tabular}{|l|c|c|c|}
\hline Type of error & $\begin{array}{c}\text { Weekdays (total } \\
1,594 \text { drugs) } \\
\mathrm{N}(\%)\end{array}$ & $\begin{array}{c}\text { Weekends (total 406 } \\
\text { drugs) } \\
\mathrm{N}(\%)\end{array}$ & P- value \\
\hline $\begin{array}{l}\text { Drug given by parents } \\
\text { (i.e. not observed by } \\
\text { nurse) }\end{array}$ & $52(3.3 \%)$ & $12(3 \%)$ & 0.87 \\
\hline $\begin{array}{l}\text { Wrong administration } \\
\text { techniques error }\end{array}$ & $46(2.9 \%)$ & $5(1.2 \%)$ & 0.0756 \\
\hline $\begin{array}{l}\text { Incorrect preparation } \\
\text { errors }\end{array}$ & $40(2.5 \%)$ & $4(1 \%)$ & 0.085 \\
\hline $\begin{array}{l}\text { Wrong time of } \\
\text { administration error (i.e. } \\
\pm 1 \text { hour of prescribed } \\
\text { time) }\end{array}$ & $24(1.5 \%)$ & $8(2 \%)$ & 0.502 \\
\hline & $162(10.2 \%)$ & $29(7.2 \%)$ & \\
\hline $\begin{array}{l}\text { Total } \\
\text { nat }\end{array}$ & & & \\
\hline
\end{tabular}




\subsubsection{Clinical significance of errors}

It was not possible to collect data on patient outcomes; however the majority of errors were unlikely to have caused serious harm to patients. Sixteen examples of poor inhaler technique were of concern. These could have resulted in poor symptom control for patients and also were not a good example to parents who were likely to have to administer such drugs at home. Three IV antibiotic doses were given without flushing, these have the potential to result in irritation to the vein. Three examples of antibiotic injections being prepared without correct mixing with the diluent had the potential to result in incorrect dose administration.

\subsubsection{Factors affecting adherence to the double checking process}

During my observation I identified a few factors which were not in my study aims. Identification of these factors may be beneficial for the hospital management. These factors may have an effect on the nurses' adherence rates to the double checking process:

- Shortage of nurses in the wards.

- High nurse workload.

- Interruptions by other nursing staff.

- Medicines received late from the pharmacy.

- Drugs distributed randomly in trolleys with little organisation included drugs for patients waiting for discharge. 


\subsection{DISCUSSION}

To our knowledge, this is the first observational study that has focused strictly on the double checking process and the adherence to hospital policy by nurses in neonatal and paediatric areas. As mentioned earlier, the observational method has been shown to be objective and more reliable than other means of spontaneous reporting or patient chart reviews (Barker 1980, Allan \& Barker 1990, Fortescue et al. 2003). It has been reported that people checking the work of others will find about $95 \%$ of all mistakes (Grissinger M. 2003, Cohen M. 2007). In this study, I identified 191 MAEs, which is a rate of $9.6 \%$. The most common type of errors (64 errors) was related to drugs given by parents without observation from nurses. Most of the errors reported with paediatric patients than with neonates. This type of error can be considered as a deviation from the hospital policy and procedures rather than an actual administration error. If one therefore excludes these errors, the error rate was reduced to $6.4 \%$ of administrations. Another study carried out in this hospital over five years ago described a MAEs rate of $1.2 \%$ (Conroy et al. 2007a), this variation in error rates between these two studies could be because this study included weekend days in the observation process and also involved a higher number of IV medications. The MAE rate reported in this study is within the range that has been reported in previous studies in paediatric patients: $5 \%$ to $27 \%$ (Nahata, 1988; Schneider et al, 1988; O'Brodovich \& Rappaport, 1991; Prot et al, 2005; Chua et al, 2010; Ghaleb et al, 2010).

\subsubsection{Nurses adherence to double checking steps}

All nurses were expected to follow the hospital double checking policy. Fifteen steps were observed and evaluated during each drug dose administration episode: 11 steps involved all drug forms and 4 steps were related to IV drugs. There was a wide ranging variation amongst nurses in their adherence to different double 
checking process steps ranging from $30 \%$ to $99 \%$. Some steps appeared to be double checked in most administrations while other steps were checked less often. This inconsistency may have resulted from disagreement between nurses or their knowledge about the double checking process, despite all of them were working in the same hospital. This is consistent with the findings of others "there was not always consistent practice between paediatric nurses, even among those working in the same area" (Dickinson et al. 2010).

Nurses checking the identification of patients by a bar coding system prior to drug administration were reported only in $17.4 \%$ of 1344 administrations in a general hospital in London (Franklin et al, 2007). Another observational study carried out in adult patients in two different hospitals in Australia tried to assess interruptions during drug administration and found that nurses checked patient identification in $41 \%$ of 4271 drug administrations (Westbrook et al. 2010).

A study conducted in the same location as this present study found that patient identification was checked in $89 \%$ of drug administrations (Conroy et al. 2007a). Our study results report a higher rate $(96 \%)$ of patient identification during the double checking process. The adherence rate to this double checking step has therefore improved since the previous study was performed in this hospital.

\subsubsection{Problem areas}

Double checking of drug dose calculation, rate of IV bolus, flush syringe labelling and drug administration by two nurses at the bedside were the areas where the nurses' adherence rate was low compared to other steps. Drug dose calculation according to the hospital policy should be performed independently (which means each nurse should calculate the dose separately and confirm the result with the other nurse). This, however, was often not obviously performed in practice during my observation period. The nurses' adherence rate to the prescribed rate of IV 
bolus was also low. This may be due to the nurses being busy with other duties or due to differences with administering very small volumes so slowly. The pharmacist's practice of endorsing prescriptions with 'bolus over 5 minutes' has changed as a result of my study to 'bolus over $3-5$ minutes' for this reason. Labelling of flush syringes was another problem area despite the printed label being available and ready to use in each ward. It is not clear why nurses did not perform these specific tasks in accordance with the hospital policy. Clearly further research is needed to seek the views of nurses in relation to these steps in the medication administration process.

\subsubsection{Adherence rate during weekdays and weekends}

The adherence rate of nurses to many of the double checking steps during weekend drug administration was significantly better compared to weekday administrations. There has been no previous published research looking at the effect of day of the week and the administration of medicines. Possible reasons are that the nurses are less likely to be interrupted at weekends by different groups of doctors and other staff which invariably occur during weekdays allowing them to concentrate better on administration procedures.

\subsubsection{Study Implications}

The low adherence rate $(30 \%)$ to independent dose calculation by the nurses was of most concern. Drug dosing errors (including prescribing, administration and dispensing) are the most common type of MEs in paediatrics (Koren et al., 1986; Kaushal et al. 2001a; Kozer et al. 2002; Ghaleb et al. 2006). Dosing errors were the most frequent cause of MEs in children resulting in fatalities in a study in the UK (Cousins et al., 2002). It is thought that independent drug dose calculation is more 
likely to pick up drug dosing errors but despite an apparent lack of this no dosing errors were identified in our study.

A specific educational or training programme for nurses about the importance of independent drug dose calculation may be beneficial. Previous research has shown that educational or training programmes have reduced MAE rates (Otero et al., 2008; Taylor et al., 2008; Raja et al., 2009; Chedoe et al., 2012). Other studies also have confirmed that educational programmes have an ability to decrease MEs in paediatrics (Cimino et al., 2004; Simpson et al., 2004). Additionally, one study has revealed that there is a strong theoretical basis for education and training interventions in reducing MEs (Conroy et al, 2007b).

\subsubsection{Study limitations}

There were a number of limitations highlighted in this study. Firstly, the study was conducted in a single hospital. One cannot, therefore, extrapolate to either other children's hospitals in the UK or to other parts of the world. The hospital is however fairly typical of small UK children hospitals. Secondly, the presence of the observer may have had an effect on the nurses and the way they administered medicines. $A$ previous study addressed validity and reliability concerns about this method, and revealed that the observation of nurses during drug administration did not significantly affect the MAE rate (Dean and Barker, 2001). Another study also found that there is no significant observer effect on the observed subject (Barker et al, 2002). This therefore would not seem to be a major limitation. A third limitation of this study was that the observer could not observe the administration of every single medication at all times. The large number of medication administrations observed, however, would suggest that this is a representative sample. 


\subsection{CONCLUSION}

In conclusion, this study found that there was a variation between paediatric nurses' adherence rate to double checking steps during medication administration. The independent drug dose calculation step had the lowest adherence rate. There was a statistically significant difference in the adherence rate to double checking steps during weekends compared to weekdays. The possible reason for this may be that the nurses were subjected to more interruptions during weekdays. Also, this study showed that the MAE rate was $9.6 \%$ of drug administrations. Drugs given by parents without observation from nurses was the most frequent type of MAE reported in this study, followed by wrong administration technique. 
CHAPTER FOUR

NURSES' KNOWLEDGE, PERCEPTION AND OPINIONS OF THE DOUBLE CHECKING PROCESS: A QUESTIONNAIRE STUDY 


\subsection{INTRODUCTION}

Nurses are more frequently involved in MEs than physicians or pharmacists (Benjamin, 2003). Nurses spend up to $40 \%$ of their work time in the medication administration process (Armitage \& Knapman, 2003). During medication administration, nurses play a significant role in ensuring patient safety because they conduct the last step that can prevent or reduce drug errors from reaching the patient.

Different reasons have been reported as to why MAEs occur. Lack of adherence to the medication administration policy and procedure, is one of the reasons identified in Chapter 3. Furthermore, paediatric nurses are responsible for checking whether a prescription is appropriate and all five of the standard 'rights' have to be implemented properly before drug administration (right medication, right dose, to the right patient by the right route at the right time).

Most descriptive studies have focused on nurses' perceptions about how and why MEs occur and their personal experiences with the causes and the reporting systems of MEs (Wakefield et al, 1998; O'Shea, 1999; Jarman et al, 2002; Karadeniz \& Cakmakçi, 2002; Mayo \& Duncan, 2004; Maryyan et al, 2007; Tang et al, 2007; Armitage, 2008; Armutlu et al, 2008; Hassan et al, 2009; Jones \& Treiber, 2010; Petrova et al, 2010; Kim et al, 2011).

A few descriptive studies have assessed nurses' perceptions of the double checking process (Dickenson et al., 2010; Conroy et al, 2012). However, little attention has been paid by researchers to evaluate the paediatric nurses' knowledge and opinions about the double checking process, and how it impacts on their practice. 
The Derbyshire Children's Hospital has a double checking policy for all medication administration for inpatients, we therefore wished to evaluate paediatric nurses' knowledge and opinions about the double checking process.

\subsection{METHODS AND MATERIALS}

A structured questionnaire was used to obtain the paediatric nurses' opinions and perceptions of the double checking process for medication administration.

This survey was performed in the Derbyshire Children's Hospital which is one of the children's hospitals in the East Midlands area of the UK. The questionnaire consisted of multiple-choice and open-ended questions (Appendix B). It was designed after the observational study (Chapter 3 ) results were analysed and was informed by its findings. The first section consisted of questions regarding medication administration and the double checking process, followed by demographic information questions. All the information in the questionnaire was anonymous and the nurses were asked to return the completed questionnaires into boxes provided in each ward. Follow-up reminders were sent to all potential participants two weeks after the distribution of the questionnaire.

\subsubsection{Participants}

All registered paediatric nurses who worked in the wards of the Derbyshire Children's Hospital and had conducted double checking for medication administration were invited to participate in this study. Questionnaire forms were distributed to 124 registered paediatric nurses throughout the four inpatient areas (Medical, Surgical, PICU and NICU) in the hospital. 


\subsubsection{Data collection procedure}

I distributed the questionnaire forms to the nurses in each unit during regular handover times. Questionnaires were placed in each ward for each nurse by name. A cover letter accompanying the questionnaire explained the objectives of the study, emphasizing that participation was voluntary, confidential and anonymous.

I collected all the completed surveys from each department and then kept them in a locked drawer in the research office (University of Nottingham, Medical School offices).

\subsubsection{Ethical consideration}

This study was considered to be service evaluation by the National Research Ethics

Service. It therefore did not require ethical or R\&D department approval. Derby Hospitals NHS Foundation Trust clinical governance procedures were followed.

\subsubsection{Data analysis}

This was a qualitative study and analysed descriptively.

\subsection{RESULTS}

\subsubsection{Response rate}

Out of 124 questionnaire forms, 5 of the forms were returned uncompleted ( 3 forms returned because the nurses were on maternity leave, 2 forms because the nurses had left the Trust).

Of the remaining 119,48 questionnaire forms were completed and returned (response rate $40 \%$ ). 


\subsubsection{Demographic and background information of respondents}

All the demographic and background information of the respondents is shown in Table 4.1. The majority (96\%) were female and most of them (35\%) were between 21 and 30 years-old. Twenty seven nurses (56\%) were full-time, with the remaining (21 nurses, $44 \%$ ) being part time. The majority of respondents (28 nurses, 58\%) had more than 10 years experience with drug preparation and administration to paediatric patients.

Table 4.1: Demographic data of the paediatric nurse respondents

\begin{tabular}{|c|c|c|}
\hline Demographic characteristic & Number (n) & Percentage \% \\
\hline \multicolumn{3}{|l|}{ Gender } \\
\hline Male & 2 & 4 \\
\hline Female & 46 & 96 \\
\hline \multicolumn{3}{|l|}{ Age (Years) } \\
\hline Under 21 & 0 & 0 \\
\hline $21-30$ & 17 & 35 \\
\hline $31-40$ & 7 & 15 \\
\hline $41-50$ & 10 & 21 \\
\hline Over 51 & 14 & 29 \\
\hline \multicolumn{3}{|l|}{$\begin{array}{l}\text { Years of experience with } \\
\text { preparation/administration to } \\
\text { paediatric patients }\end{array}$} \\
\hline Less than one year & 1 & 2 \\
\hline One to less than 2 years & 2 & 4 \\
\hline Two to less than 5 years & 6 & 13 \\
\hline Five to less than 10 years & 11 & 23 \\
\hline Over than 10 years & 28 & 58 \\
\hline
\end{tabular}




\subsubsection{Nurses' knowledge and feelings about double checking}

Approximately two-thirds of respondents ( 30 nurses, $63 \%$ ) reported that they had seen the Trust double checking policy in a written format (Table 4.2). Four nurses stated that they had seen the double checking process written in the Trust Medicines Code Policy.

When asked whether they understood the policy, the majority (40 nurses, $83 \%$ ) responded that they had clear and exact knowledge about the double checking process in their units (Table 4.2). 35 nurses $(88 \%)$ responded with comments. All comments stated incomplete definitions of the double checking process, for example "double check all children's medications" "two nurses checked prescription and patient" "medication checked by 2 trained staff and both check patients' identification". Only one nurse wrote a complete definition (i.e. "two registered nurses should check the drug dose separately, drug due, patient identification, rate, route of administration, drug administration and both of them should sign the medication chart"). More than half of the nurses (54\%) had received no training on double checking (Table 4.2). 
Table 4.2: Paediatric nurses knowledge about double checking

\begin{tabular}{llll}
\hline Item Number $(n)$ & Percentage (\%) & Comments
\end{tabular}

Have you seen the Trust

double checking process

written down either in paper

format or on the intranet?

- Yes

- No

30

18

40

8

- No

Have you undergone any

specific training in the Derbyshire Children's

Hospital, on how to do double checking for administration of medicines to paediatric patients?

- Yes

22

- No
Not seen in the Unit

$85 \%$ incomplete definition

During training period

The majority (44 nurses, 92\%) responded that they double checked all drug dosage forms with another nurse before administration for both preparation and administration stages (Table 4.3)

Similarly, 36 nurses (75\%) believed that double checking process are equally effective with both dosage forms (oral and IV), while $10(21 \%)$ respondents believed that the double checking process was more effective with IV medicines because intravenous medicines are more dangerous than oral medicines (Table 4.3). 
Table 4.3: Nurses perceptions about double checking

\begin{tabular}{lcc}
\hline Item & Number (n) & Percentage (\%) \\
\hline $\begin{array}{l}\text { Which of the following do you always double check with } \\
\text { another paediatric nurse?" } \\
\text { - Oral/IV preparation }\end{array}$ & 4 & 8 \\
- Oral/IV administration & 0 & 0 \\
- All & 44 & 92
\end{tabular}

What is the most important reason for you doing the double checking process?

- Hospital policy says that I must

- To protect children from MEs

- To learn more about the medicines.

- To protect myself from making a mistake

- $\quad 2 \& 4$

- All

Is double checking more effective with oral or intravenous medicines?"Can you explain why?

- Oral medicines

- Intravenous

- Both

- Not answered

What are the most common factors that you think have a direct effect on your ability to do double checking on your ward?

1. Shortage of paediatric nurses \& workload

2. Disturbance \& interruption

3. Unavailable second person

4. 1,2 and 3

25

52

5. 1,2

9

6. 1,3 


\subsubsection{Factors affecting nurses' adherence to double checking}

Over half ( 25 nurses, $52 \%$ ) of the respondents felt a shortage of nurses, disturbance and interruption by other staff members and an unavailable second person to carry out the double check affected their adherence to the double checking policy (Table 4.3).

\subsubsection{Differences in the double checking process during days and shifts}

Most (45 nurses, 94\%) of the respondents reported that there was "no difference" between weekdays and weekends and commented that "all times are equally busy" when following the double checking policy (Table 4.4).

More than half (25 nurses, $52 \%$ ) of the respondents believed that the double checking process was followed equally at all times and there was no difference between shift times. Fifteen nurses $(31 \%)$ however, reported that they could follow the double checking process more easily during the nightshift than other shift times. They believed that "they were less interrupted during the night shift compared to other shift times" (Table 4.4).

Also, in the survey $I$ asked the participants "Do you think the double checking process by another nurse is ineffective, effective, or very effective in detecting medication preparation and administration errors?". Over half $(26,54 \%)$ of the respondents considered that the double checking process is very effective in detecting medication preparation and administration errors. The remaining participants (22 nurses, $46 \%$ ) reported that double checking is effective in both processes. No participants believed that the double checking process is ineffective in detecting medication preparation and administration errors. 
Table 4.4: Nurses perceptions about double checking - days and times

Item

Number (n)

Percentage (\%)

Can you follow the double checking process

more easily during weekdays, weekends or is

there no difference

- Weekdays

2

4

- Weekends

1

2

- No difference

45

94

Can you follow the double checking process more easily in a specific shift time?

- Morning

1

24

- Afternoon

- Evening

- At night

- All times

- Not answered
3

15

25

2
2

6

31

52

4

\subsubsection{Recognition of medication administration errors}

The nurses perception of the number of medication preparation/administration errors that they had made or identified during the last month during the double checking process is shown in Table 4.5.

Over half (25 nurses, 52\%) of respondents reported that they had not made or identified any medication preparation/administration errors in the last month. 
How many medication preparation/administration errors do you remember making and/or finding last month that were identified during the double checking?

- No errors

- Less than 5 errors

- 5 - 10 errors
52

46

2

\subsubsection{Opinions on effectiveness}

Two open questions in this survey were designed to explore the nurses' attention to the double checking process and its effectiveness in reducing MEs. Over half (26 nurses, 54\%) of participants answered these questions. When asked about the elements of the double checking process that the nurses paid least attention to during drug administration, all respondents reported that no less attention was paid to any elements either for oral or intravenous medication administration.

One question was designed to explore the nurses' perception and their thinking about what may increase the effectiveness of the double checking process "The literature suggests that double checking is carried out in a variety of ways, with varying degrees of effectiveness, How do you think an effective process should be performed and do you do this in practice?" Ten nurses $(21 \%)$ thought that the double checking process could be more effective if it could be done without interruptions, while 8 nurses (17\%) had another view, believing that implementing the five rights of practice aids an effective double check process. 


\subsubsection{Opinions of the single checking}

One question in the survey asked the participants about single checking. Half the respondents (24 nurses, 50\%) reported that a single checking process should not be implemented for any medicines (Table 4.6). They stated that this is for safety reasons (i.e. human mistakes and errors can occur with drugs if not double checked by another), particularly with paediatric and neonatal medications. More than onethird (18 nurses, $38 \%$ ) of the respondents believed that the single checking process should be applied for certain types of medicines, for example, paracetamol and vitamins.

Table 4.6: Paediatric nurses perception about single checking

\begin{tabular}{lcc}
\hline Item & Number (n) & $\begin{array}{c}\text { Percentage } \\
\text { (\%) }\end{array}$ \\
\hline $\begin{array}{l}\text { Do you think single checking (i.e. one nurse } \\
\text { prepares and administers the medicine alone) } \\
\text { should be allowed for? }\end{array}$ & $\cdot$ & \\
$-\quad$ No medicines & 24 & 50 \\
$-\quad$ Oral medicines & 5 & 10 \\
$-\quad$ IV medicines & 0 & 0 \\
$-\quad$ All types & 1 & 2 \\
$-\quad$ Certain medicines & 18 & 38 \\
\hline
\end{tabular}

\subsubsection{Additional comments}

The last question in the survey asked the nurses if they had anything else to add that was not mentioned in the previous questions about the double checking process. Seventeen (36\%) nurses added comments. Most of the respondents (14 nurses, $29 \%$ ) reported that they agreed with, and preferred, to do double checking for all paediatric medicines; 2 respondents (4\%) also agreed with the double checking process but they indicated that it was time consuming. 


\subsection{DISCUSSION}

Only two previous studies have explored paediatric nurses opinions of the double checking process (Dickinson et al. 2010, Conroy et al. 2012). The focus of this study was to evaluate nurses' knowledge, perception and opinions of the double checking process of medicines administration in a children's hospital. Our results show that nurses have unclear knowledge and perceptions of the double checking process's definition and steps. Many believed they were aware but failed to give a good definition. This is consistent with a study by Dickinson et al (2010) who reported that clarity is needed in hospitals to achieve the best practice. In our study the exact meaning of the double checking process and its steps seemed to be unclear for many nurses. The majority of nurses $(85 \%)$ could only provide an incomplete definition of double checking. This suggests that the hospital policy for medication administration requires clarification for all staff.

Another important finding was that, over half $(54 \%)$ of the respondents stated they had had no training on the double checking process during their work in the hospital. Training for all nurses for drug administration to neonates and children in the hospital would be useful.

In addition, our study findings highlighted that the majority of nurses believed that multiple factors had a direct effect on their ability to follow the double checking process according to the hospital policy. Factors that were identified in this survey are consistent with previous studies, for example, distraction and interruption, heavy workloads (Dickinson et al. 2010, O'Shea 1999, Wakefield et al. 1998, Tang et al. 2007, Kim et al. 2011), and unavailable second checkers (Evley et al, 2010). 
Most nurses recalled making or identifying less than 5 errors in the last month. This is consistent with other studies which found the mean number of errors recalled was from 2 to 4.9 errors per nurse (Mayo \& Duncan 2004, Mrayyan et al. 2007).

The vast majority of the respondents' strongly agreed that single checking should not be introduced in the hospital. A few suggested that single checking may be useful for certain types of medicines. This variation in their opinions may be affected by their experiences with drug administration and the double checking process or may be affected by their confidence and their responsibility in their practice. This opinion is consistent with other studies findings, which was that the double checking process remains the most stable safeguard against MEs, particularly when high risk drug or complex drug dosages are used (Pape 2001, Manias et al. 2004, King 2004). In contrast, others have found that nurses welcomed the single checking process of medication administration because it gave them more accountability for medication administration than when using double checking (O'Connell et al. 2007). This study also stated that the single checking process encouraged the nurses to update their drug information and knowledge (O'Connell et al. 2007).

In addition, one study found that the majority of the nurses appreciated changing their practice to the single checking process (Jarman et al. 2002). They felt that single person checking of medications saves time and provided them with more responsibility and accountability.

Anderson \& Webster (2001) also found that the use of single checking saved nine hours per week during medication administration giving the nurses more time for patients needs. 


\subsection{STUDY LIMITATIONS}

There are several limitations in this study. The survey was conducted in only one setting. Therefore, this study's results were obtained from one children's hospital and may not be generalized to another setting or other registered paediatric nurses. Another limitation is the relatively low response rate (40\%). It is common for mailed surveys to yield limited responses (Jones et al, 2010) and this may increase when requesting sensitive information as this study did. The convenience sample might not reflect the actual population.

\subsection{CONCLUSION}

The survey results showed that the paediatric nurses suffered from insufficient knowledge and lack of clarity on the double checking process's definition and steps in the hospital policy and routine practice during medication administration. Also, this study has shown that the double checking process is supported by participants as appropriate practice in the children's hospital. However, this result supports the findings of other studies in relation to the factors that affect the nurses' adherence to medication administration and the double checking process policies. Most of the participants were agreed in their preference of the double checking process over single checking for patient safety for all types of medicines in practice. This study suggests that more training and clarification of the double checking process are required for all paediatric nurses to improve the implementation of double checking in practice. 


\section{CHAPTER FIVE}

MEDICATION ADMINISTRATION ERRORS WITH SINGLE AND DOUBLE CHECKING IN PAEDIATRIC PATIENTS:

SIMULATION STUDY 


\subsection{INTRODUCTION}

\subsubsection{Overview}

MAEs involve different types of errors including, for example, incorrect preparation, incorrect rate of intravenous (IV) administration, incorrect dose, omission and commission errors, incorrect drug, incorrect patient and the wrong formulation (Miller et al., 2007; Ghaleb et al., 2010)

Different strategies have been established, developed and implemented in an effort to reduce or prevent MEs. Double checking of medicines by two registered nurses is one such strategy that has been used to attempt to reduce or prevent MEs from reaching the patient (Conroy et al, 2012). This strategy has not yet been proven to be an effective process in reducing MEs and they continue to occur despite it.

My systematic review (Chapter 2) highlighted that there is insufficient scientific evidence to justify double checking of medicines. Therefore more studies and research are needed to evaluate double checking of the administration of medicines and its effectiveness in reducing MEs.

\subsubsection{Nurses role in medication administration}

Nurses frequently administer medications for in-patients and they are often the last line that can prevent MEs from reaching patients, as administration is the last stage of the medication process other than documentation and patient monitoring (Dowdell, 2004). A previous study has found that nurses are the profession most likely to detect MEs (Kohn et al, 2000). 


\subsubsection{Simulation study}

In the last ten years, there has been an interest in using simulation methods for the purpose of improving patient safety and patient care through a variety of applications (Gaba, 2004; Laer and Meibohm, 2011). Simulation is a technique, not a technology, to replace or amplify real experiences with guided experiences (Gaba, 2004). The use of simulation in the study of nurses' practice to provide evidence prior to new procedures being implemented in the clinical setting is relatively new. This study was conducted to reduce the knowledge gap about whether double or single checking is more effective in detecting and reducing MEs in paediatric inpatients.

A simulation study design was chosen for three reasons. Firstly, we wished to compare double and single checking processes, but in the Derbyshire Children's hospital, the drug administration policy requires double checking for all drugs and without good evidence it was thought unethical to change these. Secondly, with simulation there was no risk or hazard to patients because dummy patients were used. Thirdly, simulation can be a powerful learning tool for participants and may improve nurses' knowledge through the investigator's feedback to the participants.

This study was designed in such as way as to reflect the daily routine practice of drug preparation and administration by paediatric nurses in the hospital.

\subsection{AIMS AND OBJECTIVES}

This study was primarily intended to examine which intervention, either single or double checking, is more effective in detecting and reducing MEs in children. A secondary aim was to measure and compare the amount of time required for single checking and double checking procedures in medicines administration. 


\subsection{METHODS AND MATERIALS}

This study was an observational simulation study performed in a single children's hospital to assess the effectiveness of the double checking process by two nurses on drug administration and to compare that with a single checking process performed by the same nurses.

\subsubsection{Ethical Approval}

Ethical approval was obtained from the University of Nottingham Medical School Research Ethics Committee (Ref: N19042012 (12038) GEMS). (Appendix C). Approval was also obtained from the Derby Hospital's NHS Foundation Trust Research and Development (R\&D) department (Ref: DHRD/2012/034) (Appendix C). Written informed consent was obtained from all participating nurses (Appendix C).

\subsubsection{Recruitment}

All senior paediatric nurses were informed about the study by the investigators during a nurses' meeting. All registered paediatric nurses in the wards were informed individually using an information pack. This included an invitation letter, participant information sheet, two copies of a consent form and an empty envelope addressed with the investigator's name and address for return of consent forms for those who were willing to participate in the study (Appendix C).

The investigators explained to all participants, that entry into the study was entirely voluntary, their work would not be affected by their decision to participate or not and that they could withdraw from the study at any time. It was explained that if a participant wanted to withdraw part way through the study the data already collected would be used in analyses. Three weeks after the first invitation a reminder letter 
was sent to all nurses. The participants who replied were asked to advise the days and the times that they would be available to do the study.

\subsubsection{Simulated scenarios}

In an empty patient bed space on a medical ward, nurses who agreed to participate were given two prescriptions and two dummy patients. The required quantity of medicines was determined and purchased by the project chief investigator (Paediatric clinical pharmacist) from the pharmacy department before the study commenced. Study medicines were stored in the pharmacy when not in use.

The investigators provided each participant in each simulation session with information about the simulated patients and their medicines. They were then asked to prepare the following prescriptions:

- Two simple prescriptions (one oral analgesic medicine and one oral antibiotic).

- Two more complex prescriptions (an IV bolus of antibiotic, one requiring drawing up and one also needing reconstitution).

- Two IV infusions (one antibiotic requiring reconstitution and dilution and another antibiotic requiring a volume calculation).

Two separate scenarios with two patients each including the above requirements were designed. Different types of Medication Prescribing Errors (MPEs) and other confounders were built into each scenario involving both prescribing. and administration. Each nurse was required to prepare and administer the prescriptions in a pair with another nurse with double checking, and alone for single checking on different days. Different scenarios were used for double and single checking. No nurse did the same scenario twice. 
The scenarios varied sufficiently enough to act as an independent test. At the end of each session of the study the investigators would give feedback immediately to the participants, individually (for single checking process) or for both participants together (for double checking process) on their performance in order to improve their knowledge and skills of medication administration, and also to increase their awareness about patient safety. This was done in a friendly non critical manner.

In simulation scenario 1 (case 1) the patient was 6 years old, female, weight $20.5 \mathrm{~kg}$, had no known allergy to drugs or foods, had been admitted to the hospital with a urinary tract infection (UTI) and had pain (Figure 5.1). Prescribed drugs were:

- Paracetamol $300 \mathrm{mg}$ orally every 4 hours when required.

- Ibuprofen $120 \mathrm{mg}$ orally every 6 hours when required.

-Trimethoprim $\mathbf{4 0} \mathrm{mg}$ orally once daily for prophylaxis.

- Cefuroxime $\mathbf{4 0 0} \mathrm{mg}$ IV every 8 hours for 5 days.

- Gentamicin 50 mg IV every 8 hours (on separate chart).

Two confounders were built into this case. The first confounder: paracetamol had been given 2 hours earlier (as a once only dose on the front of the chart), and therefore the participant should not give the paracetamol dose again. The second confounder, was that gentamicin levels had been taken but no result had been recorded therefore the participant should ask the doctor or the pharmacist about the gentamicin serum level and ensure that it was safe before giving the next due dose to the patient.

The nurses should therefore administer four medicines only. A child size dummy was provided for this scenario including a patient wrist band and IV cannula. 
Figure 5.1: Simulation scenario 1 (Case 1)

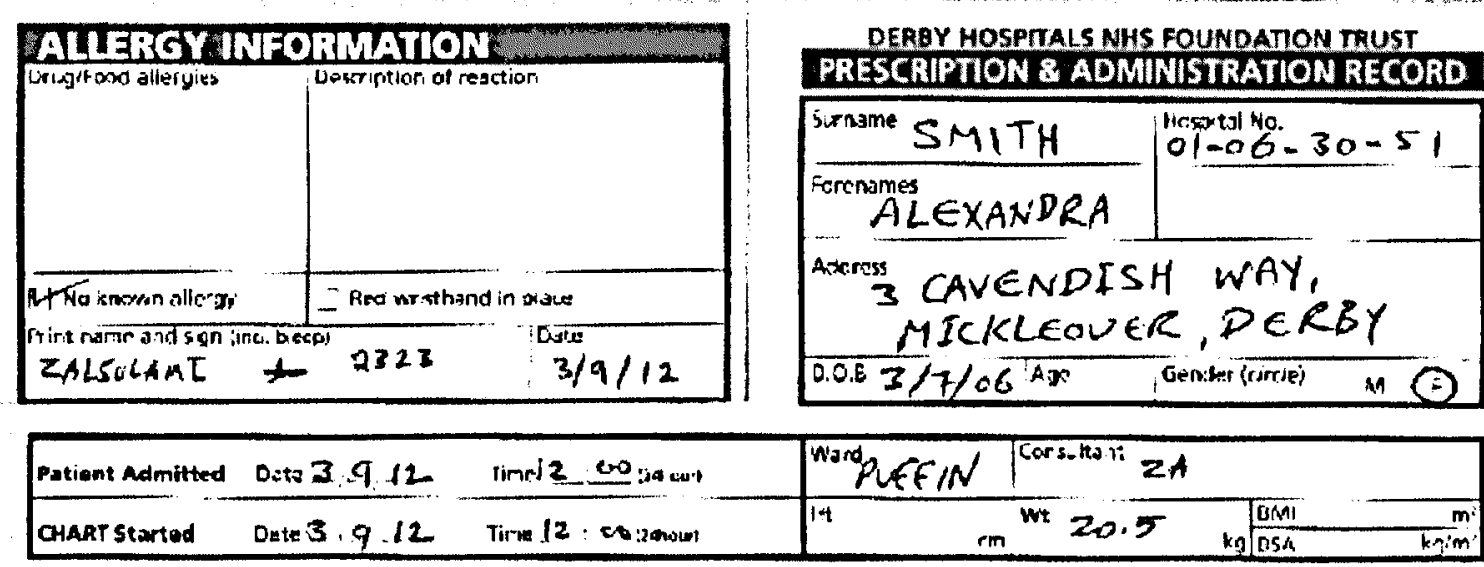

\begin{tabular}{|c|c|c|c|}
\hline \multicolumn{2}{|c|}{ Number of Maln Charts in use } & -0 & \\
\hline \multicolumn{4}{|c|}{ Supplementary Prascription Charts In uso ( $(J)$} \\
\hline \multicolumn{2}{|l|}{ [] Anticongulart } & $\square$ TFN & \\
\hline \multicolumn{2}{|l|}{ 口Ins.lin } & $\square$ PCA & \\
\hline \multicolumn{2}{|c|}{ - $П 7$ Gertamicimp/anmomycin } & Chemoth & erapy \\
\hline \multicolumn{2}{|c|}{ 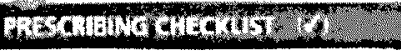 } & inces & unte \\
\hline \multicolumn{2}{|l|}{ VIE rise mexardes n iCM } & & $\therefore$ \\
\hline \multirow{2}{*}{ A.Cl risk sting } & $k=$ stiogs & & $\square$ \\
\hline & & & \\
\hline 1 I tapads ir pasiment & \multicolumn{3}{|c|}{ 口 P-gnanowareastfecting } \\
\hline 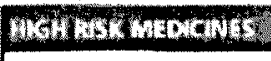 & 4 & \multicolumn{2}{|c|}{ Mefer to empresunkenl Guinetines } \\
\hline \multirow{2}{*}{ 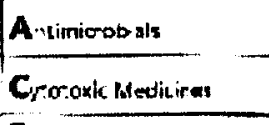 } & $B$ & \multicolumn{2}{|c|}{ 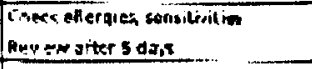 } \\
\hline & 11 & \multicolumn{2}{|c|}{ 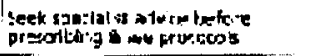 } \\
\hline \multirow{2}{*}{ 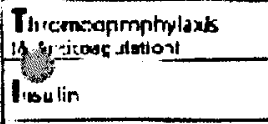 } & $\square$ & \multicolumn{2}{|c|}{ 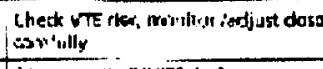 } \\
\hline & $\square$ & \multicolumn{2}{|c|}{ 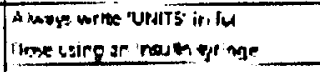 } \\
\hline Ppinalds & 1: & \multicolumn{2}{|c|}{ 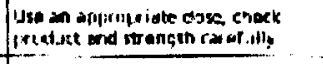 } \\
\hline Nual & $\square$ & \multicolumn{2}{|c|}{ 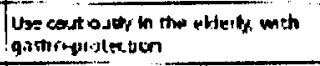 } \\
\hline Secuation & $\square$ & \multicolumn{2}{|c|}{ 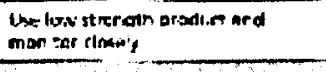 } \\
\hline
\end{tabular}

Use this space for specific information/stickers/stamps

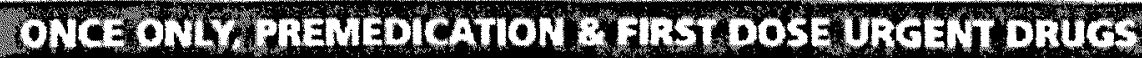

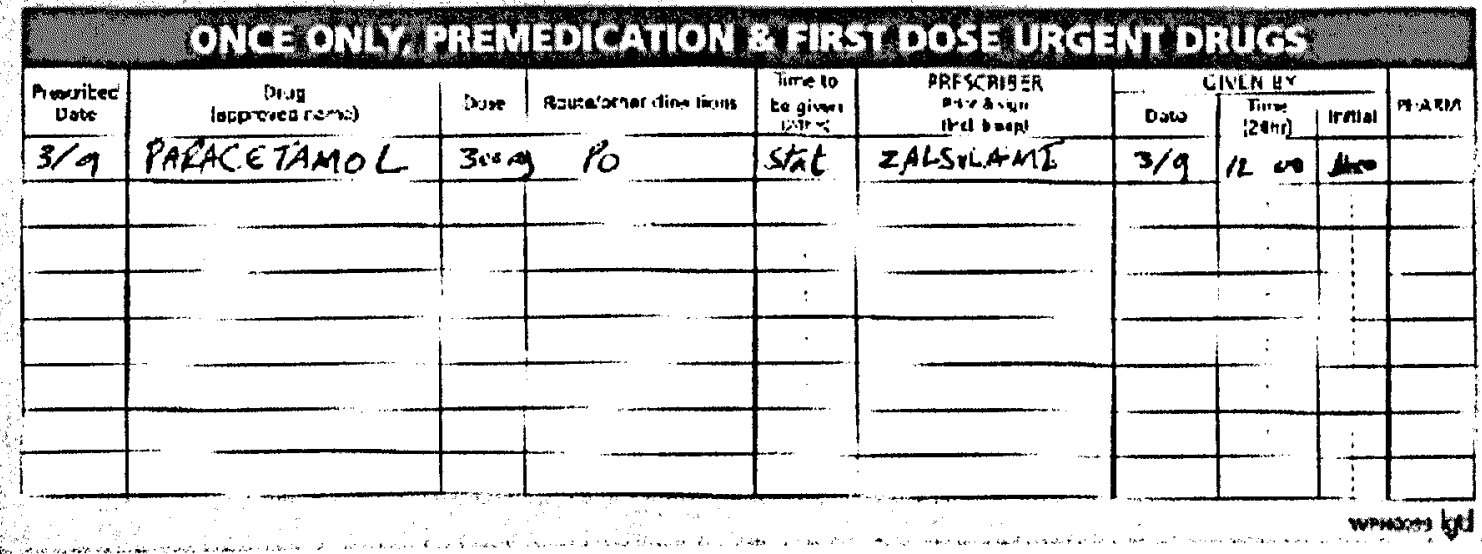




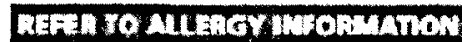

SAFE ADMINISTRATION (refer to MNETres CODE!

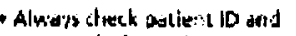
al ergles betore administrat on

- Reerort all nom iristratians ar!

dhet with ini? als Secord oneck

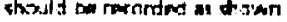

All Ton IV and utl er hok risk

medirines st ano be remat

stisted
- Acuse petiont's oun mrel sines

- Te:ord yelt-aulrivistialicon

of medisines izaMi $\boldsymbol{x}$ the

indmirestration recard

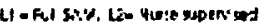

$\underbrace{\infty}_{n \infty+\infty}$

\section{GEFER TO MLERG THFORUATOW}

AECORO MEDICWES ADMINISTERED UHOER OGOPROTOCOA

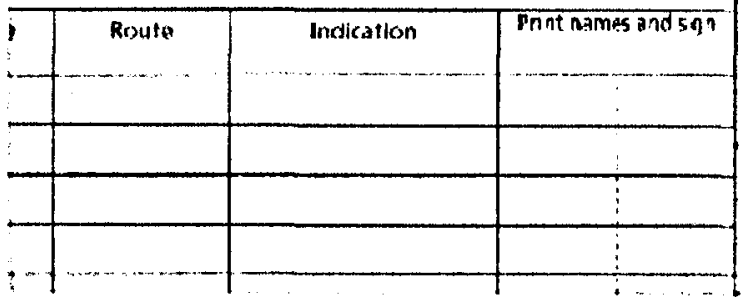

CHECK PATIE ITT NAME AND HOSPATAL MUMEER

\section{AS REOUIRE PRESCRIPTIONS}

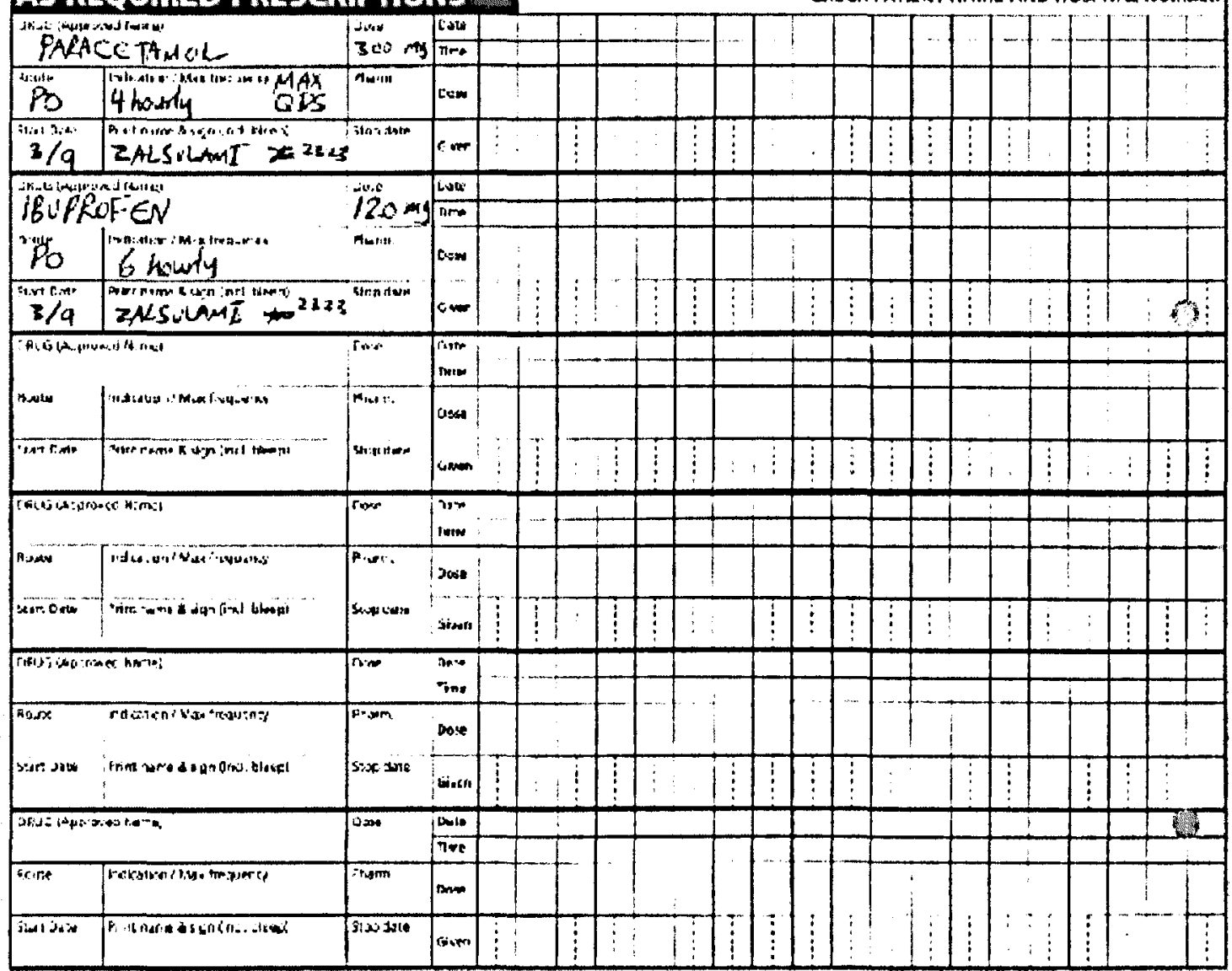

VARIABLE DOSE PRESCRIPTLONS

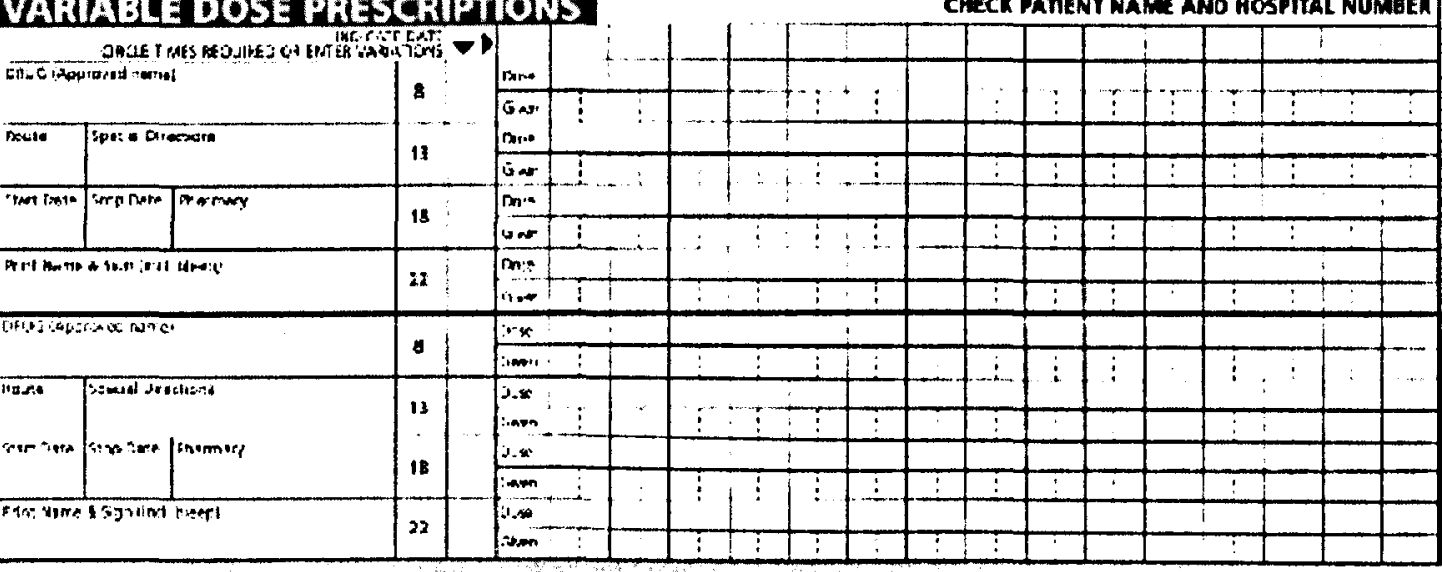




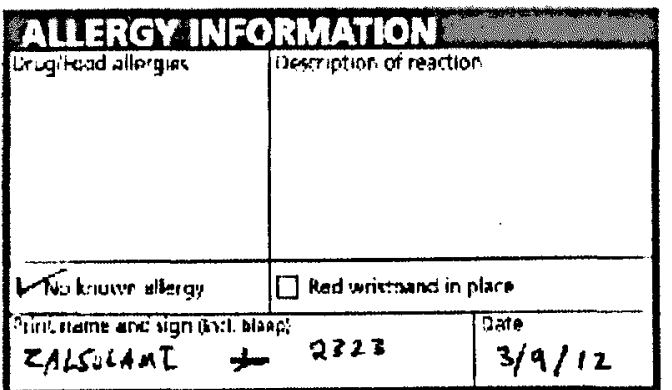

CHECK PATIENT NAME AMD HOSPITAL NUMBER

SAFE PRESCRIBING (rafor to Medichles Codk)

- Wrive Lleaty in biack all wad use aporcied names

- All aresciptlors must be fully gignoc and dated

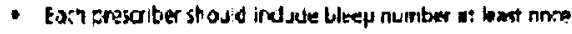

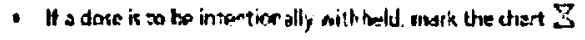

- If dixontinuing, drav a ine through, sta:e rezson, sgn 8 cale

- Cross refererse use of subpiamentery charts on front

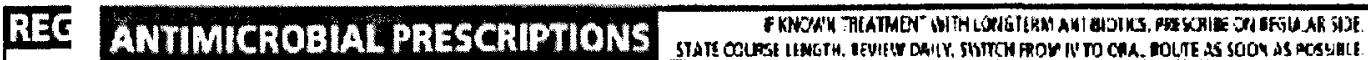

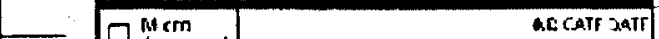

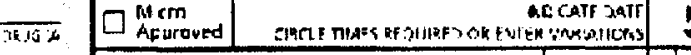

\begin{tabular}{|c|c|c|c|c|}
\hline \multirow{2}{*}{ 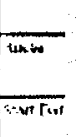 } & \multicolumn{2}{|c|}{ 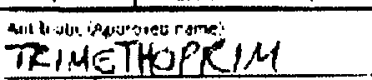 } & \multirow[t]{2}{*}{$40 \mathrm{~ms}$} & \multirow{2}{*}{$\begin{array}{l}\text { Cours } \\
\text { idsris! } \\
\text { nosm }\end{array}$} \\
\hline & $\begin{array}{l}30: 0 \\
\text { Po. }\end{array}$ & mroffylaxis & & \\
\hline & $\begin{array}{ll}31+160 \\
3 / 0\end{array}$ & 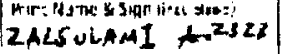 & & \\
\hline
\end{tabular}

inite

(a)

E Miren

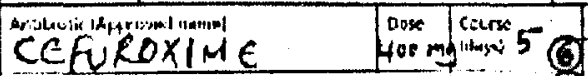

incite

iv for UTI

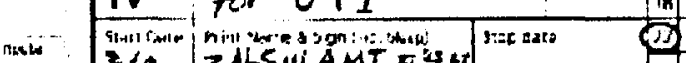

3/4 ZALS VLAMIE 48 at

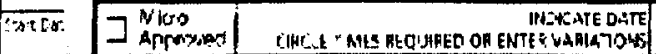

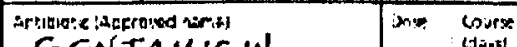
GENTAMICIN she seforate (hart pram

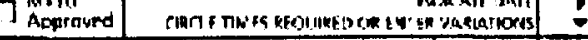

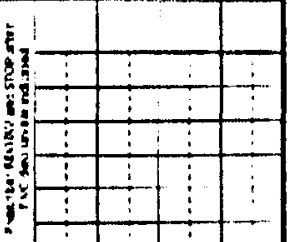

\section{VTE PROPHYLAXIS}

\section{opar natis of entekt}

ithive: 14

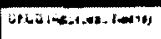

wis

Ther

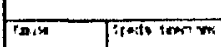

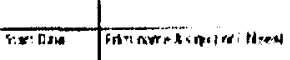

Win:

$\operatorname{lin} x$

sats tos

\section{OXYGEN}

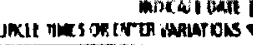

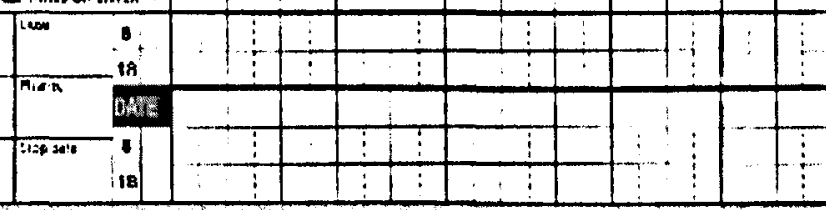



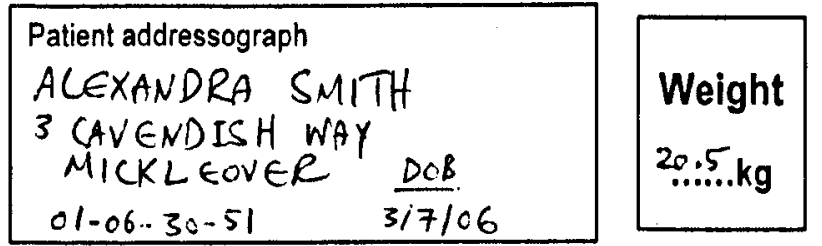

Indication for gentamicin (tick one or more):

$\square$ Pseudomonas (non-CF)

Q UTI/ pyelonephritis

o Micro / sensitivities

- For babies 0-8 weeks old - use NICU gentamicin prescription

- For CF patients - use once daily TOBRAMYCIN prescription

- For children with renal impairment - consider alternative treatment. If gentamicin is the only option, discuss with Consultant and pharmacy.

- Use dosing guidelines below, UNLESS a recent dose available for same patient in last 6 months.

\begin{tabular}{|c|c|c|}
\hline Age & $\begin{array}{c}\text { Dose regimen } \\
\text { (non-CF patient) }\end{array}$ & Preparations available \\
\hline 8 weeks to 12 years & $2.5 \mathrm{mg} / \mathrm{kg} 8$-hourly & $\begin{array}{c}10 \mathrm{mg} / \mathrm{ml} \text { and } \\
40 \mathrm{mg} / \mathrm{ml}\end{array}$ \\
\hline $12-18$ years & $2 \mathrm{mg} / \mathrm{kg} 8$-hourly & \\
\hline
\end{tabular}

\section{Therapeutic Drug Monitoring}

Target levels Trough: Less than $2 \mathrm{mg} /$

Peak: $\quad 5-10 \mathrm{mg} / \mathrm{l}$ (higher end for Pseudomonas)

- Take first level at $3^{\text {rd }}$ dose (immediately pre-dose and ONE hour post-dose)

- Interprel these levels before giving $4^{\text {th }}$ dose

- If dose CHANGED, REPEAT level at $3^{\text {rd }}$ dose of new regimen.

- If dose remains the SAME, repeat levels every 4 days

For advice on changing doses, please contact pharmacy - the table below is intended as a basic guide and does not take into account patient-specific factors.

\begin{tabular}{|c|c|}
\hline Levels & Potentlal actions - please d/w pharmacy \\
\hline $\begin{array}{l}\text { Trough }<1 \mathrm{mg} / \mathrm{l} \text {, peak } \\
\text { low }\end{array}$ & $\begin{array}{l}\text { Increase dose, usually assume linear kinetics } \\
\text { l.e. for } 20 \% \text { increase in level, increase dose by } 20 \% \text {. } \\
\text { NB: If a dose increase }>50 \% \text { required, please discuss with Senior Dr. }\end{array}$ \\
\hline $\begin{array}{l}\text { Trough 1-2mg/, peak } \\
\text { low }\end{array}$ & $\begin{array}{l}\text { Increase dose as above but consider increasing dose interval as well } \\
\text { o.g. extend from } 8 \text {-hourly to } 12 \text {-hourly. Increasing dose on top of a } \\
\text { trough level already above } 1 \mathrm{mg} / 1 \text { will cause a further increase in trough } \\
\text { level }\end{array}$ \\
\hline $\begin{array}{l}\text { Trough }<2 \mathrm{mg} / \mathrm{l} \text {, peak } \\
\text { high }\end{array}$ & $\begin{array}{l}\text { Reduce dose, usually assume linear kinetics l.e. for } 20 \% \text { reduction in } \\
\text { level, reduce dose by } 20 \% \text {. }\end{array}$ \\
\hline Trough high, peak high & $\begin{array}{l}\text { Consider omitting dose, then reduce dose and increase dose interval } \\
\text { If levels very high, consider repeating before recommencing doses }\end{array}$ \\
\hline $\begin{array}{l}\text { Trough }>2 \mathrm{mg} / \mathrm{l} \text {, peak } \\
\text { OK }\end{array}$ & Consider omitting dose, then increase dose interval \\
\hline $\begin{array}{l}\text { Trough }>2 \mathrm{mg} / \mathrm{l} \text {, peak } \\
\text { low }\end{array}$ & Consider omitting dose, then increase dose and increase dose interval \\
\hline
\end{tabular}

Pilot - February 2008 
TDM Results

\begin{tabular}{|c|c|c|c|c|c|}
\hline Levels $=r g^{\prime} L$ & Dah: & Date: & Date: & Date: & Date \\
\hline Trough $\left(<2 m g^{\prime} L\right)$ & & & & & \\
\hline Paak (5-10mad) & & & & & \\
\hline $\begin{array}{l}\text { Act on iconinue, } \\
\text { reduce dose } \\
\text { extend dose } \\
\text { irterval) }\end{array}$ & & & & & \\
\hline Dr's signature & & & & & \\
\hline
\end{tabular}

\section{Prescription}

Also prescriba "Gentamicln" on the "Regular Prescriptjon" part of treatment ca'd and add 'see atrachod sheet", Sign this entry and keep this preacription in 'patient's Coservatlon fi'e'.

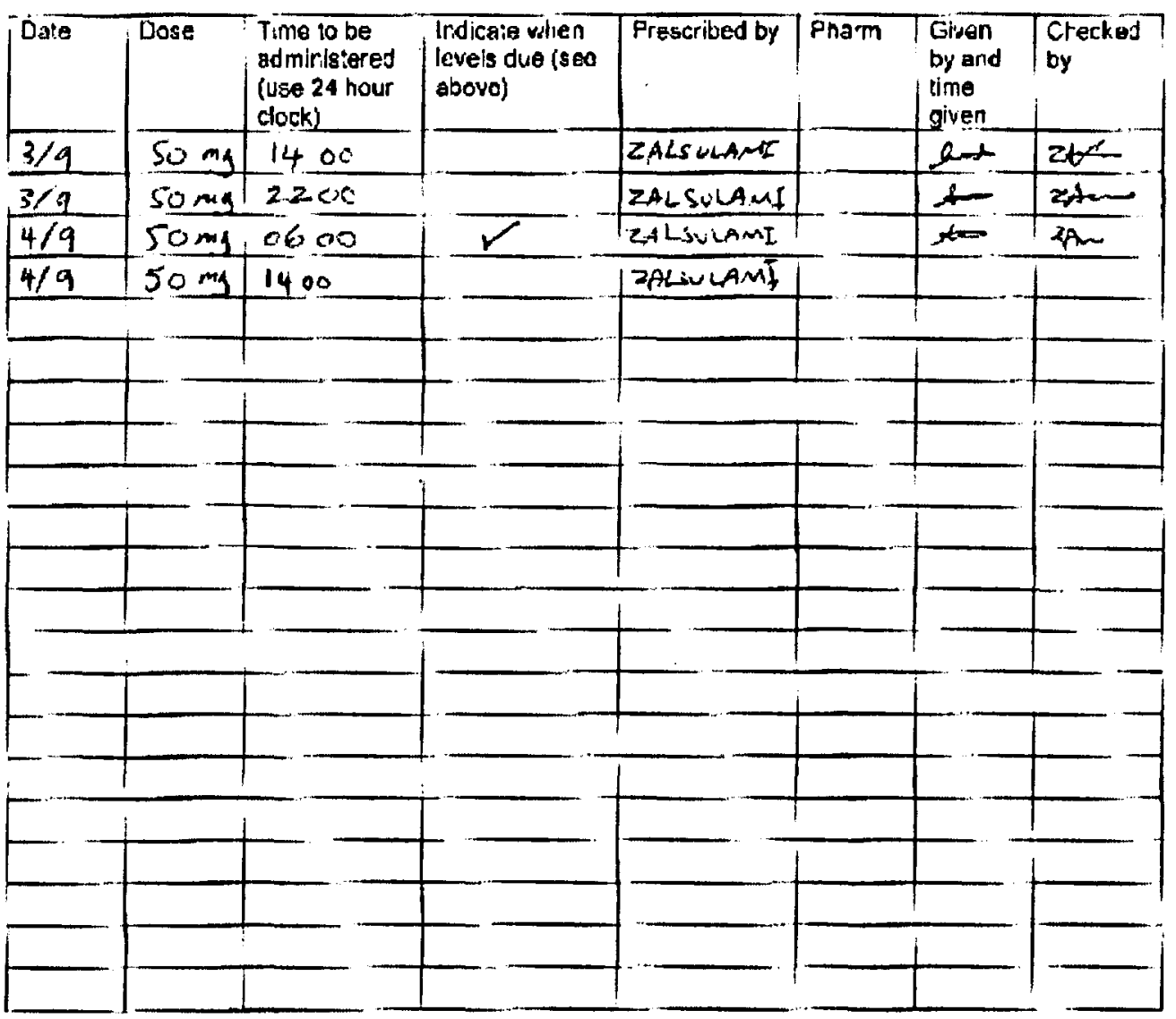

Pilal - Fobruary 2008 
In simulation scenario 1 (case 2), the patient was 5 months old, female, weight 6.7 $\mathrm{kg}$, had no known allergy to drugs or foods, and had been admitted to the medical ward with ?sepsis and ?aspiration (Figure 5.2). Prescribed drugs were:

\section{-Ceftriaxone $540 \mathrm{mg}$ IV once daily for 7 days.}

- Metronidazole $125 \mathrm{mg}$ IV every 8 hours for 7 days.

One confounder was built in to case 2. The metronidazole dose was incorrect (a rectal dose had been prescribed as IV). It was hoped that the participant would check the dose and identify that it was incorrect and request it to be corrected before administering the dose. The nurses should administer two medicines (after dose correction). A baby size dummy was provided for this scenario including a patient wrist band and IV cannula. 
Figure 5.2: Simulation scenario 1 (Case 2)

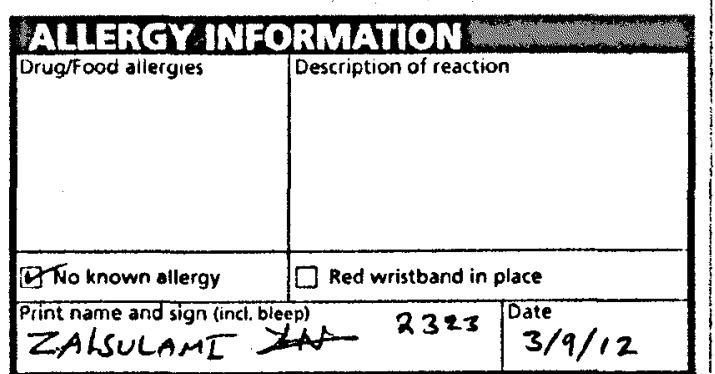

DERBY HOSPITALS NHS FOUNDATION TRUST PRESCRIPTION \& ADMINISTRATION RECORD

\begin{tabular}{|c|c|}
\hline Surname HUSSAIN & $\begin{array}{l}\text { Hospital No. } \\
02-01-33-70\end{array}$ \\
\hline forenames $A Y S H A$ & \\
\hline Address 7 HOLMES AVE. \\
SINFIN, DERBY \\
\hline $0.0 .818 / 4 / 12^{\text {Age }}$ & Gender (circle) M F \\
\hline
\end{tabular}

\begin{tabular}{|c|c|c|c|c|}
\hline Patient Admitted & Date $3,-9.12$ & Time $12: \infty$ (24hour) & Ward $R \in E I N$ & Consultant TST \\
\hline HART Startod & Date $3,9,12$ & Time (z:00 (24how) & $\mathrm{cm}$ & \begin{tabular}{ll|l} 
we & 6.7 & $\mathrm{kMI}$ \\
$\mathrm{BSA}$
\end{tabular} \\
\hline
\end{tabular}

Number of Main Charts in use ___ of __

Supplementary Prescription Charts in use $(\checkmark)$

\begin{tabular}{|l|l|l|l|}
\hline$\square$ & Anticoagulant & $\square$ & TPN \\
\hline
\end{tabular}

\begin{tabular}{l|l|l|l}
$\square$ & Insulin & $\square$ & PCA \\
\hline
\end{tabular}

\begin{tabular}{|l|l|l|l}
\hline a & GentamicinNancomycin & $\square$ & Chemotherapy \\
\hline
\end{tabular}

\begin{tabular}{|c|c|c|c|c|}
\hline \multicolumn{2}{|c|}{ 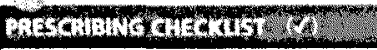 } & intiol & Dote & $\begin{array}{c}\text { High } \\
\text { 8isk } \\
\end{array}$ \\
\hline \multicolumn{2}{|c|}{ VTE risk recorded in ICM } & & & $\square$ \\
\hline AKI risk stage & CKD 5tage & & & $\square$ \\
\hline
\end{tabular}

$\square$ Hepatk impairment $\square$ Pregnantireasteeding

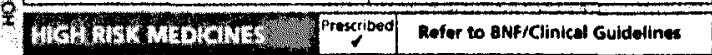

\begin{tabular}{|l|l|l|}
\hline Antimicrobials & $\square$ & Check sliergies, sensitivition \\
\hline
\end{tabular}

\begin{tabular}{|l|l|l|}
\hline Antimicrobials & $D$ & Review efter 5 days \\
\hline \hline
\end{tabular}

\begin{tabular}{|l|l|l|l|l}
\hline Cytotoxic Medicines & $\square$ & $\begin{array}{l}\text { Seet specintist ectrice before } \\
\text { prescribing \& seo protocols }\end{array}$ \\
\hline
\end{tabular}

\begin{tabular}{|l|l|l|}
\hline Thromboprophylaxis & $\square$ & Chock VTE risk, monitor /adjust dose \\
\hline
\end{tabular}

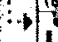

Insulin

\begin{tabular}{|l|c|l|}
\hline Insulin & $\square$ & Dose using an insulin syringe \\
\hline Opioids & $\square$ & $\begin{array}{l}\text { Use an appropriate dose, check } \\
\text { product and strength carefully }\end{array}$ \\
\hline NsalOs & $\square$ & $\begin{array}{l}\text { Use countousty in the etderty, with } \\
\text { gastro-protection }\end{array}$ \\
\hline Sedatives & $\square$ & $\begin{array}{l}\text { Use low sirength product and } \\
\text { monitor closely }\end{array}$ \\
\hline
\end{tabular}

ONCE ONLY PREMEDICATION \& FIRST DOSE URAEMT DRUOS

wartoos log

Use this space for specific information/stickers/stamps

\section{MEDICINES MANAGEMENT GHECKUST}

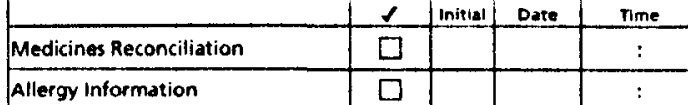

Information Sources $(\checkmark)$ Potient $\square$ POOS []$\quad$ GP $\square$ Notes $\square$ Other

Compliance aid on admission

Compliance aid assessment

Medicines information given

Discharge prescription supplied

\begin{tabular}{|c|c|c|}
\hline$f$ & Initial & Date \\
\hline$\square$ & & \\
\hline$\square$ & & \\
\hline$\square$ & & \\
\hline$\square$ & & \\
\hline$\square$ & & \\
\hline
\end{tabular}




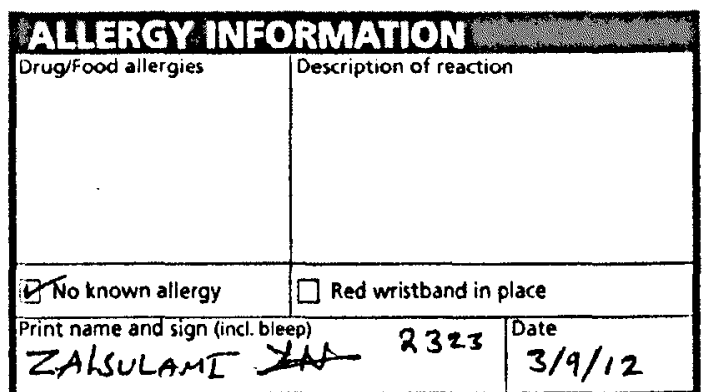

SAFE PRESCRIBING (rofer to Medicines Code)

- Write clearly in black ink and use approved names

- All prescriptions must be fully signed and dated

- Each prescriber should include bleep number at least once

- If a dose is to be intentionally withheld, mark the chart $\otimes$

- If discontinuing, draw a line through, state reason, sign \& date

- Cross reference use of supplementary charts on front

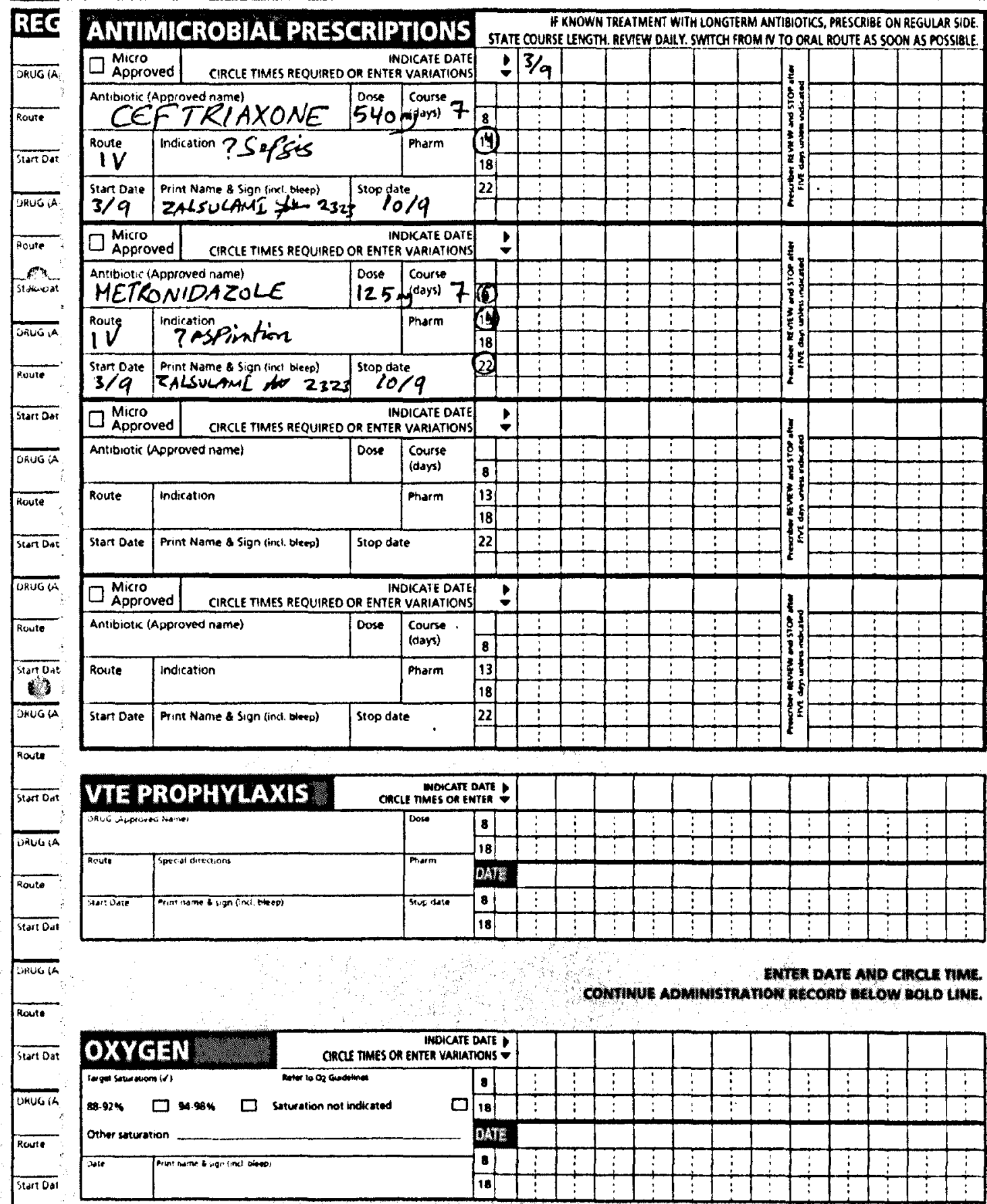


In simulation scenario 2, (Case 1), the patient was 10 years old, male, weight 32.4 $\mathrm{kg}$, was allergic to penicillin (caused rash), and was admitted to hospital with appendicitis and pain (Figure 5.3). Prescribed drugs were as follow:

- Paracetamol $650 \mathrm{mg}$ orally every 4 hours (for pain).

- Diclofenac $\mathbf{3 0} \mathrm{mg}$ orally every 8 hours (for pain).

- Cefuroxime 640 mg IV every 8 hours for 7 days.

- Metronidazole 245 mg IV every 8 hours for 7 days.

In the above case, two confounders were built into the prescription. A paracetamol dose had been given to the patient on admission, so the nurse participant should not duplicate the dose. The second confounder was that the participant should not give the cefuroxime dose until confirming with the doctor that this was acceptable given the patient's penicillin allergy. The nurses should therefore administer three medicines only. 
Figure 5.3: Simulation scenario 2 (Case 1)

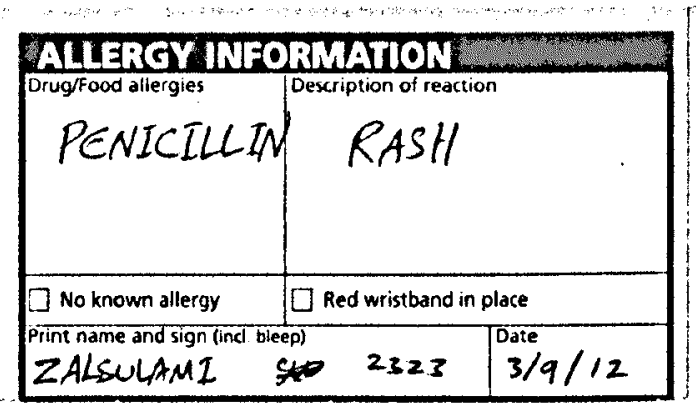

DERBY HOSPITALS NHS FOUNDATION TRUST PRESCRIPTION 8 AOMINISTRATION RECORO

\begin{tabular}{|c|c|}
\hline Surname STEVENS & $\begin{array}{l}\text { Hospital No. } \\
02-07-35-17\end{array}$ \\
\hline \multicolumn{2}{|l|}{$\begin{array}{l}\text { Forenames } \\
S T E P H \in N\end{array}$} \\
\hline \multicolumn{2}{|c|}{$\begin{array}{l}\text { Address } K I N G \text { 'S DRIVE } \\
\text { LITTLEOVER, DERBY }\end{array}$} \\
\hline $0.0 .825 / 8 / 02^{\text {Age }}$ & Gender (eircle) \\
\hline
\end{tabular}

\begin{tabular}{|c|c|c|c|c|c|c|}
\hline Patient Admitted & Date $3,9,12$ & Time 12: ov (2athours & ${ }^{\text {Ward }}$ PuffIN & $\begin{array}{r}\text { Consultant } \\
Z A\end{array}$ & & \\
\hline CAART Started & Date $3,9.12$ & Time 1 $\mathbf{z}$ : Do (24hour) & $\mathrm{cm}$ & wt 32.4 & $\mathrm{~kg} \frac{B M 1}{B S A}$ & $\frac{\mathrm{m}^{2}}{\mathrm{~kg} / \mathrm{m}^{2}}$ \\
\hline
\end{tabular}

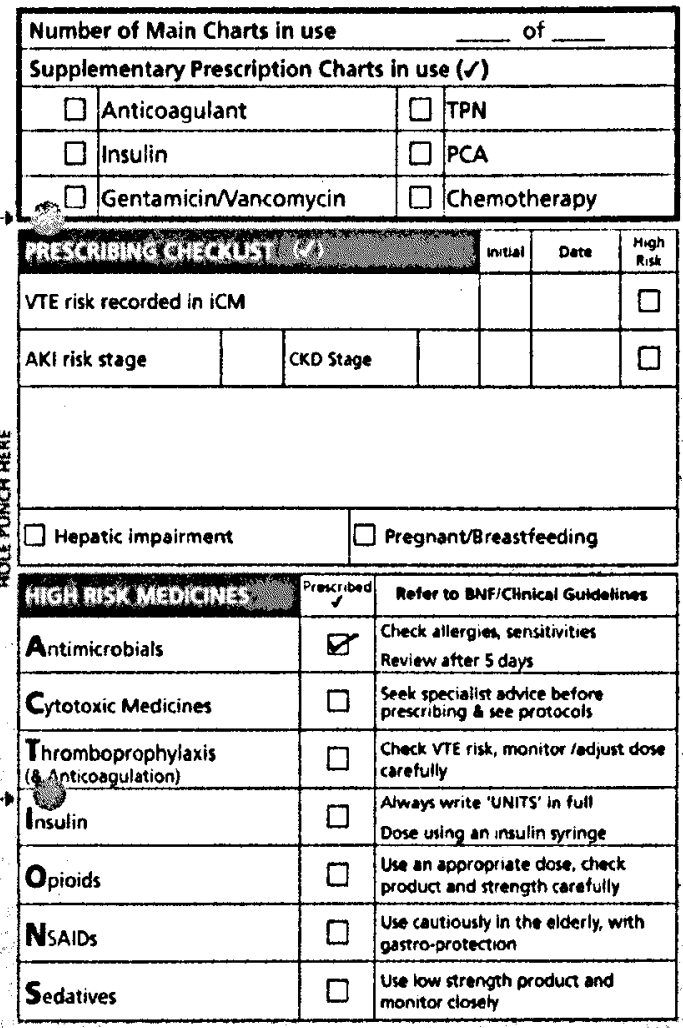

Use this space for specific information/stickers/stamps

\begin{tabular}{|c|c|c|c|c|}
\hline & 1 & Initial & Date & Time \\
\hline Medicines Reconciliation & $\square$ & & & : \\
\hline Allergy Information & $\square$ & & & : \\
\hline \multicolumn{5}{|c|}{ Information Sources ( $(N)$ patient $\square$ poOs $\square$} \\
\hline Other & & 1 & Initial & Date \\
\hline Compliance sid on admission & & $\square$ & & \\
\hline Compliance sid assessment & & $\square$ & & \\
\hline Medicines information given & & $\square$ & & \\
\hline Discharge prescription supplied & & $\square$ & & \\
\hline Referral to Community Pharmacist & & $\square$ & & \\
\hline
\end{tabular}

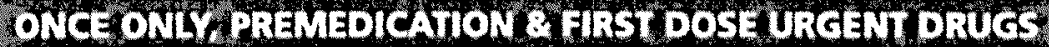

\begin{tabular}{|c|c|c|c|c|c|c|c|c|c|}
\hline \multirow{2}{*}{$\begin{array}{c}\text { Prescribed } \\
\text { Date }\end{array}$} & \multirow{2}{*}{$\begin{array}{c}\text { Orug } \\
\text { (approved name) }\end{array}$} & \multirow{2}{*}{ Dose } & \multirow{2}{*}{ Route/ other directions } & \multirow{2}{*}{$\begin{array}{l}\text { Tinie to } \\
\text { be given } \\
\text { (2then) }\end{array}$} & \multirow{2}{*}{ 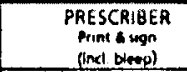 } & \multicolumn{3}{|c|}{ GIVEN BY } & \multirow{2}{*}{ PHARM. } \\
\hline & & & & & & Dose & lime & intial & \\
\hline $3 / 9$ & PARACETAMOL & 650 & Po & Stat & ZALSULAMT & $3 / 9$ & 1200 & 80 & \\
\hline & & & & : & & & . & $\vdots$ & \\
\hline & & & & $:$ & & & : & $\vdots$ & \\
\hline & & & & $:$ & & & $:$ & $\vdots$ & \\
\hline & & & & $:$ & & & : & $\vdots$ & \\
\hline & & & & $:$ & & & . & : & \\
\hline & & & & $:$ & & & 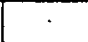 & $\vdots$ & \\
\hline & & & & $\because$ & & & $:$ & $\vdots$ & \\
\hline
\end{tabular}


SAFE ADMINISTRATION (refer to Medicines Code)

RECORD MEDICINES ADMINISTERED UNDER PGDPROTOCOL

- Always check patient $1 D$ and

allergies before administration

- Reuse patient's own medicines

- Record all administrations on

- Record self-administration

chart with initials. Second thec

should be recorded as shown

of medicines (SAM) on the

- All CDs, $N$ and other high risk

medicines should be second

checked

LI = Full SAM, Lan Murse supervised
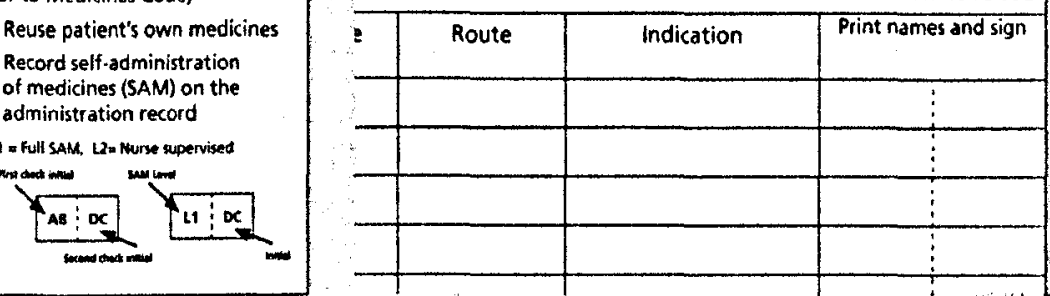

AS REQUIRED PRESCRIPTIONS

CHECK PATIENT NAME AND HOSPITAL NUMBER

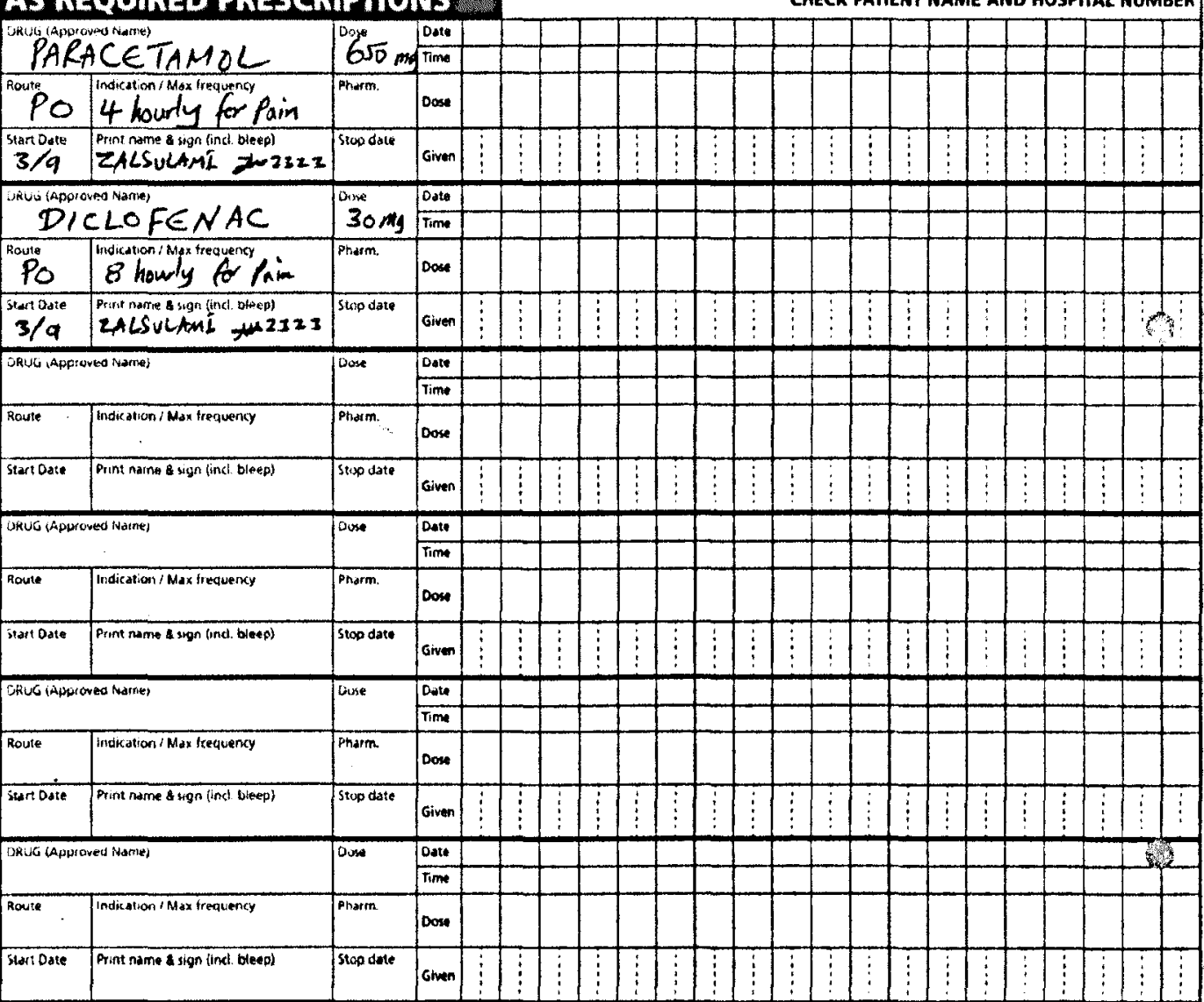

VARIABLE DOSE PRESCRIPTIONS

\begin{tabular}{|c|c|c|c|c|c|c|c|c|c|c|c|c|c|c|c|c|c|c|c|}
\hline \multicolumn{20}{|c|}{ 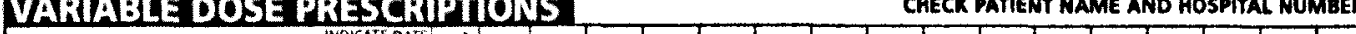 } \\
\hline \multicolumn{20}{|c|}{\begin{tabular}{|l|l|} 
CIRCLE TIMES REQUIRED OR ENTER VAATAATIONS & $\sim D$ \\
\end{tabular}} \\
\hline \multirow{2}{*}{\multicolumn{3}{|c|}{ DAUG (ADProved name) }} & \multirow{2}{*}{8} & Dose & & & & & & & & & & & & & & & \\
\hline & & & & Simen & $\vdots$ & 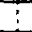 & $\vdots$ & $\vdots$ & 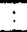 & ! & 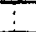 & 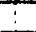 & 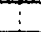 & $\because$ & $\bar{\vdots}$ & $\bar{\vdots}$ & $\overline{3}$ & : & \\
\hline \multirow[t]{2}{*}{ Route } & \multirow{2}{*}{\multicolumn{2}{|c|}{ Speciat Directions }} & \multirow{2}{*}{13} & fore & & - & & - & & & & & & & & & & & \\
\hline & & & & Geven & $\vdots$ & $i$ & $\vdots$ & $i$ & $i$ & $\vdots$ & $\vdots$ & $\vdots$ & $i$ & $\therefore$ & $\vdots$ & $i$ & $\vdots$ & $i$ & $i$ \\
\hline \multirow[t]{2}{*}{ stan oste } & \multirow[t]{2}{*}{ Seop Dorte } & \multirow[t]{2}{*}{ Pharmacy } & \multirow{2}{*}{18} & Donse & & & . & & & & - & & 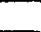 & - & & & & & \\
\hline & & & & Guen & $\vdots$ & $\vdots$ & $\vdots$ & $\vdots$ & $\vdots$ & $\vdots$ & $\vdots$ & $\vdots$ & . & : & $\vdots$ & $\vdots$ & i & $\vdots$ & $\vdots$ \\
\hline \multirow{2}{*}{\multicolumn{3}{|c|}{ Funt Narme \& Sign (inci blege }} & \multirow{2}{*}{22} & Douse & 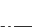 & & & & & 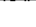 & & & & . & & & 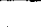 & 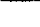 & \\
\hline & & & & Goven & $:$ & $\vdots$ & $\vdots$ & $:$ & $\vdots$ & $i$ & $\vdots$ & . & $\vdots$ & $:$ & & $\vdots$ & : & $\vdots$ & $\vdots$ \\
\hline \multirow{2}{*}{\multicolumn{3}{|c|}{ 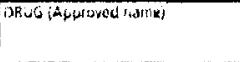 }} & \multirow{2}{*}{8} & Dose & & & & & . & & & & & & & & & & \\
\hline & & & & Gavm & $\vdots$ & $\vdots$ & $\vdots$ & $\vdots$ & $\vdots$ & $\vdots$ & $\vdots$ & 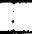 & $\vdots$ & $\vdots$ & $\vdots$ & $\div$ & $!$ & $\vdots$ & $\vdots$ \\
\hline \multirow[t]{2}{*}{ Route } & \multirow{2}{*}{\multicolumn{2}{|c|}{ Special Directwons }} & \multirow{2}{*}{13} & $\cos x$ & & & & & & & & & & & & & & & \\
\hline & & & & Given & $\vdots$ & $\vdots$ & $\vdots$ & $i$ & $\vdots$ & $\vdots$ & : & $\vdots$ & $i$ & ? & & 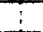 & $\vdots$ & $\vdots$ & : \\
\hline \multirow[t]{2}{*}{ Staft Dats } & \multirow[t]{2}{*}{ stow aste } & \multirow[t]{2}{*}{ Pharmacy } & \multirow{2}{*}{18} & Dose & & & & & & & & & & & & & & & \\
\hline & & & & $6 \mathrm{men}$ & $\vdots$ & $\vdots$ & $\vdots$ & $\vdots$ & $\vdots$ & ! & $\vdots$ & $\vdots$ & $!$ & $\vdots$ & $\therefore$ & $!$ & $\vdots$ & $\vdots$ & : \\
\hline \multirow{2}{*}{\multicolumn{3}{|c|}{ Print Name 4 Sigr: finct bleepl) }} & \multirow{2}{*}{22} & Dose & & & & & & & & & & & & & & & \\
\hline & & & & Genen & $i$ & $i$ & : & $\vdots$ & $\vdots$ & $\vdots$ & $\div$ & 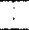 & 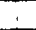 & $\vdots$ & & $:$ & $\vdots$ & $\div$ & ! \\
\hline
\end{tabular}


ALLEROY WFOBMATION

\begin{tabular}{|c|c|}
\hline PENICILLIM & $\int^{\text {Description of reaction }}$ RASH \\
\hline No known allergy & $\square$ Red wristband in place \\
\hline
\end{tabular}

CHECK PATIENT NAME AND HOSPITAL NUMBER

SAFE PRESCRIBING (refer to Medicines Code)

- Write clearly in black ink and use approved names

- All prescriptions must be fully signed and dated

- Each prescriber should include bleep number at least once

- If a dose is to be intentionally withheld, mark the chart $\square$

- If discontinuing, draw a line through, state reason, sign \& date

- Cross reference use of supplementary charts on front

\section{REC \\ ANTIMICROBIAL PRESCRIPTIONS}

H KNOWN JREAIMENT WITH LONGTERM ANTIBIOTICS PRESCRIBE ON REGULAR SIOE. STATE COURSE LENGTH. REVEW DALLY. SWTCH FROM N TO ORAL ROUTE AS SOON AS POSSIBLE. Micro
ARUG IA
APPIOVEd Antibiotic (Approves name) CEFUROXIME 640 m

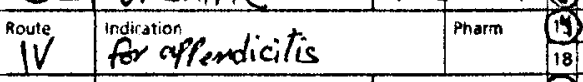

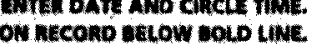

\section{OXYGEN}

WDDCATE DATE

Other soturation

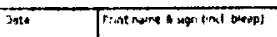

DATE 
In simulation scenario 2 (Case 2), the patient was 5 days old, male, weight $3.6 \mathrm{~kg}$, and was admitted with meningitis and was in pain (Figure 5.4). The prescribed drugs were as follow:

- Paracetamol $48 \mathrm{mg}$ orally every 4 hours.

- Ibuprofen $22 \mathrm{mg}$ orally every 6 hours.

- Cefotaxime $180 \mathrm{mg} \mathrm{IV}$ every 6 hours for 10 days.

- Amoxicillin $360 \mathrm{mg}$ IV every 6 hours for 10 days.

Three confounders were built into the Case 2. The patient allergy information had not been completed, and therefore the participant was expected to ask the parents before giving the drug to confirm that there was no allergy which would contraindicate the drug. The other errors built into this prescription were that both the cefotaxime and amoxicillin dose frequencies were written incorrectly (prescribed four times daily instead of twice daily). The nurses should therefore administer three medicines (i.e. both antibiotics after requesting the frequency of antibiotic doses to be changed to twice daily and either paracetamol or ibuprofen). 
Figure 5.4: Simulation scenario 2 (Case 2)

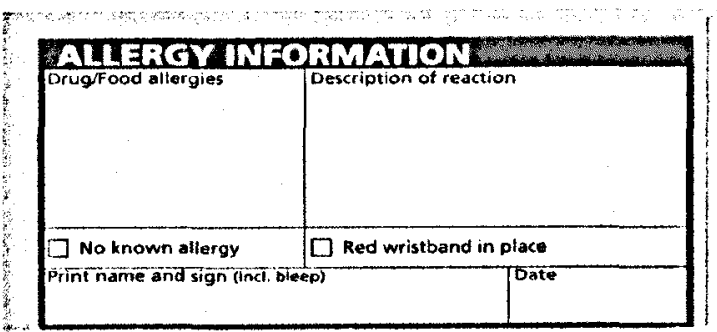

DERGY HOSPITALS MHS FOUNDATION TRUST PRESCRIPTION \& ADMINISTRATION RECORO

\begin{tabular}{|c|c|c|}
\hline \multicolumn{2}{|c|}{ Surname $B E D F O E D$} & $\begin{array}{l}\text { Haspital No. } \\
01-06\end{array}$ \\
\hline \multicolumn{3}{|c|}{ Forenames MARK } \\
\hline \multicolumn{3}{|c|}{$\begin{aligned} \text { Address } & 10 \text { GIRTON WAY } \\
& M I C K L E O U \in R, D E R B Y\end{aligned}$} \\
\hline$\overline{0.0 .828}$ & $\sqrt{8 / 2 / 2}$ /age & Gender (circle) \\
\hline
\end{tabular}

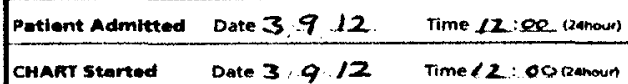
Ward $L A Y B R D$

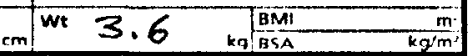

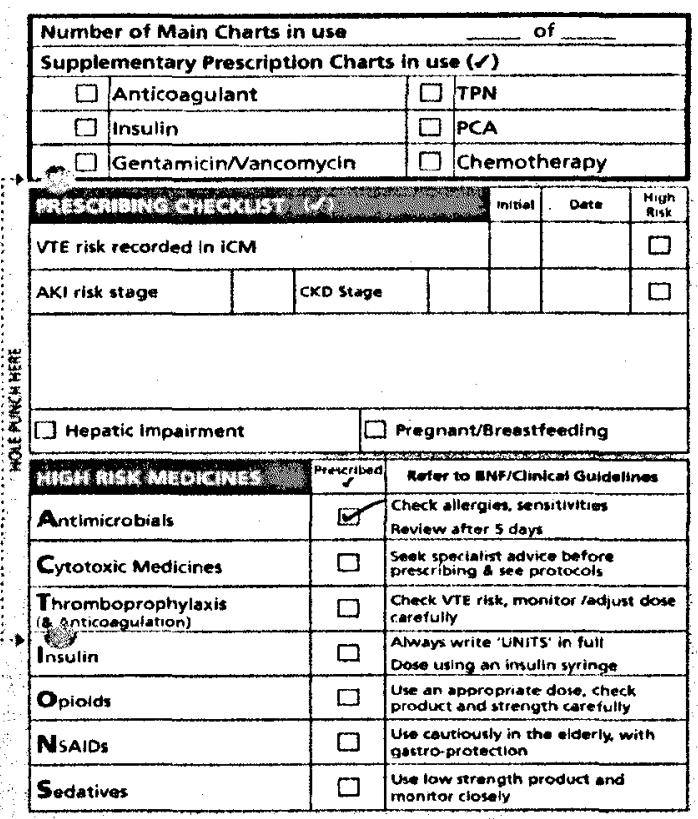

Use this space for specific information/stickers/stamps

\begin{tabular}{|c|c|c|c|c|c|c|c|c|c|}
\hline $\begin{array}{c}\text { Prescribad } \\
\text { Date }\end{array}$ & $\begin{array}{l}\text { Drug } \\
\text { (approved numo) }\end{array}$ & Dose & Route/other directions & $\begin{array}{l}\text { Time to } \\
\text { be given } \\
\text { gethey }\end{array}$ & 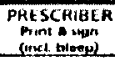 & Date & 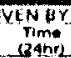 & inirtat & PHARM \\
\hline & & & & & & & $:$ & $\vdots$ & \\
\hline & & & & $:$ & & & $\therefore$ & $\vdots$ & \\
\hline & & & & $:$ & & & & $\vdots$ & \\
\hline & & & & . & & & & $\vdots$ & \\
\hline & & & & $:$ & & & & $\vdots$ & \\
\hline & & & & . & & & : & $\vdots$ & \\
\hline & & & & & & & & $\vdots$ & \\
\hline & & & & : & & & & ; & \\
\hline
\end{tabular}

\begin{tabular}{|c|c|c|c|c|}
\hline & $\checkmark$ & Imitiol & Dote & Time \\
\hline Medicinm Reconcillation & $\square$ & & & $:$ \\
\hline Allergy information & $\square$ & & & $:$ \\
\hline \multicolumn{3}{|c|}{ information Sources $(\sigma)$ Patient $\square$ poDs $\square$} & $P \square$ & es $\square$ \\
\hline other & & 1 & Initial & Date \\
\hline Compliance sid on admission & & $\square$ & & \\
\hline Complisence sid essessment & & {[]} & & \\
\hline Medicines information given & & $\square$ & & \\
\hline Discharge prescription supplied & & [] & & \\
\hline Referral to Community Phermacist & & $\square$ & & \\
\hline
\end{tabular}




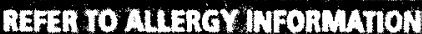

SAFE ADMINISTRATION (refer to Medicines Code)

- Always check patient 10 and allergies before administration

- Record all administrations on

chart with initials. Second check

should be recorded as shown

All COs, N and other high risk

medicines should be second

checked

- Record self-administration

of medicines (SAM) on the

administration record

41 = Full SAM, L2* Murse suporvised

$A B: D C$
- Reuse patient's own medicines

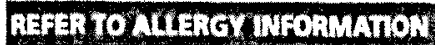

RECORD MEDICINES ADMINISTERED UNDER PGDMROTOCOL

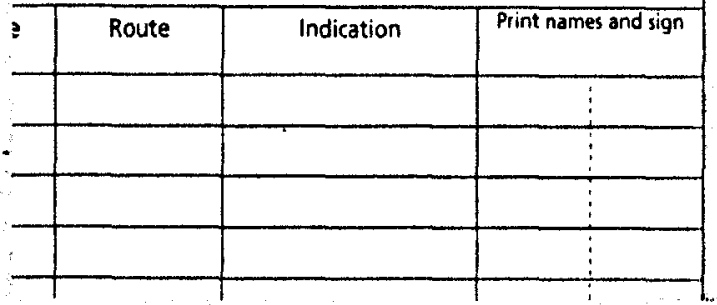

CHECK PATIENT NAME AND HOSPITAL NUMBER

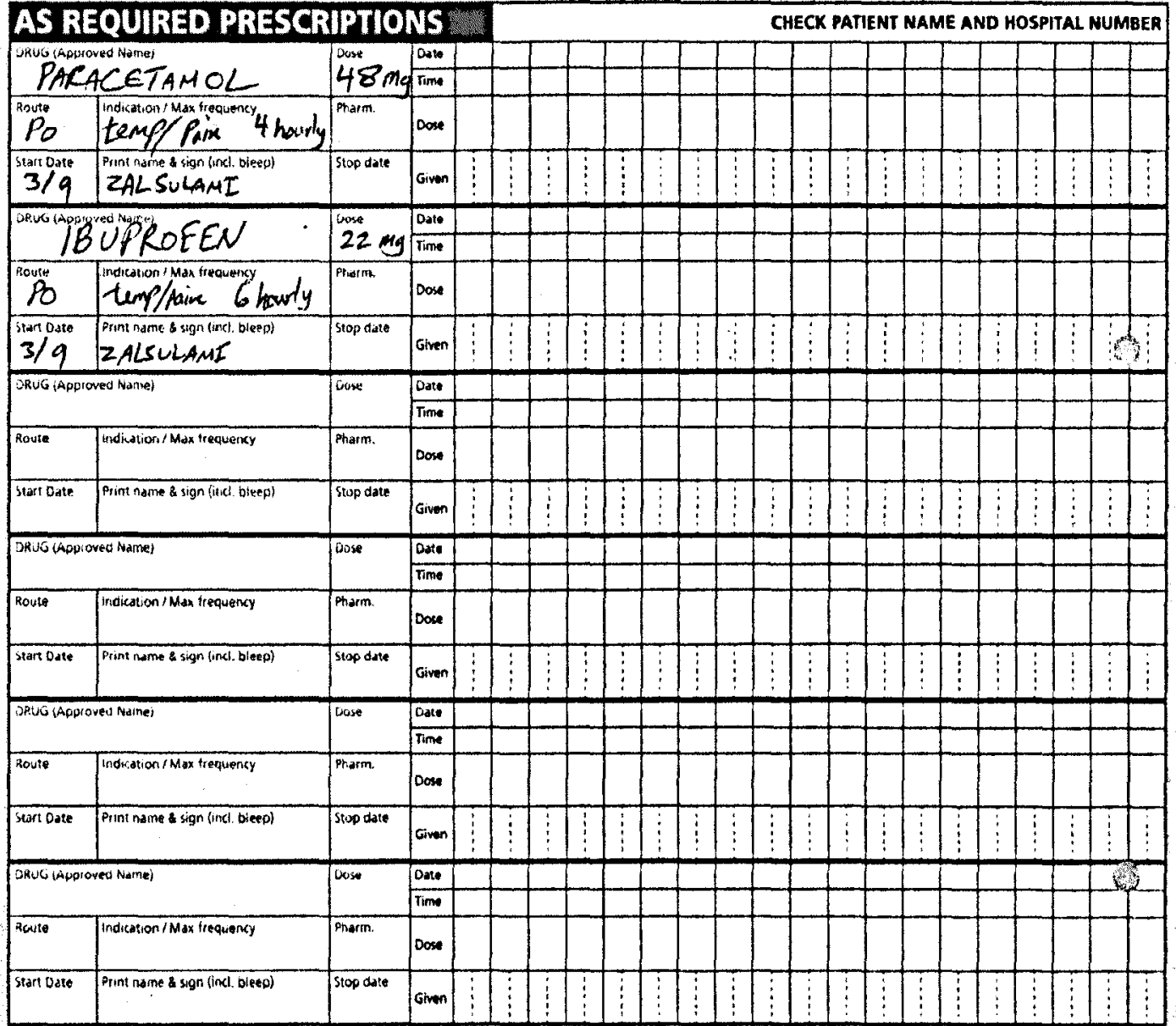

\section{VARIABLE DOSE PRESCRIPTIONS}

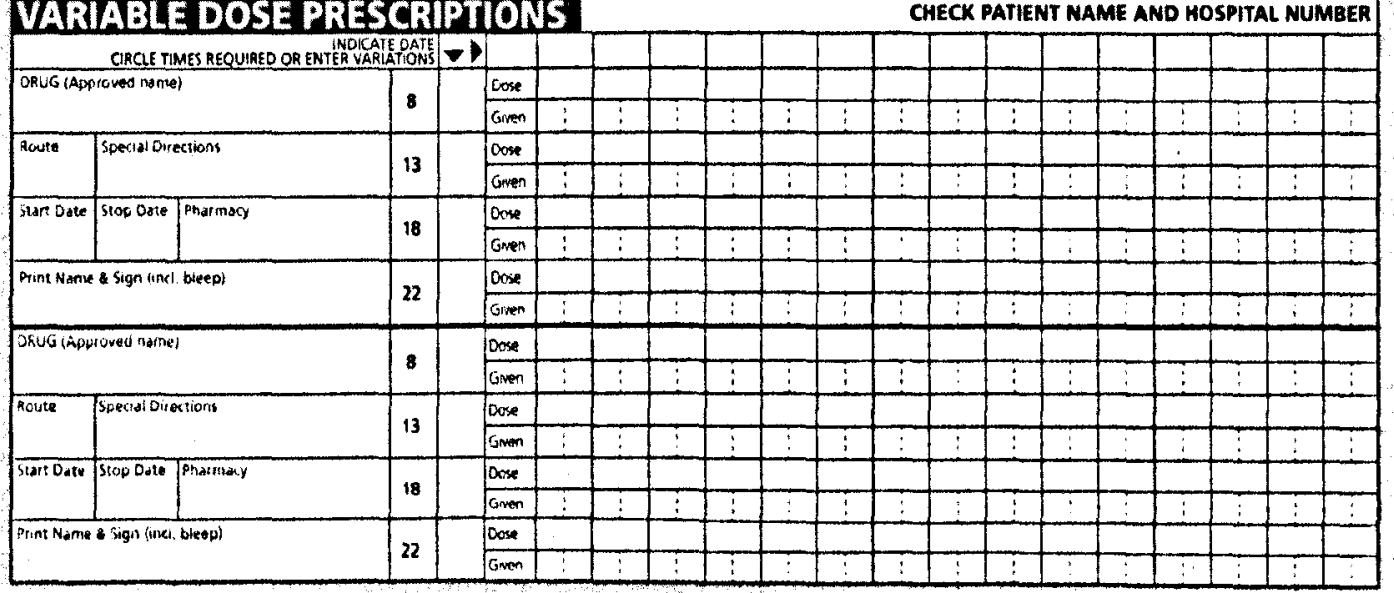




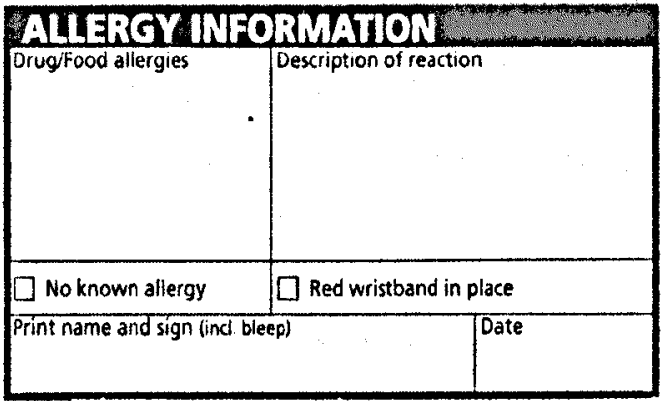

- Write clearly in black ink and use approved names

- All prescriptions must be fully signed and dated

- Each prescriber should include bleep number at least once

- If a dose is to be intentionally withiheld, mark the chart $\nabla$

- If discontinuing, draw a line through, state reason, sign \& date

- Cross reference use of supplementary charts on front

\section{REC ANTIMICROBIAL PRESCRIPTIONS}

If KNOWN TREATMENT WITH LONGTERM ANTHBOTKS, PRESCRIBE ON REGULAR SIDE.

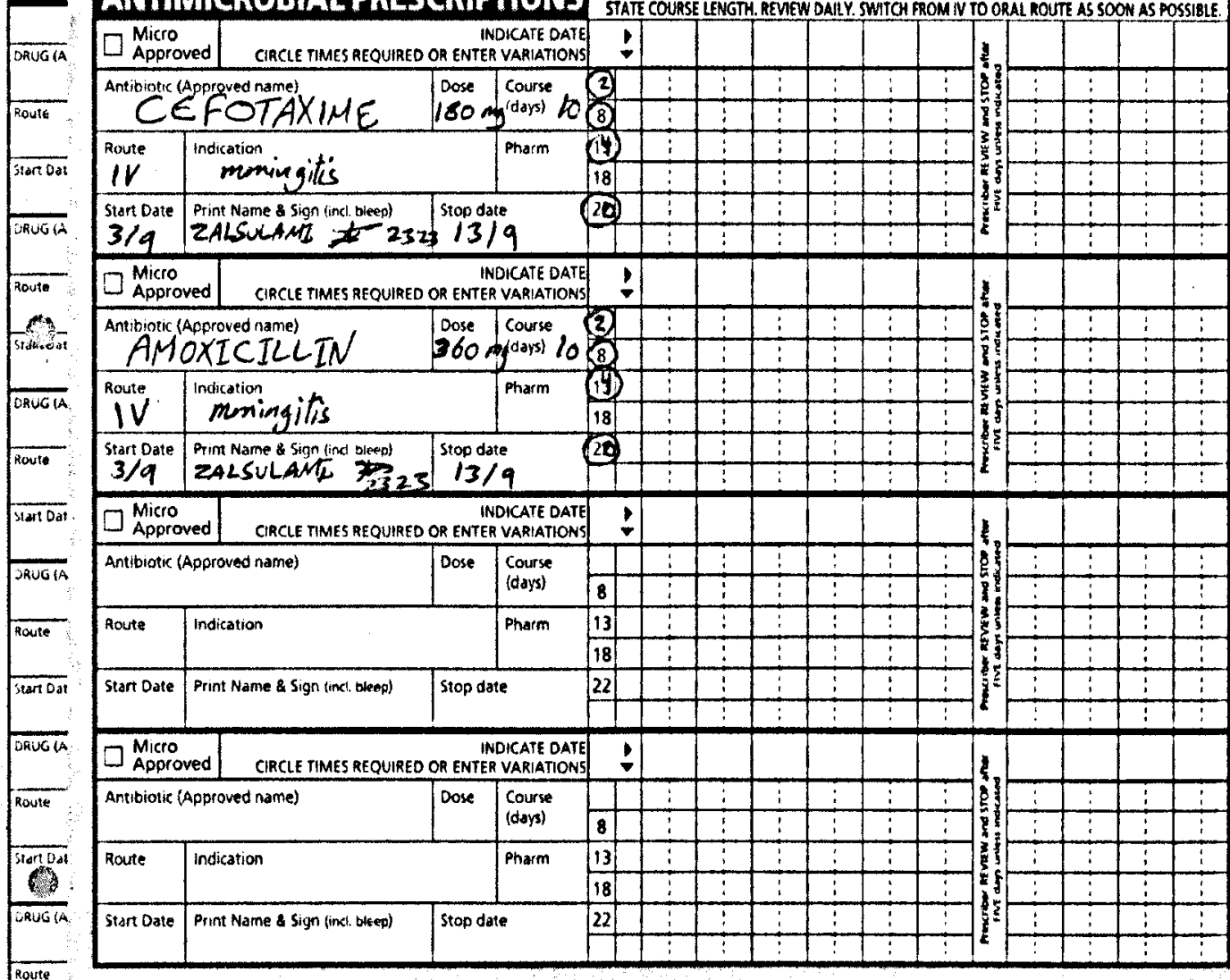

\section{VTE PROPHYLAXIS}

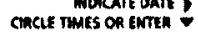

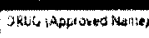

Dime

18

\section{OXYGEN} CARCLE TRMES OA ENTER VATE DATE ?

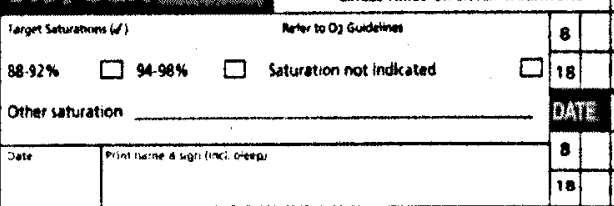


It was hoped that the participant would detect these confounders before preparing the drugs and giving these to the dummy patients. The confounders built into the prescriptions were based on common errors occurring in the hospital (which had been reported in the hospital incident reporting system). There were 3 confounders in total in scenario 1 and 5 in total in scenario 2.

\subsubsection{Inclusion/exclusion criteria}

All registered paediatric nurses in the wards of the Derbyshire Children's Hospital, who were responsible for administering medicines, were eligible to be involved in this study. Student nurses were excluded.

\subsubsection{Sample size}

All 120 registered paediatric nurses in the wards were informed about this study and invited to participate. Twenty three nurses agreed to take part. Of these, two nurses withdrew because they were moved from medical wards to the children's emergency department and both of them were unavailable to do the study. Overall, 21 nurses took part.

\subsubsection{Duration of the study}

The study was conducted over a 6 week period (from September - October) in 2012.

\subsubsection{Data collection forms}

Each simulation scenario session began with an orientation of the participants about the study and its purposes. The participants were given brief information about each clinical case and asked to give the patient medication as prescribed. Data collected included the name of the drug administered; completion of all individual steps of drug administration, start and end time of administration, and other additional observer's comments, if applicable (Appendix C). 


\subsubsection{Data analysis}

Data analysis was performed using SPSS version 17.0 for Windows. A P-value of 0.05 was considered statistically significant. Results were calculated according to the means and standard deviation with 95\% Confidence Intervals (Cl). The MannWhitney test was used to assess and measure the significance of time taken for the medication process between the two independent samples (double and single checking).

\subsection{RESULTS}

\subsubsection{Demographic data}

The study included a total of 21 participants, from different wards and areas within the hospital. In total, 10 simulations of the double checking process were conducted by 20 nurses and 20 simulations were conducted with single checking, also by 20 participants (Table 5.1). Two participants did not do both checking processes (i.e. one of the participants did single checking only and another participant did double checking only), due to time and clinical duty constraints on the nursing staff.

The participants were selected randomly for each simulation. Most of the participants (14 nurses) conducted double checking as their first simulation. Thirteen participants performed the single checking process as their second simulation (Table 5.1). 
Table 5.1: Participants distributed randomly between two simulations.

\begin{tabular}{|c|c|c|}
\hline Nurse Code & First simulation & Second simulation \\
\hline $\bar{A}$ & Scenario 1 (Double checking) & Scenario 2 (Single checking) \\
\hline B & Scenario 1 (Double checking) & Scenario 2 (Single checking) \\
\hline C & Scenario 1 (Double checking) & Scenario 2 (Single checking) \\
\hline D & Scenario 1 (Double checking) & Scenario 2 (Single checking) \\
\hline $\mathbf{E}$ & Scenario 1 (Single checking) & Scenario 2 (Double checking) \\
\hline $\mathbf{F}$ & Scenario 1 (Single checking) & Scenario 2 (Double checking) \\
\hline $\mathbf{G}$ & Scenario 1 (Single checking) & Scenario 2 (Double checking) \\
\hline H & Scenario 2 (Single checking) & Scenario 1 (Double checking) \\
\hline 1 & Scenario 1 (Double checking) & Scenario 2 (Single checking) \\
\hline$J$ & Scenario 1 (Single checking) & Scenario 2 (Double checking) \\
\hline $\mathbf{K}$ & Scenario 2 (Double checking) & Scenario 1 (Single checking) \\
\hline $\mathbf{L}$ & Scenario 2 (Double checking) & Scenario 1 (Single checking) \\
\hline $\mathbf{M}$ & Scenario 2 (Double checking) & Scenario 1 (Single checking) \\
\hline $\mathbf{N}$ & Scenario 2 (Double checking) & Scenario 1 (Single checking) \\
\hline 0 & Scenario 2 (Double checking) & Scenario 1 (Single checking) \\
\hline $\mathbf{P}$ & Scenario 2 (Double checking) & Scenario 1 (Single checking) \\
\hline $\mathbf{Q}$ & Scenario 2 (Double checking) & Scenario 1 (Single checking) \\
\hline $\mathbf{R}$ & Scenario 1 (Single checking) & Scenario 2 (Double checking) \\
\hline $\mathbf{s}$ & Scenario 2 (Single checking) & Not available to do simulation \\
\hline $\mathbf{T}$ & Scenario 1 (Double checking) & Scenario 2 (Single checking) \\
\hline $\mathbf{U}$ & Scenario 1 (Double checking) & Not available to do simulation \\
\hline
\end{tabular}




\begin{tabular}{|c|c|c|c|c|}
\hline \multirow[b]{2}{*}{ Checking } & \multicolumn{2}{|c|}{ First simulation } & \multicolumn{2}{|c|}{ Second simulation } \\
\hline & Single & Double & Single & Double \\
\hline \multicolumn{5}{|l|}{ Scenarios } \\
\hline Scenario 1 & 5 & $7^{*}$ & 7 & $1^{*}$ \\
\hline Scenario 2 & 2 & $7^{*}$ & 6 & $5^{*}$ \\
\hline Total & 7 & 14 & 13 & 6 \\
\hline
\end{tabular}

${ }^{\star}$ The odd number of simulations for nurses with double checking is explained by the presence of a nurse who had previously performed single checking.

\subsubsection{Confounders in scenarios}

Overall, a total of 118 confounders were built into the simulation sessions. A total of 76 confounders were built into the single checking scenarios and 42 into the double checking scenarios (Table 5.2).

Significantly fewer confounders were detected during single checking $(49 / 76,64 \%)$ than during double checking $(37 / 42,88 \%),(P=0.0136)$. 
Table 5.2: Confounders in the scenarios and errors made

\begin{tabular}{|c|c|c|c|c|c|c|c|c|}
\hline Checking & Scenario & $\begin{array}{c}\text { No. of } \\
\text { participants }\end{array}$ & $\begin{array}{c}\text { Total No. of drugs } \\
\text { to be } \\
\text { administered }\end{array}$ & $\begin{array}{l}\text { Total No. of } \\
\text { confounders } \\
\text { present }\end{array}$ & $\begin{array}{c}\text { Total No. of } \\
\text { confounders not } \\
\text { detected }\end{array}$ & $\begin{array}{l}\text { Total No. of } \\
\text { confounders } \\
\text { detected }\end{array}$ & $\begin{array}{l}\text { Total No. of } \\
\text { errors made by } \\
\text { participants }\end{array}$ & $\begin{array}{l}\text { Total No. of } \\
\text { near misses }\end{array}$ \\
\hline \multirow{3}{*}{$\begin{array}{l}\text { Double } \\
\text { checking }\end{array}$} & Scenario 1 & 4 pairs & 24 & 12 & 0 & 12 & 0 & 0 \\
\hline & Scenario 2 & 6 pairs & 36 & 30 & 5 & 25 & 1 & 0 \\
\hline & Total & 20 & 60 & 42 & 5 & 37 & 1 & $\mathbf{0}$ \\
\hline \multirow{3}{*}{$\begin{array}{l}\text { Single } \\
\text { checking }\end{array}$} & Scenario 1 & 12 & 72 & 36 & 10 & 26 & 1 & 1 \\
\hline & Scenario 2 & 8 & 48 & 40 & 17 & 23 & 3 & 0 \\
\hline & Total & 20 & 120 & 76 & 27 & 49 & 4 & 1 \\
\hline Overall & & & 180 & 118 & 32 & 86 & 5 & 1 \\
\hline
\end{tabular}




\subsubsection{Undetected confounders}

A total of 32 confounders were not detected. The majority (27) of these were not detected during single checking (Table 5.3).

Table 5.3: Undetected confounders for single and double checking

\begin{tabular}{|c|c|c|}
\hline Checking & Undetected confounders & Frequency \\
\hline \multirow[t]{6}{*}{ Single } & - Incomplete information & \\
\hline & - Allergy information & $8 / 12$ \\
\hline & $\begin{array}{l}\text { Drug contraindication i.e. patient is allergic to penicillin } \\
\text { and cefuroxime was given, without asking for } \\
\text { confirmation before administration). }\end{array}$ & $8 / 8$ \\
\hline & $\begin{array}{l}\text { - Incorrect dose frequency prescribed (cefotaxime, amoxicillin } \\
\text { IV doses). }\end{array}$ & $6 / 8$ \\
\hline & - Wrong dose prescribed (metronidazole IV doses). & $\mathbf{5} / 12$ \\
\hline & Total & $27 / 76$ \\
\hline \multirow[t]{4}{*}{ Double } & - Incomplete information & \\
\hline & $\begin{array}{l}\text { - Allergy information was not completed on the medication } \\
\text { chart. }\end{array}$ & $1 / 30$ \\
\hline & $\begin{array}{l}\text { - Drug contraindication i.e. patient is allergic to penicillin } \\
\text { and cefuroxime was given, without asking for } \\
\text { confirmation before administration). }\end{array}$ & $4 / 12$ \\
\hline & Total & $5 / 42$ \\
\hline
\end{tabular}

\subsubsection{Influence of simulation on participants}

There was a possibility that the nurses were more likely to detect the confounders during the second simulation, i.e. they had learnt from their first simulation. I therefore compared the number of confounders detected for the first and second simulations (Table 5.4). 14 nurses did double checking as their first participation, and 13 of these nurses did single checking as their second simulation. Surprisingly, 
these nurses were less likely to detect confounders during their second simulation than their first simulation. Additionally, 7 nurses did single checking first and 6 of these then did double checking. These nurses were slightly more likely to detect confounders during their second simulation compared to their first simulation.

Table 5.4: Comparison between first and second simulation results

\begin{tabular}{lccc}
\hline Checking & $\begin{array}{c}\text { No. of } \\
\text { participants }\end{array}$ & $\begin{array}{c}\text { No. of confounders not } \\
\text { detected (\%) }\end{array}$ & $\begin{array}{c}\text { No. of confounders } \\
\text { detected (\%) }\end{array}$ \\
\hline Double checking & 14 & $2(7)$ & $27(93)$ \\
(as $1^{\text {st }}$ simulation) & 13 & $20(40)$ & $31(60)$ \\
Single checking & 7 & & $18(72)$ \\
(as $2^{\text {nd }}$ simulation) & & $7(28)$ & $10(77)$ \\
\hline Single checking & & $3(23)$ & \\
(as $1^{\text {st }}$ simulation) \\
Double checking \\
(as $2^{\text {nd }}$ simulation)
\end{tabular}

\subsubsection{Actual errors made by participants}

Five preparation and administration errors and one near miss were identified in the simulation sessions (Table 5.5). Four errors were made during single checking and one error was made during double checking. One near miss was identified during the single checking process. 
Table 5.5: Medication errors

\begin{tabular}{lll}
\hline Checking & \multicolumn{1}{c}{ Error } & \multicolumn{1}{c}{ Near miss } \\
\hline Single & $\begin{array}{l}\text {-Wrong dose of cefotaxime IV was } \\
\text { withdrawn from vial after reconstitution } \\
(1.44 \mathrm{ml} \text { instead of } 0.9 \mathrm{ml}) .\end{array}$ & $\begin{array}{l}\text { - Paracetamol bottle was } \\
\text { selected by participant rather } \\
\text { than ibuprofen, but detected } \\
\text { before administration. }\end{array}$ \\
& - Patient was given the due dose of \\
paracetamol but the nurse did not sign the \\
chart for administration. \\
- Wrong diluent volume was added to \\
cefotaxime IV (5.4 ml instead of $2.3 \mathrm{ml})$, \\
and wrong dose was also given to the \\
patient (1.8 ml instead of 0.9 ml). \\
- Paracetamol/lbuprofen dose was due but \\
the nurse did not give the dose. \\
- Did not label the flush saline syringe. \\
\hline
\end{tabular}

\subsubsection{Time taken for medication administration}

The time taken for drug administration was similar with both the single and double checking processes (Table 5.6). 
Table 5.6: Time taken for drug administration

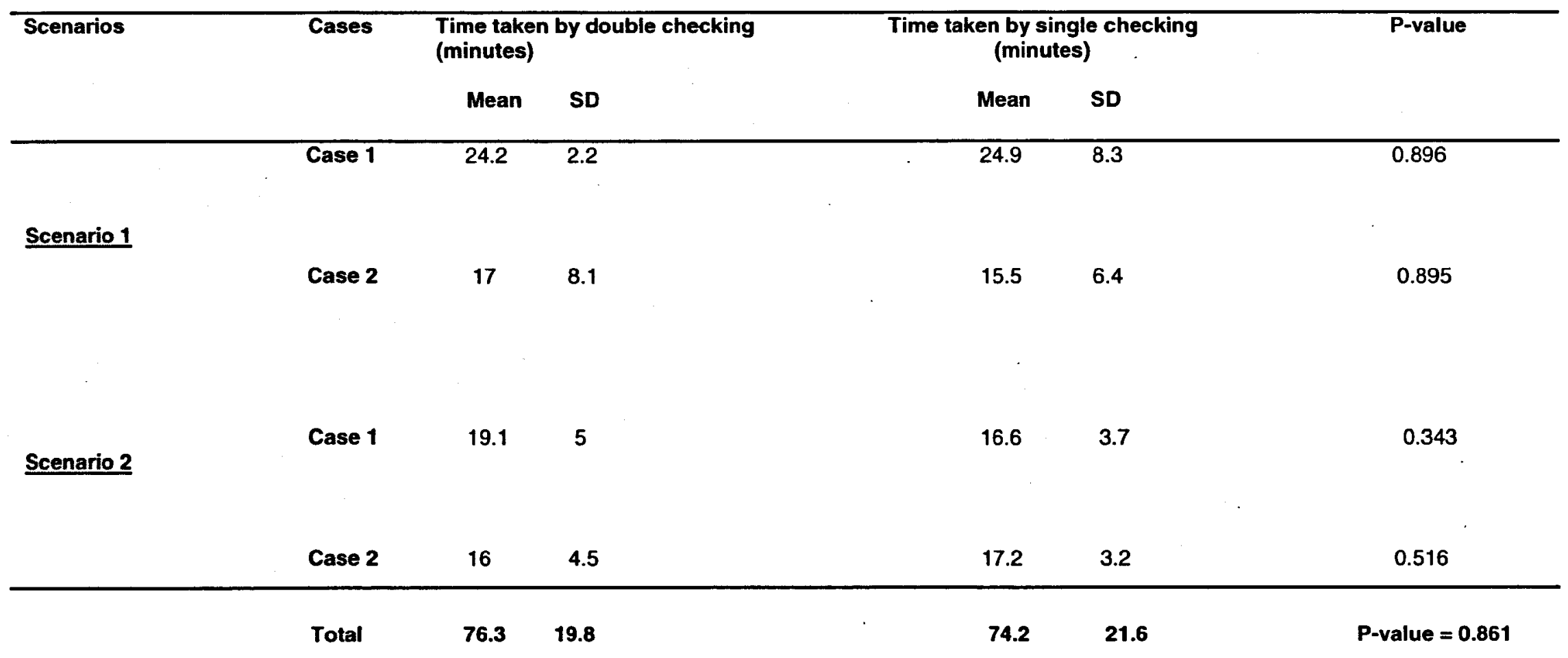




\subsubsection{Qualitative evaluation}

The level of knowledge and confidence among the participants and the clinical performance feedback for participants, were interesting issues arising out of this part of the study.

\subsubsection{Level of confidence}

None of the participants were familiar with the single checking process except one nurse, who had previously worked in a children's hospital that used the single checking process for medication administration. This participant was clearly more confident than the other nurses when required to do the single checking process, but did not detect all confounders in that session (she missed a drug contraindication confounder). All other participants checked the BNF-C at every step to confirm their information. Most of the participants also tried to confirm the correct information with the investigators or seek reassurance during the medication preparation and administration. The level of confidence and unfamiliarity of most nurses with the single checking process may have affected their detection of the confounders that were built in to each prescription in the single checking process.

\subsubsection{Clinical performance feedback}

At the end of each simulation session, the chief investigator and I gave the participants feedback on their performance in order to improve their knowledge and skills of the double checking process and medication administration. If the participants did the process according to the hospital policy and procedure and when no errors were made by participants then positive feedback was given. If there was any step missed, or not performed properly or any confounders undetected or errors made during the medication administration process the participants were made aware of these in a supportive and friendly manner. 
All participants in this study accepted the feedback that they received from the investigators and most of them stated that they had learned new information.

\subsection{DISCUSSION}

This observational simulation study was conducted to determine whether single or double checking is most effective in identifying and reducing MEs in a children's hospital. To our knowledge it is the first simulation study conducted to assess the effectiveness of double checking in paediatric hospital. As reported in Chapter 2, from the literature only one quantitative study has previously compared single and double checking and that study was in a geriatric hospital.

Our study showed that single checking detected significantly fewer confounders than double checking $(P=0.0136)$. Additionally, there were a greater number of actual errors that occurred with single checking than double checking. These findings are in contrast with the previous study by Jarman et al (2002) which was conducted in an adult hospital. Jarman et al's (2002) study suggested that single checking was as safe as double checking. However, paediatric patients are more susceptible to MEs, which may occur up to three times more often than in adult patients (Kaushal et al., 2001a). Our findings suggest that double checking is more effective than single checking. It is possible, however, that the lack of detection of confounders and errors made with single checking by our nurses, was due to their inexperience in the hospital with single checking.

One nurse commented that

"I have 20 years experience in drug administration but this is the first time that I prepared and administered the drug to the patient alone without double checking with another nurse". 
"All my work experience as a paediatric nurse was with neonatal patients. I did not give drugs to a child patient before".

Another participant refused to do a simulated single checking process and justified it saying

"I do not have enough knowledge and experience to prepare IV drugs by myself".

The difference between the two processes in terms of drug administration time was not significant. However, two nurses were involved in the double checking process and the committed time therefore is effectively doubled. In our study however the time measured and assessed was for the checking process itself and not according to the number of nurses. Previous studies found that the use of a single checking process in drug administration round saved up to 9 hours per week (Anderson \& Webster 2001), and 17 hours of nursing time per 1000 medications administered (Kruse et al. 1992), which came from just one nurse being involved.

\subsection{Barriers and challenges}

Nurses are obviously required to provide care for patients, ahead of anything else. The researcher therefore faced various issues and challenges during this study's implementation. One of the most significant challenges faced was the recruitment of nurses to be involved in the study. All the nurses working in the wards received full information about the study. Unfortunately, after one month, only 6 nurses had agreed to participate.

After this stage the chief investigator and I worked intensively for a few days to persuade as many nurses as possible from different wards to participate. In the end 23 nurses agreed. 
The second biggest challenge that I met was matching two nurses together to do double checking for medication administration. Each nurse was required twice, once alone to do single checking and once with another nurse as part of the double checking process. The single checking process was less challenging to arrange logistically because only one nurse's agreement and availability was needed. Matching the availability of two nurses for double checking from either the same or different areas was however, a significant challenge, because different nurses worked in different wards, within different ward situations, and at different shift times. To address this, I drew up a timetable to arrange involvement of all the participants and for them to do different scenarios or prescriptions in each session, without a repetition of scenarios.

I spent a lot of time checking nurse availability but on a few days either both nurses or one nurse was unavailable due to the ward being busy, so they did not have enough time to take part. In addition, I tried to prepare the environment and place of the study to be as close to real practice as possible. Dummy patients were ready in each session with an IV cannula and patient wristbands to make it as realistic as possible.

Real medicines were prepared and administered by the participants according to the prescriptions. All medicines had been purchased from and stored in the pharmacy department within the hospital. I collected the medicines every day from the pharmacy and returned them all after the sessions finished each day, in order to store the drugs in a safe place.

In addition, the study was conducted at a critical time for the nurses because many changes were happening in the hospital, so most of the nurses were busy with interviews and taking up new positions during the study time. These changes also affected recruitment rates. 


\subsection{Limitations}

A few limitations have been highlighted in this study. Firstly, we only had 21 nurses participate in our study due to the reasons above. Secondly, the study participants were all recruited from one children's hospital and all of them were familiar with double checking but only one of them was familiar with single checking, so the results may not be generalisable to other hospitals. Finally, the participants may have been more cautious in the second scenario after they had done the first scenario which may have affected the study results for both checking processes. Analysis of the results did not show this however.

\subsection{Future research}

Although the design of the simulation study has safety advantages over other study designs, there are a few areas identified from this study that can be highlighted for future development and research. For example, the comparison between two groups of nurses from two different children's hospitals having different levels of experience with single and double checking would be helpful for future studies.

\subsection{CONCLUSION}

This study highlighted that the double checking process is more likely to identify errors and contraindicated drugs than single checking. Less errors were made with double checking compared to single checking. The time taken for drug administration was similar between these two processes. The confidence and familiarity of the nurses was lower with single checking compared to the double checking process. 


\section{CHAPTER SIX}

MEDICATION ERRORS IN THE MIDDLE EAST COUNTRIES: A SYSTEMATIC REVIEW OF THE LITERATURE 


\subsection{INTRODUCTION}

The Middle East region is strategically, politically and economically important for the whole world. There are fifteen countries between Western Asia and North Africa which make up the Middle East region (World Bank, 2007). All of these countries speak the same language except for Iran and Israel. Economically, Middle Eastern countries are ranked by the World Bank according to their Gross Domestic Product (GDP) on Purchasing Power Parity (PPP) per capita. The High Income Countries (HIC) includes Qatar, United Arab Emirates (UAE), Bahrain, Saudi Arabia, Kuwait, Israel and Oman. The Upper-Middle Income Countries (UMIC) are Iran, Jordan and Lebanon. The Lower-Middle Income Countries (LMIC) are Egypt, Palestine, Syria, Yemen and Iraq (World Bank, 2007). The Gulf countries (Qatar, Bahrain, Oman, Saudi Arabia, Kuwait and U.A.E) which are a part of the Middle East, have established the Gulf Co-operation Council (GCC) which has placed increasing emphasis on an improved healthcare system during the last decade. In most of these countries the governments are the main provider of the health care service system.

\subsubsection{Patients behaviour}

Many people in the Middle East fear hospital admission because they think that the hospital is a place of misfortune where people go to die. The use of medications in the Middle East is common and this is partly because a preventive care system does not exist. Many patients complain about doctors if they have not received a prescription or have not received what they want to receive from medications (Lipson \& Meleis, 1983). Many patients in the Middle East have different behaviour compared to other patients in other places in the world regarding medication dosage forms, colour and quantity. For example, they prefer injections over other dosage forms, coloured pills over uncoloured and larger tablets over smaller ones (Lipson \& 
Meleis, 1983). In addition, the main problems that health care professionals may face with Middle East patients are the difficulty in obtaining clear and complete information from them which may affect their diagnosis and treatment plan. This is especially the case when the disease is in a critical place or sensitive area. The Compliance, Modalities by Population, Lifestyle and Geography (COMPLY) study in the Middle East revealed that patient behavior - particularly the failure to complete full courses of medication - reduces the effectiveness of antibiotic treatment of infections (Arabian Business, 2007). This study identified a tendency to stop taking medication once symptoms disappear. A survey conducted among 4,500 people in 11 countries, revealed that only six in ten people understood that taking an antibiotic improperly may reduce its effectiveness (Arabian Business, 2007). Communication between the clinicians and Middle East patients may be somewhat difficult as the Middle East patient's family often has more chance to communicate with the clinicians and ask questions than the patient himself. A lack of education about medication use and diseases is common among rural and less educated people.

The population of Middle East countries is approximately 300 million with a population growth rate of $1.86 \%$ (United Nations, 2010). Elderly people of 65 years or over represent $3.63 \%$ of the total population of Middle East people compared to $10 \%$ in developed countries (United Nations, 2010). Middle East countries have a higher proportion of children with $35 \%$ of all people under the age of 15 years compared to $18 \%$ in developed countries (United Nations, 2010). The International Diabetes Foundation estimates that 26.6 million adults ( $8.6 \%$ of the population) in the Middle East and North Africa currently have diabetes (International Diabetes Federation, 2009). Obesity rates in the Middle East and North Africa are also among the highest in the world, particularly in the Gulf countries. 


\subsubsection{Medication Errors}

MEs occur in all countries of the world and are under-reported (Osborne et al., 1999), particularly in LIC and UMIC. MEs present a universal problem and can cause serious consequences for the patients, especially for patients with acute complex medical conditions (Kozer, 2009).

In the UK around 7000 doses of medication are administered daily in a typical NHS hospital. MEs represent around $10-20 \%$ of all reported adverse events in NHS hospitals (DoH, 2004). The incidence and nature of MEs in UK hospitals are similar to those reported in the US (Dean et al. 2002). Prescribing errors occur in $1.5 \%$ of prescriptions, and administration errors occur in $3-8 \%$ of oral doses (Dean, 1999; Dean et al., 2002).

Most of the research on MEs has been conducted in the Western HIC. Information on the incidence of MEs in the Eastern HIC, LIC and LMIC is limited. Different countries have different health care systems.

A recent world report shows that the use of generic and essential medicines may have increased slightly over the past 20 years in developing countries, overall use of medicines has increased and compliance with guidelines has remained low (Kohler \& Baghdadi - Sabeti, 2011). Data from the World Health Organisation (WHO) database show that more than $80 \%$ of all prescribed medicines in developing countries are dispensed by unqualified personnel and the average dispensing time for each patient is one minute (Kohler and Baghdadi-Sabeti, 2011). Only half of patients are told how to take their medicines, and about one third of patients do not know how to take their medicines immediately on leaving the facility. 20-50\% of medicines dispensed are not labelled (Kohler and Baghdadi-Sabeti, 2011). In such circumstances it is not surprising that patient adherence to medicines is poor. 
In this research I have focused on Middle East countries because no previous systematic review has been conducted about MEs in those countries. However, I am from Saudi Arabia and I wished to highlight the problem of MEs in Middle East countries in the hope that this will help decision makers to develop a response to increase the awareness among health care organisations in those countries. Another reason is that the Middle East Pharmaceutical market is projected to grow at a Compound Annual Growth Rate of around 11\% during 2010/2011 (Pharmaceutical Drug Manufacturers, 2010).

In addition, another reason to conduct this review was that in most Middle Eastern countries the patients can obtain medicines from a community pharmacy without prescriptions. A lack of information on the incidence and nature of MEs in Middle East countries is the final reason to do this research.

\subsection{AIMS AND OBJECTIVES}

This systematic literature review aimed to review studies of the incidence and types of MEs in Middle East countries, and to identify the main contributing factors for MEs in those countries.

\subsection{METHODS}

\subsubsection{Search Strategy}

A systematic review of literature relating to MEs in prescribing, transcribing, dispensing, administration and documentation in adults and children in Middle Eastern countries was conducted in October 2011. The following electronic databases were searched: Embase (1980 - October 2011), Medline (1948 October 2011), Pubmed (until October 2011), British Nursing Index (1985 - October 
2011) and Cumulative Index to Nursing \& Allied Health Literature (CINAHL) (1982 October 2011). These databases were used to ensure that all articles were included in this search. The search strategy included all ages and all languages. Also, all searches involved all types of trials and studies. Reference lists of all included articles were also reviewed manually to check for other relevant articles.

\subsubsection{Search Terms}

In this review the following key words were used as search terms: medication error (s), prescribing error (s), dispensing error(s), administration error(s), documentation error (s), transcribing error(s), medication mistake(s), drug mistake(s), prescribing mistake(s), dispensing mistake(s), administration mistake(s), transcribing mistake (s), wrong medication, wrong drug (s), wrong dose (s), wrong route of administration, wrong calculation(s), physician(s), pharmacist (s) and nurse(s). Each of these key words were combined using "OR" then combined using "AND" with Middle East and also with the names of the appropriate countries (15 countries). There was no restriction on the type of the patient or age that was included, or language of the publication.

\subsubsection{Review procedure}

From previous systematic reviews in this area of research, different researchers found that the studies' results were heterogeneous, as they were conducted in different countries and used different methods to collect data (Ghaleb et al., 2006; Conroy et al., 2007). For this reason in this review I did not try to analyse the data from a statistical viewpoint but the results are summarised according to the type of MEs. 


\subsubsection{Inclusion/Exclusion criteria}

In this systematic review I included any type of study, randomised controlled trials and other research methods such as non-randomised controlled trials, longitudinal studies, cohort or case-control studies, or descriptive studies that reported the incidence of MEs or identified the causes of MEs in the Middle East countries, either in adults or children. I excluded any review studies, letters, conference papers, opinions, reports or editorial papers.

\subsubsection{Quality assessment}

In this systematic review a quality assessment of the studies was performed. I reviewed all the relevant studies based on 12 criteria adapted from two previous studies in MEs (Allan \& Barker, 1990; Ghaleb et al, 2006). The criteria were adapted to apply to any type of MEs study. Additionally, I evaluated and assessed the ethical approval obtained for each study. I therefore evaluated the papers according to the following 13 criteria.

1. Aims/objectives of the study clearly stated.

2. Definition of what constitutes a ME.

3. Error categories specified (for example, omission errors; wrong dose errors, etc.)

4. Error categories defined (for example, omission error: when a patient has not received his or her medication by the time the next dose is due (insulin)).

5. Presence of a clearly defined denominator.

6. Data collection method described clearly.

7. Setting in which study conducted described. 
8. Sampling and calculation of sample size described (unit of measurement).

9. Reliability measures. (e.g. methods of measuring the stability or consistency of questionnaire scores over time).

10. Measures in place to ensure that results are valid.

11. Limitations of study listed.

12. Mention of any assumptions made.

13. Ethical approval.

\subsection{RESULTS}

\subsubsection{Search results}

The results of this search can be found in figure 6.1. More than 5,080 articles were excluded from their titles and abstracts as the papers were not related to the specified countries or not relevant to MEs. 204 articles remained for full text review. A further 163 articles were excluded again because they were not relevant to the topic, not related to the specified countries and others were opinion articles, letters, editorials and reports.

A few studies evaluated both MEs and inappropriate use of medicines. These studies used the American National Coordinating Council for MEs Reporting and Prevention (DoH, 2004) definition. I have therefore included all these studies in my systematic review.

Forty-one articles were identified to be relevant. Four additional relevant studies were identified after hand searching of the references of these studies. 
As a final result, 45 articles appeared to be relevant and are included in this systematic review as shown in figure 6.1 (The abstracts were in English but the full text of four studies were in other languages, 3 in Persian and 1 in Hebrew), and those papers were translated into the English language. 


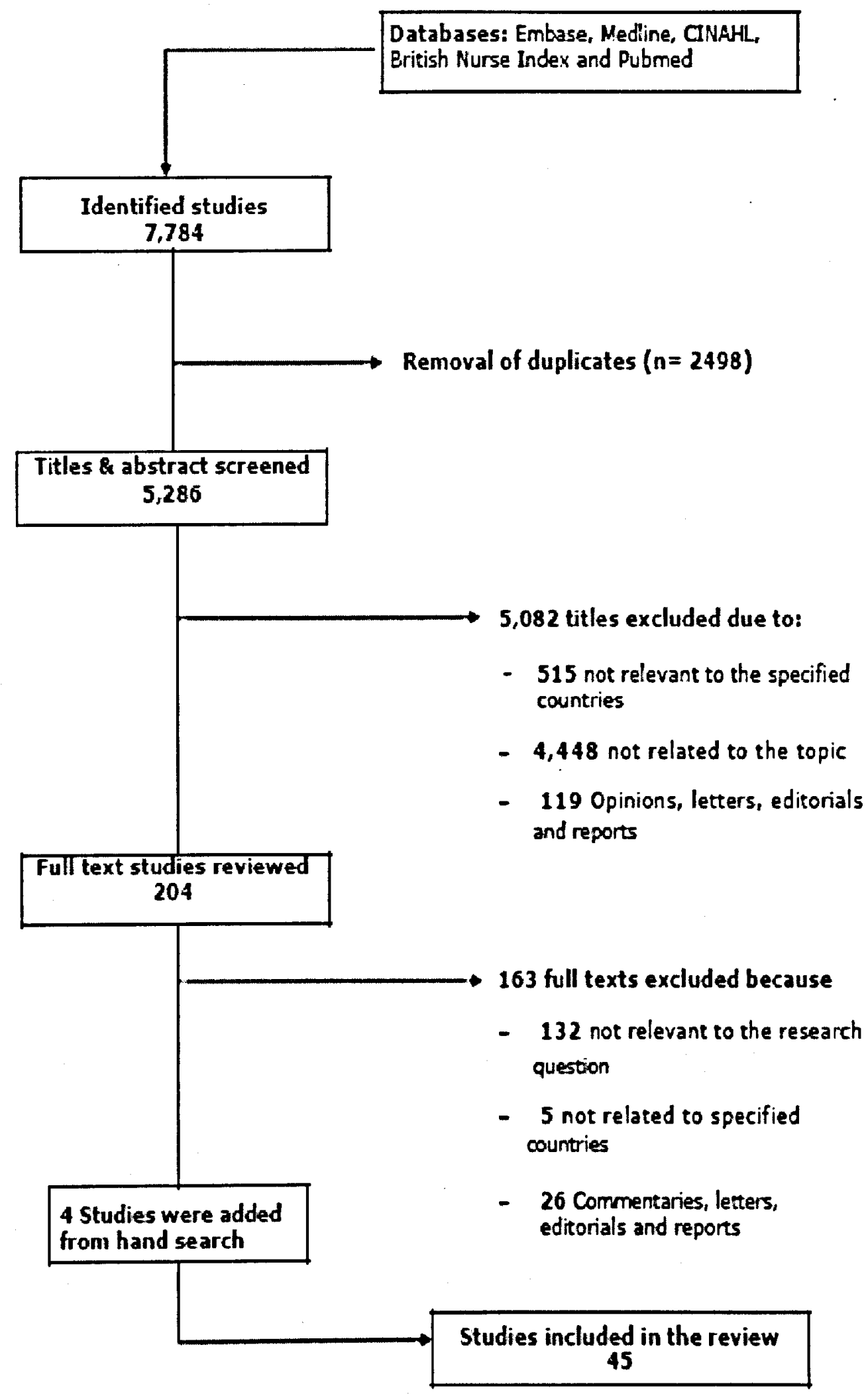

Figure 6.1: Flow chart for search and review process. 


\subsubsection{Countries with data}

The search produced data for 10 of the 15 countries of the traditional Middle East.

There was no available data on MEs in the following countries: Yemen, Kuwait, Iraq, Oman and Syria. The 45 studies included 13 studies in Iran, 10 studies in Israel and 9 studies from Saudi Arabia. These and the remaining studies are shown in Table 6.1.

Table 6.1: Describes the number of studies for each country.

\begin{tabular}{|c|c|}
\hline COUNTRY & NUMBER OF STUDIES \\
\hline IRAN & 13 \\
\hline ISRAEL & 10 \\
\hline SAUDI ARABIA & 9 \\
\hline BAHRAIN & 4 \\
\hline Egypt & 3 \\
\hline JORDAN & 2 \\
\hline QATAR & 1 \\
\hline UNITED ARAB EMIRATES & 1 \\
\hline PALESTINE & 1 \\
\hline LEBANON & $\overline{1}$ \\
\hline OMAN & 0 \\
\hline SYRIA & 0 \\
\hline YEMEN & 0 \\
\hline KUWAIT & 0 \\
\hline$\overline{I R A Q}$ & 0 \\
\hline TOTAL & 45 \\
\hline
\end{tabular}




\subsubsection{Quality assessment of studies}

After the application of the quality assessment criteria, no study met all the 13 criteria. Only 1 study fulfilled 10 criteria, 3 studies met 9 criteria, and 5 met 8 criteria. The remaining studies met 7 or less criteria (Figure 6.2). All individual data for quality assessment criteria for each study are given in Appendix D. It was noted that 10 of the 45 studies did not specify the type of MEs. Also, it was noted that 14 of the 45 studies did not clearly state their ethical approval. This does not mean that these studies were conducted without approval.

\section{Quality assessment criteria}

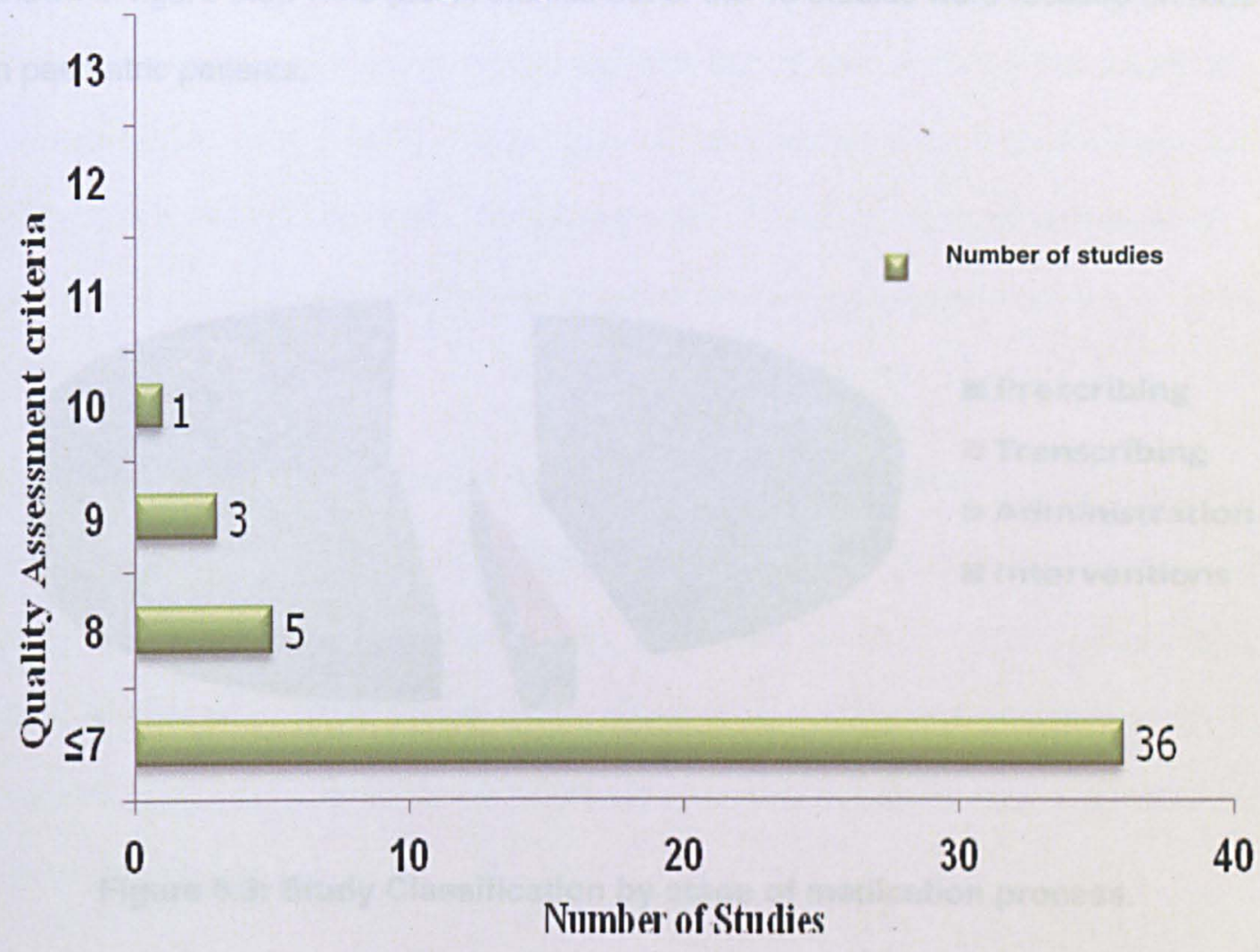

Figure 6.2: Quality Assessment criteria of included studies. 


\subsubsection{Types of included studies}

Twenty-one of the 45 studies assessed prescribing errors as shown in Tables 6.26.5. Most (seven) of these studies were conducted in Saudi Arabia and in Israel (five). One study assessed transcribing errors (Table 6.6). Eleven studies measured medication administration errors and most of these studies were performed in Iran (Table 6.7-6.9). The remaining 12 studies were intervention studies that have been performed in Middle Eastern countries for adults and paediatric patients. Four of these studies were conducted in Israel. There were no studies identified which evaluated dispensing errors and documentation errors in Middle East countries, (as shown in figure 6.3$)$. Nine (20\%) studies out of the 45 studies were focused on MEs in paediatric patients.

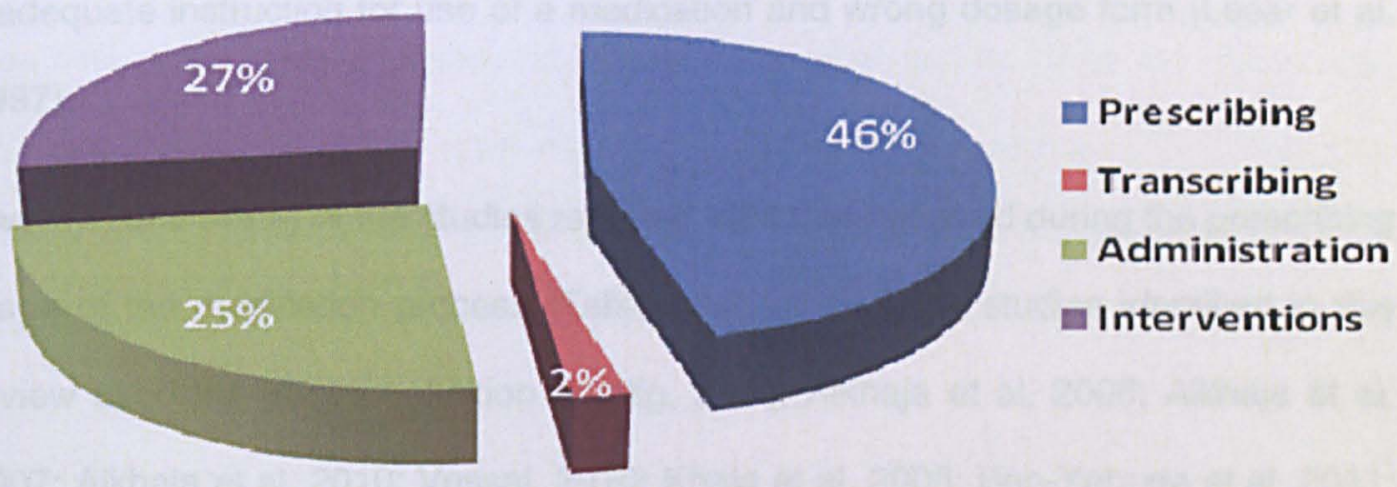

Figure 6.3: Study Classification by stage of medication process. 


\subsubsection{Incidence of medication errors}

The incidence of MEs in this review differs between studies because different methodologies and different definitions have been used. In this review I classified the results according to where they occurred during the medication treatment process, i.e. prescribing, transcribing and administration (Figure 6.4). I also divided each study according to whether it had been a prospective, retrospective or questionnaire study. In addition, all the intervention studies were classified in separate tables and divided according to the type of patients, i.e. adults or children.

\subsubsection{Prescribing errors}

Prescribing errors have been defined as MEs that occurred during the prescribing process (Lesar et al., 1997). These include the incorrect selection of medication, wrong dose, wrong strength, wrong frequency, incorrect route of administration, inadequate instruction for use of a medication and wrong dosage form (Lesar et al, 1997).

Twenty - one (46\%) of the studies reported MEs that occurred during the prescribing stage of the medication process (Tables 6.2 - 6.4). Eight studies identified in this review used the above definition (Lustig, 2000; Alkhaja et al, 2005; Alkhaja et al, 2007; Alkhaja et al, 2010; Vessal, 2010; Khaja et al, 2008; Ben-Yehuda et al, 2011; Aljeraisy et al, 2011), while the remaining studies did not clearly state a definition of prescribing errors.

Thirteen of the 21 prescribing errors studies were prospective and were conducted in 6 countries (Lustig, 2000; Alkhaja et al, 2005; Alkhaja et al, 2007; Alkhaja et al, 2010; Vessal, 2010; AlKhaja et al, 2008; Ben-Yehuda et al, 2011; Azoulay et al, 2005; Sweileh et al, 2007; Sabry et al, 2009; Neyaz et al, 2011; Aldhawailie, 2011; Khoja et al, 2011). Five were retrospective studies (Aljeraisy et al, 2011; Irshaid et al, 
2005; Valizadeh et al, 2008; Lifshitz et al, 2012; Dibbi et al, 2006), and the remaining 3 studies were questionnaires (Vaknin et al, 2003; Bar-Oz et al, 2008; Magzoub et al, 2011). Four studies assessed prescribing errors in children (Alkhaja et al, 2007; Alkhaja et al, 2010; Valizadeh et al, 2008; Aljeraisy et al, 2011).

The prospective study design was the most common method used among those studies to detect MEs at the prescribing stage (Alkhaja et al, 2005; Azoulay et al, 2005; Vessal, 2010; Neyaz et al, 2011; Khoja et al, 2011). Other studies used different designs. Ben-Yehuda and colleagues used a case-control study design, the control group included patients of the same sex and age ( \pm 2 years) who were admitted to the same department in the same year and month but for whom no MEs were observed (Ben-Yehuda et al, 2011).

Estimates of the results were difficult to compare between studies because rates of error were expressed differently. AlKhaja et al. reported the highest error rate which was detected in $90.5 \%$ of prescriptions (AlKhaja et al, 2007), while the lowest rate, reported by Al-Dhawailie, was detected in $7.1 \%$ of prescriptions (Al-Dhawailie, 2011). This difference in error rate was due to the difference in the setting between these two studies, one being conducted in primary care (AlKhaja et al, 2007), and the other in a teaching hospital (AI-Dhawailie, 2011).

Serious prescribing errors were measured in two studies. Al-Jeraisy et al. reported that $78.8 \%$ of errors detected were potentially harmful (Al-Jeraisy et al, 2011). In contrast, Khoja et al. found that only $0.15 \%$ of prescribing errors in their study were serious for patients (Khoja et al, 2011). This large difference in the rates of serious errors between the two studies was due to the difference in the MEs definitions used, and also in the study settings. One study was conducted in a tertiary care setting (Al-Jeraisy et al., 2011) and the other conducted in primary care (Khoja et al., 2011). 
The most common types of prescribing errors reported among the Middle East countries were incorrect dose, wrong frequency and wrong strength.

Out of 13 prospective studies, 4 were carried out in Bahrain by one group, 3 in Saudi, 2 studies in each of Iran and Israel and one study in each of Palestine and Egypt. Most of these studies used the number of prescriptions as a denominator for error incidence rate, and identified a high incidence rate of prescribing errors $(60.6 \%$ - 90.5\%) (Lustig, 2000; Alkhaja et al., 2005). Four of the 13 studies found that incorrect drug dose was the most frequently reported error (Lustig, 2000; Sweileh et al, 2007; Sabry et al, 2009; Ben-Yehuda et al, 2011). Other studies reported duration of therapy, wrong frequency and wrong strength as the most frequent error (Alkhaja et al, 2010; Vessal, 2010; Aldhawailie, 2011). One study aimed to determine whether appropriate dosage adjustments were made for drugs used by patients with renal impairment and found that dosing errors were common among these types of patients during their hospitalization (Sweileh et al, 2007). This study also identified that doctor's inadequacies in clinical pharmacokinetic knowledge of prescribed drugs was the key factor for prescribing errors among renal impairment patients (Sweileh et al, 2007). 
Table 6.2: Prospective observational studies describing prescribing errors

\begin{tabular}{|c|c|c|c|c|c|}
\hline STUDY & COUNTRY & SETTING & STUDY DESIGN & STUDY SAMPLE & KEY FINDINGS \\
\hline Lustig, 2000 & Israel & General Hospital & $\begin{array}{l}\text { Prescriptions were reviewed in } \\
\text { pharmacy, for six month period. }\end{array}$ & 14,385 prescriptions & $\begin{array}{l}160 \text { medication errors were detected } \\
\text { Error rate was } 11.2 \text { per } 1000 \text { prescriptions } \\
97(60.6 \%) \text { were prescribing errors } \\
63(39.4 \%) \text { were therapy errors (i.e. incorrect choice of } \\
\text { drugs, incorrect drug or interactions between drugs). } \\
\text { Incorrect dosage } 44(27.5 \%) \text { was the most common type }\end{array}$ \\
\hline $\begin{array}{l}\text { Alkhaja et al, } \\
2005\end{array}$ & Bahrain & $\begin{array}{l}18 \text { health care } \\
\text { centres } \\
\text { (pharmacies) }\end{array}$ & $\begin{array}{l}\text { Prescriptions with errors were } \\
\text { collected on a daily basis by the } \\
\text { pharmacists during first two weeks } \\
\text { of September } 2003 \text {. Prescription } \\
\text { errors were classified to omission } \\
\text { errors (incomplete prescription } \\
\text { components), commission errors } \\
\text { (incorrect written components) } \\
\text { and integration (potential drug- } \\
\text { drug interaction or drug allergies) }\end{array}$ & 77,511 Prescriptions & $\begin{array}{l}5,959(7.7 \%) \text { out of } 77511 \text { prescriptions were identified } \\
\text { to contain errors. } \\
\text { The number of drug items in the } 5,959 \text { prescriptions was } \\
16091 \text {. } \\
13630(84.7 \%) \text { drug items were identified with errors } \\
23692 \text { errors were identified. These included omission } \\
22180(93.6 \%) \text { and commission } 1512(6.3 \%) \text { errors. } \\
\text { Errors of integration were in } 548(9.2 \%) \text { prescription. }\end{array}$ \\
\hline $\begin{array}{l}\text { Azoulay et al, } \\
2005\end{array}$ & Iran & $\begin{array}{l}\text { Teaching } \\
\text { hospital }\end{array}$ & $\begin{array}{l}\text { Prescriptions from elderly patient } \\
\text { visits to physicians were collected } \\
\text { during study period (from } \\
\text { September to December 2002) }\end{array}$ & $\begin{array}{l}3000 \text { elderly patients } \\
\text { prescriptions ( } \geq 65 \\
\text { years old). }\end{array}$ & $\begin{array}{l}829(27 \%) \text { patients received at least one inappropriate } \\
\text { prescription (unnecessary medication or having a high } \\
\text { risk of adverse drug reaction) } \\
285(9.5 \%) \text { patients had at least one drug interaction }\end{array}$ \\
\hline
\end{tabular}


Table 6.2: Contd

\begin{tabular}{|c|c|c|c|c|c|}
\hline STUDY & COUNTRY & SETTING & STUDY DESIGN & $\begin{array}{l}\text { STUDY } \\
\text { SAMPLE }\end{array}$ & KEY FINDINGS \\
\hline $\begin{array}{l}\text { Al-Khaja et } \\
\text { al, } 2007\end{array}$ & Bahrain & $\begin{array}{l}20 \text { health care } \\
\text { centres (those } \\
\text { who treat infants) }\end{array}$ & $\begin{array}{l}\text { Prescriptions dispensed for infants were } \\
\text { collected on daily basis by the pharmacists } \\
\text { from } 9-23 \text { May } 2004 \text {. }\end{array}$ & $\begin{array}{l}2282 \\
\text { prescriptions }\end{array}$ & $\begin{array}{l}2066(90.5 \%) \text { prescription were identified to contain } 7667 \\
\text { errors of omission, commission and errors of integration. } \\
4282(74.5 \%) \text { out of } 5745 \text { medications contained drug } \\
\text { related errors } \\
4146(54.1 \%) \text { out of } 7667 \text { errors were with omission } \\
\text { errors, length of therapy/quantity }(27.7 \%) \text { and dosage } \\
\text { form ( } 12.8 \%) \text { were the common omission errors } \\
3338(43.5 \%) \text { out of } 7667 \text { errors were commission } \\
\text { errors, dosing frequency was incorrectly written in } 20.8 \% \text {, } \\
\text { and dose-strength was incorrectly stated in } 17.7 \% \\
183(2.4 \%) \text { out of } 7667 \text { errors were integration errors } \\
\text { such as adverse drug-drug interactions were possible. }\end{array}$ \\
\hline $\begin{array}{l}\text { Sabry et } \\
\text { al, } 2009\end{array}$ & $\begin{array}{ll}\text { Egypt } & \text { Te } \\
& \text { IC }\end{array}$ & $\begin{array}{l}\text { aching hospital, } \\
\text { S }\end{array}$ & $\begin{array}{l}\text { Direct observational study by pharmacist was } \\
\text { conducted to report and record the frequency of } \\
\text { medication related problems in the ICU, for one } \\
\text { year period. }\end{array}$ & $\begin{array}{l}220 \text { ICU patients } \\
\text { and } 2286 \\
\text { medications }\end{array}$ & $\begin{array}{l}619 \text { medication related problems were detected in a total } \\
\text { of } 213 \text { patients. Only } 3.18 \% \text { of the patients were free of } \\
\text { any medication related problems. Incorrect dosing } \\
\text { regimen was the most common reported errors in the ICU } \\
\text { followed by duplication and prescribing unnecessary } \\
\text { medication, } 136(21.97 \%), 72(12 \%) \text {, respectively. }\end{array}$ \\
\hline
\end{tabular}


Table 6.2: Contd

\begin{tabular}{|c|c|c|c|c|c|}
\hline STUDY & COUNTI & SETTING & STUDY DESIGN & STUDY SAMPLE & KEY FINDINGS \\
\hline $\begin{array}{l}\text { Al-Khaja } \\
\text { et al, } \\
2010\end{array}$ & Bahrain & $\begin{array}{l}18 \text { health care } \\
\text { centres } \\
\text { (pharmacies) }\end{array}$ & $\begin{array}{l}\text { ant prescriptions with iron preparations were } \\
\text { llected \& reviewed from 9-23 May } 2004 \text { (two } \\
\text { eeks) }\end{array}$ & 2,282 Prescriptions & $\begin{array}{l}159(7 \%) \text { of prescriptions included an iron } \\
\text { preparation. } 42(26.4 \%) \text { out of } 159 \\
\text { prescriptions were issued without dosage } \\
\text { forms and } 14(8.8 \%) \text { without duration of } \\
\text { therapy. Prescribing of unavailable paediatric } \\
\text { dosage forms was in } 11(6.9 \%) \text {. }\end{array}$ \\
\hline $\begin{array}{l}\text { Vessal, } \\
2010\end{array}$ & Iran & Teaching Hospita & $\begin{array}{l}\text { Medication order sheets \& drug orders In } \\
\text { nephrology ward were reviewed by clinical } \\
\text { pharmacist for four months. }\end{array}$ & $\begin{array}{l}76 \text { adult patients and } 818 \\
\text { medications }\end{array}$ & $\begin{array}{l}86(10.5 \%) \text { prescription errors were detected in } \\
46(60.5 \%) \text { of the admissions } \\
\text { Error rate was } 10.5 \text { per } 100 \text { medication orders } \\
\text { Wrong frequency ( } 37.2 \%) \text {, wrong drug } \\
\text { selection }(19.8 \%) \text {, and overdose }(12.8 \%) \text { were } \\
\text { the most common types of errors }\end{array}$ \\
\hline $\begin{array}{l}\text { Neyaz et } \\
\text { al, } 2011\end{array}$ & $\begin{array}{l}\text { Saudi } \\
\text { Arabia }\end{array}$ & $\begin{array}{l}10 \text { Primary } \\
\text { health care } \\
\text { centres ( } 5 \\
\text { public, } 5 \\
\text { private), Riyadh }\end{array}$ & $\begin{array}{l}\text { Two-methods; prescription reviewed and } \\
\text { questionnaire completed by physicians for } \\
\text { prescription quality assessment (one day } \\
\text { study) in public and private health care centres }\end{array}$ & $\begin{array}{l}600 \text { prescriptions selected } \\
\text { randomly, written by } 87 \\
\text { Physicians ( } 47 \text { public, } 40 \\
\text { private) }\end{array}$ & $\begin{array}{l}64(72 \%) \text { physicians were classified as writing } \\
\text { low quality prescription } \\
23(28 \%) \text { physicians were classified as writing } \\
\text { high quality prescriptions }\end{array}$ \\
\hline $\begin{array}{l}\text { Al- } \\
\text { Dhawailie, } \\
2011\end{array}$ & $\begin{array}{l}\text { Saudi } \\
\text { Arabia }\end{array}$ & $\begin{array}{l}\text { University teaching } \\
\text { hospital, medical } \\
\text { wards only }\end{array}$ & $\begin{array}{l}\text { Medication charts and orders data collected } \\
\text { daily by ward phamacists, for one month } \\
\text { period (Nov-Dec 2009). }\end{array}$ & $\begin{array}{l}1582 \text { written medication } \\
\text { orders }\end{array}$ & $\begin{array}{l}113(7.1 \%) \text { prescribing errors were detected } \\
\text { Most common errors were wrong strength } 39 \\
(35 \%) \text { Followed by wrong dose frequency } 26 \\
(23 \%)\end{array}$ \\
\hline
\end{tabular}


Table 6.2: Contd

\begin{tabular}{|c|c|c|c|c|c|}
\hline STUDY & COUNTF & SETTING & STUDY DESIGN & STUDY SAMPLE & KEY FINDINGS \\
\hline $\begin{array}{l}\text { Al-Khaja et } \\
\text { al, } 2008\end{array}$ & Bahrain & $\begin{array}{l}3 \text { health care centres } \\
\text { (training centres) }\end{array}$ & $\begin{array}{l}\text { Prescriptions issued by the } \\
\text { residents were collected by } \\
\text { pharmacists in May } 2004 \text { and May } \\
2005 \text {. }\end{array}$ & 2692 prescriptions & $\begin{array}{l}2372(88.1 \%) \text { prescriptions had errors of } \\
\text { omission, commission and integration errors } \\
\text { The total numbers of errors were } 7139 \text {. } \\
\text { Of } 5880 \text { medication prescribed, } 4447(75.6 \%) \\
\text { had drug related errors. } \\
4972(69.6 \%) \text { out of } 7139 \text { errors were major } \\
\text { omission errors, dosage forms and length of } \\
\text { treatment were not specified in } 39.4 \% \text { and } \\
18.5 \%, \text { respectively. } \\
1759(24.7 \%) \text { out of } 7139 \text { errors were } \\
\text { commission errors, dosing frequency and } \\
\text { incorrect strength/dose were the most common } \\
\text { errors } 19.9 \% \text { and } 2.7 \% \text {, respectively. } \\
\text { Integration errors were } 408 \text { (5.7\%) of the overall } \\
\text { prescribing errors. }\end{array}$ \\
\hline $\begin{array}{l}\text { Khoja et, } \\
2011\end{array}$ & $\begin{array}{l}\text { Saudi } \\
\text { Arabia }\end{array}$ & $\begin{array}{l}10 \text { Primary health care centres } \\
\text { ( } 5 \text { public / } 5 \text { private), Riyadh }\end{array}$ & $\begin{array}{l}\text { All medication prescriptions were } \\
\text { analysed for one working day } \\
\text { between public \& private }\end{array}$ & 5299 prescriptions & $\begin{array}{l}990(18.7 \%) \text { prescribing errors identified } \\
\text { Only } 8(0.15 \%) \text { prescribing errors had serious } \\
\text { effect on the patients. }\end{array}$ \\
\hline $\begin{array}{l}\text { Ben-Yehuda } \\
\text { et al, } 2011\end{array}$ & Israel & Teaching hospital & $\begin{array}{l}\text { Cohort Case-Control study } \\
\text { conducted for } 18 \text { month period. }\end{array}$ & $\begin{array}{l}274 \text { elderly patients ( } 137 \\
\text { patients harmful MEs } \\
\text { group, and } 137 \text { control } \\
\text { group) }\end{array}$ & $\begin{array}{l}137 \text { MEs were identified in patients group, } \\
63(46 \%) \text { errors were prescribing. } \\
74(54 \%) \text { errors were transcribing. }\end{array}$ \\
\hline
\end{tabular}


Five retrospective studies describing prescribing errors in the Middle East countries were identified (Table 6.3). Three studies were conducted in Saudi Arabia and one study in each of Iran and Israel. Of these, two studies were conducted in paediatric patients (Valizadeh et al, 2008; Al-Jeraisy et al, 2011) and 3 in adults (Irshaid et al, 2005; Dibbi et al., 2006; Lifshitz et al, 2012). The main finding from these retrospective studies was that the incidences of MEs were high $(36.1 \%-56 \%)$ in both types of patients (adults and paediatrics). MEs in the Emergency Department were higher than in Emergency vehicles (Lifshitz et al, 2012). Like the prospective studies the retrospective studies also identified dosing errors to have the highest incidence rate. 
Table 6.3: Retrospective studies describing prescribing errors

\begin{tabular}{|c|c|c|c|c|c|}
\hline STUDY & COUNTRY & SETTING & STUDY DESIGN & DY SAMPLE & KEY FINDINGS \\
\hline Irshaid et al, 2005 & Saudi Arabia & Teaching hospital & $\begin{array}{l}\text { All prescriptions obtained during one year } \\
\text { period from pharmacy were analysed by } \\
\text { pharmacists and physicians. }\end{array}$ & 3796 prescriptions & $\begin{array}{l}\text { No prescription contained the } \\
\text { patient's weight } \\
94 \% \text { of prescriptions had no } \\
\text { quantity indicated } \\
90.7 \% \text { of prescriptions had } \\
\text { incomplete instructions for patient }\end{array}$ \\
\hline $\begin{array}{l}\text { Valizadeh et al, } \\
2008\end{array}$ & Iran & $\begin{array}{c}\text { Paediatric hospital } \\
.\end{array}$ & $\begin{array}{l}\text { Descriptive cross-sectional and hospital } \\
\text { information based study was performed from } \\
\text { January-June } 2004\end{array}$ & 898 medical charts & $\begin{array}{l}74.1 \% \text { of medication orders did not } \\
\text { contain drug administration } \\
\text { precautions } \\
47.8 \% \text { time of drug administration } \\
\text { were not recorded }\end{array}$ \\
\hline Lifshitz et al, 2012 & Israel & $\begin{array}{l}\text { Teaching hospital, } \\
\text { Emergency Department } \\
\text { and Emergency vehicles } \\
\text { (ambulances) }\end{array}$ & $\begin{array}{l}\text { Charts review was performed by two } \\
\text { physicians for adult patients transferred by } \\
\text { ambulance to large hospital, from January- } \\
\text { December } 2007 \text {. }\end{array}$ & 471 patient charts & $\begin{array}{l}24(12.7 \%) \text { of } 188 \text { patients in } \\
\text { vehicle were subject to MEs } \\
120(36.1 \%) \text { of } 332 \text { patients had } \\
\text { MEs in ED } \\
\text { MEs in the ED were more than in } \\
\text { emergency vehicles }\end{array}$ \\
\hline
\end{tabular}


Table 6.3: Contd.

\begin{tabular}{|c|c|c|c|c|c|}
\hline STUDY & COUNTRY & SETTING & STUDY DESIGN & STUDY SAMPLE & KEY FINDINGS \\
\hline $\begin{array}{l}\text { Al-Jeraisy et al, } \\
2001\end{array}$ & $\begin{array}{l}\text { Saudi } \\
\text { Arabia }\end{array}$ & $\begin{array}{l}\text { Tertiary care hospital, } \\
\text { PICU and general } \\
\text { paediatric wards }\end{array}$ & $\begin{array}{l}\text { Study of paediatric physician } \\
\text { medication orders for five weeks }\end{array}$ & 2,380 medication orders & $\begin{array}{l}1,333 \text { medication errors were found } \\
1,051(78.8 \%) \text { errors were potentially } \\
\text { harmful } \\
\text { Incidence rate was } 56 \text { errors per } 100 \\
\text { medication orders } \\
\text { Dose errors were the highest incidence } \\
(22.1 \%) \\
452(33.9 \%) \text { errors occurred in PICU. }\end{array}$ \\
\hline Dibbi et al, 2006 & $\begin{array}{l}\text { Saudi } \\
\text { Arabia }\end{array}$ & General Hospital & $\begin{array}{l}\text { Medical records were reviewed for adults } \\
\text { from June } 2000 \text {-June } 2002\end{array}$ & 2627 patient files & $\begin{array}{l}3963 \text { medication errors were identified } \\
60 \% \text { of patient files contained one error } \\
30 \% \text { of patient files contained two errors } \\
10 \% \text { of patient files contained three errors or } \\
\text { more } \\
\text { In } 1223(46.5 \%) \text { patient files, human factors } \\
\text { were the main cause of MEs } \\
\text { The most common type of errors were the } \\
\text { wrong strength }(34.8 \%) \text { in } 914 \text { patients }\end{array}$ \\
\hline
\end{tabular}


The third type of study describing prescribing errors was questionnaire studies (Table 6.4). Three questionnaire studies were identified in this review. Two surveys were in Israel and 1 was in Saudi Arabia. All of these studies agreed that physicians have limited information about drug prescribing and pharmacology (Vaknin et al, 2003; Bar-Oz et al, 2008; Magzoub et al, 2011). 
Table 6.4: Questionnaire studies describing prescribing errors

\begin{tabular}{|c|c|c|c|c|c|}
\hline STUDY & COUNTRY & SETTING & STUDY DESIGN & STUDY SAMPLE & KEY FINDINGS \\
\hline $\begin{array}{l}\text { Vaknin et al, } \\
2003\end{array}$ & Israel & $N / A$ & Questionnaire & $N / A$ & $\begin{array}{l}\text { Only } 46(18 \%) \text { out of } 256 \text { doctor } \\
\text { orders, and } 82(37 \%) \text { out of } 224 \\
\text { nurses transcriptions were written } \\
\text { according to the hospital standard. } \\
\text { The rate of compliance with } \\
\text { Emergency department policy was } 10 \\
(3 \%) \text { out of } 319 \text { doctors orders, and } \\
80(25 \%) \text { of nurses transcriptions }\end{array}$ \\
\hline $\begin{array}{l}\text { Bar-Oz et al, } \\
2008\end{array}$ & Israel & N/A & $\begin{array}{l}\text { Structured questionnaire was sent to } 9320 \text { active } \\
\text { physicians, to evaluate the rate of } \\
\text { acknowledgment of MEs as reported by } \\
\text { physicians, with questions on the rate and type of } \\
\text { MEs that they had encountered during their career }\end{array}$ & $\begin{array}{l}627(6.7 \%) \text { physicians } \\
\text { responded }\end{array}$ & $\begin{array}{l}470(78.9 \%) \text { physician made an error } \\
\text { in prescribing } \\
376(63.1 \%) \text { physicians made more } \\
\text { than one error } \\
94(15.8 \%) \text { physicians made one error }\end{array}$ \\
\hline
\end{tabular}




\subsubsection{Types of errors}

Incorrect dose was the most common type of error reported in 12 studies (Lustig et al., 2000; Alkhaja et al., 2005; Alkhaja et al., 2007; Alkhaja et al., 2008; Sabry et al., 2009; Alkhaja et al., 2010; Vessal, 2010; Aldhawailie, 2011; Khaja et al., 2011; BenYehuda et al, 2011; Al-Jeraisy et al, 2011; Lifshita et al, 2012) as shown in Table 6.5. This review revealed that the incidence rates of dosing errors in the Middle East countries fluctuated from $0.15 \%$ to $34.8 \%$ of total prescriptions (Table 6.5 ). Also, other studies included wrong frequency (Alkhaja et al, 2007; Vessal, 2010), wrong strength (Aldhawailie, 2011; Alkhaja et al, 2007, Alkhaja et al, 2005), wrong or missing dosage form (Alkhaja et al, 2010; Alkhaja et al, 2007; Alkhaja et al, 2005; Alkhaja et al, 2008) and duration of therapy not stated (Alkhaja et al, 2010; Alkhaja et al, 2008; Alkhaja et al, 2007; Alkhaja et al, 2005). 
Table 6.5: prescriptions with dosing errors

\begin{tabular}{|c|c|c|c|c|}
\hline Country (setting) & $\begin{array}{l}\text { No. of prescriptions or } \\
\text { medication orders }\end{array}$ & Dosing errors (number) & Dosing errors (\%) & References \\
\hline Israel (General hospital) & 14,385 prescriptions & 44 prescriptions & 0.3 & Lustig, 2000 \\
\hline Bahrain (Primary care) & 77,511 prescriptions & 1,413 prescriptions & 1.8 & Alkhaja et al, 2005 \\
\hline Bahrain (Primary care) & 2,282 prescriptions & 795 prescriptions & 34.8 & Alkhaja et al, 2007 \\
\hline Egypt (Teaching hospital) & 2,286 medication prescribed & 503 medication prescribed & 22 & Sabry et al, 2009 \\
\hline Bahrain (Primary care) & 2,282 prescriptions & 60 prescriptions & 2.6 & Alkhaja et al, 2010 \\
\hline Iran (Teaching hospital) & 86 prescriptions & 11 prescriptions & 12.8 & Vessal, 2010 \\
\hline Saudi (Primary care) & 1,582 medication orders & 14 medication orders & 0.89 & Aldhawailie, 2011 \\
\hline Saudi (Primary care) & 5,299 prescriptions & 8 prescriptions & 0.15 & Khoja et al, 2011 \\
\hline Bahrain (Primary care) & 5880 medication orders & 397 medication orders & 6.7 & Khaja et al, 2008 \\
\hline Israel (Teaching hospital) & 4736 prescriptions & 31 prescriptions & 0.65 & Ben-Yehuda et al, 2011 \\
\hline Israel (Teaching hospital) & 471 medication orders & 12 medication orders & 2.5 & Lifshitz et al, 2012 \\
\hline Saudi (Tertiary hospital) & 2,380 medication orders & 526 medication orders & 22.1 & Aljeraisy et al, 2011 \\
\hline
\end{tabular}




\subsubsection{Transcribing errors}

One prospective study of transcription errors using a direct observational method was performed in Iran (Table 6.6) (Fahimi et al, 2009). Transcribing errors were defined as any deviation in transcribing a medication order from the previous step.

A direct observational method was used in this study. A total of 287 charts with 558 opportunities for error (OEs) were analysed. Of those OEs, $167(30 \%)$ resulted in errors. Omission transcription errors (patients did not receive the medication that was ordered) were the highest (52\%) type of errors identified in this study. 
Table 6.6: Prospective studies describing transcribing errors

STUDY SAMPLE

287 medication charts

were reviewed during

study period
KEY FINDINGS

289 errors were identified with average one error per

chart

Omission error was rated as the highest (52\%)

transcription error. 


\subsubsection{Administration errors}

Administration errors have been defined as a discrepancy between the drug therapy received by the patient and that intended by the prescriber or according to standard hospital policies and procedures (Greengold et al, 2003; Dean, 1999). Three studies used the above definition (Fahimi et al, 2008; Drach-Zahavy \& Pud, 2010; Alshara, 2011), while the remaining eight studies mainly used general definitions of MEs rather than a MAEs definition.

Two of 11 administration errors studies were prospective studies and conducted in 2 countries (Table 6.7) (Fahimi et al, 2008; Drach-Zahavy and Pud, 2010). One of these studies, in Israel, used a variety of methods (observations, interviews and administrative data) (Drach-Zahavy and Pud, 2010), and the other study was an observational study in Iran which assessed the administration of IV drugs (Fahimi et al, 2008). The variation between the studies definitions and the methods used for data collection made comparisons difficult. The study that defined errors in preparation and administration, found that the error rates were higher in the administration process compared to the preparation process in intravenous medications, and within the administration process the technique of administration of bolus injection was the most common error (43.4\%) (Fahimi et al, 2008). 
Table 6.7: Prospective studies describing administration errors

\begin{tabular}{|c|c|c|c|c|c|}
\hline STUDY & COUNTRY & SETTING & STUDY DESIGN & STUDY SAMPLE & KEY FINDINGS \\
\hline $\begin{array}{l}\text { Fahimi et al, } \\
2008\end{array}$ & Iran & Teaching hospital, ICU & $\begin{array}{l}\text { Random observational study for } \\
\text { preparation and administration of } \\
\text { IV drugs by nurses in the ICU was } \\
\text { conducted by pharmacist ( } 16 \\
\text { days) }\end{array}$ & $\begin{array}{l}524 \text { preparations and } \\
\text { administrations process }\end{array}$ & $\begin{array}{l}380(9.4 \%) \text { errors were identified out of } 4040 \\
\text { opportunities for errors } \\
33.6 \% \text { were related to the preparation process } \\
66.4 \% \text { were to the administration process. } 43.4 \% \text { of } \\
\text { errors were the injection of bolus doses faster than } \\
\text { recommended }\end{array}$ \\
\hline $\begin{array}{l}\text { Drach-Zahavy } \\
\text { \& Pud, } 2010\end{array}$ & Israel & $\begin{array}{l}\text { Three hospitals, } 32 \\
\text { surgical and internal } \\
\text { medicine wards }\end{array}$ & $\begin{array}{l}\text { Multi methods (observations, } \\
\text { interviews and administrative } \\
\text { data) were conducted to test the } \\
\text { effectiveness of learning } \\
\text { mechanisms to limit medication } \\
\text { administration errors. Data were } \\
\text { collected during } 2006 \text {. }\end{array}$ & 173 nurses & $\begin{array}{l}\text { One patient in three was exposed to medication } \\
\text { administration error each time they received } \\
\text { medication }\end{array}$ \\
\hline
\end{tabular}


Two studies were retrospective and conducted in 2 countries (Saab et al, 2006; Sadat-Ali et al, 2010) (Table 6.8). The error rates reported in administration errors studies overall ranged from $9.4 \%$ to $80 \%$ (Fahimi et al, 2008; Saab et al, 2006). Saab et al. reviewed patient records and confirmed their results through interviews with patients (Saab et al, 2006). This study also found that the use of an inappropriate drug was higher when patients used both over-the-counter (OTC) and prescription medicines (Saab et al, 2006). Sadat-Ali and colleagues assessed the prevalence and characteristics of MEs in patients admitted to a teaching hospital. The authors found that the prevalence of MEs was low (1.58 per 1000 admission) and this could be due to under reporting of the errors (Sadat-Ali et al, 2010). This is likely to be due to the method used in the study, which was a retrospective review of incident reports - notorious for underestimation of error rates (Sadat-Ali et al, 2010). In addition, the authors revealed that most of the MEs (50\%) occurred during the night shift (Sadat-Ali et al, 2010). 
Table 6.8: Retrospective studies describing administration errors

\begin{tabular}{|c|c|c|c|c|c|}
\hline STUDY & COUNTRY & SETTING & STUDY DESIGN & STUDY SAMPLE & KEY FINDINGS \\
\hline $\begin{array}{l}\text { Saab et al, } \\
2006\end{array}$ & Lebanon & $\begin{array}{l}10 \text { different } \\
\text { community } \\
\text { pharmacies }\end{array}$ & $\begin{array}{l}\text { Each patient profile was reviewed } \\
\text { and to confirm patient record } \\
\text { information, in-person interviews, } \\
\text { from November } 2004 \text { to May } 2005 \\
\text { by qualified pharmacists. }\end{array}$ & 277 elderly patients & $\begin{array}{l}59.6 \% \text { of the patients were taking at least one } \\
\text { inappropriate medication } \\
\text { Missing doses were in } 18.8 \% \text { of the patients with } \\
\text { inappropriate drug use } \\
\text { Inappropriate frequency of administration was in } \\
13 \% \text { of the patients with inappropriate drug use }\end{array}$ \\
\hline $\begin{array}{l}\text { Sadat-Ali et } \\
\text { al, } 2010\end{array}$ & Saudi Arabia & Teaching Hospital & $\begin{array}{l}\text { Incident reports documented by } \\
\text { physicians and nurses were } \\
\text { collected from January } 2008 \text { - } \\
\text { December } 2009\end{array}$ & 23957 admissions & $\begin{array}{l}38 \text { medication errors were reported, } 24 \text { with adults, and } \\
14 \text { with children } \\
\text { Incidence rate of medication error was } 1.58 \text { per } 1000 \\
\text { admission } \\
\text { Missed medication was the most common error in } 15 \\
(39.5 \%) \text { patients, mainly in paediatric medicine and } \\
\text { obstetrics } \\
19(50 \%) \text { of the errors occurred during night shift }\end{array}$ \\
\hline
\end{tabular}


Seven questionnaire studies of nurses' perceptions of describing administration errors (Table 6.9), 5 studies were conducted in Iran and 2 in Jordan. All these studies evaluated nurses and student nurses opinion about the drug administration errors in their area of work (Table 6.9). Two studies reported the rate of nurses failing to report MEs. This ranged from $17.1 \%$ to $60 \%$ (Marryan et al, 2007) (Koohestani et al, 2008). Wrong patient and wrong dose of medication were the most common error reported. 
Table 6.9: Questionnaire studies of nurses perceptions of describing administration errors

\begin{tabular}{|c|c|c|c|c|c|}
\hline STUDY & COUNTRY & SETTING & STUDY DESIGN & STUDY SAMPLE & KEY FINDINGS \\
\hline $\begin{array}{l}\text { Mrayyan et al, } \\
2007\end{array}$ & Jordan & 24 hospitals & $\begin{array}{l}\text { Descriptive study of nurses' } \\
\text { perceptions about rate, causes and } \\
\text { reporting of MEs }\end{array}$ & 799 registered nurse & $\begin{array}{l}\text { Average number of recalled MEs per nurse was } 2.2 \\
42.1 \% \text { of MEs rate were reported to nurse managers } \\
60 \% \text { of nurses failed to report MEs because they } \\
\text { were afraid that they might lose their jobs }\end{array}$ \\
\hline $\begin{array}{l}\text { Koohestani \& } \\
\text { Baghcheghi, } 2008\end{array}$ & Iran & $\begin{array}{l}\text { Cardiac Care } \\
\text { Unit }\end{array}$ & $\begin{array}{l}\text { Descriptive study to determine the } \\
\text { frequency, type and causes of } \\
\text { MEs in cardiac care unit. }\end{array}$ & 60 nursing students & $\begin{array}{l}10 \% \text { of nursing students had made medication errors } \\
48.3 \% \text { of nursing students did not report any errors. } \\
\text { Incorrect drug calculation, poor pharmacologic knowledge } \\
\text { were the most common type of errors }\end{array}$ \\
\hline $\begin{array}{l}\text { Koohestani et al, } \\
2008\end{array}$ & Iran & $\begin{array}{l}\text { Teaching } \\
\text { hospital }\end{array}$ & $\begin{array}{l}\text { Descriptive study was conducted to } \\
\text { investigate the frequency, type and } \\
\text { causes of MEs of nursing student. }\end{array}$ & 76 nursing students & $\begin{array}{l}17.1 \% \text { of nursing students reported medication errors } \\
\text { Wrong dose of medication was the most common type of } \\
\text { error. } \\
\text { Poor pharmacological knowledge was the most common } \\
\text { cause of error. }\end{array}$ \\
\hline $\begin{array}{l}\text { Koohestani \& } \\
\text { Baghcheghi, } 2009\end{array}$ & Iran & $\begin{array}{l}\text { Three nursing } \\
\text { schools at } \\
\text { University of } \\
\text { Medical } \\
\text { Sciences }\end{array}$ & $\begin{array}{l}\text { Descriptive study was conducted } \\
\text { using self -report questionnaires, in } \\
\text { winter } 2008 \text {. }\end{array}$ & 240 nursing students & $\begin{array}{l}\text { Response rate was } 100 \% \\
124 \text { medication administration errors were made by } \\
\text { students } \\
\text { Only } 80 \% \text { of them were reported to instructors. } \\
1.93 \text { MAEs were recalled for each student nurse. } \\
\text { Administrative barriers and fear were the main two reasons } \\
\text { for not reporting MAEs among nursing students }\end{array}$ \\
\hline
\end{tabular}


Table 6.9: Contd

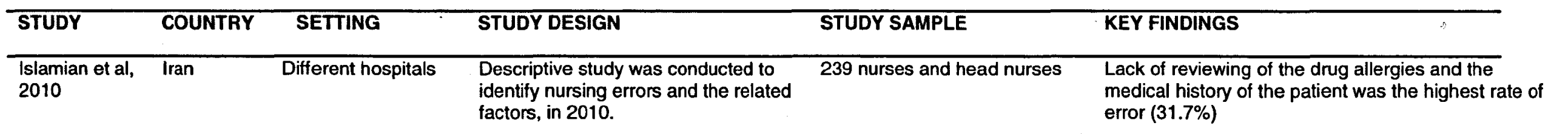

Al-Shara et al, Jordan

2011

Joolaee et al, Iran

2011
Teaching Hospital

Descriptive study to determine the types, stages, and factors contributing to MEs and related area of improvement.

Six educational/ non-educational hospitals were selected
Descriptive study was performed to evaluate the relationship between the incidence and reporting of MEs by nurses and work conditions, from November 2008 to May 2009.
126 registered nurses

Disregarding the administration time for prescription of the medicine error rate was $31.7 \%$

Wrong patient (26.2\%) and wrong dosage $(22.2 \%)$ were the highest types of MEs reported.

Rates of MEs of nurses, physicians and pharmacists were $48.4 \%, 31.7 \%, 11.1 \%$.

Heavy workload (41.4\%), and new staff $(20.6 \%)$ were the main causes of MEs

19.5 ME cases were recalled by each nurse

1.3 cases of MEs were reported by each nurse during three months

Relationship between error incidence and nursing work load was statistically significant ( $P \leq 0.0001$ )

There was no significant relationship between reporting the occurred error and nurses' work conditions ( $P \leq 0.255)$. 


\subsubsection{Interventional studies}

Twelve $(27 \%)$ studies were identified describing interventions used to reduce MEs. Of these, seven interventions were implemented on adult patients (Table 6.10) and five interventions on paediatric and neonatal patients (Table 6.11). The interventions had been evaluated in studies from 3 months to 3 years, and most studies involved a comparison of computerised drug order entry system, with or without Clinical Decision Support Systems (CDSS), and/or with handwritten prescriptions. The outcomes for all interventions were positive and led to the prevention and reduction of MEs.

Four out of 7 studies (interventions) were identified that specifically examined the role of the clinical pharmacist in reducing MEs (Elnour et al, 2008; Hooper et al, 2009; Abou - alsoud et al, 2010; Khalili et al, 2011). All these studies were assessed and implemented on adult patients only. These interventions led to a significant reduction in the number of MEs. Most of the interventions detected were in the prescribing stage. Incorrect drug dosing, incorrect drug choice and drug interactions were the most common errors detected by clinical pharmacists. One of the intervention studies used a self-reported questionnaire design to collect data after the clinical pharmacists established training and educational materials for inpatient nurses about MEs but there was no MEs data actually observed or collected (Elnour et al, 2008). 
Table 6.10: Interventional studies describing MEs in adults

\begin{tabular}{|c|c|c|c|c|c|}
\hline STUDY & COUNTRY & SETTING & INTERVENTION & STUDY SAMPLE & KEY FINDINGS \\
\hline $\begin{array}{l}\text { (Oliven et al., } \\
\text { 2002) }\end{array}$ & Israel & $\begin{array}{l}\text { Teaching Hospital, } \\
\text { Internal medicine } \\
\text { department }\end{array}$ & $\begin{array}{l}\text { Comparison between prescription orders } \\
\text { using comprehensive CDOE system and } \\
\text { handwritten prescription orders in similar } \\
\text { department, evaluated by physicians. }\end{array}$ & $\begin{array}{l}4600 \text { hospitalization } \\
\text { days }\end{array}$ & $\begin{array}{l}\text { Prescribing errors occurring in } \\
\text { handwritten orders were } 11.3 \% \\
\text { errors, compared to } 3.2 \% \text { errors in } \\
\text { computerized drug orders per } 100 \\
\text { hospitalization day } \\
\text { The use of CDOE was associated with } \\
\text { a significant reduction in mean } \\
\text { hospital stay. }\end{array}$ \\
\hline $\begin{array}{l}\text { (Oliven et al., } \\
2005 \text { ) }\end{array}$ & Israel & $\begin{array}{l}\text { Teaching Hospital, Internal } \\
\text { medicine } A \text { and } B\end{array}$ & $\begin{array}{l}\text { Comparison between CDOE and } \\
\text { handwritten drug orders in a similar } \\
\text { department. Prescribing Errors (PEs) } \\
\text { weredivided into, Type } 1 \text { PEs: relating to } \\
\text { the individual patient, Type } 2 \text { PEs } \\
\text { resulting from drug - laboratory, drug - } \\
\text { disease, and drug - allergy interaction. }\end{array}$ & $\begin{array}{l}1350 \text { adult patients } \\
\text { ( } 641 \text { handwritten, } 709 \\
\text { CDOE). }\end{array}$ & $\begin{array}{l}\text { Incidence of type } 1 \text { PEs was } 5.21 \text { in } \\
\text { handwritten orders and } 1.36 \text { in CDOE } \\
\text { orders per } 100 \text { hospitalization days. } \\
\text { Incidence of type } 2 \text { PEs were more } \\
\text { common } 7.2 \text { in handwritten orders, } \\
\text { and } 3.02 \text { in CDOE orders per } 100 \\
\text { hospitalization days } \\
\text { CDOE has a large impact on the } \\
\text { prevention of prescribing errors }\end{array}$ \\
\hline $\begin{array}{l}\text { (Elnour et al., } \\
\text { 2008) }\end{array}$ & U.A.E & Teaching Hospital & $\begin{array}{l}\text { Clinical pharmacists established training } \\
\text { and educational materials for inpatient } \\
\text { nurses about MEs, Pre/Post self - } \\
\text { reported questionnaire used to collect } \\
\text { data, duration of study from September } \\
2006 \text { to December } 2006 \text {. }\end{array}$ & 370 nurses & $\begin{array}{l}\text { There were differences in the } \\
\text { knowledge of nurses about the causes } \\
\text { and reporting of medication errors. } \\
\text { The clinical pharmacist's program has } \\
\text { improved knowledge of the in-patient } \\
\text { nursing staft in terms of raising their } \\
\text { awareness about medication errors }\end{array}$ \\
\hline
\end{tabular}

CDOE: Computerized Drug Order Entry; PEs: Prescribing Errors; MEs: Medication Errors; U.A.E: United Arab Emirates 
Table 6.10: Contd

\begin{tabular}{|c|c|c|c|c|c|}
\hline STUDY & COUNTRY & SETTING & INTERVENTION & STUDY SAMPLE & KEY FINDINGS \\
\hline $\begin{array}{l}\text { (Hooper et al., } \\
2009)\end{array}$ & Qatar & $\begin{array}{l}\text { Four PHC } \\
\text { Services }\end{array}$ & $\begin{array}{l}\text { Pharmacists in four clinics within the } \\
\text { service used online, integrated health } \\
\text { care software to document all clinical } \\
\text { interventions made. Study conducted } \\
\text { from January to March } 2008\end{array}$ & 82,800 patients & $\begin{array}{l}589 \text { patient prescriptions were intercepted for suspected } \\
\text { errors } \\
10.8 \% \text { of the total prescriptions intercepted were for } \\
\text { children } \\
54 \% \text { of all interventions were related to drug choice } \\
\text { problems } \\
42 \% \text { of the interventions related to drug safety problem } \\
51 \% \text { of the interventions were related to dosing errors }\end{array}$ \\
\hline $\begin{array}{l}\text { (Abou Alsoud } \\
\text { et al., 2010) }\end{array}$ & Egypt & $\begin{array}{l}\text { Teaching hospital, } \\
\text { National cancer } \\
\text { centre }\end{array}$ & $\begin{array}{l}\text { Clinical pharmacy interventions } \\
\text { (Detecting MEs, correcting those } \\
\text { errors, sending recommendations to } \\
\text { medical staff) were documented in } \\
\text { the study for one year period. }\end{array}$ & $\begin{array}{l}100 \text { patients ( } 89 \\
\text { adults and } 11 \\
\text { paediatrics) }\end{array}$ & $\begin{array}{l}\text { The clinical pharmacy interventions reduced the number } \\
\text { of MEs from } 1548 \text { to } 444 \text { error which was statistically } \\
\text { significant }(P=0.004) \text {. } \\
76 \% \text { of the errors recorded occurred in the prescribing } \\
\text { stage } \\
20 \% \text { in the administration stage and } 3.8 \% \text { in the } \\
\text { dispensing stage }\end{array}$ \\
\hline $\begin{array}{l}\text { (Khalili et al., } \\
\text { 2011) }\end{array}$ & Iran & $\begin{array}{l}\text { Teaching } \\
\text { Hospital, } \\
\text { Infectious } \\
\text { diseases ward }\end{array}$ & $\begin{array}{l}\text { To assess the role of the clinical } \\
\text { pharmacists intervention in } \\
\text { detecting and preventing of MEs } \\
\text { that occurred in one year period. }\end{array}$ & 861 patients & $\begin{array}{l}112 \text { MEs were detected by clinical pharmacists, (0.13 errors } \\
\text { per patient) } \\
\text { Physicians were responsible for MEs more than nurses and } \\
\text { patients } 55(49.1 \%), 54(48.2 \%) \text {, and } 3(2.7 \%) \text {, respectively } \\
\text { Drug dosing, drug choice, drug use and drug interaction were } \\
\text { the most common error types }\end{array}$ \\
\hline
\end{tabular}


Table 6.10: Contd

\begin{tabular}{|c|c|c|c|c|c|}
\hline STUDY & COUNTRY & SETTING & INTERVENTION & STUDY SAMPLE & KEY FINDINGS \\
\hline $\begin{array}{l}\text { (Qureshi et } \\
\text { al., 2011) }\end{array}$ & $\begin{array}{l}\text { Saudi } \\
\text { Arabia }\end{array}$ & $\begin{array}{l}\text { Three } \\
\text { Government } \\
\text { centres }\end{array}$ & $\begin{array}{l}\text { Three types of intervention were evaluated: Pre- } \\
\text { intervention sites ( } 5 \text { health care centres), and } \\
\text { Post-intervention sites ( } 3 \text { health care centres, } \\
\text { each receiving a different intervention): } \\
\text { 1. Training physicians about quality } \\
\text { prescribing. } \\
\text { 2. Regulatory and administrative measures } \\
\text { to improve rational drug prescribing. } \\
\text { 3. Multi - faceted approach using previous } \\
2 \text { strategies plus additional elements. }\end{array}$ & 61 physicians & $\begin{array}{l}\text { All } 3 \text { types of intervention improved the } \\
\text { quality of physicians' prescriptions } \\
\text { In Pre intervention } 198(8 \%) \text { out of } 2463 \\
\text { prescribed drugs were with major errors } \\
8(3.9 \%) \text { out of } 206 \text { prescribed drugs } \\
\text { analysed during training intervention had } \\
\text { major errors, } 94 \text { ( } 46 \%) \text { out of } 204 \\
\text { prescribed drugs during administrative } \\
\text { intervention had major errors, and } 2 \% \text { were } \\
\text { in post intervention: training, administrative } \\
\text { and multiple, respectively. } \\
\text { Educationalists need to develop targeted } \\
\text { courses in drug prescribing to assist in } \\
\text { developing the prescribing skills of } \\
\text { physicians. }\end{array}$ \\
\hline
\end{tabular}


In paediatric and neonatal patients, the computerised physician order entry intervention, with and without CDSS, was the most commonly used intervention. All interventions that were implemented in paediatric patients found that MEs rates decreased after the CDSS was added to the computerised physician order entry system (Table 6.11). Vardi et al in their first part of the study found that only 3 errors were identified in 13124 prescriptions (Vardi et al, 2007) but this was much lower than the expected rate for errors. There are a few possible explanations for this, one of which is that errors happen but are not reported and this leads to unrealistic study results. Another possible explanation may be that when an error is detected, the observers or researchers may feel that it is not important enough to be reported if it does not cause any problem.

In addition, one study among the interventional studies in paediatric patients was conducted to compare two different medication order entry methods: the Physician Order Entry (POE) and Nurse Order Entry (Kazemi et al, 2010). The authors found that the error rates decreased within the Nursing Order Entry (NOE) period compared to the errors within the POE period (Kazemi et al, 2010). 
Table 6.11: Interventional studies describing MEs in paediatric and neonatal patients

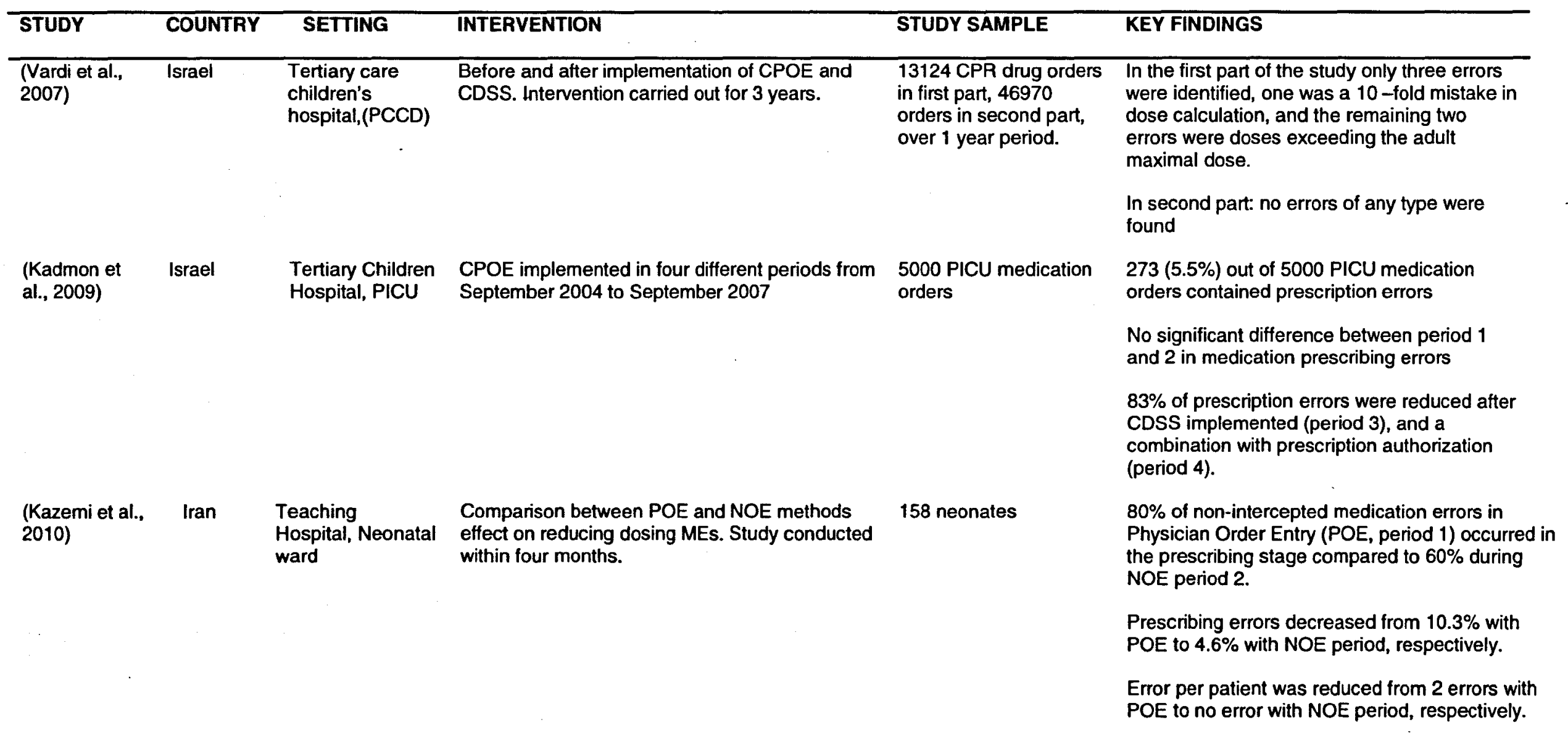

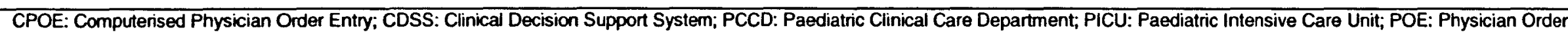
Entry; NOE: Nurse Order Entry. 
Table 6.11: Contd

\begin{tabular}{|c|c|c|c|c|c|}
\hline STUDY & COUNTRY & SETTING & INTERVENTION & STUDY SAMPLE & KEY FINDINGS \\
\hline $\begin{array}{l}\text { (Kazemi et al., } \\
\text { 2011) }\end{array}$ & Iran & $\begin{array}{l}\text { Tertiary Care } \\
\text { Hospital, } \\
\text { Neonatal ward }\end{array}$ & $\begin{array}{l}\text { Comparison of the CPOE effect without and } \\
\text { with CDSS in three periods, for } 7.5 \text { months } \\
\text { period. }\end{array}$ & $\begin{array}{l}248 \text { patients were included } \\
\text { in this study }\end{array}$ & $\begin{array}{l}\text { Medication errors rates before intervention } \\
\text { implemented (Period 1) was } 53 \% \\
\text { After the CPOE implemented without CDSS the } \\
\text { MEs rate was } 51 \% \\
\text { After CDSS was added to the CPOE the MEs } \\
\text { rate was } 34 \% \\
\text { Overdose was the most frequent type of MEs }\end{array}$ \\
\hline $\begin{array}{l}\text { (Alagha et al., } \\
\text { 2011) }\end{array}$ & Egypt & $\begin{array}{l}\text { Teaching hospital, } \\
\text { PICU }\end{array}$ & $\begin{array}{l}\text { Pre-Post intervention (physician education; new } \\
\text { medication chart; physician feedback) study of } \\
\text { prescribing errors in PICU was conducted for } \\
10 \text { months period. }\end{array}$ & $\begin{array}{l}\text { Pre-intervention, } 1417 \\
\text { medication orders were } \\
\text { evaluated for } 139 \\
\text { patients } \\
\text { Post-intervention, } 1096 \\
\text { orders for } 101 \text { patients }\end{array}$ & $\begin{array}{l}\text { Of Pre-intervention orders } 1107(78.1 \%) \\
\text { had at least one prescribing errors } \\
\text { The intervention resulted in significant } \\
\text { reduction in prescribing error rate to } 35.2 \% \\
\text { post-intervention ( } P<0.001) \\
\text { The intervention resulted also in a } \\
\text { significant reduction in the rate of } \\
\text { potentially severe errors from } 29.7 \% \text { pre- } \\
\text { intervention to } 7 \% \text { post-intervention } \\
(P<0.001)\end{array}$ \\
\hline
\end{tabular}

PICU: Paediatric Intensive Care Unit. 


\subsubsection{Medications involved in medication errors studies}

Differences in the reporting of medications between studies results were obvious; some studies involved the medications names, and others listed the therapeutic class. Most of the errors were related to antihistamines (Alkhaja et al, 2008; Azoulay et al, 2005; Alkhaja et al, 2007), antibiotics (Sabry et al, 2009; Lustig A, 2000; Sweileh et al, 2007; Alagha et al, 2011) and anticoagulants (Khalili et al, 2011; Koohestani et al, 2008; Alagha et al, 2011).

In addition, medications reported in studies that were conducted on paediatric patients found that antihistamines, paracetamol, electrolytes and bronchodilator drugs were the most common drugs associated with errors (Alkhaja et al, 2007; Aljeraisy et al, 2011). These are however the most frequently prescribed drugs in this area, particularly antihistamine drugs, because the weather in most of the Middle East countries have dust or storms which lead to allergies which require treatment with antihistamine drugs.

\subsubsection{Severity of reported medication errors}

The majority of studies did not assess the clinical consequences of reported MEs. Six (13\%, 6/45) attempted to classify the severity of the MEs (Lustig, 2000; Aljeraisy et al, 2011; Aldhawailie, 2011; Lifshitz et al, 2012; Dibbi et al, 2006) (Table 6.12). Only one study reported the severity of the MEs in detail, but was a retrospective study (Aljeraisy et al, 2011). Two other studies were retrospective (Valizadeh et al, 2008; Dibbi et al, 2006), while the other three were prospective studies (Lustig, 2000; Aldhawailie, 2011; Lifshitz et al, 2012). One study reported 26 deaths and felt that MEs were a contributory factor (Dibbi et al, 2006). 
Table 6.12: Clinical consequences of reported medication errors

\begin{tabular}{|c|c|c|c|c|}
\hline Country & Type of error & Medicines & Clinical consequences & Reference \\
\hline Israel & $\begin{array}{l}\text { Prescribing } \\
\text { errors }\end{array}$ & $\begin{array}{l}\text { Anti-infectives, } \\
\text { TPN, cytotoxics }\end{array}$ & $\begin{array}{l}\text { Errors divided into potentially } \\
\text { serious, clinically significant } \\
\text { and clinically non-significant. } \\
\text { MEs most frequent in } \\
\text { haemato-oncology and these } \\
\text { were the errors that had } \\
\text { greatest clinical significance }\end{array}$ & Lustig, 2000 \\
\hline $\begin{array}{l}\text { Saudi } \\
\text { Arabia }\end{array}$ & $\begin{array}{l}\text { Prescribing } \\
\text { errors }\end{array}$ & Not stated & $\begin{array}{l}\text { Examples of potentially } \\
\text { serious errors were given } \\
\text { including tenfold errors of } \\
\text { amphotericin and captopril }\end{array}$ & $\begin{array}{l}\text { Aldhawailie, } \\
2011\end{array}$ \\
\hline Israel & $\begin{array}{l}\text { Prescribing } \\
\text { errors }\end{array}$ & $\begin{array}{l}\text { Cardiovascular } \\
\text { drugs }\end{array}$ & $\begin{array}{l}14 \mathrm{MEs}(8 \%) \text { were clinically } \\
\text { significant. There were also } 3 \\
(2 \%) \text { severe MEs }\end{array}$ & $\begin{array}{l}\text { Valizadeh et al, } \\
2008\end{array}$ \\
\hline $\begin{array}{l}\text { Saudi } \\
\text { Arabia }\end{array}$ & $\begin{array}{l}\text { Prescribing } \\
\text { errors }\end{array}$ & $\begin{array}{l}\text { IV fluids, antibiotics, } \\
\text { bronchodilators, } \\
\text { opioid analgesics, } \\
\text { cardiovascular } \\
\text { drugs, sedatives }\end{array}$ & $\begin{array}{l}\text { Majority of MEs were } \\
\text { potentially harmful (1051, } \\
79 \%)\end{array}$ & $\begin{array}{l}\text { Aljeraisy ot al, } \\
2011\end{array}$ \\
\hline $\begin{array}{l}\text { Saudi } \\
\text { Arabia }\end{array}$ & $\begin{array}{l}\text { Prescribing and } \\
\text { administration } \\
\text { errors }\end{array}$ & $\begin{array}{l}\text { Antibiotics, } \\
\text { cardiovascular } \\
\text { drugs }\end{array}$ & $\begin{array}{l}\text { MEs were a contributory } \\
\text { factor to } 26 \text { deaths }\end{array}$ & Dibbi et al, 2006 \\
\hline Iran & $\begin{array}{l}\text { Administration } \\
\text { errors }\end{array}$ & $\begin{array}{l}\text { Antibiotics, } \\
\text { antacids, } \\
\text { corticosteroids }\end{array}$ & $\begin{array}{l}\text { No clinically significant errors } \\
\text { detected }\end{array}$ & $\begin{array}{l}\text { Fahimi et al, } \\
2008\end{array}$ \\
\hline
\end{tabular}




\subsubsection{Factors contributing to medication errors}

The determination of factors contributing to MEs is an important aspect in this review because preventing MEs from reaching the patient depends on a sound knowledge of the causes or contributing factors. The factors contributing to MEs were reported in 12 studies. Differences in contributing factors between studies were due to the difference between countries and health care systems in Middle East countries. The most common factors reported in this review are as follows:

\subsubsection{Lack of knowledge of prescribing skills}

Several studies identified in the review have cited lack of knowledge of prescribing skills as a contributory factor to MEs (Al-khaja et al., 2008, Al-Dhawailie, 2011, Irshaid et al., 2005). Al-Khaja et al. evaluated the prescription skills of final year residents in a family practice residency programme in Bahrain for those who had and had not graduated with problem based learning (Al-Khaja et al., 2008). Their study concluded that the prescription writing skill of the final year residents in a family practice residency programme was suboptimal for all graduates.

Another study in Saudi Arabia highlighted that the lack of knowledge of prescribing skills was the main cause of errors (Al-Dhawailie, 2011), Irshaid and colleagues in Saudi Arabia found poor handwriting was a serious problem in prescribing and was a major cause of MEs. Poor handwriting may lead to pharmacy dispensing the wrong drug (Irshaid t al, 2005).

\subsubsection{Lack of pharmacological knowledge between physicians and nurses}

Physicians are accountable for the medication they prescribe and this requires knowledge of the indication, dosing, mechanism of action and side effects of medicines. Nurses also have to update their knowledge of drugs. With an increasing number of medicines available, physicians and nurses are responsible for updating 
their knowledge of medicines. Different studies in this review revealed that a lack of pharmacological knowledge between physicians and nurses is a contributory factor to MEs in the Middle East countries. Sweileh and colleagues performed a crosssectional study in Palestine to determine whether appropriate dosage adjustments were made for drugs that are nephrotoxic in patients with renal impairment. This study revealed that dosing errors were common among patients with renal impairment during hospitalization and the inadequacy of physician's knowledge of clinical pharmacokinetics was a contributing factor for MEs (Sweileh et al., 2007). However, an interventional study performed in Egypt by clinical pharmacists found that when the clinical pharmacists' activities focussed on improving physician drug knowledge and awareness of errors shown, there was an effective reduction in the rate of prescribing errors and their severity in PICU (Alagha et al., 2011).

Drug name confusion was one of the most common causes of MEs in a hospital in Saudi Arabia e.g. Cefoxtem which could be confused with Cefotaxem (Dibbi et al, 2006).

Two studies have been conducted in Iran to identify the factors contributing to MEs (Koohestani et al, 2008, Islamian et al, 2010). The first was a descriptive study to investigate the frequency, type and causes of MEs of nursing students in Iran and found that most of the causes of MEs were related to poor pharmacological knowledge and drug calculation errors (Koohestani et al, 2008). The second study was conducted to assess the nursing error rate and related factors. The results of this study showed that all the nurses believed that more than one factor was involved in errors. The highest rate of errors had been related to lack of compiling and reviewing the history of patient's consumed medicines, lack of observing the appropriate time for prescribed medicines and lack of assessing the laboratory tests of patients with respect to relevant medicines (Islamian et al., 2010). 


\subsubsection{Poor compliance with drug prescribing and administration guidelines}

Although medication prescribing and administration guidelines and policies exist in all the Middle East countries, it would appear from the identified studies that the adherence to these guidelines and policies was poor. Al-Khaja et al. concluded that a lack of adherence to the basic prescribing information and adherence to essential drug lists could have contributed to MEs (Al-Khaja et al, 2007; Al-Khaja et al, 2005). In addition, Vaknin and colleagues in their survey study checked compliance in relation to hospital standards, with regards to the quality of the medication administration process, and highlighted that poor compliance to guidelines on the part of doctors and nurses have an effect on the quality of medication administration (Vaknin et al, 2003).

\subsubsection{Unreported medication errors}

Reporting MEs improves patient safety and provides helpful information for the prevention of MEs for future practice. Koohestani et al. found that medication administration error occurrences among nursing students were often underreported due to administrative barriers and fear of decreasing evaluation scores (Koohestani et al, 2009). Another two studies in this review found that unreported MEs in hospitals may be due to the hospital staff not knowing the true extent of the problem; there is a need to raise the awareness of the importance of reporting MEs (Sadat et al, 2010; Elnour et al, 2008).

Another study conducted in Jordan to describe nurses' perceptions about various issues related to MEs, found that the nurses failed to report MEs because they were afraid that they might be subjected to disciplinary actions or even lose their jobs (Mrayyan et al, 2007). 


\subsubsection{Heavy workload and new staff}

Heavy workload and errors due to new staff have been shown as a high cause of MEs in different studies in the Middle East (Al-Shara M, 2011; Joolaee et al, 2011). Al-Shara et al. conducted an exploratory study to determine the factors contributing to MEs and related areas for improvement, as perceived by nurses (Table 6.10 ). The authors found that the highest level of MEs was $48.4 \%$ and related to nurses; the main causes being a heavy workload and new staff (Al-Shara M, 2011). Another study has been performed to determine the relationship between medication error incidents and working conditions, as reported by Iranian nurses in different hospitals (Joolaee et al, 2011). The authors revealed a relationship between nursing MEs and working conditions as being statistically significant and contributing to MEs (Joolaee et al, 2011).

\subsubsection{Miscommunications between health care professionals}

Among the reviewed studies, four studies argued that poor communications between prescribers, nurses and pharmacists were a common contributing factor for MEs in the Middle East region (Dibbi et al, 2006; Al-khaja et al, 2010; Al-Dhwailie A, 2011; Alagha et al, 2011). Such miscommunication leads to misinterpretation of orders particularly in the prescribing stage. For example, heparin orders failed to specify the type of heparin (whether it is calcium or sodium) (Dibbi et al., 2006).

In general, most of the studies focused on the urgent need for educational programmes in medical schools and in health care organisations for all health care professionals. A priority was to improve the prescribing skills of physicians and the procedure of drug administration for nurses (Azoulay et al, 2005; Sweileh et al, 2007; Bar-Oz et al, 2008; Qureshi et al, 2011; Hooper et al, 2009; Irshaid et al, 2005;). All these studies recommended educational programmes to prevent the occurrence of MEs and to enhance patient safety. Another study emphasised the need for 
continuous education and implementation of clinical pharmacist's interventions (Khalili et al, 2011).

\subsection{DISCUSSION}

MEs are an important variable reflecting the effectiveness of patient safety services. In turn, it is essential to realise the weak points of health care professionals and the systems they work in the medication treatment process and to try to make improvements to avoid occurrence of these errors. Although it is well recognised that medication use can improve patient health, this review revealed that studies of MEs in Middle East countries were few in number compared to the total number of MEs in other parts of the world, particularly in children.

To our knowledge, there are no previous systematic reviews that have evaluated MEs in Middle East countries. The aim of this systematic review was to review studies of the incidence and types of MEs in Middle East countries and to identify the main contributory factors involved. The studies reviewed were varied in terms of their objectives, definitions, settings, methods of detection and evaluation of MEs.

\subsubsection{A limited and unclear picture}

This systematic literature review has shown that the scientific literature on MEs published in Middle East countries is limited. No information was available on five of the countries included in the review. Many studies focused mainly on elderly people. The quality of the studies was low as more than $80 \%$ of identified studies met less than 7 criteria in the quality assessment. 


\subsubsection{Prescribing errors}

Many differences were found with regard to how the studies reported and identified MEs. In this review, most of the MEs studies in Middle East countries evaluated the MEs during the prescribing stage. Reported incidence rates of prescribing errors in this review broadly ranged from $7.1 \%$ to $90.5 \%$ of medication orders. Other studies have shown that a high rate of prescribing errors is an international problem (Lewis et al, 2009; Dean et al, 2002). In a previous systematic review conducted in the UK to identify the prevalence, incidence and nature of prescribing errors in hospital inpatients, prescribing errors were found to be a common occurrence (Lewis et al, 2009), and this is consistent with our findings. The incidence of prescribing errors in that review however were $2-14 \%$ of medication orders (Lewis et al, 2009), which is lower than that found in our review of MEs in Middle East countries.

Another study in the UK however found that prescribing errors rates vary widely, ranging from $0.3 \%$ to $39.1 \%$ of medication orders (Franklin et al, 2005). From this information it appears that the incidence rate of prescribing errors in the Middle East countries is higher than that reported in other countries in the world, for example in the UK.

In addition, my review reveals that dosing error rates in prescriptions vary widely from $0.15 \%$ to $34.8 \%$ of total prescriptions, higher than the rates reported by other studies (Barker et al., 2002; Lisby et al., 2005) Barker et al reported that $19 \%$ of doses contained errors (Barker et al., 2002) and another study found that $28 \%$ of dosing errors occurred at the prescribing stage (Lisby et al., 2005).

In contrast, a previous systematic review found that dose or frequency error rates ranged from $30 \%$ to $42 \%$ of errors that occurred on admission to the hospital (Tam et al., 2005). 


\subsubsection{Transcribing errors}

Although some studies classified the transcribing stage as the third important area in the medication treatment process, Lisby et al. have identified the transcribing stage as the area in which most errors occur (Lisby et al., 2005). In this review only one study assessed transcribing errors and we found that over $50 \%$ of omission errors occurred at the transcription stage. This is consistent with the findings of other studies (Lisby et al, 2005; Jimenez-Muñoz et al, 2010). The shortage of studies of this stage of medication treatment may distort the reality of the incidence rate of errors.

\subsubsection{Administration errors}

My review showed that the reported incidence rate of administration errors is $9.4 \%$ to $80 \%$ of drug administrations. This range is higher than that reported in other studies in developed countries. Two observational studies found that the MAEs rate in the acute care setting varied between $14.9 \%$ and $32.4 \%$ (Tissot et al., 2003; Schneider et al., 1998). In my review only one observational study determined the frequency of MEs occurring during the preparation and administration of intravenous drugs in an intensive care unit, and found that the rate of errors in drug administration (66.4\%) was higher than in preparation (33.6\%) (Fahimi et al., 2008). One study also found that the MAEs rates for intravenous medication are significantly higher than other types of medications (Wirtz et al., 2003). Wirtz et al observed the preparation error rate as $26 \%$ and the administration error rate as $34 \%$ (Wirtz et al, 2003). The study findings are therefore consistent with previous studies' results that highlighted the occurrence of administration errors of intravenous medication are more frequently than preparation errors.

Armitage and Knapman found that the frequency of administration errors ranges from $2.4 \%$ to $47.5 \%$, depending on the drug distribution system in place (e.g. Unit 
dose dispensing systems) (Armitage, 2003). In the UK a recent report by the NPSA highlighted that $56 \%$ of reported errors associated with severe harm occurred at the administration step (NPSA, 2007).

\subsubsection{Frequency and Types of medication errors}

My study results indicate that the most common types of errors reported were incorrect drug dose, wrong frequency and wrong strength during the prescribing stage. This is consistent with previous studies' results. In comparison studies of MEs in US and UK hospitals, the authors found that incorrect doses were the most common type of error in UK hospitals and also in US hospitals (Dean et al., 1995). The NPSA reported that the most common type of MEs that occurred in the NHS was wrong dose or wrong frequency of medications (NPSA, 2009), and this is consistent with the findings in my review.

\subsubsection{Contributory factors for medication errors}

Based on my review results, the main factor contributing to the MEs in the Middle East countries is poor knowledge of medicines in both doctors (prescribers) and nurses (administering drugs), and this finding is compatible with other studies' results concerning this point (O'Shea, 1999). Educational programmes for drug prescribers and nurses concerning drug therapy are urgently needed to avoid drug errors and to improve patient safety. Different studies have found that clinical pharmacists play a significant role in delivering training and competency assessment (Conroy et al., 2008).

\subsubsection{Limitations of this review}

Some limitations of this review should be considered in interpreting the results. The search strategy and search terms were designed in order to be as comprehensive as possible but the databases used were directly biased to English language 
research and studies. I cannot therefore be sure whether or not some studies have been missed because the original languages of the included countries of the Middle East is not English; all of the included countries speak Arabic except Iran (Persian) and Israel (Hebrew). The use of a limited number of databases for the search could be another source of missed information.

\subsubsection{Further research}

There are a number of areas identified in this review that can be targeted for future development and research. Further research is needed to explore the incidence of MEs and the contributory factors that lead to MEs in the Middle East countries. Additional research is also needed to evaluate the incidence rate and the greatest impact factors on the dispensing and documentation stages of the medication treatment process. More research is needed to measure the severity of the MEs among those countries and also assessment of the interventions designed to reduce MEs, such as educational and training programmes, are urgently needed. In addition, strong co-operation between the Middle East countries in future is a very important issue in order to develop the process of medication treatment in these countries.

\subsection{CONCLUSION}

As the first systematic review to describe MEs in Middle East countries, this review aimed to find out what scientific literature has previously reported on or evaluated MEs in Middle East countries. Although the studies related to MEs in the Middle East countries were relatively few in number, there was a wide variation between studies in the incidence error rates reported, and this may due to the variations in the terms of their definitions of MEs, settings and the methodologies used to detect MEs among Middle East countries. Most of the studies on MEs were conducted on 
adult patients, while very few MEs studies have been performed in paediatric hospitals. Many studies focused on prescribing errors and factors contributing to MEs. This study highlighted that the prescribing error rates varied widely from $7.1 \%$ to $90.5 \%$ of prescriptions. Dosing errors were the most common reported errors in the studies with a range from $0.15 \%$ to $34.8 \%$. In drug administration, the error rates were from $9.4 \%$ to $80 \%$ of drug administration. Poor knowledge of medicines was the main contributory factor of MEs for both prescribers and nurses administering drugs. From this review, I can conclude that the Middle East countries urgently need to introduce educational programmes to improve the prescribing skills and knowledge of prescribers, and also other programmes to encourage nurses to improve their quality of drug administration.

\subsection{RECOMMENDATIONS FOR FUTURE RESEARCH}

According to the review results, the following recommendations are suggested to decision makers to improve the medication safety or reduce MEs in Middle East countries.

- Increase the awareness of MEs between health care professionals.

- Prescribers need to pay more attention to drug dose calculation.

- Improve the MEs reporting system and policy among the Middle East countries without any barriers, and encourage health care professionals to report MEs, and clarify the importance of MEs reporting process.

- Clinical consequences of MEs should be assessed and evaluated in future studies

- Perform more research on MEs involving prescription and non-prescription drugs, particularly in paediatric hospitals in Middle East countries. 
- Carry out regular intensive educational and training programmes in pharmacotherapy for undergraduate medical and paramedical students to improve patient safety:

- Educational programmes by clinical pharmacists and clinical pharmacologists on drug therapy are urgently needed for doctors and nurses. 
CHAPTER SEVEN

\section{CONCLUSION}




\subsection{INTRODUCTION}

Most of the published studies about double checking before my work were qualitative rather than quantitative. Despite that, different authors have different opinions about double checking in practice. Some of them supported double checking and others single checking. Those who support double checking feel that it reduces MEs. The other suggested benefit of double checking is that it can improve the nurses knowledge of medication administration (Dickinson et al., 2010).

The opponents of double checking stated that deference to authority, reduction of responsibility and automatic processing mean that double checking does not prevent MEs (Armitage, 2008). Kruse et al (2002) found that there was no significant differences in error rates between double checking and single checking in three clinical services.

In this thesis, I have tried to add new evidence about the double checking process as a strategy that is used in different hospitals to prevent MEs and also to improve patient safety in the paediatric population.

\subsection{SUMMARY OF FINDINGS}

There were only 16 studies identified in my systematic review of double checking and most of these were qualitative studies. Only three studies were quantitative (Kruse et al., 1992; Ross et al., 2000; White et al., 2010). These three studies were conducted in different places and with different types of patients. The first study was conducted in three wards in a geriatric hospital, and reported a lower error rate with double checking. However, the difference was not statistically significant and the clinical advantages were unclear (Kruse et al., 1992). The second study was carried out in the pharmacy within a large children's hospital in the UK. Dispensing errors 
were lower after double checking but reported error rates were very low (Ross et al., 2000). The third study was a simulation study of outpatients in a chemotherapy centre in a Canadian hospital. A reduction in errors in patient identification occurred with a checklist process (White et al., 2010). So, my systematic review concluded that there was insufficient evidence to justify the double checking of medicines to reduce MEs.

I decided with my supervisors to do three different studies (Chapters 3 - 5). Those studies were conducted because it is unethical to perform a randomised controlled trial study of single versus double checking on children since there is a lack of evidence to support this as being safe.

The main findings from the prospective observational study (Chapter 3 ) were that there was variation between paediatric nurses adherence to double checking steps during medication administration. Drug dose calculation, the rate of administering intravenous bolus drugs, labelling of flush syringes and the administration of medicines to the patients without supervision from both nurses were the steps with the lowest adherence rates.

In addition, this study identified 191 MAEs with an error rate of $9.6 \%$ of drug administrations. The most frequent type of administration errors involved the medicine being given to the parents to administer to the child when the nurse was not present.

The second study conducted was a questionnaire study (Chapter 4). This study revealed that the nurses have unclear knowledge and perceptions of the double checking policy and its implementation in practice. The findings from this study therefore confirmed the findings obtained from my previous observational study. This suggests that paediatric nurses in the hospital need more education of the double checking policy in the medication administration process. 
The third study was a simulation study involving 21 paediatric nurses (Chapter 5). Overall, 118 confounders were built into the simulation sessions. These were prescribing errors and lack of information available to allow the nurses to safely administer medicines without first questioning the researcher. 27 (35\%) confounders were not detected during single checking compared to only $5(12 \%)$ during double checking. Significantly fewer confounders $(49,64 \%)$ were detected during single checking compared to double checking $(37,88 \%)(P=0.0136)$.

Double checking was significantly more likely to identify errors and contraindicated drugs than single checking. The difference between the two processes in terms of drug administration time was not statistically significant, although two nurses were required for the double checking process effectively doubling the time. Five MEs and one near miss were made. These involved 4 errors and 1 near miss with single checking and just one 1 error during double checking. This may be due to the participants being less confident and unfamiliar with single checking leading to an increased risk of errors to occur.

I decided to do a systematic review of MEs in the Middle East countries because I am originally from the Middle East (Saudi Arabia), and I have plans in the future to do more research on MEs in the Middle East. This study can be considered as the first step towards my future research.

My systematic review (Chapter 6) revealed that the MEs studies in the Middle East countries were limited in numbers particularly with paediatric patients and also the identified studies were of poor quality. This systematic review showed that the lack of knowledge about medicines among doctors and nurses. was identified as a major contributory factor of MEs. 


\subsection{PRACTICE IMPLICATIONS}

Based on the above findings I have the following suggestions for all healthcare professionals (particularly those who are working in children's hospitals), decision makers in the children's hospitals, and researchers in this field:

1. Double checking appears to be more effective than single checking.

2. More quantitative studies are needed to investigate the relationship between MEs and staffing conditions in the children's hospitals.

3. Better clarification of the double checking steps is required for all nurses in the hospitals who use the process.

4. Educational programmes should be established for nurses to improve nurses' adherence to the double checking process and to improve their lack of knowledge and clarity about the double checking steps.

5. In the Middle East, awareness of MEs should be increased among healthcare professionals and researchers in this area.

6. The quality of MEs studies in the Middle East should be improved.

7. Educational and training programmes about drug information and administration in the Middle East countries should be established by clinical pharmacists and clinical pharmacologists in the hospitals.

\subsection{LIMITATIONS OF THIS THESIS}

In this thesis there were two systematic reviews (Chapter $2 \& 6$ ), and some limitations of those reviews were considered and discussed in detail within each chapter. 
The clinical studies I conducted were performed in one children's hospital and that may affect the generalisability of the findings. My presence may have had an effect on the nurses during their medication preparation, particularly on IV drug preparation. This may have increased their adherence to the double checking steps as they knew that they were being closely observed. Alternatively it may have made them nervous and distracted them, however I tried hard not to do this.

Because the Derbyshire Children's Hospital policy for drug administration requires two nurses to do double checking before each drug dose administration, the nurses in the hospital are familiar with double checking but not with single checking. This may have affected their performance and level of confidence with the single checking process when I compared these two checking processes in the simulation study.

\subsection{FINAL CONCLUSION}

Finally, this research has achieved its main objectives; to get a clearer evaluation of the effectiveness of double checking. There was variation in the adherence rate to the different steps of the double checking process and also a lack of clarity of the double checking process details among paediatric nurses. Double checking is seen to be more effective than single checking in reducing MEs in children. More needs to be done in the Middle East in relation to research in this area. Educational programmes of prescribers are required to improve their prescribing skills, and also for nurses to improve their knowledge about medication administration. 


\section{REFERENCES}


ABOU ALSOUD N, ELHAMAMSY M, ALZAWAHRY $H$. (2010) Effects of clinical pharmacist interventions on clinical outcomes in oncology patients. Research Journal of Medicine and Medical Sciences 5 (2), 133- 141.

ALAGHA H, BADARY O, IBAAHIM H, SABRI N. (2011) Reducing prescribing errors in the paediatric intensive care unit: an experiance from Egypt. Acta Paediatrica 100, e169-e174.

ALDHAWAILIE A. (2011) Inpatient prescribing errors and pharmacist intervention at a teaching hospital in Saudi Arabia. Saudi Pharmaceutical Journal 19, 193-196.

ALJERAISY M, ALANAZI M, ABOLFOTOUH M. (2011) Medication prescribing errors in a pediatric inpatient tertiary care setting in Saudi Arabia. BMC Res Notes 4, 294.

ALKHAJA K, ALANSARI T, DAMANHORI A, SEQUEIRA R. (2007) Evaluation of drug utilization and prescribing errors in infants: A primary care prescription-based study. Health Policy 81, 350-357.

ALKHAJA K, ALANSARI T, SEQUEIRA R. (2005) An evaluation of prescribing errors in primary care in Bahrain. International Journal of Clinical Pharmacology and Therapeutics 43, 294-301.

ALKHAJA K, SEQUEIRA R, ALANSARI T, DAMANHORI A, JAMES $H$, HANDU S. (2010) Pediatric iron preparation for infants in Bahrain: some therapeutic concerns. International Journal of Clinical Pharmacology and Therapeutics 48, 200-205.

ALLAN E, BARKER K. (1990) Fundamentals of medication errors research. American Journal of Hospital Pharmacy 47, 555-571

ALSHARA M. (2011) Factors contributing to medication errors in Jordan: a nursing perspective. Iranian Journal of Nursing and Midwifery Research 16, 1 - 4. 
AMERICAN ACADEMY OF PEDIATRICS. (2003) Prevention of medication errors in the pediatric inpatient setting. Pediatrics 112, $431-436$.

ANDERSON D, WEBSTER C. (2001) A systems approach to the reduction of medication error on the hospital ward. Journal of Advanced Nursing 35, 34 - 41.

ANTONOW J, SMITH A, SILVER M. (2000) Medication error reporting: a survey of nursing staff. Journal of Nursing Care Quality 15, 42 - 48.

ARABIAN BUSINESS (2007) Patient behaviour reducing effectiveness of medical treatment in the Middle East. Available:http://www.arabianbusiness.com/pressrelease/?pressReleaseld=2055. (Accessed 18 October 2011).

ARMITAGE G. (2008) Double checking medicines: defence against error or contributory factor? Journal of Evaluation in Clinical Practice 14, 513 - 519.

ARMITAGE G, KNAPMAN H. (2003) Adverse events in drug administration: a literature review. Journal of Nursing Management 11, 130 - 140.

ARMUTLU M, FOLEY M, SURETTE J, BELZILE E, MCCUSKER J. (2008) Survey of nursing perceptions of medication administration practices, perceived sources of errors and reporting behaviours. Healthcare Quarterly 11, 58 - 65 .

ARONSON J. (2009) Medication errors: definitions and classification. British Journal of Clinical Pharmacology 67, 599 - 604.

AZOULAY L, ZARGARZADEH A, SALAHSHOURI Z, ORAICHI D, BERARD A. (2005) Inappropriate medication prescribing in community-dwelling elderly people living in Iran. European Journal of Clinical Pharmacology 61, 913 - 919.

BARKER K. (1980) Data collection techniques: observation. American Journal of Hospital Pharmacy 37, 1235-1243. 
BARKER K, FLYNN E, PEPPER G, BATES D, MIKEAL R. (2002) Medication errors observed in 36 health care facilities. Archives of Internal Medicine 162, 16, 1897 1903.

BARKER K \& McCONNELL W. (1962) The problems of detecting medication errors in hospitals. American Journal of Hospital Pharmacy 19, $360-369$.

BARKER K, MIKEAL R, PEARSON R, ILLIG N, MORSE M. (1982) Medication errors in nursing homes and small hospitals. American Journal of Health-System Pharmacy 39, 6, $987-991$.

BAR-OZ B, GOLDMAN M, LAHAT E, GREENBERG R, AVGIL M, BLAY A, HERMAN A, BERKOVITCH M. (2008) Medication errors and response bias: the tip of the iceberg. Israel Medical Association Journal 10, 771 - 774.

BATES D, CULLEN D, LAIRD N, PETERSEN L, SMALL S, SERVI D, LAFFEL G, SWEITZER B, SHEA B, HALLISEY R, et al. (1995) Incidence of adverse drug events and potential adverse drug events. Implications for prevention. ADE Prevention Study Group. Journal of American Medical Association 274, 29 - 34.

BATES D, TEICH J, LEE J, SEGER D, KUPERMAN G, MALUF N, BOYLE D, LEAPE L. (1999) The impact of computerized physician order entry on medication error prevention. Journal of the American Medical Informatics Association 6, 313 321.

BENJAMIN D. (2003) Reducing medication errors and increasing patient safety. Journal of Clinical Pharmacology 43, 768 - 783. 
BEN-YEHUDA A, BITTON Y, SHARON P, ROTFELD E, ARMON T, MUSZKAT M. (2011) Risk factors for prescribing and transcribing medication errors among elderly patients during acute hospitalization: A cohort, case-control study. Drugs and Aging 28: $491-500$.

BHASALE A, MILLER G, REID S, BRITT H. (1998) Analysing potential harm in Australian general practice: an incident-monitoring study. Medical Journal of Australia 169, 73-76.

CHAPPELL K, NEWMAN C. (2004) Potential tenfold drug overdoses on a neonatal unit. Archives of Disease in Childhood Fetal and Neonatal Edition 89, F483.

CHEDOE I, MOLENDIJK H, HOSPES W, VAN DEN HEUVEL E, TAXIS K. (2012) The effect of a multifaceted educational intervention on medication preparation and administration errors in neonatal care. Archives of Disease in Childhood Fetal Neonatal Edition 97 (6), F449 - F455.

CHOONARA I. (2009) Children's medicines-a global problem. Archives of Disease in Childhood 94, 467.

CHUA S, HUI M, OMAR A. (2010) Drug administration errors in paediatric wards: a direct observation approach. European Journal of Pediatrics 169 (5), 603-611.

CIMINO M, KIRSCHBAUM M, BRODSKY L, SHAHA S. (2004) Assessing medication prescribing errors in pediatric intensive care units. Pediatric Critical Care Medicine 5, $124-132$.

COHEN M. (2007) Medication errors. Five flaws in drug delivery. Nursing 37 (9), 10. 
COLPAERT K, CLAUS B, SOMERS A, VANDEWOUDE $K$, ROBAYS $H$, DECRUYENAERE J. (2006) Impact of computerized physician order entry on medication prescription errors in the intensive care unit: a controlled cross-sectional trial. Critical Care 10, R21.

CONDREN M, STUDEBAKER I, JOHN B. (2009) Prescribing errors in Pediatric clinic. Clinical Pediatrics 49, 49-53.

CONROY S. (2011) Association between licence status and medication errors. Archives of Disease in Childhood 96, $305-306$.

CONROY S, APPLEBY K, BOSTOCK D, UNSWORTH V, COUSINS D. (2007a) Medication errors in a children's hospital. Paediatric and Perinatal Drug Therapy 8 , $1,18-25$.

CONROY S, CHOONARA I, IMPICCIATORE P, MOHN A, ARNELL H, RANE A, KNOEPPEL C, SEYBERTH H, PANDOLFINI C, RAFFAELLI M. (2000) Survey of unlicensed and off label drug use in paediatric wards in European countries. British Medical Journal 320, $79-82$.

CONROY S, DAVAR Z, JONES S. (2012) Use of checking systems in medicines administration with children and young people. Nursing Children and Young People $24,3,20-24$.

CONROY S, NORTH C, FOX T, HAINES L, PLANNER C, ERSKINE P, WONG I, SAMMONS H. (2008) Educational interventions to reduce prescribing errors. Archives of Disease in Childhood 93, 313 - 315.

CONROY S, SWEIS D, PLANNER C, YEUNG V, COLLIER J, HAINES L, WONG I. (2007b) Interventions to reduce dosing errors in children: a systematic review of the literature. Drug Safety 30, 1111 - 1125. 
COOKE G. (2004) Involving children in planning healthcare: the Derby experience. Paediatrics and Child Health Home 14, 246 - 251.

COUSINS D, CLARKSON A, CONROY S, CHOONARA I. (2002) Medication errors in children - An eight year review using press reports. Paediatric and Perinatal Drug Therapy 5, 52 - 58.

DAVIS L, WARE R, McCANN D, KEOGH S, WATSON K. (2010) Factors influencing paediatric nurses' responses to medication administration. Quality and Safety in Health Care 19, 1 - 3.

DEAN B. (1999) Errors in medication administration. Intensive Care Medicine 25, 341-342.

DEAN B, ALLAN E, BARBER N, BARKER K (1995) Comparison of medication errors in an American and a British hospitals. American journal of health-system pharmacy 52, $2543-2549$.

DEAN B, BARBER N. (2001) Validity and reliability of observational methods for studying medication administration errors. American Journal of Health System Pharmacy 58,1, 54 - 59.

DEAN B, BARBER N, SCHACHTER M. (2000) What is a prescribing error? Quality in Health Care 9, 232 - 237.

DEAN B, SCHACHTER M, VINCENT C, BARBER N (2002) Prescribing errors in hospital inpatients: their incidence and clinical significance. Quality and Safety in Health Care 11, 340 - 344.

DEPARTMENT OF HEALTH (2004) Building a safer NHS for Patients: Improving Medication Safety. London UK. 
DIBBI H, ALABRASHY H, HUSSAIN W, FATANI M, KARIMA T. (2006) Causes and outcome of medication errors in hospitalized patients. Saudi Medical Journal 27, $1489-1492$.

DICKINSON A, MCCALL E, TWOMEY B, JAMES N. (2010) Paediatric nurses' understanding of the process and procedure of double-checking medications. Journal of Clinical Nursing 19, 728 - 735.

DONYAI P, O'GRADY K, JACKLIN A, BARBER N, FRANKLIN B. (2008) The effects of electronic prescribing on the quality of prescribing. British Journal of Clinical Pharmacology 65, 230-237.

DOWDELL E. (2004) Pediatric medical errors part 1: A pediatric drug overdose case. Pediatric Nursing 30, 4, $328-330$.

DRACH-ZAHAVY A, PUD D. (2010) Learning mechanisms to limit medication administration errors. Journal of Advanced Nursing 66, 794 - 805.

DUGGAN L, KRON T, HOWLETT S, SKOV A, O'BRIEN P. (1997) An independent check of treatment plan, prescription and dose calculation as a QA procedure. Radiotherapy and Oncology 42, 3, 297 - 301.

ELNOUR A, ELLAHHAM N, ALQASSAS H. (2008) Raising the awareness of inpatient nursing staff about medication errors. Pharmacy World and Science 30, 182-190.

EVLEY R, RUSSELL J, MATHEW D, HALL R, GEMMELL L, MAHAJAN R. (2010) Confirming the drugs administered during anaesthesia: a feasibility study in the pilot National Health Service sites, UK. British Journal of Anaesthesia 105, 289 - 296. 
FAHIMI F, ARIAPANAH P, FAIZI M, SHAFAGHI B, NAMDAR R, ARDAKANI M. (2008) Errors in preparation and administration of intravenous medications in the intensive care unit of a teaching hospital: an observational study. Australian Critical Care 21, $110-116$.

FAHIMI $F$, ABBASI NAZARI M, ABRISHAMI R, SISTANIZAD M, MAZIDI T, FAGHIHI T, SOLTANI R, BANIASADI S. (2009) Transcription errors observed in a teaching hospital. Archives of Iranian Medicine 12, $173-175$.

FERNER R, ARONSON J. (2006) Clarification of terminology in medication errors: definitions and classification. Drug Safety 29, 1011-22.

FLYNN E, BARKER K, PEPPER G, BATES D, MIKEAL R. (2002) Comparison of methods for detecting medication errors in 36 hospitals and skilled-nursing facilities. American Journal of Health-System Pharmacy 59, 436 - 446.

FOLLI H, POOLE R, BENITZ W, RUSSO J. (1987) Medication error prevention by clinical pharmacists in two children's hospitals. Pediatrics 79, 718 - 722

FORTESCUE $E$, KAUSHAL R, LANDRIGAN C, MCKENNA $K$, CLAPP $M$, FEDERICO F, GOLDMANN D, BATES D, (2003) Prioritizing strategies for preventing medication errors and adverse drug events in pediatric inpatients. Pediatrics, 111, 722 - 729

FOUSHEE H. (1984) Dyads and triads at 35,000 feet: Factors affecting group process and aircrew performance. American Psychologist, 39, 885 - 893.

FRANKLIN B, O'GRADY K, DONYAI P, JACKLIN A, BARBER N. (2007) The impact of a closed-loop electronic prescribing and administration system on prescribing errors, administration errors and staff-time: a before - and - after study. Quality and Safety in Health Care 16, 4, 279 - 284. 
FRANKLIN B, VINCENT C, SCHACHTER M, BARBER N. (2005) The incidence of prescribing errors in hospital inpatients: an overview of the research methods. Drug Safety 28, 891-900.

FRY M, DACEY C. (2007) Factors contributing to incidents in medicine administration. Part 2. British Journal of Nursing 16, 11, $676-681$.

GABA D. (2004) The future vision of simulation in health care. Quality and Safety of Health Care 13 (Suppl 1), i2 - i10.

GANDHI T, BARTEL S, SHULMAN L, VERRIER D, BURDICK E, CLEARY A, ROTHSCHILD J, LEAPE L, BATES D. (2005) Medication safety in the ambulatory chemotherapy setting. Cancer 104, 2477 - 2483.

GHALEB M, BARBER N, FRANKLIN B, WONG I. (2010) The incidence and nature of prescribing and medication administration errors in paediatric inpatients. Archives of Disease in Childhood 95, $113-118$.

GHALEB M, BARBER N, FRANKLIN B, YEUNG V, KHAKI Z, WONG, I. (2006) Systematic review of medication errors in pediatric patients. Annals of Pharmacotherapy 40, 1766-76.

GLOVER M, SUSSMANE J. (2002) Assessing pediatrics residents' mathematical skills for prescribing medication: a need for improved training. Academic Medicine $77,1007-1010$

GREENGOLD N, SHANE R, SCHNEIDER P, FLYNN E, ELASHOFF J, HOYING C, BARKER K, BOLTON L. (2003) The impact of dedicated medication nurses on the medication administration error rate: a randomized controlled trial. Archives of Internal Medicine 163, 2359 - 2367. 
GRISSINGER M. (2003) The virtues of independent double checks: they really are worth your time! Institute for Safe Medication Practices Medication Safety Alert March 8, 5,1.

HALES B, PRONOVOST P. (2006) The checklist - a tool for error management and performance improvement. Journal of Critical Care, 21, 231-235.

HASSAN H, DAS S, SE H, DAMICA K, LETCHIMI S, MAT S, PACKIAVATHY R, ZULKIFLI S. (2009) A study on nurses' perception on the medication error at one of the hospitals in East Malaysia. La Clinica Terapeutica 160, 477 - 479.

HEATON A, WEBB D, MAXWELL S. (2008) Undergraduate preparation for prescribing: the views of 2413 UK medical students and recent graduates. British Journal of Clinical Pharmacology 66, 128-34.

HODGKINSON B, KOCH S, NAY R, NICHOLS K. (2006) Strategies to reduce medication errors with reference to older adults. International Journal of EvidenceBased Healthcare 4, 2-41.

HOLDSWORTH M, FICHTL R, BEHTA M, RAISCH D, MENDEZ-RICO E, ADAMS A, GREIFER M, BOSTWICK S, GREENWALD B. (2003). Incidence and impact of adverse drug events in pediatric inpatients. Archives of Pediatrics and Adolescent Medicine 157, 60 - 65 .

HOOPER R, ADAM A, KHEIR N. (2009) Pharmacist-documented interventions during the dispensing process in a primary health care facility in Qatar. Drug Health Care and Patient Safety 1, $73-80$.

HUGHES R, EDGERTON E. (2005) Reducing pediatric medication errors: children are especially at risk for medication errors. American Journal of Nursing 105, 79-80, $82,85$. 
INSTITUTE FOR SAFETY MEDICATION PRACTICES (ISMP) (2005) Lowering the risk of medication errors: independent safety checks. ISMP Canada Safety Bulletin 5.

INSTITUTE OF MEDICINE (IOM) (2001) Crossing the quality chasm: A new health system for the $21^{\text {st }}$ Century, Washington DC.

INTERNATIONAL DIABETES FEDERATION (IDF) (2009) Diabetes Atlas, 4th edition. Brussels, Belgium: International Diabetes Federation.

http://www.idf.org/sites/default/files/The_Global_Burden.pdf), (accessed 10 June 2013).

INTERNATIONAL NUCLEAR SAFETY ADVISORY GROUP (INSAG) (1991) Basic safety principle for nuclear power plants, safety series No 75-INSAG-3, IAEA, Vienna. http://www-

pub.iaea.org/MTCD/publications/PDF/Pub882_web.pdf,(accessed 10 June 2013).

IRSHAID Y, ALHOMRANI M, HAMDI A, ADJEPON-YAMORAH K, MAHFOUZ A. (2005) Compliance with good practice in prescription writing at outpatient clinics in Saudi Arabia. Eastern Mediterranean Health Journal 11, 922 - 928.

ISLAMIAN J, TAHERI F, BAHRAMI M, MOJDEH S. (2010) Assessing the nursing error rate and related factors from the view of nursing staff. Iran Journal of Nursing and Midwifery Research 15, 272 - 277.

JARMAN H, JACOBS E, ZIELINKSI V. (2002) Medication study supports registered nurses' competence for single checking. International Journal of Nursing Practice 8, $330-335$. 
JENSEN L, MERRY A, WEBSTER C, WELLER J, LARSSON L. (2004) Evidence based strategies for preventing drug administration errors during anaesthesia. Anaesthesia 59, 493 - 504.

JIMENEZ MUNIOZ A, MIGUEZ A, PEREZ M, ESCRIBANO M, GARCIA M, SAEZ M. (2010) Medication error prevalence. International Journal of Health Care Quality Assurance 23, 328 - 338.

JONES J, TREIBER L. (2010) When the 5 rights go wrong: medication errors from the nursing perspective. Journal of Nursing Care Quality 25, 3, 240 - 247.

JOOLAEE S, HAJIBABAEE F, PEYROVI H, HAGHANI H, BAHRANI N. (2011) The relationship between incidence and report of medication errors and working conditions. International Nursing Review 58, 37 - 44.

KADMON G, BRON-HARLEY E, NAHUM E, SCHILLER O, HASKI G, SHONFELD T. (2009) Computerized order entry with limited decision support to prevent prescription errors in a PICU. Pediatrics 124, 935 - 940.

KARADENIZ G, ÇAKMAKÇI A. (2002) Nurses' perceptions of medication errors. International Journal of Clinical Pharmacology Research 22, 111 - 116.

KAUSHAL R, BATES D, ABRAMSON E, SOUKUP J, GOLDMANN D. (2008) Unitbased clinical pharmacists' prevention of serious medication errors in pediatric inpatients. American Journal of Health-System Pharmacy 65, 1254 - 1260.

KAUSHAL R, BATES D, LANDRIGAN C, MCKENNA K, CLAPP M, FEDERICO F, GOLDMANN D. (2001a) Medication errors and adverse drug events in pediatric inpatients. Journal of American Medical Association 285, 2114 - 2120. 
KAUSHAL R, BARKER K, BATES D. (2001b). How can information technology improve patient safety and reduce medication errors in children's health care? Archives of Pediatrics and Adolescent Medicine 155, 1002 - 1007.

KAZEMI A, ELLENIUS J, POURASGHAR F, TOFIGHI S, SALEHI A, AMANATI A, FORS U. (2011) The effect of computerized physician order entry and decision support system on medication errors in the neonatal ward: Experiences from an Iranian Teaching hospital. Journal of Medical Systems 35, 25 - 37.

KAZEMI A, FORS U, TOFIGHI S, TESSMA M, ELLENIUS J. (2010) Physician Order Entry Or Nurse Order Entry? Comparison of Two Implementation Strategies for a Computerized Order Entry System Aimed at Reducing Dising Medication Errors. Journal of Medical Internet Research 12, e5.

KHAJA K, SEQUEIRA R, ALANSARI T, DAMANHORI A. (2008) Prescription writing skills of residents in a family practice residency programme in Bahrain. Postgraduate Medical Journal 84, 198 - 204.

KHALILI H, FARSAEI S, REZAEE H, DASHTI-KHAVIDAKI S. (2011) Role of clinical pharmacists' interventions in detection and prevention of medication errors in a medical ward. International Journal of Clinical Pharmacy 33, 281 - 284.

KHOJA T, NEYAZ Y, QURESHI N, MAGZOUB M, HAYCOX A, WALLEY T. (2011) Medication errors in primary care in Riyadh city, Saudi Arabia. Eastern Mediterranean health journal 17, $156 \cdot 159$.

KIM K, KWON S, KIM J, CHO S. (2011) Nurses' perception of medication errors and their contributing factors in South Korea. Journal of Nursing Management 19, 346-353. 
KING R. (2004) Nurses' perception of their pharmacology educational needs. Journal of Advanced Nursing 45, $392-400$.

KING W, PAICE N, RANGREJ J, FORESTELL G, SWARTZ R. (2003) The effect of computerized physician order entry on medication errors and adverse drug events in pediatric inpatients. Pediatrics, 112, $506-509$.

KOHLER J \& BAGHDADI-SABETI G. (2011) The World Medicines Situation Report. Washington DC, 2011.

KOHN L, CORRIGAN J, DONALDSON M. (2000) To Err Is Human: Building a Safer Health System. A report of the Committee on Quality of Health Care in America, Institute of Medicine. Washington, DC: National Academy Press, 2000.

KOOHESTANI H, BAGHCHEGHI N. (2008) Investigation medication errors of nursing students in cardiac care unit. Scientific Journal of Forensic Medicine 13, $249-255$.

KOOHESTANI H, BAGHCHEGHI N. (2009) Barriers to the reporting of medication administration errors among nursing students. Australian Journal of Advanced Nursing 27, $66-74$.

KOOHESTANI H, BAGHCHEGHI N, KHOSRAVI S. (2008) Frequency, type and causes of medication errors in student nurses. Iran Journal of Nursing 21, 17 - 27.

KOREN G, BARZILAY Z, GREENWALD M. (1986) Tenfold errors in administration of drug doses: a neglected iatrogenic disease in pediatrics. Pediatrics $77,848-849$.

KOREN G, REICH A, HALES B. (1991) The role of clinical pharmacists in preventing potentially fatal ten-fold medication errors in children. Journal of Pharmacy Technology 7, 219 - 221.

KOZER E. (2009) Medication errors in children. Paediatric Drugs 11, 52 - 54. 
KOZER E, SCOLNIK D, KEAYS T, SHI K, LUK T, KOREN G. (2002) Large errors in the dosing of medications for children. New England Journal of Medicine 346, 11751176.

KRUSE H, JOHNSON A, O'CONNELL D, CLARKE T. (1992) Administering nonrestricted medications in hospital: the implications and cost of using two nurses. Australian Clinical Review 12, 77 - 83.

LÄER S, MEIBOHM B. (2011) Study design and simulation approach. Handbook of Experimental Pharmacology 205, 125- 148.

LEAPE L, BATES D, CULLEN D, COOPER J, DEMONACO H, GALLIVAM T, HALLISEY R, IVES J, LAIRD N, LAFFEL G. (1995) System analysis of adverse drug events. Journal of the American Medical Association 274(1), 35 - 43.

LEAPE L, CULLEN D, CLAPP M, BURDICK E, DEMONACO $\mathrm{H}$, ERICKSON J, BATES D. (1999) Pharmacist participation on physician rounds and adverse drug events in the intensive care unit. Journal of the American Medical Association 282, $267-270$.

LEHMANN C, KIM G. (2005) Prevention of medication errors. Clinics Perinatology $32,107-123$.

LESAR T, BRICEHLAND L, DELCOURE K, PARMALEE J, MASTA-GORNIC V, POHL H. (1990) Medication prescribing errors in a teaching hospital. Journal of the American Medical Association 263, 2329 - 2334.

LESAR T, BRICELAND L, STEIN D. (1997) Factors related to errors in medication prescribing. Journal of the American Medical Association 277, 312 -317. 
LEUNG S, CHONG S, ARTHUR D. (2007) Reducing Medication Errors: Development of A New Model of Drug Administration for Enhancing Safe Nursing Practice. Asian Journal of Nursing 10, 191 - 199.

LEWIS P, DORNAN T, TAYLOR D, TULLY M, WASS V, ASHCROFT D. (2009) Prevalence, incidence and nature of prescribing errors in hospital inpatients: a systematic review. Drug Safety 32, 379 - 389.

LIFSHITZ A, GOLDSTEIN L, SHARIST M, STRUGO R, ASULIN E, BARHAIM S, FEIGENBERG Z, BERKONITCH M, KOZER E. (2012) Medication prescribing errors in the prehospital setting and in the ED. American journal of emergency medicine 30, $5,726-731$.

LIPSON J, MELEIS A. (1983) Issues in health care of Middle Eastern patients. Western Journal of Medicine 139, $854-861$.

LISBY M, NIELSEN L, MAINZ J. (2005) Errors in the medication process: frequency, type, and potential clinical consequences. International Journal for Quality and Health Care 17, 15 - 22.

LUSTIG A. (2000) Medication error prevention by pharmacists - An Israeli solution. Pharmacy World Science 22, 21 - 25.

MAGZOUB M, NEYAZ Y, KHOJA T, QURESHI N, HAYCOX A, WALLEY T. (2011) Determinants of physicians' medication prescribing behaviour in primary care in Riyadh city, Saudi Arabia. Eastern Mediterranean Health Journal 17,160 - 166.

MAHAJAN R, MATHEWS L, RUSSELL J, GEMMELL L. (2009) 'Wrong drug' errors during anaesthesia as reported to the National Reporting and Learning System in the UK. European Journal of Anaesthesiology 26, 17AP1 - AP17. 
MAHONEY C, BERARD-COLLINS C, COLEMAN R, AMARAL J, COTTER C. (2007) Effects of an integrated clinical information system on medication safety in a multihospital setting. American Journal of Health-System Pharmacy 64, 1969 - 1977.

MANIAS E, AITKEN R, DUNNING T. (2004) Decision-making models used by 'graduate nurses' managing patients' medications. Journal of Advanced Nursing 47, $270-278$

MANIAS E, AITKEN R, DUNNING T. (2005) How graduate nurses use protocols to manage patients' medications. Journal of Clinical Nursing 14, 935 - 944.

MAYO A, DUNCAN D. (2004) Nurse perceptions of medication errors: what we need to know for patient safety. Journal of Nursing Care Quality 19, 209-217.

MCINTYRE J, CONROY S, AVERY A, CORNS H, CHOONARA I. (2000) Unlicensed and off label prescribing of drugs in general practice. Archives of Disease in Childhood 83, 498 - 501.

MERRY A, WEBSTER C. (2008) Medication error in New Zealand - time to act. New Zealand Medical Journal 121, 6 - 9.

MILLER M, ROBINSON K, LUBOMSKI L, RINKE M, PRONOVOST P. (2007) Medication errors in paediatric care: a systematic review of epidemiology and an evaluation of evidence supporting reduction strategy recommendations. Quality and Safety in Health Care 16, 116 - 126.

MRAYYAN M, SHISHANI K, ALFAOURI I. (2007) Rate, causes and reporting of medication errors in Jordan: nurses' perspectives. Journal of Nursing Management $15,659-670$.

NAHATA M. (1988) Paediatric drug therapy II - drug administration errors. Journal of Clinical Pharmacology \& Therapeutic 13, 6, 399 - 402. 
NATIONAL PATIENT SAFETY AGENCY (2007a) The fourth report from the patient safety observatory. Safety in Doses: medication safety incidents in the NHS. Patient safety observational report. London: NPSA.

NATIONAL PATIENT SAFETY AGENCY (2007b) Safety in Doses: Medication Safety Incidents in the NHS. London: NPSA.

NATIONAL PATIENT SAFETY AGENCY (2009). The report from the patient safety observatory. Safety in Doses: Improving the use of medicines in the NHS. London: NPSA.

NAYLOR R (2002) Medication errors: Lessons for education and healthcare. Chapter 9 (Errors in health care: a major cause for concern), pp281. Radcliffe Medical Press, 2002.

NEYAZ Y, KHOJA T, QURESHI N, MAGZOUB M, HAYCOX A, WALLEY T. (2011) Predictors of quality of medication prescribing in primary care in Riyadh city, Saudi Arabai. Eastern Mediterranean Health Journal 17, 167 - 171.

NIXON P, DHILLON S. (1996) Medication errors in paediatrics. Progress in Practice: UKCPA Autumn Symposium 18-19.

O'BRODOVICH M, RAPPAPORT P. (1991) A study pre and post unit dose conversion in a pediatric hospital. Canadian Journal of Hospital Pharmacy 44, 1, 5 15,50 .

O'CONNELL B, CRAWFORD S, TULL A, GASKIN C. (2007) Nurses' attitudes to single checking medications: Before and after its use. International Journal of Nursing Practice 13, 377 - 382.

O'SHEA E. (1999) Factors contributing to medication errors: a literature review. Journal of Clinical Nursing 8, 5, 496 - 504. 
OLIVEN A, MICHALAKE I, ZALMAN D, DORMAN E, YESHURUN D, ODEH M. (2005) Prevention of prescription errors by computerized, on-line surveillance of drug order entry. International Journal of Medical Informatics 74, 377 - 386.

OLIVEN A, ZALMAN D, SHILANKOV Y, YESHURUN D, ODEH M. (2002) Prevention of prescription errors by computerized, on-line, individual patient related surveillance of drug order entry. Studies in health technology and informatics 90 , $632-634$

OSBORNE J, BLAIS K, HAYES J. (1999) Nurses' perceptions: when is it a medication error? Journal of Nursing Administration 29, 33 - 38.

OTERO P, LEYTON A, MARIANI G, CERLANI CERNADAS J. (2008) Medication errors in pediatric inpatients: prevalence and results of a prevention program. Pediatrics 122, e737 - e743.

PAPE T. (2001) Searching for the final answer: factors contributing to medication administration errors. Journal of Continuing Education in Nursing 32, 152 - 160.

PAULY - O'NEIL S. (2009) Beyond the five rights: improving patient safety in pediatric medication administration through simulation. Clinical Simulation in Nursing 5, e181 - e186.

PEPPER G. (1995) Errors in drug administration by nurses. American Journal of Health - System Pharmacists 52, $390-395$.

PETROVA E, BALDACCHINO D, CAMILLERI M. (2010) Nurses' perceptions of medication errors in Malta. Nursing Standard 24, $41-48$. 
PHARMACEUTICAL DRUG MANUFACTURES (2010) Pharmaceutical Market

Trends 2010/2011. Available on this URL (http://www.pharmaceutical-drug manufacturers.com/articles/pharmaceutical-market-trends-2010.html(accessed October 2011).

PHILLIPS D, CHRISTENFELD N, GLYNN L. (1998) Increase in US medication error deaths between 1983 - 1993. Lancet 351, 643-644.

POON E, CINA J, CHURCHILL W, PATEL N, FEATHERSTONE E, ROTHSCHILD J, KEOHANE C, WHITTEMORE A, BATES D, GANDHI T. (2006) Medication dispensing errors and potential adverse drug events before and after implementing bar code technology in the pharmacy. Annals of Internal Medicine 145, $426-434$.

POTTS A, BARR F, GREGORY D, WRIGHT L, PATEL N. (2004) Computerized physician order entry and medication errors in a pediatric critical care unit. Pediatrics; 113, 59 - 63.

PROT S, FONTAN J, ALBERTI C, BOURDON O, FARNOUX C, MACHER M, FOUREAU A, FAYE A, BEAUFILS F, GOTTOT S, BRION F. (2005) Drug administration errors and their determinants in pediatric in-patients. International Journal for Quality in Health Care 17, 5, 381 - 389.

QURESHI N, NEYAZ Y, KHOJA T, MAGZOUB M, HAYCOX A, WALLEY T. (2011) Effectiveness of three interventions on primary care physicians' medication prescribing in Riyadh city, Saudi Arabia. Eastern Mediterranean Health Journal 17, $172-179$.

RAJA L, BOO N, ROHANA J, CHEAH F. (2009) A quality assurance study on the administration of medication by nurses in a neonatal intensive care unit. Singapore Medical Journal 50(1), $68-72$. 
RAJU T, KECSKES S, THORNTON J, PERRY M, FELDMAN S. (1989) Medication errors in neonatal and paediatric intensive-care units. Lancet 334 (8659), $374-376$.

RECKMANN M, WESTBROOK J, KOH Y, LO C, DAY R. (2009) Does computerized provider order entry reduce prescribing errors for hospital inpatients? A systematic review. Journal of the American Medical Informatics Association 16, 613-623.

ROSS L, WALLACE J, PATON J, STEPHENSON T. (2000) Medication errors in a paediatric teaching hospital in the UK: five years operational experience. Archives of Disease in Childhood 83, $492-497$.

ROWE C, KOREN T, KOREN G. (1998) Errors by paediatric residents in calculating drug doses. Archives of Disease in Childhood 79, 56 - 58.

SAAB Y, HACHEM A, SINNO S, EL-MOALEM H. (2006) Inappropriate medication use in elderly Lebanese outpatients: prevalence and risk factors. Drug Aging 23, $743-752$.

SABRY N, FARID S, AZIZ E. (2009) Role of the pharmacists in identification of medication related problems in the ICU: a preliminary screening study in an Egyptian Teaching Hospital. Australian Journal of Basic and Applied Science 3, $995-1003$.

SADAT-ALI M, ALSHAFEI B, ALTURKI R, AHMED S, ALABBAS S, ALOMRAN A. (2010) Medication administration errors in Eastern Saudi Arabia. Saudi Medical Journal 31, 1257 - 1259.

SAMMONS H, CONROY S. (2008) How do we ensure safe prescribing for children? Archives of Disease in Childhood 93, 98 - 99. 
SANGHERA N, CHAN P, KHAKI Z, PLANNER C, LEE K, CRANSWICK N, WONG I. (2006) Interventions of hospital pharmacists in improving drug therapy in children: a systematic literature review. Drug Safety 29, 1031 - 1047.

SCHNEIDER M, COTTING J, PANNATIER A. (1998) Evaluation of nurses' errors associated in the preparation and administration of medication in a pediatric intensive care unit. Pharmacy World and Science 20, 4, 178 - 182.

SCOTT H. (2002) Increasing number of patients are being given wrong drugs. British Journal of Nursing 11, 4.

SHEU S-J, WEI I-L, CHEN C-H, YU S, TANG F-I. (2008) Using snowball sampling method with nurses to understand medication administration errors. Journal of Clinical Nursing 18, $559-569$.

SHULMAN R, SINGER M, GOLDSTONE J, BELLINGAN G. (2005) Medication errors: a prospective cohort study of hand-written and computerised physician order entry in the intensive care unit. Critical Care 9, R516 - R521.

SIMPSON J, LYNCH R, GRANT J, ALROOMI L. (2004) Reducing medication errors in the neonatal intensive care unit. Archives of Disease in Childhood Fetal Neonatal Edition 89 (6), F480 - F482.

SIMPSON N. (2001) Advocacy White Paper: Bar Coding for Patient Safety. Healthcare Information and Management Systems Society. (http://www.idshealthcare.com/Common/Paper/Paper_69/himms_barcoding.pdf (accessed 10 June 2013).

STAVROUDIS T, MILLER M, LEHMANN C. (2008) Medication errors in Neonates. Clinics in Perinatology 35, $141-161$. 
STEBBING C, WONG I, KAUSHAL R, JAFFE A. (2007) The role of communication in paediatric drug safety. Archives of Disease in Childhood 92, 440 - 445.

STEPHENSON T. (2000) Commentary: medication errors in a pediatric teaching hospital in the UK: five year operational experience. Archives of Disease in Childhood 83, 497.

STRATTON K, BLEGEN M, PEPPER G, VAUGHN T. (2004) Reporting of medication errors by pediatric nurses. Journal of Pediatric Nursing 19, $385-392$.

SWEILEH W, JANEM S, SAWALHA A, ABU-TAHA A, ZYOUD S, SABRI I. (2007) Medication dosing errors in hospitalized patients with renal impairment: a study in Palestine. Pharmacoepideiology and Drug Safety 16, 908 - 912.

TAM V, KNOWLES S, CORNISH P. (2005) Frequency, Type and Clinical Importance of Medication History Errors at Admission to Hospital: A Systematic Review. Canadian Medical Association Journal 173, 510 - 15.

TANG F-I, SHEU S-J, YU S, WEI I-L, CHEN C-H. (2007) Nurses relate the contributing factors involved in medication errors. Journal of Clinical Nursing 16, 447-457.

TAYLOR J, LOAN L, KAMARA J, BLACKBURN S, WHITNEY D. (2008) Medication administration variances before and after implementation of computerized physician order entry in a neonatal intensive care unit. Pediatrics 121, 123-128.

TISSOT E, CORNETTE C, LIMAT S, MOURAND J, BECKER M, ETIEVENT J, DUPOND J, JACQUET M, WORONOFF-LIMIS M. (2003) Observational study of potential risk factors of medication administration errors. Pharmacy World \& Science $25,6,264-268$. 
TOFT B, MASCIE-TAYLOR H. (2005) Involuntary automaticity: a work-system induced risk to safe health care. Health Services Management Research 18, 211 216.

TURNER S, LONGWORTH A, NUNN A, CHOONARA I. (1998) Unlicensed and off label drug use in paediatric wards: prospective study. British Medical Journal 316, $343-345$

U D. (2003) Double-checking: does it work? Medication safety alerts. Canadian Journal of Hospital Pharmacy 56, 167 - 169.

UNITED NATIONS. World population prospects: The 2010 Revision. New York: United Nations, 2010

VAIDYA V, SOWAN A, MILLS M, SOEKEN K, GAFFOOR M, HILMAS E. (2006) Evaluating the safety and efficiency of a CPOE system for continuous medication infusions in a pediatric ICU. AMIA, Annual Symposium Proceedings Archive 1128.

VAKNIN O, WINGART-EMEREL E, STERN Z. (2003) The quality of medication orders: Can it be improved? Harefuah 2003, 42, 490-494.

VALIZADEH F, GHASEMI S, NAGAFI S, DELFAN B, MOHSENZADEH A. (2008) Errors in medication orders and the nursing staff's reports in medical notes of children. Iranian Journal of Pediatrics 18, 33 - 40.

VARDI A, EFRATI O, LEVIN L, MATOK I, RUBINSTEIN M, PARET G, BARZILAY Z. (2007) Prevention of potential errors in resuscitation medications orders by means of a computerised physician order entry in paediatric critical care. Resuscitation 73, $400-406$.

VESSAL G. (2010) Detection of prescription errors by a unit-based clinical pharmacist in a nephrology ward. Pharmacy World and Science 32, 59 - 65. 
VINCER M, MURRAY J, YUILL A, ALLEN A, EVANS J, STINSON D. (1989) Drug error and incidents in a neonatal intensive care unit: a quality assurance activity. American Journal of Diseases of Children $143(6), 737-740$.

WAKEFIELD D, WAKEFIELD P, UDEN-HOLMAN T, BLEGEN M. (1998) Nurses' perceptions of why medication administration errors occur. Journal of the Academy of Medical-Surgical Nurses 7,1, $39-44$.

WESTBROOK J, WOODS A, ROB M, DUNSMUIR W, DAY R. (2010) Association of interruptions with an increased risk and severity of medication administration errors. Archives of Internal Medicine 170, 8, 683 - 690.

WHITE R, TRBOVICH P, EASTY A, SAVAGE P, TRIP K, HYLANDS S. (2010) Checking it twice: an evaluation of checklists for detecting medication errors at the bedside using a chemotherapy model. Quality \& Safety in Health Care 19, 6, 562567.

WORLD HEALTH ORGANIZATION (WHO) (2007) Make medicines child size (www.who.int/childmedicines/en) (accessed 10 June 2013).

WILSON D, MCARTNEY R, NEWCOMBE R, MCARTNEY R, GRACIE J, KIRK C, STUART A. (1998) Medication errors in paediatric practice: insights from a continuous quality improvement approach. European Journal of Pediatrics, 157, 769 $-774$.

WINSON G. (1991) A survey of nurses' attitudes towards single administration of medicines. Nursing Practice 4, 20 - 23.

WIRTZ V, BARBER N, TAXIS K. (2003) An observational study of intravenous medication errors in the United Kingdom and in Germany. Pharmacy World and Science 25, $104-111$. 
WONG I, CONROY S, COLLIER J. (2007) Co-operative of safety of medicines in children (COSMIC): Scoping study to identify and analyse interventions used to reduce errors in calculation of paediatric drug. Report to the Patient Safety Research Programme (Policy Research Programme of the Department of Health), October

2007.www.haps.bham.ac.uk/publichealth/psrp/documents/PS026_COSMIC_Final_ Rep ort.pdf (accessed 22/07/11)

WONG I, GHALEB M, FRANKLIN B. BARBER N. (2004) Incidence and nature of dosing errors in paediatric medication: A systematic review. Drug Safety 27, 661 670.

WONG I, WONG L, CRANSWICK N. (2009) Minimising medication errors in children. Archives of Disease in Childhood 94, $161-164$.

WORLD BANK. (2007) World Development Indicators 2007, Washington DC. The World Bank. 
APPENDICES 


\section{APPENDIX A}




\section{DERBY HOSPITALS NHS FOUNDATION TRUST}

\section{LETTER OF AUTHORISATION}

This Statement and its appendices sel out the particulars of the Honorary Appointment of Zayad Alsulami with the Derby Hospitals NHS Foundation Trust for a placement in the Children's Hospltal as a PhD Student from 23/4/12 to 31/12/13.

The terms of this appointment are as follows:

1. There is no Contract of Employment or Employer/Employee relationship between the Trust and yourseif.

2. You will not receive any salary from the Trust whilst undertaking the Honorary Appointment.

3. You are requested to respect the guidance and directions given by the Specialist Support Servlies Divislon dusing itic ienwie of your Hultorary Appuintmerl.

4. It is a condition of your appointment that you will submrt, at any reasonable time, to a medical examination by a medical practilioner nominated by the Derty Hospitals NHS Foundation Trust.

5. You must at all times observe Trust rules and regulations in relation to Fire. Health and Safety and Security.

6. Should you be involved in an accident during your Honorary Appointment with the Trust then you must report this to the Specialist Support Services Division An official record must be made in the DivisionDepartment Aocident Book where the accident occurred and a Staff Accident Form must be completed. You will have the status of a voluntary worker as far as legal liability and accidents are concerned and there is no need for you to lake out any extra special insurance, unless of course you choose voluntarily to do so.

7. The Trust will not normally accept any responsibility in respect of then of. or loss or damage to, personal property. You are recommended to investigate the possibility of insuring yourself and take advantage of any facilities in the Trust which may exist for the safekeeping of property.

8. Alt staff involved in the care and treatment of patients during the course of their employment are covered by NHS indemnily for acts or omissions which amount to clinical negligence. This does not covar work which is or is deemed to be outside of their appointment including work undertaken as part of private practice, whether on Trust premises or not, or as part of personal research.

9. You are at all times expected to carry out your duties in accordance with the Trust's Policies and Procedures, agreed clinical protocols and in accordance with their professional codes of practice.

10. Any uniform, protective clothing or other ifems which may be issued to you remain the property of the Trust and must be retumed on termination of your appointment.

11. If appropriate, your appointment is subject to you being registered with your professional or appropriate statutory body and you will be required to produce evidence of your registration.

12. Members of staff should only know or possess personal data about patients or employees where their job/rale explicitly permits it. 
Personal data held on a computer may only be held or processed by a member of staff in accardance with the principles of the Data Protection Act 1998. Access to computers is strictly limited under the terms of the Computer Misuse Act 1990

You have a right and a duty under the Procedure for Dealing with Staff Concerns on Health Service Matters to make known any concerns you may have on health service activities. The Procedure enables you to raise concerns, in confidence, with Trust officers, Trade Unions, Professional Organisations. Statutory Bodies or Professional Bodies.

\section{Research Governance Framework}

The Trust supports and promoles high quality research as part of its aim to develop and Implement best practice in the delivery of care and to contribute to the national body of research designed to enhance clinical practice. Any research which you undertake as an employee of the Trust must comply with Trust policies and procedures and the Research Governance Framework and all research undertaken must be approved by an NHS Research Ethics Committee.

Finally, I would wish to emphasise to you the confidential nature of Health Service work, not only in relation to patient information which is of course strictly confidential, but also in respect of Security of information relating to members of staff, and to the business interests of the Trust of which you may become aware during the course of your Honorary Appointment with the Trust.

If you agree to accept the Honorary Appointment offered in this letter of the terms specified. please sign the attached and return one copy to Human Resources, London Road Community Hospital. The second copy is for your relention.

Yours sincerely

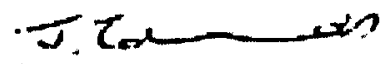

Human Resource Assistant

on behalf of the Derby Hospitals NHS Foundation Trust

Date: 9 May 2012. 


\section{DATA COLLECTION FORM}

WARD NAME (DEPARTMENT):

Patient Initial:

D.O.B:

WEIGHT:

DIAGNOSIS:

BED NO:

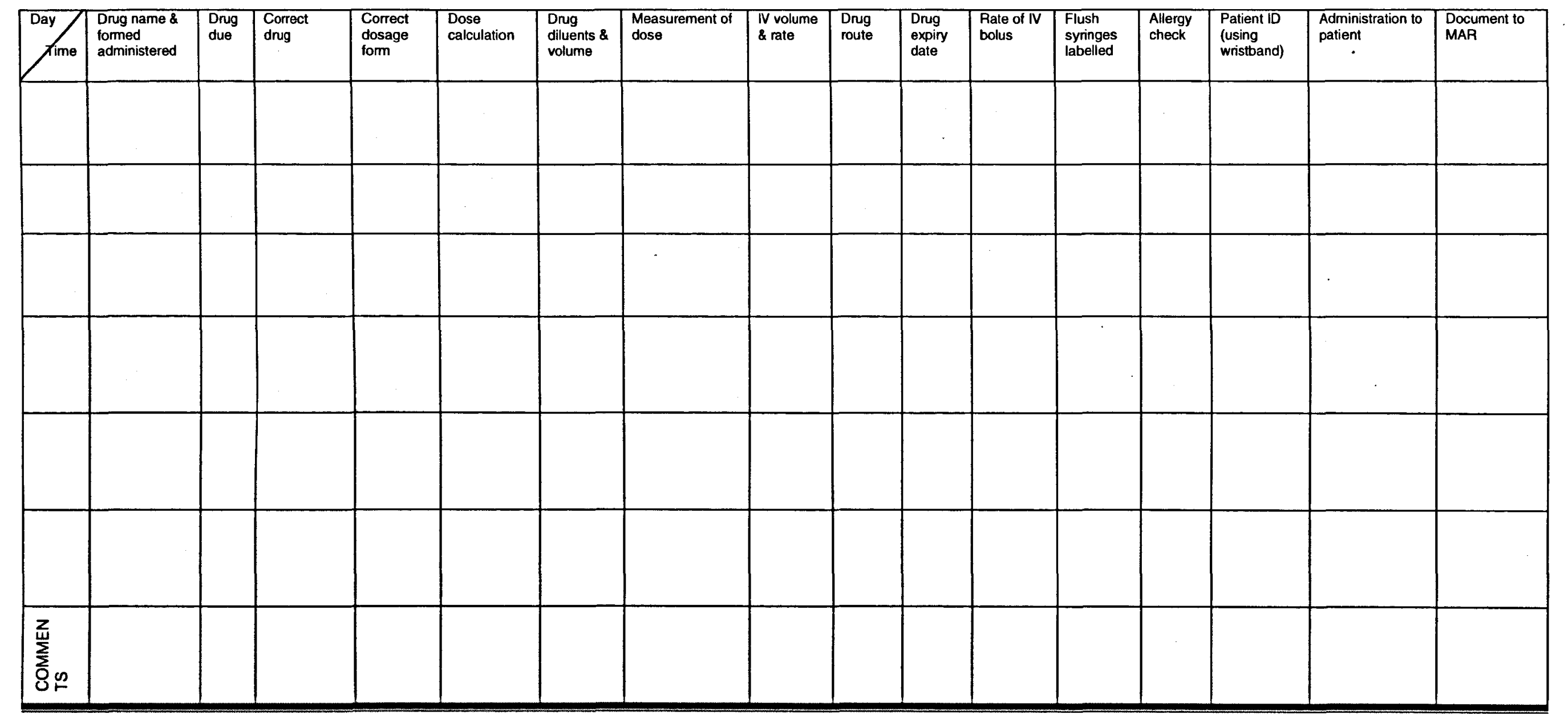

NON-CHECKED $=0$, CHECKED $=1$, NOT APPLICABLE $=2$ 


\section{Interpretation of data collection form content}

\section{Demographic information:}

Details of the patient initial, date of birth and weight should be collected by observer.

\section{Drug name \& form:}

The approved name (generic) of the selected medicine should be checked and confirmed by both nurses with the prescribed drug on the prescription chart.

\section{Drug due:}

The both nurses should be checked the frequency of the prescribed medication that the time of administration is correct including confirming where the last dose was given.

\section{Correct drug:}

The pharmacy label and all instruction or any precaution stated should be checked by both nurses.

\section{Correct dosage form:}

The dosage form for each prescribed drug should be checked with the one that is prepared for administration and its appropriateness for the patient clinical situation.

\section{Dose calculation:}

Two qualified nurses should independently calculate the drug dose that to be prepared or administered and confirming the result with each other of the prescribed drug.

\section{Measurement of dose:}

The two nurses should be prepared and checked the drug dose before administration.

\section{Drug route:}

The route of drug administration should be checked and confirmed by nurses and should be suitable for the patient situation and age.

\section{Drug expiry date:}

Check the drug expiry date before administration and that it is in acceptable condition to be considered effective.

\section{Rate of IV bolus:}

Check the drug concentration and administer correct dose at proper push rate.

\section{I.V infusion volume and rate:}


The two paediatric nurses should be checked the volume and the rate of the pump over a determined time interval for the prescribed drug.

\section{Drug diluents and volume:}

The two qualified paediatric nurses should be checked that the appropriate diluents and volume have been used according to the hospital intravenous preparation guidelines.

\section{Drug allergy:}

The patient drug or food allergy should be checked by both nurses by asking the patient himself or his parents and comparing that with what is written in medication chart

\section{Patient ID (using wristband):}

The patient name, date of birth and ID number that written on wristband should be checked by two nurses and comparing that with the information written on the medication chart

\section{Administration to the patient:}

Both nurses should be present at the patient bed to administer the medicines to the patient. When the parents want to give the medicine to their child both nurses should witness the patient when he/she take the medicine.

\section{Documentation to MAR:}

Both nurses should be document and record the drug administration information after the giving the prescribed drug and sign for each medication administration episode. 


\section{CONSENT FORM}

MEDICINES ADMINISTRATION OBSERVATION PROJECT

\section{Name of Researcher:}

Name of Parent / Care:

Please initial box

The researcher will directly observe the nurse who is going to give medication to the patient from preparation until administration. During that time the observer will be collecting data by specific data collection forms. This study will take place over four months. Also, during this study there are no discomforts or stresses and no risks on the patient.

1. I understand that participation is voluntary and that I am free to withdraw at any time, without giving any reason, and without my medical care or legal rights being affected. I understand that should I withdraw then the information collected so far cannot be erased and that this information may still be used in the project analysis.

2. I understand that data collected from this study will be looked at by authorised individuals from the University of Nottingham, the research group and regulatory authorities where it is relevant to my taking part in this study. I give permission for these individuals to have access to these records and to collect. store, analyse and publish information obtained from participation in this study. I understand that my child's personal details will be not be recorded.

3. I agree for my child's medicines administration to be observed.

Name of Parent / Care

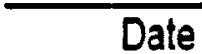

Signature

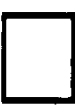


APPENDIX B

223 


\section{A SURVEY OF PAEDIATRIC NURSES' PERCEPTIONS OF DOUBLE CHECKING OF MEDICATION ADMINISTRATION IN CHILDREN HOSPITAL}

\section{PURPOSE}

This survey has been designed to evaluate paediatric nurses' knowledge of and opinion on the double checking process and how this process impacts on the paediatric nurses' practice.

\section{ELIGIBILITY}

Registered paediatric nurses at Derbyshire Children's Hospital, who have responsibility for administering medicines, will be eligible for inclusion into the survey.

\section{CONFIDENTIALITY}

No identifying information will be collected from you and your responses are therefore anonymous. All information obtained as a result of this survey is considered confidential.

\section{PARTICIPATION}

The decision regarding participation in this survey is entirely voluntary. You can withdraw at any time without any penalty.

\section{IF YOU HAVE ANY QUESTION ABOUT THIS SURVEY PLEASE CONTACT:}

Chief Investigator:

Phone number:

Email address:

OR

Co-Investigator:

Phone number:

Email address:

\section{Dr Sharon Conroy}

01332724692

Sharon.conroy@nottingham.ac.uk

Mr Zayed Alsulami

01332724721

mzxza@nottingham.ac.uk 


\section{DOUBLE CHECKING MEDICINES ADMINISTRATION IN CHILDREN - WHAT DO YOU THINK?}

Dear colleague,

As part of a PhD student project we wish to find out what you think about double checking medicines administration. We hope that you will be able to help us by completing and returning this questionnaire. It asks for your views on the double checking process and its effectiveness in preventing medication administration errors in paediatric patients.

Completing this questionnaire will take about 10 minutes. Please return it to us by putting your completed form in the enclosed envelope in the box provided in your clinical area or ward.

Please remember that we would like to know what happens in real life and what you think - not the ideal or the best practice. There are no wrong or right answers and all answers will be anonymous and confidential.

If you prefer not to answer particular questions please leave them blank.

If you have any queries, please don't hesitate to contact us using the details below.

We look forward to your response and many thanks for your participation.

Best Wishes

Zaved Alsulami

PhD student

Phone number: 01332724721

Email:mzxza@nottingham.ac.uk

\section{Dr Sharon Conroy}

Lecturer in Paediatric Clinical Pharmacy, Academic Division of Child Health, University of Nottingham Medical School at Derby

Phone number: 01332724692

Email: sharon.conroy@nottingham.ac.uk 
1. Have you seen the Trust double checking process written down (either in paper format or on the intranet)?
口Yes
$\square$ No

Comments.

2. Do you know exactly what the Trust double checking process should involve? If so, Can you briefly tell us?
$\square$ Yes
$\square$ No

Comments.

3. Have you undergone any specific training in the Derbyshire Children's Hospital, on how to do double checking for administration of medicines to paediatric patients? If so, when was it, who was involved and what did the session consist of?
$\square$ Yes
$\square$ No

Comments.

4. Which of the following do you always double check with another paediatric nurse?
$\square$ Oral preparation
$\square$ Oral administration
Intravenous preparation
口 Intravenous administration

5. What is the main reason for you doing the double checking process? Please choose the one most important to you.

$\square$ Because the hospital policy says that I must.

$\square$ To protect children from medication errors.

$\square$ To learn more about the medicines.

$\square$ To protect myself from making a mistake. 
6. Is double checking more effective with oral or IV medicines? Can you explain why?

$\square$ Oral medicines, explain

why.

$\checkmark$ Intravenous, explain

why.

Comments.

7. What are the most common factors that you think have a direct effect on your ability to do double checking on your ward? (Tick any you think apply)

$\checkmark$ Shortage of paediatric nurses and workload.

$\square$ Disturbance and interruption by other staff members.

口 Unavailable second person to carry out the double check.

$\square$ Trust double checking process is unclear.

$\checkmark$ Time consuming process without any effect on patient safety.

8. Do you think the double checking process by another nurse is effective in detecting medication preparation and administration errors?

- Medication preparation errors

- Medication administration errors
$\square$ Ineffective
$\square$ Ineffective
$\square$ Effective
$\square$ Effective
$\square$ Very effective
$\square$ Very effective

9. Can you follow the double checking process more easily on:-

$\square$ Weekdays, if so why.

$\square$ Weekends, if so why.

$\square$ No difference, if so why.

10. Can you follow the double checking process more easily in the:

$\square$ Morning (08:00- 12:00)? If so

why. 
$\square$ Afternoon (12:00-16:00)? If so

why.

$\square$ Evening (16:00-20:00)? If so

why.

$\square$ At night (20:00-08:00)? If so

why.

11. How many medication preparation/administration errors do you remember making and/or finding last month that were identified during the double checking process?

$\square$ No errors

$\square$ Less than five errors. $\square$ 5 - 10 errors.

$\square$ More than 10 errors.

12. What are the three elements of the double checking process you are least likely to pay attention to when you are performing a check during medication preparation and administration?

\section{IV medications}

$\square$
$\square$
$\square$

\section{Oral medications}

$\square$

口

13. The literature suggests that double checking is carried out in a variety of ways, with varying degrees of effectiveness. How do you think an effective process should be performed and do you do this in practise?

14. Do you think single checking (i.e. one nurse prepares and administers the medicine alone) should be allowed for:

$\square$ Oral medicines only? If so why,

口 Intravenous medicines only? If so why,

$\square$ All types of medicines? If so why, 
$\square$ No medicines? If so why

$\square$ Certain medicines? If so which medicines and why,

15. Do you have anything else that you wish to say about the double checking process? 
1. Gender
$\checkmark$ Female
$\square$ Male

2. Age Group (Years)
$\square$ Under 21
$\square 21-30$
$\square$ 31-40 口 41-50
$\square 51+$

3. How long in total have you worked as a paediatric nurse?

口 Less than 12 months

$\square$ One year to less than two years

$\square$ Two years to less than five years

$\square$ Five years to less than 10 years

$\square$ Over 10 years

4. What is your current employment status?
口 Permanent full-time
$\square$ Temporary full-time
$\square$ Permanent part-time
$\square$ Temporary part-time

5. How long in total have you prepared and administered medicines for paediatric patients?

$\square$ Less than 12 months

$\square$ One year to less than two years

$\square$ Two years to less than five years

$\square$ Five years to less than 10 years

$\square$ Over 10 years

Thank you very much for vour participation!

Please return in the box provided on the ward. 
APPENDIX C 
Dr Sharon Conroy

Academic Division of Child Health

Hedical School

Royal Derby Hospitals

Uttoexter Road

Derby

DE22 3DT
Medical School Research Ethics Committee

Division of Therapeutics \& Molecular Medicine

D Floor, South Block Queen's Medical Centre Nottingham

NG7 2UH

Tel: $+44(0) 1158231063$

Fax: +44(0) 1158231059

\section{Dear Dr Conroy}

Ethics Reference No: N19042012 (12038) GEMS

Study Title: Simulation Study of Paedlatric Drug Administration Procedures

Chief Investigator: Dr Sharon Conroy, Lecturer in Paediatric Clinical Pharmacy, Academic Division of Child Health, School of Graduate Entry Medicine, Derby Co Investigators: Mr Zayed N Alsulami, PHD Student, Professor Imti Choonara, Professor in Child Health, Academic Division of Child Health, School of Graduate Entry Medicine, Derby

Duration of Study: 05/2012-10/2012 6 months No of Participants: 30

Thank you for your letter dated 9th May 2012 responding to the issues raised by the committee. The following documents have been received:

- NhsRdForm.pdf 05/04/2012

- 12038 Simulation study protocol final v1.doc 05/04/2012

- 12038 consent form DC project final v1.doc 05/04/2012

- 12038 Simulation study PIS final v1.docx 05/04/2012

- 12038 Reminder Letter of Invitation simulation final v1.doc 05/04/2012

- FullDatasetTrialForm(3).pdf 05/04/2012

- Med School ethics application simulation study May 12.doc 15/5/2012

- E-mail response to Committee 09 May 2012 12:51

- 12038 Simulation study PIS final v2.doc 09/5/2012

These have been reviewed and are satisfactory and the study is approved.

Approval is given on the understanding that the Conditions of Approval set out below are followed.

\section{Conditions of Approval}

You must follow the protocol agreed and any changes to the protocol will require prior Ethics' Committee approval.

This study is approved for the period of active recruitment requested. The Committee also provides a further 5 year approval for any necessary work to be performed on the study which may arise in the process of publication and peer review. 
You promptly inform the Chairman of the Research Ethics Committee of

(i) Deviations from or changes to the protocol which are made to eliminate immediate hazards to the research subjects.

(ii) Any changes that increase the risk to subjects and/or affect significantly the conduct of the research.

(iii) All adverse drug reactions that are both serious and unexpected.

(iv) New information that may affect adversely the safety of the subjects or the conduct of the study.

(v) The attached End of Project Progress Report is completed and returned when the study has finished.

Yours sincerely

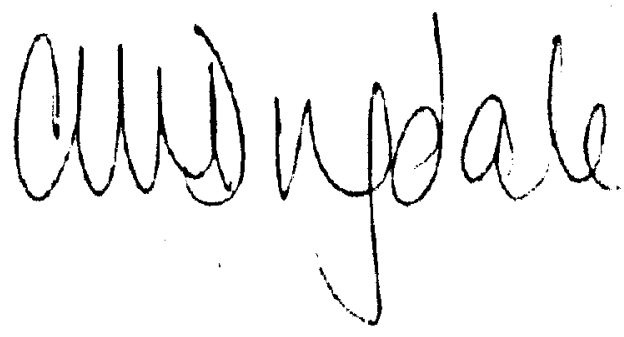

\section{Dr Clodagh Dugdale}

Chair, Nottingham University Medical School Research Ethics Committee 
GHF Reseash \& imcrabon Depart ent

ISSUED

24 JUL 2012

\section{Derby Hospitals WRS}

NHS Foundation Trust

\section{Research and Development Office}

TRUST APPROVAL LETTER
Royal Derby Hospital Uttoxeter Road Derby DE22 JNE

Tel: 01332340131 Minicom: 01332254944 contactus derbyhospitals nhs uk unw derbyhaspitals nhisuk

\section{Dr Sharon Conroy}

Lecturer in Paediatnc Clinical Pharmacy

Academic Division of Child Health

University of Nottingham Medical School

Royal Derby Hospital

Dear Dr Comroy - Sucaror

Ro: Double chocking and medication administration errors in paediatric patients simulation study

R\&D Ref: DHRO/2012/034

I am pleased to confirm Trust management approval for you to proceed in accordance with the agreed protosol, the Trust's financial procedures for research and development and the Research Governance Framework (which includes the Data Prolection Act 1998 and the Health \& Safety at Work Act 1974).

Please supply tha following to Dr Teresa Greve. Assistant Director of R\&D:

- the actual start and end dates of this study (before the atudy commences).

- details of any publications arising from this research project.

- anal report and a report every six months if the study duration is greater than six months

- notification of any SUSARS, amendments, urgent safety measures or if the trial is abandoned

Please note that approval for this study is dependent on full compliance with all of the above conditions.

This project did not require ethical review by a Research Ethics Committee under the UK Health Departments' Govemance Arrangements for Research Ethics Committees (GATREC) in accordance with the NRES algorithm dated August 2011.

I would like to take this opportunity to wish you every success with this study

Yours sincerely,

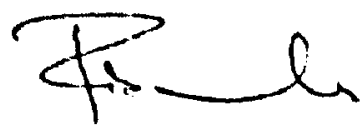

Prof. Richard Donnelly MD, PhD, FRCP, FRACP

Director of Research a Development 
R \& D referenæ: OHRD-2012-034

\title{
Derby Hospitals WRS
}

NHS Foundation Trust

\author{
Royal Derby Hospital \\ Uttoxeter Road \\ Derby \\ DE22 3AE
}

Tel: 01332340131

Minicom: 01332254944

contactusederbyhospitals.nhs.uk

uww derbyhospulals.nhs.uk

In accordance with your application and subsequent $R \& D$ approval dated 24th July 2012, the following documentation was reviewed and may therefore be used on the above study with Trust approval.

- Protocol Final Version 1.0 dated 03.04 .12

- Consent Form Final version 1.0 dated 02.04 .12

- Participant Information Sheet Final version 2.0 dated 09.05 .12

- Reminder Letter of Invitation v1 dated 04.01.12

- Letter of Invitation v1 dated 0401.12 
DOUBLE CHECKING AND MEDICATION ERRORS IN PAEDIATRIC PATIENTS:

A SIMULATION STUDY

Letter of invitation to participate in a study to determine whether single or double checking is more effective in detecting errors when administering medicines to children

\section{Dear Colleague,}

My name is Zayed Alsulami and I am a second year PhD student in the Academic Division of Child Health at the University of Nottingham. Together with my supervisor Dr Sharon Conroy (paediatric pharmacist) I am conducting a study to evaluate the effectiveness of double checking processes in reducing drug administration errors in paediatric inpatients. We would very much like you to help with a simulation study using dummy patients to examine whether single or double checking is more effective in detecting and reducing medication administration errors.

Please read the attached participant information sheet. If you are happy and interested in participating, please complete and sign the consent forms. Please keep one copy of the consent form for yourself and return the other one to me in the envelope provided using the box provided on the ward.

If you have any questions about the study please contact the Chief Investigator, $\mathrm{Dr}$ Sharon Conroy on extension 7224692 or email:

Sharon.Conroy@nottingham.ac.uk

Your participation in this study is highly valued.

Best regards,

\section{Zayed Alsulami}

Postgraduate student

Academic Division of Child Health, Graduate Entry Medicine and Health Science

The Medical School, Derby, University of Nottingham,

DE22 3DT, Derby, UK

Email: mzxza@nottingham.ac.uk

Tel: $+44(0) 1332724692$ 
Participant Information Sheet

Final Version 2.0: 9/5/12

\section{DOUBLE CHECKING AND MEDICATION ERRORS \\ IN PAEDIATRIC PATIENTS - SIMULATION STUDY}

\section{Name of Researcher(s): Sharon Conroy and Zayed Alsulami}

We would like to invite you to take part in our research study. Before you decide we would like you to understand why the research is being done and what it would involve for you. One of our team will go through the information sheet with you and answer any questions you have. Talk to others about the study if you wish. Ask us if there is anything that is not clear.

\section{What is the purpose of the study?}

The study is part of a PhD project and will evaluate the effectiveness of double checking processes in reducing medication errors in paediatric inpatients and to find out whether single checking is as effective as double checking.

\section{Why have I been invited?}

You are being invited to take part because you are a registered paediatric nurse at the Derbyshire Children's Hospital and you have responsibility for administering medicines to children. We are inviting all nurses in the hospital like you to take part.

\section{Do I have to take part?}

It is up to you to decide whether or not to take part. If you do decide to take part you will be given this information sheet to keep and be asked to sign a consent form. If you decide to take part you are still free to withdraw at any time and without giving a reason. This would not affect your legal rights.

\section{What will happen to me if I take part?}

Nurses who agree to participate will be given a prescription scenario in a room on Puffin ward and be asked to prepare and administer drugs used commonly on the wards to a dummy patient. They will be asked to prepare and administer the drugs in pairs with double checking as they do in everyday practice and then (on a different 
day) a similar prescription alone (single checking). Participation is anticipated to take a maximum of two hours in total.

All data collected during this exercise will be identified by a participant code. Individual results will not be shared with the Trust and will not affect your work in any way. You will be given feedback on your performance by the chief investigator for your own professional development. If gross bad practice is identified however, then this will be discussed with you and your manager will be informed if deemed necessary by the Chief Investigator of the study.

\section{Expenses and payments}

Participants will not be paid to participate in the study.

\section{What are the possible disadvantages and risks of taking part?}

There are no risks to participation. The only "disadvantage" is the time that you will be asked to set aside to take part.

\section{What are the possible benefits of taking part?}

We cannot promise the study will help you directly but the information we get from this study may help to decide whether single or double checking of medicines administration to children is most effective in reducing medication errors in children. You will also be given feedback on your performance by the Chief Investigator for your own professional development.

\section{What happens when the research study stops?}

We will analyse our results, write papers to publish them in paediatric journals and also tell others about our findings at meetings and conferences.

\section{What if there is a problem?}

If you have a concern or question about any aspect of this study, you should ask to speak to the researchers who will do their best to answer your questions. The researcher's contact details are given at the end of this information sheet. If you remain unhappy and wish to complain formally, you can do this by contacting the Ethics Committee Secretary, Mrs Louise Sabir, Division of Therapeutics and Molecular Medicine, D Floor, South Block, Queen's Medical Centre, Nottingham, NG7 2 UH.

Telephone: $01158231063 . \quad$ E-mail:louise.sabir@nottingham.ac.uk. 
Others may know that you have taken part in the study but all data collected and results obtained will be identified only by a code. Your name will not be collected or used in any way other than it being on the consent form which you will be asked to sign before you take part. All data that we collect will be stored in locked offices in the University of Nottingham and/or on password protected computer systems. No one in the Trust will be informed about how individual nurses performed in the study (though please see note above regarding gross bad practice). We will follow ethical and legal practice and all information about you will be handled in confidence.

If you join the study, some parts of the data collected for the study may be looked at by authorised persons from the University of Nottingham. The data may also be looked at by authorised people to check that the study is being carried out correctly. All will have a duty of confidentiality to you as a research participant and we will do our best to meet this duty.

No information which will identify you will be collected during the course of the research (other than the consent form) and all information will be kept strictly confidential, stored in a secure and locked office, and on a password protected database. Any information about you which leaves the hospital will be anonymous and a unique code will be used so that you cannot be recognised from it.

All research data will be kept securely for 7 years. After this time the data will be disposed of securely. During this time all precautions will be taken by all those involved to maintain the confidentiality of all data. Only members of the research team will have access to your personal data.

If any participant makes us aware of something which may require reporting then this will be done through the hospital's incident reporting system.

\section{What will happen if I don't want to carry on with the study?}

Your participation is voluntary and you are free to withdraw at any time, without giving any reason, and without your legal rights being affected. If you withdraw then the information collected so far cannot be erased and this information may still be used in the project analysis.

\section{What will happen to the results of the research study?}

Once we have analysed our results we will write papers to publish them in paediatric journals and also tell others about our findings at meetings and conferences. We hope this will be done within a few months/year of the study finishing. The project will also be written up as part of one the researchers PhD project. You will not be identified in any report/publication. 


\section{Who is organising and funding the research?}

This research is being organised and funded by the University of Nottingham.

\section{Who has reviewed the study?}

All research in the NHS is looked at by independent group of people, called a Research Ethics Committee, to protect your interests. This study has been reviewed and given favourable opinion by University of Nottingham Medical School Research Ethics Committee.

\section{Further information and contact details}

If you would like further information please contact Dr Sharon Conroy, Lecturer in Paediatric Clinical Pharmacy, The Medical School, Derbyshire Children's Hospital, Uttoxeter Road, Derby, DE22 3DT.

Tel: 01332724692 or

Email: Sharon.conroy@nottingham.ac.uk. 


\section{A SIMULATION STUDY}

Reminder letter of invitation to participate in a study to determine whether single or double checking is more effective in detecting errors when administering medicines to children

\section{Dear Colleague,}

My name is Zayed Alsulami and I am a second year PhD student in the Academic Division of Child Health at the University of Nottingham. I contacted you recently about the above study but have not yet heard from you hence this gentle reminder. Together with my supervisor Dr Sharon Conroy (paediatric pharmacist) I am conducting a study to evaluate the effectiveness of double checking processes in reducing drug administration errors in paediatric inpatients. We would very much like you to help with a simulation study using dummy patients to examine whether single or double checking is more effective in detecting and reducing medication administration errors.

Please read the attached participant information sheet. If you are happy and interested in participating, please complete and sign the consent form.

If you have any questions about the study please contact the Chief Investigator, $\mathrm{Dr}$ Sharon Conroy on extension 7224692 or email:

Sharon.Conroy@nottingham.ac.uk

Your participation in this study is highly valued.

Best regards,

Zayed Alsulami

Postgraduate student

Academic Division of Child Health

Graduate Entry Medicine and Health Science

The Medical School, Derby

Nottingham University

DE22 3DT, Derby, UK

Email: mzxza@ nottingham.ac.uk

Tel: $+44(0) 1332724692$ 
CONSENT FORM

(Final version 1.0: 2/4/12)

\section{DOUBLE CHECKING AND MEDICATION ADMINISTRATION ERRORS IN PAEDIATRIC PATIENTS}

\section{REC ref: N19042012 (12038) GEMS}

\section{Name of Researcher:}

\section{Name of Participant:}

Please initial box

1. I confirm that I have read and understand the information sheet version number 2 dated 9/5/2012 for the above study and have had the opportunity to ask questions.

2. I understand that my participation is voluntary and that I am free to withdraw at any time, without giving any reason, and without my legal rights being affected. I understand that should I withdraw then the information collected so far cannot be erased and that this information may still be used in the project analysis.

3. I understand that data collected in the study may be looked at by authorised individuals from the University of Nottingham, the research group and regulatory authorities where it is relevant to my taking part in this study. I give permission for these individuals to have access to these records and to collect, store, analyse and publish information obtained from my participation in this study. I understand that my personal details will be kept confidential.

4. I agree to take part in the above study.

Name of Participant

Date

Signature

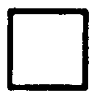

Date

Signature 
DATA COLLECTION FORM FOR SIMULATION STUDY

DRUG NAME and FORM ADMINISTERED (

Scenario Name:

Participant Code:

Date:

Observer:

Time start:

Time finish:

\begin{tabular}{|c|c|c|}
\hline $\begin{array}{l}\text { Drug administration } \\
\text { process }\end{array}$ & $\begin{array}{l}\text { Double Checking } \\
1^{\text {st }} \\
2^{\text {nd }}\end{array}$ & Comments \\
\hline Drug due & & \\
\hline Correct drug & & \\
\hline Correct dosage form & & \\
\hline Dose calculation & & \\
\hline Drug diluents \& volume & & \\
\hline Measurement of dose & & \\
\hline IV volume \& rate & & \\
\hline Drug route & & \\
\hline Drug expiry date & & \\
\hline Rate of IV bolus & & \\
\hline Flush Syringes labelled & & \\
\hline Allergy check & & \\
\hline Patient ID (wristband) & & \\
\hline $\begin{array}{l}\text { Administration to } \\
\text { patient }\end{array}$ & & \\
\hline Document to MAR & & \\
\hline
\end{tabular}

Not checked $=0$, Checked $=1$

MAR (Medication Administration Record) 
DATA COLLECTION FORM FOR SIMULATION STUDY

DRUG NAME and FORM ADMINISTERED (

Scenario Name:

Participant Code:

Date:

Observer:

Time start:

Time finish:

\begin{tabular}{|c|c|c|}
\hline $\begin{array}{l}\text { Drug administration } \\
\text { process }\end{array}$ & Single Checking & Comments \\
\hline Drug due & & \\
\hline Correct drug & & \\
\hline Correct dosage form & & \\
\hline Dose calculation & & \\
\hline Drug diluents \& volume & & \\
\hline Measurement of dose & & \\
\hline IV volume \& rate & & \\
\hline Drug route & & \\
\hline Drug expiry date & & \\
\hline Rate of IV bolus & & \\
\hline Flush Syringes labelled & & \\
\hline Allergy check & & \\
\hline Patient ID (wristband) & & \\
\hline $\begin{array}{l}\text { Administration to } \\
\text { patient }\end{array}$ & & \\
\hline Document to MAR & & \\
\hline
\end{tabular}

MAR (Medication Administration Record) 
APPENDIX D 


\section{Quality assessment criteria are included:}

1. Aims/objectives of the study clearly stated.

2. Definition of what constitutes a ME.

3. Error categories specified (for example, omission errors; wrong dose errors, etc.)

4. Error categories defined (for example, omission error: when a patient has not received his or her medication by the time the next dose is due (insulin)).

5. Presence of a clearly defined denominator.

6. Data collection method described clearly.

7. Setting in which study conducted described.

8. Sampling and calculation of sample size described (unit of measurement).

9. Reliability measures. (e.g. methods of measuring the stability or consistency of questionnaire scores over time).

10. Measures in place to ensure that results are valid.

11. Limitations of study listed.

12. Mention of any assumptions made.

13. Ethical approval. 
Quality assessment criteria of each individual study

\begin{tabular}{|c|c|c|c|}
\hline $\begin{array}{l}\text { Study Authors } \\
\text { (Year) }\end{array}$ & Country & Criteria available & Fulfilled \\
\hline $\begin{array}{c}\text { Ben-Yehuda et al. } \\
\text { (2011) }\end{array}$ & Israel & $1,2,3,4,6,7,8,9,11,13$ & $10 / 13$ \\
\hline Joolaee et al. (2011) & Iran & $1,2,3,6,7,8,9,11,13$ & $9 / 13$ \\
\hline Lifshitz et al. (2011) & Israel & $1,2,3,4,6,7,8,11,13$ & $9 / 13$ \\
\hline Alagha et al. (2011) & Egypt & $1,2,3,4,5,6,7,11,13$ & $9 / 13$ \\
\hline Fahimi et al. (2008) & Iran & $1,2,3,5,6,7,11,13$ & $8 / 13$ \\
\hline Kazemi et al. (2010) & Iran & $1,2,3,4,6,7,9,11$ & $8 / 13$ \\
\hline $\begin{array}{l}\text { Kadmon et al. } \\
(2009)\end{array}$ & Israel & $1,2,3,4,7,9,11,13$ & $8 / 13$ \\
\hline $\begin{array}{c}\text { Aljeraisy et al. } \\
(2011)\end{array}$ & Saudi & $1,2,3,4,6,7,11,13$ & $8 / 13$ \\
\hline Alkhaja et al. (2005) & Bahrain & $1,2,3,4,6,7,9,11$ & $8 / 13$ \\
\hline $\begin{array}{l}\text { Drach-Zahavy \& Pud } \\
\qquad(2010)\end{array}$ & Israel & $1,2,6,7,8,11,13$ & $7 / 13$ \\
\hline Saab et al. (2006) & Lebanon & $1,3,6,7,8,11,13$ & $7 / 13$ \\
\hline Vessal G. (2010) & Iran & $1,2,3,4,6,7,11$ & $7 / 13$ \\
\hline $\begin{array}{c}\text { Koohestani et al. } \\
(2009)\end{array}$ & Iran & $1,3,4,7,11,12,13$ & $7 / 13$ \\
\hline Kazemi et al. (2011) & Iran & $1,2,3,4,7,11,13$ & $7 / 13$ \\
\hline $\begin{array}{l}\text { Koohestani et al. } \\
(2008)\end{array}$ & Iran & $1,2,3,4,6,11,13$ & $7 / 13$ \\
\hline Azoulay et al. (2005) & Iran & $1,3,4,6,7,13$ & $6 / 13$ \\
\hline Lusting (2000) & Israel & $1,2,3,4,7,13$ & $6 / 13$ \\
\hline Khoja et al. (2011) & Saudi & $1,2,3,4,6,7$ & $6 / 13$ \\
\hline Alkhaja et al. (2008) & Bahrain & $1,3,4,5,6,7$ & $6 / 13$ \\
\hline Alkhaja et al. (2010) & Bahrain & $1,2,3,4,6,7$ & $6 / 13$ \\
\hline Sabry et al. (2009) & Egypt & $1,2,3,6,7,11$ & $6 / 13$ \\
\hline Qurashi et al. (2011) & Saudi & $1,3,4,6,7,13$ & $6 / 13$ \\
\hline
\end{tabular}




\begin{tabular}{|c|c|c|c|}
\hline $\begin{array}{c}\text { Mrayyan et al. } \\
(2007)\end{array}$ & Jordan & $1,2,3,6,7,13$ & $6 / 13$ \\
\hline Al-Shara M. (2011) & Jordan & $1,2,3,6,7,13$ & $6 / 13$ \\
\hline Khalili et al. (2011) & Iran & $1,2,3,4,7,13$ & $6 / 13$ \\
\hline Oliven et al. (2005) & Israel & $1,2,3,4,6,7$ & $6 / 13$ \\
\hline Neyaz et al. (2011) & Saudi & $1,6,7,9,11,13$ & $6 / 13$ \\
\hline Alkhaja et al. (2007) & Bahrain & $1,3,4,6,7,13$ & $6 / 13$ \\
\hline Fahimi et al. (2009) & Iran & $1,2,3,4,7,13$ & $6 / 13$ \\
\hline $\begin{array}{c}\text { Abou alsoud et al. } \\
(2010)\end{array}$ & Egypt & $1,3,6,7,11,13$ & $6 / 13$ \\
\hline Hooper et al. (2009) & Qatar & $1,2,3,4,7$ & $5 / 13$ \\
\hline $\begin{array}{c}\text { Koohestani et al. } \\
(2008)\end{array}$ & Iran & $1,3,6,7,13$ & $5 / 13$ \\
\hline $\begin{array}{l}\text { Sadat-Ali et al. } \\
\text { (2011) }\end{array}$ & Saudi & $1,2,7,11,13$ & $5 / 13$ \\
\hline Sweileh et al. (2007) & Palestine & $1,3,4,6,7$ & $5 / 13$ \\
\hline Vardi et al. (2007) & Israel & $1,6,7,9,13$ & $5 / 13$ \\
\hline Vaknin et al. (2003) & Israel & $1,2,3,4,13$ & $5 / 13$ \\
\hline $\begin{array}{c}\text { Valizadeh et al. } \\
(2008)\end{array}$ & Iran & $1,2,4,6,7$ & $5 / 13$ \\
\hline $\begin{array}{c}\text { Aldhawailie A. } \\
\text { (2011) }\end{array}$ & Saudi & $1,3,7,13$ & $4 / 13$ \\
\hline $\begin{array}{c}\text { Magzoub et al. } \\
(2011)\end{array}$ & Saudi & $1,6,7,13$ & $4 / 13$ \\
\hline Irshaid et al. (2005) & Saudi & $1,6,7,13$ & $4 / 13$ \\
\hline Bar-Oz et al. (2008) & Israel & $1,6,11,13$ & $4 / 13$ \\
\hline $\begin{array}{c}\text { Islamian et al. } \\
(2010)\end{array}$ & Iran & $1,6,7,13$ & $4 / 13$ \\
\hline Dibbi et al. (2006) & Saudi & $1,3,7$ & $3 / 13$ \\
\hline Elnour et al. (2008) & $\begin{array}{c}\text { United Arab } \\
\text { Emirates }\end{array}$ & 1,7 & $2 / 13$ \\
\hline Oliven et al. (2002) & Israel & 6,7 & $2 / 13$ \\
\hline
\end{tabular}

